Manoel Leopoldino Rocha de Farias

\title{
RECUPERAÇÃO AVANÇADA DE ÓLEOS PESADOS POR INJEÇÃO DE EMULSÕES DILUÍDAS DE ÓLEO EM ÁGUA
}

Tese de Doutorado

Tese apresentada como requisito parcial para obtenção do título de Doutor em Engenharia Mecânica pelo Programa de Pós-graduação em Engenharia Mecânica da PUC-Rio

Orientador: Prof. Márcio da Silveira Carvalho Co-orientador: Antônio Luiz Serra de Souza 
Manoel Leopoldino Rocha de Farias

\section{RECUPERAÇÃO AVANÇADA DE ÓLEOS PESADOS POR INJEÇÃO DE EMULSÕES DILUÍDAS DE ÓLEO EM ÁGUA}

Tese apresentada como requisito parcial para obtenção do título de Doutor em Engenharia Mecânica pelo Programa de Pós-Graduação em Engenharia Mecânica do Departamento de Engenharia Mecânica do Centro Técnico Científico da PUC-Rio. Aprovada pela Comissão Examinadora abaixo assinada.

Prof. Márcio da Silveira Carvalho Orientador

Departamento de Engenharia Mecânica da PUC-Rio

Antônio Luiz Serra de Souza

Co-orientador CENPES/PETROBRAS

Prof. Adriano dos Santos Escola de Química da UFRN

Prof. Paulo Roberto de Souza Mendes Departamento de Engenharia Mecânica da PUC-Rio

Prof. Luis Glauber Rodrigues

Petrobras

Prof. Eurípedes do Amaral Vargas Jr. Departamento de Engenharia Civil da PUC-Rio

Prof. José Eugênio Leal Coordenador Setorial do Centro Técnico Científico - PUC-Rio

Rio de Janeiro, 8 Julho de 2013 
Todos os direitos reservados. É proibida da reprodução total ou parcial do trabalho sem a autorização da universidade, do autor e dos orientadores.

\section{Manoel Leopoldino Rocha de Farias}

Graduou-se em Engenharia Civil na UFJF em 1989. Especialização em Engenharia Econômica pela Faculdade Machado Sobrinho em 1990. Mestre em Engenharia Civil pela UFF em 1995. Atua como Engenheiro de Petróleo na Petrobras desde 2002.

Ficha Catalográfica

Farias, Manoel Leopoldino Rocha de

Recuperação avançada de óleos pesados por injeção em emulsões diluídas de óleo em água / Manoel Leopoldino Rocha de Farias ; orientador: Márcio da Silveira Carvalho ; co-orientador: Antônio Luiz Serra de Souza. - 2013.

219 f.: il. (color.); 29,7 cm

1. Tese (doutorado)-Pontifícia Universidade Católica do Rio de Janeiro, Departamento de Engenharia Mecânica, 2013.

Inclui referências bibliográficas

1. Engenharia mecânica - Teses. 2. Óleos pesados. 3. Emulsões. 4. Surfactantes. 5. Recuperação avançada de petróleo. 6. Tomografia. 7. Meios porosos. I. Carvalho, Márcio da Silveira. II. Souza, Antônio Luiz Serra de. III. Pontifícia Universidade Católica do Rio de Janeiro. Departamento de Engenharia Mecânica. IV. Título. 
A minha esposa Paula e aos Meus filhos Pedro e Eduardo. 


\section{Agradecimentos}

A Deus por ter me concedido o dom de enxergar em cada dificuldade uma oportunidade.

Aos meus pais por todo investimento feito na minha educação.

A minha família pelo suporte em toda essa caminhada, suportando os meus muitos momentos de mau humor. Peço desculpas pelas minhas ausências nesses quase 5 anos.

Aos meus orientadores Márcio da Silveira Carvalho e Antônio Luiz Serra por acreditarem no meu projeto desde o início e pela orientação acadêmica ao longo do trabalho.

A PETROBRAS pela liberação em tempo parcial para essa pesquisa e pelo suporte financeiro no Brasil e nos Estados Unidos.

Aos meus gerentes diretos Marcelo Marinho Alves e José Fernando Rosalba pela compreensão por alguns períodos de maior afastamento das atividades profissionais.

Aos gerentes do CENPES Priscila Moczydlower e Eugênio Campagnolo pela liberação dos equipamentos no Laboratório de Interação Rocha-Fluido para execução do programa experimental.

Aos Prof. Clarence Miller e George Hirasaki pela oportunidade de me aperfeiçoar junto ao grupo de pesquisa por eles coordenado na Rice University.

Ao meu amigo José Salinas por toda dedicação de me ensinar não só a operar os equipamentos, mas também pela ajuda na adaptação inicial à rotina da Rice University.

Aos colegas do CENPES/PETROBRAS Cláudio Furtado, Carlos Henrique Araújo, Aline Machado de Azevedo e Rafaella Magliano pela ajuda na obtenção de preciosos recursos para complemento do programa experimental. Um 
agradecimento extra ao Cláudio pelas orientações e esclarecimentos fundamentais em Química.

Aos técnicos do laboratório de Interação Rocha-Fluido do CENPES Rafael Paiva, Pedro Fernandes, Igor Domingos, Samuel Ferreira e Mônica Rasga pelo apoio na montagem dos experimentos.

Ao pessoal do Laboratório de Tomografia de Raios X do CENPES Áurea Pereira, Fabiane da Silva e Elisabete Campos por toda ajuda na execução e interpretação das imagens tomográficas. 


\section{Resumo}

Farias, Manoel Leopoldino Rocha de; Carvalho, Márcio da Silveira; Souza, Antônio Luiz Serra de. Recuperação avançada de óleos pesados por injeção em emulsões diluídas de óleo em água, Rio de Janeiro, 2013, 219p. Tese de Doutorado - Departamento de Engenharia Mecânica, Pontifícia Universidade Católica do Rio de Janeiro.

A injeção de água é o método de recuperação secundário mais utilizado no mundo. Mesmo em situações em que esse método não é o mais adequado, a facilidade de implantação e os menores custos comparativos impõem esse método como a opção selecionada. Em campos de óleo pesado, a razão de mobilidade desfavorável e as heterogeneidades de reservatório precipitam a formação de digitações viscosas e altos valores de saturação residual de óleo, levando a baixos fatores finais de recuperação. Os poços produtores desses campos produzem com altas frações de água muito rapidamente. $\mathrm{O}$ tratamento da água produzida é o principal custo operacional desses campos. O uso de emulsões diluídas de óleo em água foi avaliado como método de controle de mobilidade. Foi desenvolvido um extenso programa experimental em sandpacks de areia de sílica e plugs de arenito (Berea e Bentheimer) de forma a comparar as recuperações finais de óleo, perfis de pressão de injeção e razões água-óleo acumuladas nos casos de injeção de água, injeção de surfactantes e macroemulsões. Todos os meios porosos ensaiados foram saturados com petróleo cru originário da Bacia de Campos $\left(20^{\circ} \mathrm{API}\right)$. Um estudo paramétrico foi feito de forma a identificar a influência da vazão de injeção, distribuição de tamanhos de gotas de óleo emulsionadas, concentração de óleo e permeabilidade no desempenho das emulsões injetadas. O programa foi complementado com um ensaio 3D (arenito Castlegate na configuração 1/4 de fivespot) onde o fluido injetado foi dopado com Iodeto de Potássio para permitir melhor visualização da modificação de saturações de óleo e água com um tomógrafo de raios $\mathrm{X}$. Os resultados obtidos indicaram ganhos na produção de 
óleo e redução da razão água-óleo acumulada. A possibilidade de preparar as emulsões óleo-água a serem injetadas a partir da água produzida pelo próprio campo traz um grande ganho ambiental ao se reduzir o descarte superficial de água oleosa. $\mathrm{O}$ efluente se transforma em um recurso.

\section{Palavras-Chave}

Óleos pesados; emulsões; surfactantes; recuperação avançada de petróleo; tomografia; meios porosos. 


\section{Abstract}

Farias, Manoel Leopoldino Rocha de; Carvalho, Márcio da Silveira (advisor); Souza, Antônio Luiz Serra de (co-advisor). Improved heavy oil recovery by injection of diluted oil-in-water emulsions, Rio de Janeiro, 2013, 219p. Doctoral Thesis - Departamento de Engenharia Mecânica, Pontifícia Universidade Católica do Rio de Janeiro.

Water injection is the most used secondary recovery method in the world. This option is generally chosen even in situations where it is not the most efficient alternative to recover the oil due to its comparative simple implementation and lower operational costs. In heavy oilfields, the unfavorable mobility ratio between injection and displaced fluids in addition to reservoir heterogeneities cause water fingering phenomenon, high residual oil saturation and consequently poor final oil recoveries. Producer wells start to produce high water cuts very soon. Produced water treatment for surface disposal is the main operational cost in these oilfields. The use of diluted oil-in-water macroemulsions was evaluated as a mobility control method for these cases. An extensive experimental program was performed using silica sandpacks and sandstone plugs (Berea and Bentheimer) in order to evaluate final oil recovery factors, cumulative water-oil ratio and pressure behavior, comparing water injection, surfactant solution injection and oil-in-water injection. All porous media were saturated with crude oil from Campos Basin $\left(20^{\circ}\right.$ API). A parametric study was performed to identify the effect of injection rate, oil droplets size distributions, emulsion oil concentration and permeability level in emulsion injection performance. The experimental program was completed by an $\mathrm{X}$-Ray computerized tomography monitored experiment in a Castlegate sandstone block (1/4 five-spot configuration). This block was submitted to an alternate water/emulsion/water injection. All injection fluids were doped with Potassium Iodide in order to better visualize oil and water saturations changes during this experiment. The results obtained have indicated final oil recovery improvement 
and cumulative water/oil reduction. The possibility, after some treatment, to prepare diluted oil-in-water emulsions using produced water from the oilfield brings the additional environmental benefit to emulsion injection. It would be a way to convert an effluent in a resource with clear environmental advantages.

\section{Keywords}

Heavy oils; emulsions; surfactants; EOR; tomography; porous media. 


\section{Sumário}

1. Visão Geral do Trabalho

28

2. Fundamentos da Produção de Óleos Viscosos, Injeção e Gerenciamento de Água

2.1. Introdução

30

2.2. Critérios de Classificação do Petróleo 32

2.3. Formação do Petróleo 33

$\begin{array}{ll}\text { 2.4. Mecanismos de Produção } & 37\end{array}$

2.5. Estado da Arte 57

2.6. Especificação da Água de Relnjeção 62

2.7. Conclusões 64

3. Surfactantes e Emulsões 66

3.1. Introdução 66

3.2. Tensão Superficial e Energia Superficial Livre 66

$\begin{array}{ll}\text { 3.3. Molhabilidade } & 68\end{array}$

3.4. Surfactantes ou Tensoativos $\quad 70$

$\begin{array}{ll}\text { 3.5. Emulsões } & 75\end{array}$

$\begin{array}{ll}\text { 3.6. Microemulsões } & 79\end{array}$

4. Modelagem da Injeção de Emulsões em Meios Porosos 83

4.1. Introdução 83

4.2. Experimentos de McAuliffe 84

4.3. Modelo de Devereux $\quad 87$

4.4. Modelo de Alvarado e Marsden 89

4.5. Modelo de Soo e Radke 90

4.6. Modelo de Mendez (1999) 100 
4.7. Modelo de Cobos (2009) 101

$\begin{array}{ll}\text { 4.8. Experimentos de Guillen } & 104\end{array}$

$\begin{array}{ll}\text { 4.9. Modelo de Romero (2011) } & 107\end{array}$

$\begin{array}{lr}\text { 4.10. Conclusões } & 108\end{array}$

5. Programa Experimental Inicial - Ensaios de Fluxo 1-D 110

$\begin{array}{ll}\text { 5.1. Objetivos do trabalho } & 110\end{array}$

$\begin{array}{lr}\text { 5.2. Ensaios iniciais } & 110\end{array}$

$\begin{array}{ll}\text { 5.3. Materiais e Métodos } & 111\end{array}$

5.4. Ensaios em Meios Porosos Saturados apenas com a $\begin{array}{lr}\text { fase aquosa } & 112\end{array}$

5.5. Ensaios 1-D de recuperação de óleo por emulsões 118

5.6. Estudo Paramétrico 1-D 126

$\begin{array}{ll}\text { 5.7. Conclusões } & 146\end{array}$

6 . Ensaio 3D Monitorado em Tomógrafo de Raios X 148

$\begin{array}{lc}\text { 6.1. Introdução } & 148\end{array}$

$\begin{array}{lr}\text { 6.2. Objetivos } & 148\end{array}$

$\begin{array}{ll}\text { 6.3. Materiais e Métodos } & 149\end{array}$

6.4. Revisão Teórica 152

6.5. Descrição do Ensaio 156

$\begin{array}{lr}\text { 6.6. Resultados } & 157\end{array}$

6.7. Imagens Tomográficas 162

7 . Conclusões, Recomendações e Sugestões para Trabalhos

$\begin{array}{ll}\text { Futuros. } & 175\end{array}$

$\begin{array}{lr}\text { 7.1. Conclusões } & 175\end{array}$

$\begin{array}{ll}\text { 7.2. Recomendações para trabalhos futuros } & 177\end{array}$ 
Referências Bibliográficas

8. Apêndices 186

8.1. Medidas das propriedades das rochas e fluidos. 186

8.2. Paper SPE 152290

8.3. Paper COBEM 2013 


\section{Lista de Figuras}

Figura 1 - Projeção da participação do petróleo na matriz energética mundial nas próximas décadas [1].

Figura 2 - Sistemas de produção de petróleo em ambiente offshore. Da esquerda para a direita aparecem um navio tanque acoplado a uma monobóia, uma plataforma fixa de produção, uma plataforma de produção semi-submersível e um FPSO (Fonte: Banco de Imagens Petrobras).

Figura 3 - Representação esquemática do sistema petrolífero (disponível em petroleumsupport.com).

Figura 4 - Tipos de armadilhas geralmente encontradas em reservatórios de petróleo (disponível em http://www.geologues-prospecteurs.fr).

Figura 5 - Sistema petrolífero de óleo pesado na Western Basin no Canadá [3].

Figura 6 - Faixas esperadas das frações recuperadas de petróleo em cada etapa da explotação de uma jazida de petróleo (adaptado de U.S. DOE).

Figura 7 - Exemplos de mecanismo de produção em reservatórios de petróleo.

Figura 8 - Problemas de varrido areal em reservatórios

(a) digitação viscosa e (b) existência de corredores de alta permeabilidade [6].

Figura 9 - Problemas de varrido volumétrico [6]

Figura 10 - Formação de digitação viscosa em bloco de arenito saturado com óleo viscoso submetido à injeção de água pela face inferior [7]. A sequência mostra a evolução do fingering viscoso com a injeção de água acumulada.

Figura 11 - Representação esquemática do deslocamento do óleo por água no modelo de poro duplo [57].

Figura 12 - Representação do fenômeno do snap-off de gotas em um poro (adaptado de [4]). 
Figura 13 - Mecanismos que explicam a formação de uma saturação de óleo remanescente [4].

Figura 14 - Influência da variação do número de capilaridade na diminuição da saturação de óleo remanescente após a injeção de água [56].

Figura 15 - Fatores críticos a serem considerados no gerenciamento de água [22].

Figura 16 - Variação do aspecto da água produzida em função do teor de óleo e graxas. O TOG varia desde 10000 ppm (amostra no extremo esquerdo) até zero na extremidade direita [24].

Figura 17 - Sistema de separação submarina do campo de Tordis (SSBI) (http://org.uib.no/cipr/Workshop/2009/CO2/Present /Mid/TordisIncident2008.pdf).

Figura 18 - Representação esquemática do sistema de separação submarina água-óleo a ser instalado no campo de Marlim [16].

Figura 19 - Diagrama simplificado do sistema de reinjeção na plataforma P-35 do campo de Marlim [15].

Figura 20 - Comparativo de custos das tecnologias disponíveis para tratamento da água produzida [21].

Figura 21 - Representação da tensão superficial e do balanço das forças nas moléculas na interface e no interior do líquido

Figura 22 - Conceito de tensão interfacial.

Figura 23 - Equilíbrio de uma gota de líquido em contato com um sólido.

Figura 24 - Molhabilidade em rochas-reservatório [13].

Figura 25 - Representação esquemática de uma molécula de surfactante.

Figura 26 - Representação de uma molécula etoxilada de lauriletersulfato de sódio. O grupo eteno aparece destacado entre parênteses. 
Figura 27 - Representação esquemática de um surfactante baseado em sal quartenário de amônio.

Os radicais $\mathrm{R}$ podem ser ou não de um mesmo grupo funcional. Também é possível conexão entre eles. 71

Figura 28 - Molécula da dietanolamida de ácido graxo de coco. 72

Figura 29 - Cocoamidapropil betaina 2

Figura 30 - Influência do cátion metálico no tipo da emulsão formada.

Figura 31 - Classificação das emulsões baseada no tamanho das gotas da fase dispersa.

Figura 32 - Representação esquemática da ação dos surfactantes na estabilização de gotas. $\quad 76$

Figura 33 - Representação esquemática da agregação. 77

Figura 34 - Representação esquemática da coalescência. 77

Figura 35 - Representação esquemática das correlações entre os parâmetros envolvidos no mecanismo de estabilização de emulsões [44].

Figura 36 - Representação esquemática de uma emulsão de óleo em água com concentração de surfactante acima da CMC.

Figura 37 - Possíveis arranjos de micelas de acordo com a interpretação de dados experimentais. (a) esféricas,

(b) lamelar, (c) inversa ou reversa, (d) disco e

(e) cilíndrico ou barra [45].

Figura 38 - Classificação de Winsor.

Figura 39 - Representação esquemática de um diagrama ternário óleo-água-surfactante indicando a região de formação de microemulsão [42].

Figura 40 - Gota retida em uma garganta de poro [50].

Figura 41 - Histórico da produção de líquido, óleo e da razão água-óleo (RAO) durante o piloto de injeção de emulsão no campo de Midway Sunset [47].

Figura 42 - Representação dos fenômenos de interceptação 
de gotas e bloqueio de poros [53].

Figura 43 - Representação dos fenômenos de bloqueio

de poros e redistribuição de fluxo [55].

Figura 44 - Fotos ao microscópio do escoamento de uma emulsão através de uma garganta de poro [59].

Figura 45 - Evolução da pressão de injeção relativa ao evento da passagem de uma gota grande através de uma garganta de poro [59].

Figura 46 - Evolução do fator de recuperação de óleo (curva azul) e da pressão de injeção (curva vermelha).

As áreas marcadas em azul claro correspondem aos períodos de injeção de emulsão [59].

Figura 47 - Efeito da injeção da emulsão no controle da digitação viscosa. A fase aquosa (água injetada e a fase contínua da emulsão) aparece marcada em verde. Na sequência dos quadros está destacada a formação de um banco de óleo deslocado pela emulsão [60].

Figura 48 - Foto ao microscópio indicando a ação da emulsão ao nível de poros [60].

Figura 49 - Esquema do ensaio de injeção alternada de água e emulsão em plugs conectados em paralelo [60].

Figura 50 - Preparação dos sandpacks para

avaliação do uso de emulsões na recuperação de petróleo

- adaptado de [65].

Figura 51 - Representação esquemática dos

experimentos iniciais feitos em sandpacks 20/40.

Figura 52 - aspecto visual dos efluentes coletas

na injeção de emulsão produzida no frit \# $5 \mu \mathrm{m}$.

Figura 53 - aspecto visual dos efluentes coletas

na injeção de emulsão produzida no frit \# $10 \mu \mathrm{m}$.

Figura 54 - aspecto visual dos efluentes coletas

na injeção de emulsão produzida no frit \# $25 \mu \mathrm{m}$.

Figura 55 - Gráfico de Hall esquemático e sua interpretação.

Figura 56 - Gráfico de Hall e para o mesmo experimento. 
Figura 57 - aspecto final do sandpack após

injeção de emulsão preparada no frit \#25 $\mu \mathrm{m}$.

Figura 58 - aspecto final do sandpack após injeção de

emulsão preparada no frit \#10 $\mu \mathrm{m}$.

Figura 59 - Representação esquemática do ensaio de

deslocamento de petróleo por diferentes métodos

(injeção de água, emulsão e surfactante) [65].

Figura 60 - Evolução da fração líquida de

óleo recuperada nos experimentos de injeção a

Iternada nos experimentos 1, 2, 3, 4 e 9.

Figura 61 - Comportamento do diferencial de

pressão de injeção experimentos 1, 2, 3,4 e 9.

Figura 62 - Evolução da fração de óleo recuperada

nos experimentos de injeção alternada nos

experimentos 5,6,7 e 8 .

Figura 63 - - Comportamento de pressão nos

experimentos 5, 6, 7 e. 8

Figura 64 - Aspecto final dos sandpacks nas proximidades dos pontos de injeção.

Figura 65 - Evolução da fração de óleo recuperada em cada experimento. A concentração de óleo na legenda se refere ao $2^{0}$ volume poroso injetado em cada amostra.

Figura 66 - Comportamento do diferencial de pressão nos ensaios realizados (a curva em linha cheia é do ensaio de injeção de água do mar).

Figura 67 - Fatores de recuperação de óleo a cada

volume poroso injetado nos ensaios para avaliar a influência da vazão de injeção nos resultados da injeção de emulsões.

Figura 68 - Saturação dos plugs com água de formação desaerada em bomba de vácuo.

Figura 69 - Comparativo das frações recuperadas a cada volume poroso injetado para os plugs de arenito Berea ensaiados. A legenda se refere à fase injetada no segundo volume poroso. 
Figura 70 - Comparativo das frações recuperadas

a cada volume poroso injetado para os plugs

de arenito Bentheimer ensaiados.

Figura 71 - Evolução do diferencial de pressão nos experimentos com arenito Bentheimer. A legenda se refere à fase injetada no segundo volume poroso.

Figura 72 - Modelo 3D de simulação CMG STARS ${ }^{\circledR}$ composto por 360 células distribuídas uniformemente em 20 camadas. A figura foi gerada no CMG ModelBuider®.

Figura 73 - Curva de permeabilidades relativas do óleo e da água utilizada no ajuste das produções observadas na injeção do banco inicial de água do mar sintética (ensaio realizado com vazão constante de $0.3 \mathrm{~mL} / \mathrm{min}$ ).

Figura 74 - Ajuste do histórico de produção de óleo e água - injeção de 3 volumes porosos de água do mar sintética com vazão $q=0.3 \mathrm{ml} / \mathrm{min}$. As curvas contínuas são a saída do modelo STARS e os pontos são os dados experimentais.

Figura 75 - Curvas de permeabilidade relativa correspondentes à tensão interfacial mínima.

Figura 76 - Parâmetros de adsorção do surfactante ajustados para os sandpacks de sílica.

Figura 77 - Ajuste de histórico - 1 VP AM + 1 VP sol.

Surfactante +1 VP AM $-\mathrm{q}=0.30 \mathrm{ml} / \mathrm{min}$.

Figura 78 - Ajuste de histórico - 0.5 VP AM + 1.5 VP sol.

Surfactante +1 VP AM $-\mathrm{q}=0.30 \mathrm{ml} / \mathrm{min}$

Figura 79 - Parâmetros de adsorção do processo de captura de gotas emulsionadas (concentração de óleo 1\% $\mathrm{v} / \mathrm{v}$ e \#frit $60 \mu \mathrm{m}$ ). Os valores são os obtidos no ajuste ótimo.

Figura 80 - Curvas de permeabilidade relativa utilizadas no ajuste do modelo de injeção alternada de água-emulsão-água (1 VP AM: 1 VP emulsão: 1 VP AM).

Figura 81 - Ajuste do histórico de produção de óleo no ensaio de injeção alternada 
água/emulsão/água no (sandpack 111).

Figura 82 - Ajuste da produção de água no

ensaio de injeção alternada água/emulsão (sandpack 111).

Figura 83 - Vazões de óleo simuladas no STARS

para o ensaio de injeção alternada água/emulsão/água

no sandpack 111.

Figura 84 - Distribuição de gotas emulsionadas e

stimada pelo STARS.

Figura 85 - Seção transversal esquemática

(diagonal que une os poços) do bloco de arenito Castlegate ensaiado. Os detalhes da preparação não estão representados em escala.

Figura 86 - Primeira etapa da preparação dos blocos

de arenito Castlegate feita no Laboratório de Estruturas

do Programa de Engenharia Civil da COPPE/UFRJ.

Figura 87 - Etapa final da preparação dos blocos de arenito Castlegate na configuração $1 / 4$ de 5 -spot feita no Laboratório de Interação Rocha-Fluido do CENPES/PETROBRAS.

Figura 88 - Representação esquemática de um tubo de raios catódicos [75]

Figura 89- Atenuação de um feixe de raios $\mathrm{X}$ incidente em uma amostra [69].

Figura 90 - Representação esquemática do movimento do gantry.

Figura 91 - Processo de reconstrução das imagens tomográficas [69].

Figura 92 - Montagem do ensaio. (A) Tomógrafo médico G\&E BrightSpeed 16 canais; (B) Bomba HPLC Jasco modelo PU-2086i; (C) Aquisição de dados em microcomputador PC; (D) Transdutor de pressão Yokogawa modelo EJA130A ; (E) Bloco de arenito Castlegate; (F) Mesa deslizante do tomógrafo; (G) Gantry do tomógrafo. Os graus de liberdade da mesa e do gantry estão indicados.

Figura 93 - Modelo de simulação STARS utilizado no 
ajuste da injeção inicial de água e extrapolação da produção.

Figura 94 - Curva de permeabilidade relativa obtida

no ajuste do modelo.

Figura 95 - Ajuste de histórico de produção de óleo com os dados da injeção de água inicial (0.5 VP) e extrapolação da produção de óleo, caso apenas água fosse injetada no sistema.

Figura 96 - Ajuste de histórico da produção de água e extrapolação dos resultados.

Figura 97 - Evolução da pressão de fluxo e fração

de óleo recuperada no ensaio 3D.

Figura 98 - Evolução da razão água-óleo cumulativa.

Figura 99 - Evolução da produção de óleo e água durante o ensaio.

Figura 100 - Convenção para geração das imagens transversais.

Figura 101 - Imagens tomográficas "brutas" da injeção inicial de água do mar sintética.

Figura 102 - Imagens tomográficas "brutas" na seção 75 mm.

Figura 103 - Mapa diferença 3D obtido na injeção do banco de água inicial $\left(\mathrm{W}_{\mathrm{inj}}=0.03 \mathrm{VP}\right)$. A área invadida pelo fluido injetado aparece destacada.

Figura 104 - Mapa diferença 3D obtido na injeção do banco de água inicial $\left(\mathrm{W}_{\mathrm{inj}}=0.20 \mathrm{VP}\right)$. É possível observar que o breakthrough da água de injeção no poço produtor é iminente.

Figura 105 - Mapa diferença 3D obtido na injeção do banco de água inicial $\left(\mathrm{W}_{\mathrm{inj}}=0.41 \mathrm{VP}\right)$. Observa-se que a água de injeção está sendo produzida em todo intervalo completado do poço produtor.

Figura 106 - Mapa diferença 3D obtido na injeção do banco de água inicial $\left(\mathrm{W}_{\mathrm{inj}}=0.50 \mathrm{VP}\right)$.

Figura 107 - Mapa diferença 3D obtido na injeção do banco de emulsão (0.25 VP injetados).

Figura 108 - Mapa diferença 3D obtido na injeção do banco 
de emulsão (0.43 VP injetados).

Figura 109 - Mapa diferença 3D obtido na injeção do

banco de emulsão (0.54 VP injetados).

170

Figura 110 - Mapa diferença 3D obtido na injeção do banco de emulsão (0.84 VP).

Figura 111 - Mapa diferença 3D obtido na injeção do banco

de emulsão (1 VP).

Figura 112 - Mapa de diferença 3D, após a injeção

de 0.89 VP de emulsão, na diagonal que o poço injetor e o poço produtor.

Figura 113 - Mapa diferença 3D na injeção do banco de água final (0.21 VP injetados).

Figura 114 - Mapa diferença 3D na injeção do banco de água final (0.41 VP injetados).

Figura 115 - Mapa diferença 3D na injeção do banco de água final (0.61 VP injetados).

Figura 116 - Mapa diferença 3D na injeção do banco de água final (0.89 VP injetados).

Figura 117 - Mapa diferença 3D na injeção do banco de água final (1.0 VP injetado).

Figura 118 - Gráfico semi-log de variação da viscosidade do óleo com a taxa de cisalhamento.

Figura 119 - Ajuste dos parâmetros do modelo Power-law para o óleo do MLL-10 (K=3.36 e $n=-0.19)$.

Figura 120 - Distribuição dos tamanhos de gotas da emulsão preparada no frit de abertura nominal $10 \mu \mathrm{m}$.

Figura 121 - Distribuição dos tamanhos de gotas da emulsão preparada no frit de abertura nominal $25 \mu \mathrm{m}$.

Figura 122 - Distribuição dos tamanhos de gotas da emulsão preparada no frit de abertura nominal $60 \mu \mathrm{m}$.

Figura 123 - Representação esquemática do ensaio da gota pendente reversa [66].

Figura 124 - Parâmetros para o cálculo da tensão interfacial [66]. 
Figura 125 - Equilíbrio da gota de óleo no interior da solução aquosa [66].

Figura 126 - Representação esquemática de um tensiômetro de gota girante.

Figura 127 - Foto ao microscópio do ensaio de medida da tensão interfacial óleo/solução (f).

Figura 128 - Curva vazão $x$ diferencial de pressão

para uma amostra de arenito Berea. 


\section{Lista de Abreviaturas}

API - American Petroleum Institute;

BSW - Basic Sediments and Water;

CDC - Capillary Desaturation Curve;

CONAMA - Conselho Nacional do Meio Ambiente;

DOE - U. S. Department of Energy;

EOR - Enhanced Oil Recovery;

FPSO - Floating Production Storage and Offloading;

LDA - lamina d'água;

NORM - Naturally Occurring Radioactive Materials;

NPD - Norwegian Petroleum Directorate;

PWRI - Produced Water Re-injection;

RAO - Razão água-óleo;

RAP - Reinjeção da Água Produzida;

$\mathrm{RF}$ - Recovery Factor;

SSAO - Separador Submarino Água-Óleo;

TOG - Teor de óleos e graxas presente na água produzida, geralmente expresso em $\mathrm{mg} / \mathrm{L}$ ou ppm;

TSS - Teor de Sólidos Suspensos;

UEP - Unidade Estacionária de Produção;

URS - Unidade de remoção de sulfato;

IAPF - Injeção de água acima da pressão de fratura;

HLB - hydrophilic-lipophilic balance;

CMC - concentração micelar crítica;

STARS - Steam Thermal and Advanced Process Reservoir Simulator;

CMG - Computer Modelling Group;

HPLC - High-Performance Liquid Chromatography;

CT - Computarized Tomography;

HU - Hounsfield Unit; 


\section{Lista de Símbolos}

\section{Latinas Maiúsculas}

Ca - número de capilaridade

$\mathrm{Ca}^{*}$ - número de capilaridade crítico;

$D[p, q]$ - diâmetro médio da distribuição de tamanhos de partículas;

$D_{d}$ - diâmetro médio das gotas emulsionadas;

$D_{p}$ - diâmetro de poro;

$\mathrm{D}_{\mathrm{t}}$ - diâmetro da garganta de poro;

$E_{D}$ - eficiência de deslocamento;

$E_{H}$ - eficiência de deslocamento areal;

$E_{R}$ - eficiência de recuperação de óleo;

$E_{V}$ - eficiência de deslocamento vertical;

$\mathrm{I}$ - intensidade do raio $\mathrm{X}$ após a atenuação devido à passagem pelo meio;

$\mathrm{I}_{0}$ - intensidade do raio $\mathrm{X}$ incidente;

$\mathrm{K}$ - permeabilidade absoluta, índice de consistência do fluido;

$\mathrm{K}_{\mathrm{A}}, \mathrm{K}_{\mathrm{B}}$ - parâmetros de ajuste;

$\mathrm{K}_{\mathrm{r}}$ - permeabilidade relativa;

$\mathrm{L}$ - comprimento;

$\mathrm{M}$ - razão de mobilidade;

$\mathrm{N}_{\mathrm{c}}$ - número capilar;

$\mathrm{N}_{\mathrm{p}}$ - produção acumulada de óleo;

$\mathrm{P}_{\mathrm{c}}$ - pressão capilar;

$\mathrm{R}$ - raio;

Re - número de Reynolds;

$\mathrm{S}_{\mathrm{d}}$ - saturação de gotas capturadas atrás da frente de avanço;

Sor - saturação de óleo residual;

$\mathrm{S}_{\mathrm{wi}}$ - saturação de água inicial;

$\mathrm{S}_{\text {wir }}$ - saturação de água irredutível;

$U$ - velocidade de Darcy; 
$\mathrm{V}$ - volume;

$\mathrm{W}_{\mathrm{p}}$ - produção acumulada de água.

\section{Latinas Minúsculas}

c - concentração;

$\mathrm{d}_{\mathrm{i}}$ - diâmetro médio das partículas da classe i;

W- trabalho;

$\mathrm{x}$ - deslocamento;

$f$ - fator de bloqueio;

$\mathrm{f}_{\mathrm{i}}$ - frequência da classe de tamanho de partículas $\mathrm{i}$;

g - aceleração da gravidade;

$\mathrm{m}$ - massa;

$\mathrm{n}$ - expoente do modelo de potência, número de capilares;

q - vazão;

$\mathrm{u}$ - velocidade de fluxo;

$\mathrm{x}_{\mathrm{f}}$ - posição adimensional da frente de avanço;

\section{Gregas Maiúsculas}

$\partial$ - operador derivada parcial;

$\Delta$ - variação, diferença;

\section{Gregas Minúsculas}

$\dot{\gamma}$ - taxa de cisalhamento;

$\mu$ - viscosidade absoluta, coeficiente de atenuação do meio; 
$\alpha$ - coeficiente de redistribuição de fluxo, razão entre os raios médios das gotas emulsionadas e dos capilares;

$\alpha^{*}$ - razão crítica entre os raios médios das gotas emulsionadas e dos capilares;

$\beta$ - coeficiente de restrição de fluxo ou dano, fator de forma;

$\theta$ - ângulo de contato;

$\theta_{p}$ - fração da emulsão que flui pelos poros com diâmetro p;

$\lambda$ - coeficiente de filtração

$\rho$ - densidade absoluta;

$\sigma$ - tensão interfacial, concentração de partículas retidas por unidade de volume;

$\tau$ - tensão de cisalhamento, número de volumes porosos injetados;

$\sigma-$ tensão superficial, fator de retardamento capilar;

$\Phi-$ porosidade;

$\Phi$ - potencial; 


\section{Visão Geral do Trabalho}

O presente trabalho apresenta os resultados de um estudo na área do fluxo de macroemulsões óleo-água preparadas com petróleo viscoso da Bacia de Campos em meios porosos (sandpacks de sílica e amostras de arenito). Foi investigado o potencial uso desse tipo de emulsão como um agente de recuperação melhorada de petróleo.

Como será discutido ao longo da introdução desse trabalho, a reinjeção da água produzida representa uma forte tendência da indústria do petróleo. Em muitos casos, a água produzida pode ser descrita como uma emulsão óleo-água diluída. Apesar dos vários avanços nessa direção, o comportamento do escoamento desse fluido complexo no espaço poroso de um reservatório não é completamente conhecido. O objetivo desse trabalho é contribuir para um melhor entendimento de como emulsões óleo-água escoam em um meio poroso e como o comportamento do escoamento pode ser utilizado para o aumento da recuperação de petróleo. $O$ trabalho apresenta resultados experimentais que evidenciam este fato tanto para uma configuração 1-D como para uma configuração de "1/4 de five-spot". Um modelo macroscópico é proposto e usado para descrever o comportamento observado experimentalmente.

O trabalho está dividido em mais seis capítulos da seguinte forma:

O Capítulo 2 contém uma revisão bibliográfica sobre produção de óleos viscosos, injeção de água e gerenciamento da água produzida em campos de petróleo.

O Capítulo 3 descreve os critérios básicos para seleção de surfactantes, mecanismos da formação e estabilidade de emulsões, além de uma breve nota sobre microemulsões.

O Capítulo 4 apresenta os modelos para descrição do fluxo de emulsões em meios porosos. 
O Capítulo 5 mostra os resultados obtidos no programa experimental de injeção de macroemulsões em uma configuração 1D, utilizando sandpacks de sílica e amostras de arenito Berea e Bentheimer. Os meios porosos ensaiados cobriram um intervalo de permeabilidades de 60 a $7000 \mathrm{mD}$. Um estudo paramétrico foi feito a fim de verificar a influência de fatores como vazão de injeção, concentração de óleo emulsionado e distribuição de tamanho de gotas no fator de recuperação final de óleo em meios porosos. Os meios porosos foram saturados com o mesmo petróleo utilizado na preparação das emulsões. Durante todo o programa experimental as macroemulsões foram preparadas com uma solução aquosa de surfactante e Cloreto de Sódio preparada com água deionizada, ou seja, sem presença de sólidos. Essa é uma diferença importante entre as macroemulsões preparadas para os experimentos e uma água produzida real. Alguns resultados experimentais foram ajustados utilizando um simulador de fluxo comercial (CMG STARS ${ }^{\circledR}$ ). Para a injeção alternada de água e macroemulsões, o ajuste foi feito combinando a alteração das curvas de permeabilidade relativas do óleo e da água com a introdução de um parâmetro de adsorção de gotas emulsionadas.

O Capítulo 6 contém os resultados de um ensaio de injeção de macroemulsão em um bloco de arenito Castlegate (K=440 mD) preparado na configuração de $1 / 4$ de five-spot. $O$ deslocamento dos fluidos no meio poroso foi monitorado com o uso de tomografia computadorizada de Raios X, permitindo a visualização das modificações no padrão de fluxo provocadas pela injeção da emulsão no meio poroso.

O Capítulo 7 resume o que se pode concluir a partir dos resultados experimentais e contém sugestões para trabalhos futuros. 


\section{Fundamentos da Produção de Óleos Viscosos, Injeção e Gerenciamento de Água}

\subsection{Introdução}

O petróleo é uma substância oleosa, inflamável, geralmente menos densa que a água com cheiro característico e coloração variando entre o negro e o castanho claro, passando pelo verde e castanho-escuro. Quimicamente falando, todo petróleo é uma complexa mistura de hidrocarbonetos com diversos tipos de impurezas como compostos de Nitrogênio, Enxofre e Oxigênio, além de alguns metais como Níquel e Vanádio. As diferentes proporções de hidrocarbonetos e impurezas conferem ao óleo de cada jazida diferentes características físico-químicas e valor comercial.

A relevância do petróleo e gás na matriz energética mundial fica evidenciada na Figura 1. Apesar da crescente participação futura de outras formas de energia, esses hidrocarbonetos responderão por mais da metade da oferta de energia mundial nos próximos anos. Além disso, a cadeia de petróleo e gás tem importância fundamental em diversos outros setores da indústria como fertilizantes, plásticos, tintas e medicamentos.

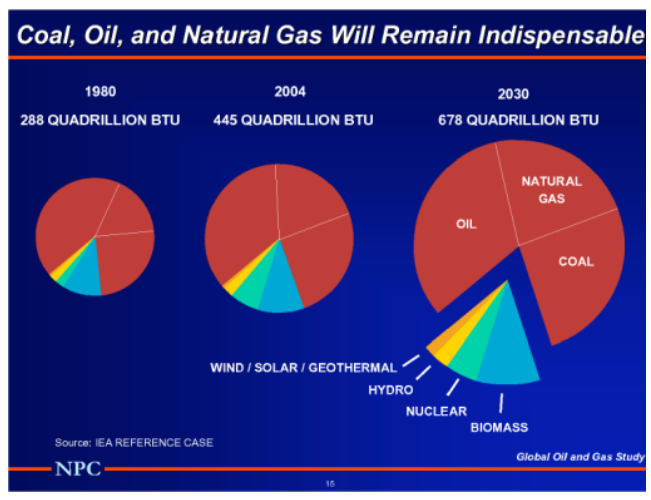

Figura 1 - Projeção da participação do petróleo na matriz energética mundial nas próximas décadas [1]. 
Boa parte do óleo e gás por produzir virá de fontes não convencionais como acumulações em folhelhos, reservatórios de baixa permeabilidade e areias betuminosas. Além dos recursos não convencionais, espera-se um aumento da participação da produção de óleos viscosos de campos de águas profundas. O esforço para aumento do fator de recuperação dos campos de petróleo inclui várias iniciativas como o adensamento da malha de drenagem, a perfuração de poços especiais (horizontais, multifraturados, completação inteligente, etc), intensivo uso de técnicas de monitoramento da movimentação dos fluidos no interior do reservatório (sísmica 4D e traçadores), além da aplicação de técnicas para recuperação melhorada de petróleo (injeção de vapor, surfactantes, polímeros, etc). A escolha de um conjunto de técnicas para melhoria da recuperação de uma jazida dependerá de diversos aspectos técnicos e econômicos.

Em campos marítimos de óleos viscosos, apenas alguns poucos métodos são capazes de atender aos requisitos de viabilidade técnica e econômica, geralmente a injeção de água ou água viscosificada com polímeros.

Do ponto de vista da produção, as características mais importantes são a densidade e a viscosidade do petróleo nos diversos níveis de pressão e temperatura que o fluido experimenta desde o fluxo na rochareservatório (meio poroso), elevação na coluna e linha de produção até a entrada nas facilidades de separação. $\mathrm{Na}$ verdade, a produção de petróleo envolve, na maioria dos casos, a produção, elevação e processamento de óleo, água e gás (Figura 2). 


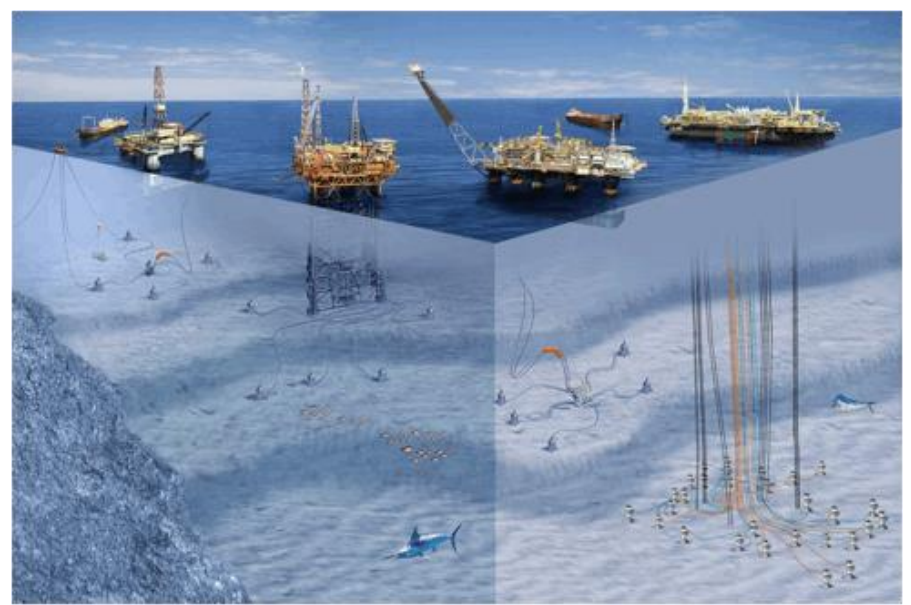

Figura 2 - Sistemas de produção de petróleo em ambiente offshore. Da esquerda para a direita aparecem um navio tanque acoplado a uma monobóia, uma plataforma fixa de produção, uma plataforma de produção semi-submersível e um FPSO (Fonte: Banco de Imagens Petrobras).

\subsection{Critérios de Classificação do Petróleo}

A medida do grau API de um óleo é a primeira classificação de um petróleo:

$$
A P I=\frac{141.5}{d_{o}}-131.5
$$

Onde $\mathrm{d}_{\mathrm{o}}$ é a densidade do óleo em relação à água a $60^{\circ} \mathrm{F}$.

De acordo com o critério do API, tem-se:

- Petróleos Leves $\rightarrow$ densidade inferior a $870 \mathrm{~kg} / \mathrm{m}^{3}$ (API > 31);

- Petróleos Médios $\rightarrow$ densidade entre 870 e $920 \mathrm{~kg} / \mathrm{m}^{3}(22.3$ < $\mathrm{API}<31.1)$;

- Petróleos Pesados $\rightarrow$ densidade entre 920 e 1000 kg/m³ (10 $<\mathrm{API}<22.3)$;

- Petróleos Extrapesados $\rightarrow$ densidade acima de $1000 \mathrm{~kg} / \mathrm{m}^{3}$ $(\mathrm{API}<10)$. 
A viscosidade de um petróleo está fortemente relacionada à sua densidade. De maneira geral, os óleos de baixo grau API são mais viscosos, ou seja, seu escoamento durante a produção se dá com maior perda de carga, levando, em muitos casos, à necessidade de emprego de poços, tecnologias de produção e elevação mais caras. Como, em linhas gerais, o valor comercial de um petróleo é menor para graus API mais baixos, o desafio da produção comercial desse tipo de petróleo é imenso, principalmente nas acumulações offshore.

Outros critérios de classificação e valoração incluem a visão do refinador como:

- Teor de sais e sedimentos - afeta a vida útil das instalações de refino (corrosão);

- Teor de enxofre - afetam a qualidade dos produtos refinados;

- Presença de Níquel e Vanádio - contaminam e inativam os catalisadores nas unidades de craqueamento;

- Fator de caracterização (KUOP) - é uma correlação que indica qual a natureza predominante do petróleo (parafínico ou aromático);

- Presença de ácidos naftênicos;

Uma discussão detalhada sobre essa classificação pode ser encontrada na referência [5].

\subsection{Formação do Petróleo}

A maior parte do petróleo existente na crosta terrestre foi originada a partir de sedimentos orgânicos depositados em ambientes anóxidos e convertidos em hidrocarbonetos quando submetidos à ação de pressões e temperaturas adequadas.

Um sistema petrolífero ativo compreende a existência e o funcionamento síncronos de quatro elementos (rochas geradoras, rochas-reservatório, rochas selantes e armadilhas) e dois fenômenos geológicos dependentes do tempo (migração e sincronismo). 
A rocha geradora é o local de acumulação da matéria orgânica. Os sedimentos que irão compor uma rocha geradora contém teor de matéria orgânica (Carbono Orgânico Total - COT) entre 2 e 8\% tipicamente, embora, em situações mais raras, seja possível encontrar rochas com COT de até $24 \%$. A matéria orgânica pode vir de várias fontes como fitoplâncton e zôoplancton depositados em ambientes marinhos ou lacustres. O mais importante é o ambiente deposicional seja anóxido a fim de garantir sua preservação. A continuidade do processo deposicional vai soterrando esse material, aplicando pressão e temperatura adequadas. A qualidade do hidrocarboneto gerado dependerá da origem dos sedimentos e do histórico de pressão e temperatura a que a rocha geradora foi submetida.

Processo de geração de petróleo e gás aumenta a pressão na rocha geradora, forçando a sua migração para porções mais altas da bacia sedimentar. A migração se dá geralmente por um sistema de fraturas conectando as rochas geradoras às porções mais altas da bacia.

Após a migração, o petróleo formado pode percolar até a superfície (exsudações naturais) ou se depositar em uma rocha porosa (rochareservatório). Um reservatório somente será capaz de armazenar o petróleo se houver uma estrutura chamada armadilha ("trapa") capaz de impedir seu fluxo até a superfície. Normalmente, essa condição é garantida pela existência de uma camada de rocha acima do reservatório capaz de impedir a continuidade da subida do hidrocarboneto até a superfície (rocha-selante).

O sucesso de um sistema petrolífero ainda depende do sincronismo, ou seja, que todos os elementos citados anteriormente existam no tempo "certo" em termos geológicos. A Figura 3 mostra esquematicamente um sistema petrolífero. 


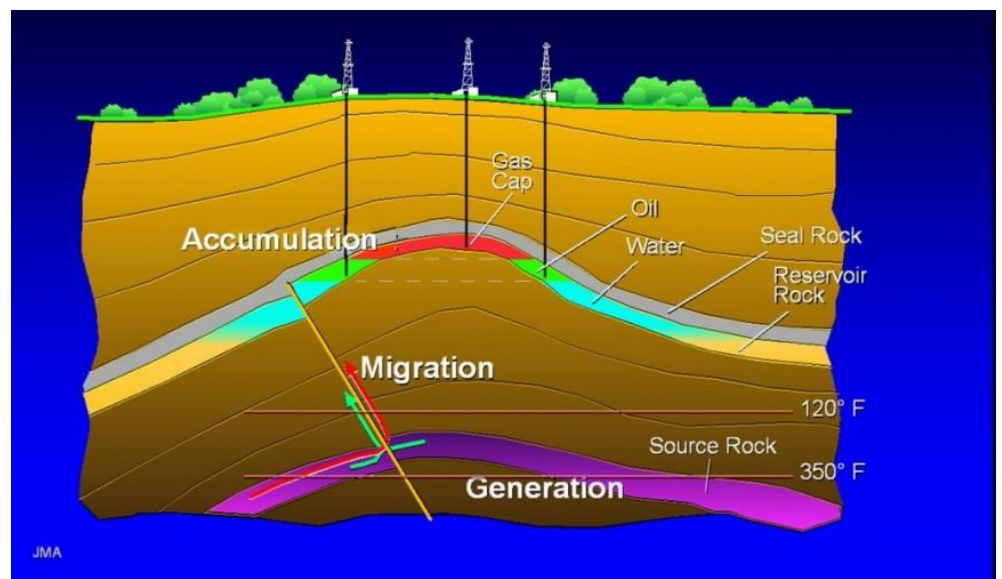

Figura 3 - Representação esquemática do sistema petrolífero (disponível em petroleumsupport.com).

A ocorrência do petróleo é relativamente comum na crosta terrestre, mas apenas algumas acumulações possuem volumes e qualidade adequados para a produção em escala comercial ("campos de petróleo").

A Figura 4 mostra alguns tipos de armadilhas encontradas em reservatórios de petróleo.

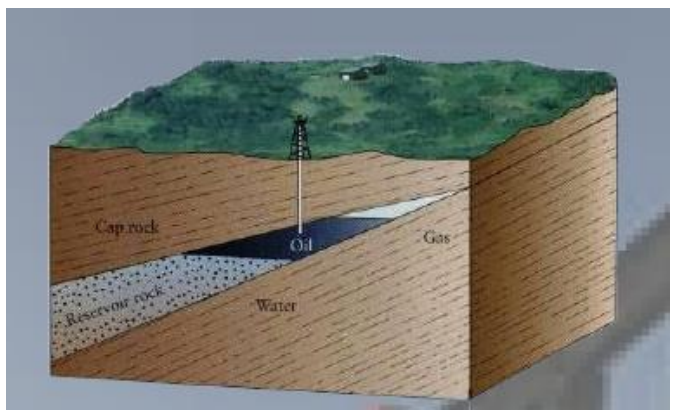

Estratigráfica

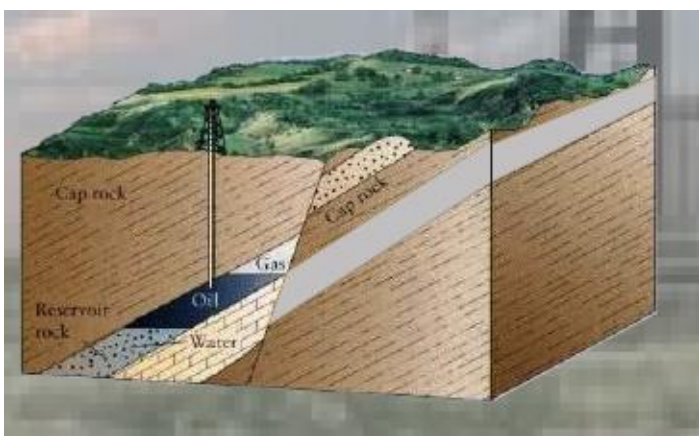

Falha

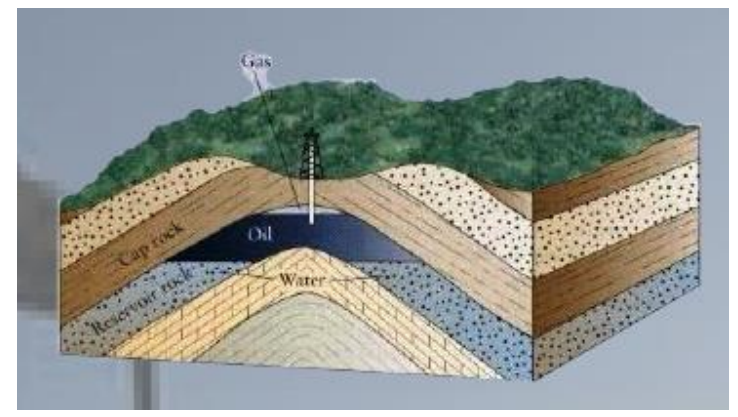

Anticlinal

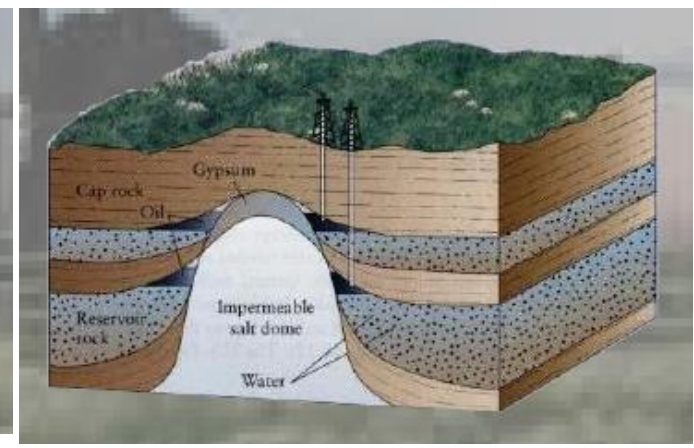

Domo de sal

Figura 4 - Tipos de armadilhas geralmente encontradas em reservatórios de petróleo (disponível em http://www.geologues-prospecteurs.fr). 
É importante destacar que o sistema petrolífero é dinâmico e susceptível a modificações ao longo do tempo geológico. Reservatórios com pequeno cobrimento sedimentar correm o risco de receberem aporte de águas superficiais (meteóricas). Essas águas acabam expondo fortemente o petróleo à ação bacteriana. As frações mais leves são usadas como fonte de energia no processo metabólico dessas bactérias. O óleo restante fica rico em frações intermediárias e pesadas, resultando em uma mistura mais densa e viscosa. Grandes depósitos de óleo viscoso biodegradado são encontrados em várias partes do mundo como, por exemplo, no Cinturão do Orinoco (Venezuela) e Canadá (região próxima da cidade de Calgary). No Brasil, importantes acumulações desse tipo de óleo existem no Rio Grande do Norte ("onshore") e em alguns campos de águas profundas da Bacia de Campos.

Reservatórios muito rasos podem ser tão expostos à ação bacteriana que somente as frações sólidas e semi-sólidas restam (betume). Esse hidrocarboneto não flui em condições de reservatório. Esse é o caso das areias betuminosas do Canadá onde baixa profundidade permite que o depósito de hidrocarbonetos seja minerado [3] (Figura 5).

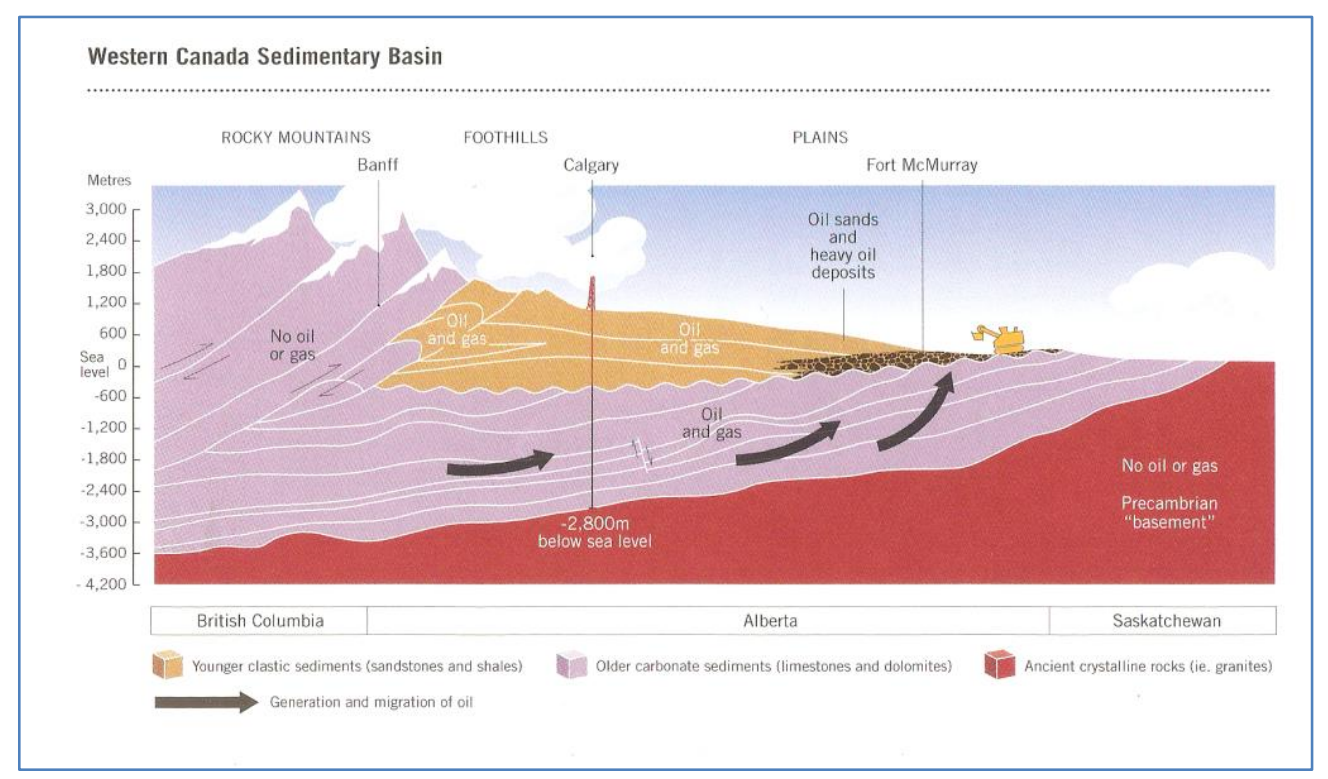

Figura 5 - Sistema petrolífero de óleo pesado na Western Basin no Canadá [3]. 


\subsection{Mecanismos de Produção}

\subsubsection{Introdução}

A produção de um campo de petróleo se dá por vários mecanismos. Cada mecanismo representa uma força motriz capaz de deslocar o óleo desde o meio poroso até os poços produtores do campo. A forma mais simples é aproveitar a energia potencial do reservatório, isto é, o diferencial de pressão entre a rocha-reservatório e a entrada das facilidades de produção. Quando esse diferencial de pressão é suficiente para elevar o petróleo até as facilidades de produção, o campo é denominado surgente. Esse mecanismo, infelizmente, conduz geralmente a fatores de recuperação final de óleo muito pequenos.

A recuperação final de uma jazida cresce quando ela recebe alguma suplementação de energia de forma natural (influxo de água de um aquífero adjacente à zona de óleo, expansão do gás em solução ou de uma capa de gás pré-existente) ou com a implantação de um projeto de injeção de um fluido no reservatório (gás ou líquido). A Figura 6 destaca os valores típicos das frações de óleo recuperadas em cada etapa da explotação de uma jazida de petróleo.

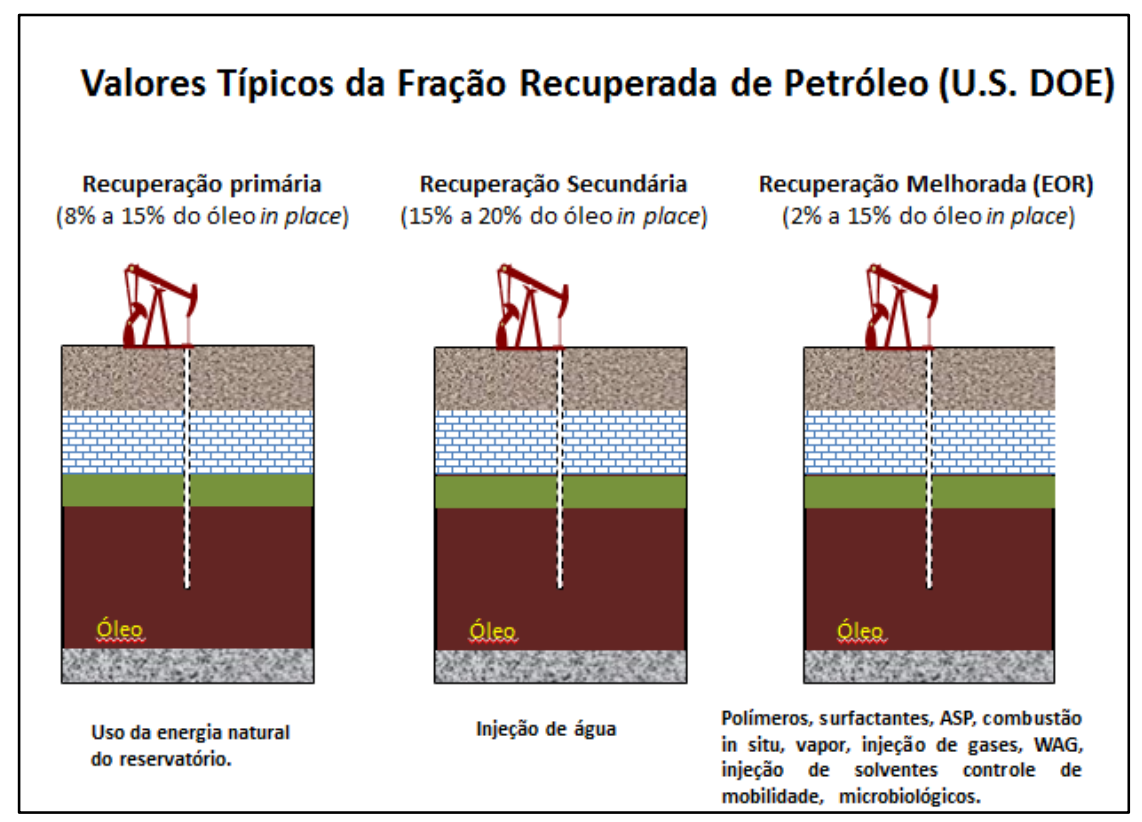

Figura 6 - Faixas esperadas das frações recuperadas de petróleo em cada etapa da explotação de uma jazida de petróleo (adaptado de U.S. DOE). 
A Figura 7 mostra alguns mecanismos de produção encontrados em reservatórios de petróleo.

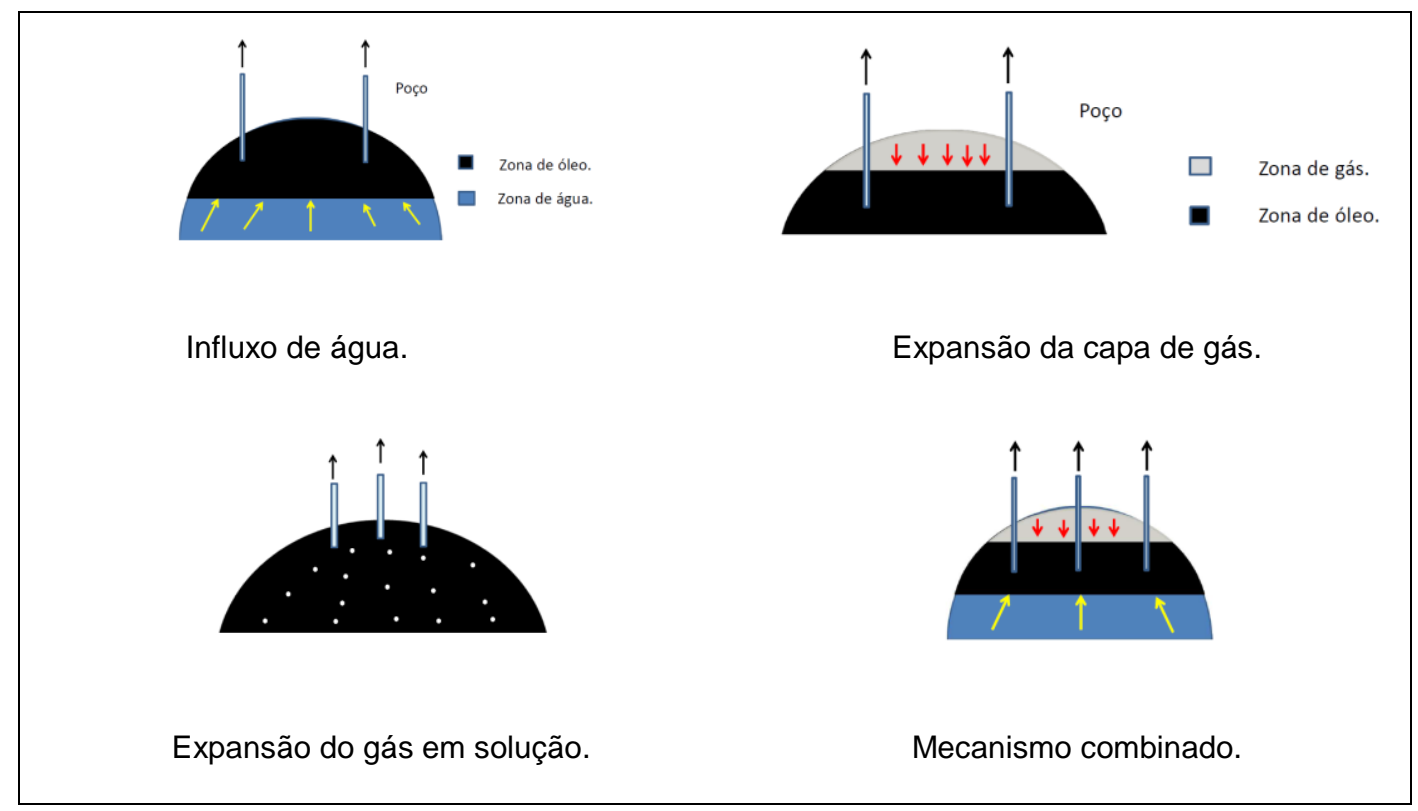

Figura 7 - Exemplos de mecanismo de produção em reservatórios de petróleo.

$\mathrm{Na}$ maioria dos projetos de explotação de petróleo, o reservatório requer suplementação de energia para manter as vazões requeridas para garantia de sua economicidade. Em campos de óleo leve ou intermediário, o método mais utilizado no mundo é a injeção de água. Em campos terrestres de óleo pesado, a injeção de vapor é largamente utilizada. Um dos maiores desafios atuais da indústria do petróleo é a produção de óleos de grau API mais baixos em ambiente offshore de lâmina d'água profunda. Nesse caso, apenas a injeção de água atende aos critérios de economicidade dos projetos, mas os fatores de recuperação final são muito baixos. Esse problema será discutido na seção a seguir.

\subsubsection{Injeção de Água e Razão de Mobilidade}

A injeção de água é o método mais utilizado na recuperação secundária de petróleo no mundo. Entretanto, os fatores de recuperação de óleo são muito baixos para óleos pesados, principalmente devido à razão de mobilidade muito alta. A razão de mobilidade é definida por: 


$$
M=\frac{\left(K_{w} @ S_{o r}\right) / \mu_{w}}{\left(K_{o} @ S_{w i}\right) / \mu_{o}}
$$

Onde:

$\mathrm{S}_{\mathrm{wi}}$ - saturação de água inicial no reservatório;

$S_{\text {or }}$ - saturação de óleo residual (imóvel) após a injeção de água;

$K_{w} @ S_{o r}$, - permeabilidade do meio á água na saturação de óleo residual;

$K_{o} @ S_{w i}$ - permeabilidade do meio ao óleo na saturação de água inicial;

$\mu_{w}, \mu_{o}$ - viscosidades da água e do óleo em condições de reservatório.

Razões de mobilidade muito maiores que 1, indicam que a água é muito mais móvel que o óleo no reservatório, impondo ao projeto produções de grandes volumes de água prematuramente. Esse é o caso dos campos de óleos viscosos submetidos a projetos de recuperação suplementar por injeção de água. Com exceção do pré-sal no Brasil e do campo de Kashagan no Cazaquistão, as descobertas mais importantes nas últimas décadas foram de acumulações de óleo médio a pesado em ambiente offshore de lâmina d'água profunda. Nesse tipo de projeto, o principal custo operacional é o tratamento da água produzida para descarte no mar.

Além disso, as heterogeneidades do reservatório, tais como a existência de regiões com pior qualidade permoporosa, falhas geológicas isolando partes do reservatório e caminhos de alta permeabilidade ligando diretamente injetores e produtores, prejudicam o varrido volumétrico do reservatório e potencializam a formação das digitações viscosas. A Figura 8 mostra, esquematicamente, a formação da digitação viscosa ("viscous fingering") e os efeitos da existência de corredores de alta permeabilidade em um reservatório de petróleo, enquanto a Figura 9 representa o efeito causado pela existência de combinada dos dois efeitos na eficiência de varrido volumétrico de óleo.

A eficiência de recuperação de óleo através da injeção de água é calculada pelo produto: 


$$
E_{R}=E_{H} \cdot E_{V} \cdot E_{D}
$$

Onde:

$E_{H}$ - eficiência de varrido areal;

$E_{V}$ - eficiência de varrido vertical;

$E_{D}$ - eficiência de deslocamento.

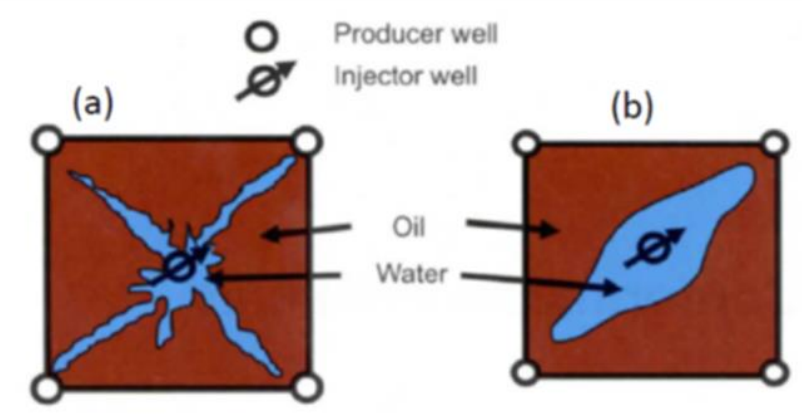

Figura 8 - Problemas de varrido areal em reservatórios (a) digitação viscosa e (b) existência de corredores de alta permeabilidade [6].

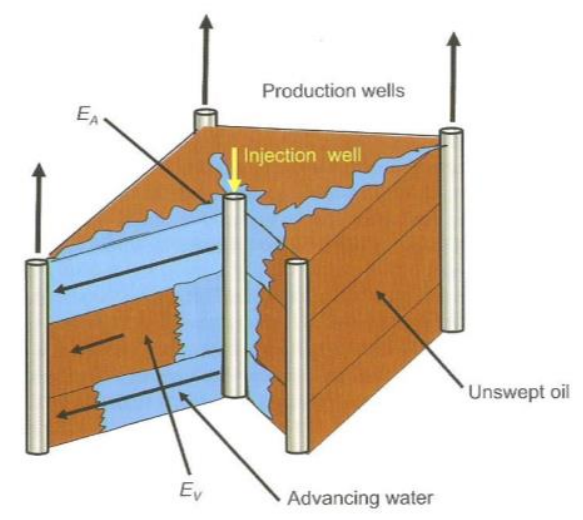

Figura 9 - Problemas de varrido volumétrico [6]

A Figura 10 mostra a formação de digitações viscosas em um bloco de arenito Bentheimer saturado com petróleo viscoso submetido à injeção de água. A trajetória da água injetada (tons de branco) é mostrada em função do volume cumulativo injetado. 


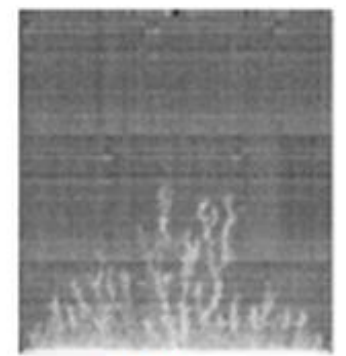

$0,01 \mathrm{VP}$

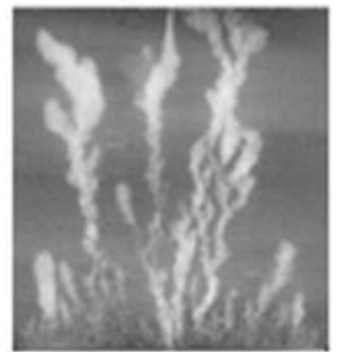

$0,14 \mathrm{VP}$

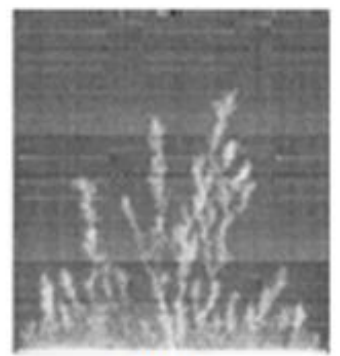

0,02 VP

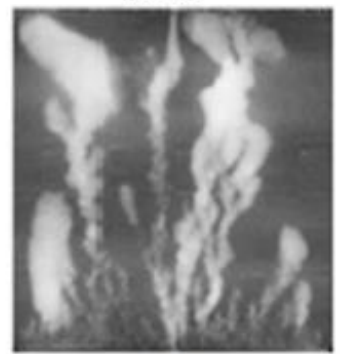

$0,53 \mathrm{VP}$

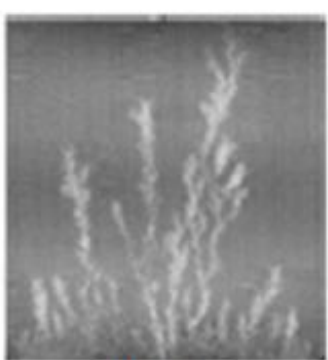

0,04 VP

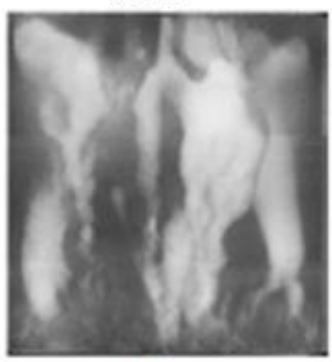

$2,3 \mathrm{VP}$

Figura 10 - Formação de digitação viscosa em bloco de arenito saturado com óleo viscoso submetido à injeção de água pela face inferior [7]. A sequência mostra a evolução do fingering viscoso com a injeção de água acumulada.

O surgimento e propagação de fingering viscoso são evitados quando a velocidade de fluxo no reservatório é menor que um valor crítico $v_{c}$, dado pela equação (4), [8]:

$$
\left(\frac{\mu_{2}}{k_{2}}-\frac{\mu_{1}}{k_{1}}\right) \cdot v_{c}+\left(\rho_{2}-\rho_{1}\right) \cdot g \cdot \cos \alpha=0
$$

Onde:

$\mu_{1}, \quad \mu_{2}-$ viscosidades dos fluidos deslocado e deslocante, respectivamente;

$\mathrm{k}_{1}, \mathrm{k}_{2}$ - permeabilidades do meio aos fluidos deslocado e deslocante;

$\rho_{1}, \rho_{2}-$ densidades absolutas dos fluidos deslocado e deslocante;

$\mathrm{g}$ - aceleração da gravidade;

$\alpha$ - inclinação do reservatório.

Manter a velocidade de fluxo no reservatório abaixo de $\mathrm{v}_{\mathrm{c}}$ conduz, em geral, a vazões de produção antieconômicas.

A eficiência de deslocamento está ligada diretamente ao padrão de fluxo trifásico de água, óleo e gás em escala microscópica pelo meio poroso. 
O controle de mobilidade em reservatórios, que leva a um aumento da eficiência de varrido, pode ser feito basicamente de 2 maneiras:

a) aumento da viscosidade do fluido deslocante (polímeros); e

b) Redução da permeabilidade relativa da água pelo emprego de algum agente capaz de bloquear o fluxo dessa fase em áreas já previamente lavadas.

Além da razão de mobilidades, o fator de recuperação final de um reservatório de petróleo é dependente de outros 5 fatores críticos:

- Comportamento de fases;

- Tensão interfacial;

- Distrbuição de tamanhos de poros;

- Molhabilidade;

- Efeitos gravitacionais

O comportamento de fases é particularmente importante em reservatórios submetidos à injeção de gás (miscível ou não) e solventes. Existem diversos tipos de gás que podem ser injetados como $\mathrm{CO}_{2}, \mathrm{~N}_{2}$, gás pobre (predomínio de metano na composição), gás rico (misturas de metano, etano e propano) ou misturas dos gases citados. O gás injetado no reservatório contacta o óleo remanescente entrando em equilíbrio termodinâmico. Nesse processo, algumas frações de hidrocarboneto são deslocadas para o fluido injetado, enriquecendo essa fase. Há a formação de um banco de hidrocarboneto que é deslocado até os produtores.

Os efeitos de molhabilidade influenciam a saturação de óleo irredutível no reservatório. Em rochas molhadas preferencialmente pelo óleo, esse fica aderido às paredes dos poros, levando a baixos fatores de recuperação. Nesses casos, existem aditivos químicos inversores de molhabilidade que podem incrementar significativamente a recuperação de óleo. 
A tensão interfacial entre as fases dificulta o deslocamento do óleo através dos poros. A diminuição da tensão interfacial é obtida pela adição de surfactantes na água de injeção.

Os reservatórios com distribuição de tamanhos de poros mais uniforme são menos propensos à formação de caminhos preferenciais na injeção de água. O resultado é um varrido mais uniforme do reservatório com maiores produções acumuladas de óleo.

Os efeitos gravitacionais são importantes em reservatórios mais espessos, onde a água de injeção se desloca para a base do reservatório e desloca a coluna de óleo verticalmente para cima na direção dos poços produtores. Esse efeito também depende da relação entre as permeabilidades vertical e horizontal. Nos reservatórios de menores espessuras, a água de injeção desloca "horizontalmente" o óleo na direção dos produtores com maior risco da formação de digitações viscosas ("fingering").

A distribuição do óleo remanescente na rocha-reservatório é explicada pelos modelos conceituais de poro-duplo e de quebra de gotas.

\subsubsection{Modelo de Poro Duplo (1959)}

O modelo "doublet pore" fornece uma visão qualitativa da posição do óleo remanescente após a passagem da frente de água. Assumindo-se as seguintes hipóteses:

- Escoamento de Hagen-Pouseille nos poros, idealizados como um feixe de capilares paralelos;

- Deslocamento dos fluidos a baixa velocidade tornando o processo quasi-estático;

- Rocha molhável à água;

- A presença da interface não perturba o fluxo nos capilares.

Considere um meio poroso hipotético composto apenas por duas classes de diâmetros de poros: poros "largos" e poros "estreitos". Durante o deslocamento dos fluidos, a interface água-óleo se desloca mais 
rapidamente nos poros estreitos devido ao maior nível de pressão capilar. A consequência é que a água de injeção atinge a saída comum aos poros mais rapidamente por esse caminho (Figura 11). Quando a água atinge esse ponto, ocorre uma invasão parcial dos poros largos e o consequente bloqueio de parte do óleo nessa classe de poros ("bypass" de gotas). A gota se encontra retida pela ação da pressão capilar aplicada agora em suas duas extremidades. Esse modelo simples permite concluir que:

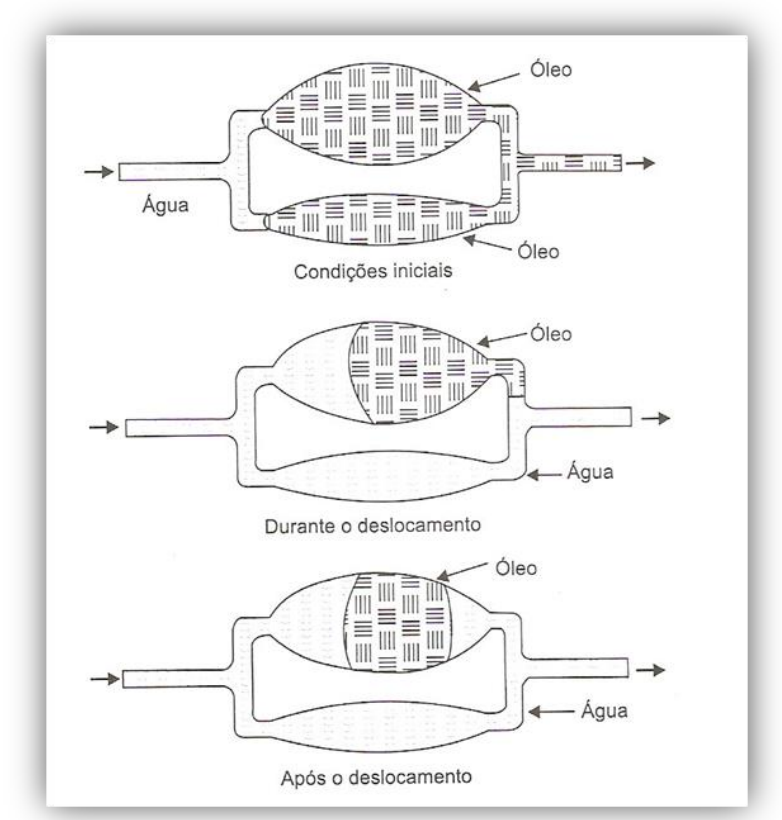

Figura 11 - Representação esquemática do deslocamento do óleo por água no modelo de poro duplo [57].

- O óleo remanescente após a injeção de água se encontra predominantemente nos poros de maior diâmetro (para rochas com molhabilidade preferencial à água);

- A diminuição das forças capilares pode provocar uma diminuição da saturação de óleo remanescente na rocha, pois a diferença de velocidade de avanço da frente nos dois poros será menor.

Segundo Rosa et al. [57], esse mecanismo é responsável por cerca de $60 \%$ a $90 \%$ de todo o óleo remanescente após a injeção de água. A 
parcela restante fica em zonas ultrapassadas pela água de injeção e em área isoladas do reservatório.

\subsubsection{Fenômento de Quebra de Gotas (1976)}

O fenômeno de quebra de gotas ("snap-off") também considera o meio poroso como um conjunto de capilares com a fase molhante (geralmente a água) envolvendo as paredes dos tubos (grãos de rocha). A pressão capilar é calculada levando em conta geometrias típicas das gargantas de poro. Em cada garganta é feito o balanço das forças aplicadas. As gotas de óleo são retidas sempre que o valor da pressão capilar à jusante é maior que o da pressão à montante da gota. $\mathrm{O}$ resultado é uma distribuição de gotas de óleo remanescente no reservatório devido ao aprisionamento capilar. A condição para uma gota fluir através de uma garganta é dada por:

$$
\Delta \emptyset_{w}+\Delta \rho \cdot g \cdot \Delta L \cdot \operatorname{sen} \theta \geq \Delta P_{c}
$$

Onde:

$\Delta \emptyset_{w}$ - diferença de potencial entre as fases molhante e não-molhante;

$\Delta \rho=\rho_{\text {água }}-\rho_{\text {óleo }} ;$

$\Delta L$ - comprimento da gota de óleo;

$\Delta P_{c}$ - diferença entre a pressão capilar a montante e a jusante da gota.

A Equação (5) indica que o escoamento da gota é condicionado pelo balanço entre as forças viscosas e capilares.

Quando a fase molhante é embebida no meio poroso (ex: injeção de água em arenitos), ela tende naturalmente a fluir ao longo das paredes do poro durante o deslocamento da fase não-molhante (tipicamente o óleo para os arenitos). A ocorrência de "bypass" ou "snap-off" é principalmente determinada pela razão entre o diâmetro da garganta $\left(D_{t}\right)$ e o diâmetro do poro $\left(D_{p}\right)$. A razão $D p / D t$ é conhecida como razão de aspecto do poro. Para razões de aspectos próximas de 1, a fase não-molhante é essencialmente deslocada pela fase molhante. Entretanto, para poros 
com razões de aspecto altas ( $D p / D t>2)$, a fase molhante tende a se movimentar próxima da parede e acaba por formar um anel em torno da gota de fase não-molhante ("snap-off"). O bloqueio capilar se estabelece quando a fase molhante atinge a extremidade oposta do poro. $\mathrm{O}$ "snapoff" é mais intenso para pequenos ângulos de contato entre a fase molhante e a parede do poro. A Figura 12 representa o fenômeno descrito.

a) Injecão da fase molhante $\mathrm{Dp} / \mathrm{Dt} \approx 1$

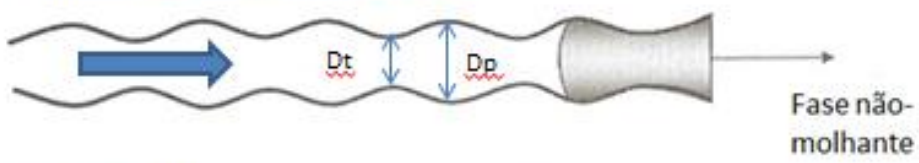

b) Injecão da fase molhante $\mathrm{Dp} / \mathrm{Dt}$ grande

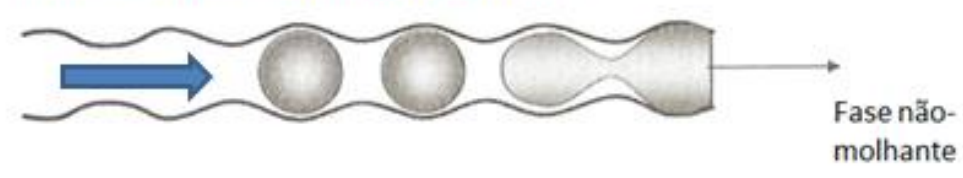

Trapeamento da fase n por snap-off em alto contraste Dt/Dp

Figura 12 - Representação do fenômeno do snap-off de gotas em um poro (adaptado de [4]).

Em um reservatório de petróleo, os poros são distribuídos em diversas classes de tamanho e a saturação de óleo remanescente depende da relação entre as forças viscosas e as forças capilares. $\mathrm{Na}$ realidade, o fenômeno observado é uma combinação dos efeitos descritos pelos 2 modelos anteriores (Figura 13).

(a) stable displacement (no trapping)
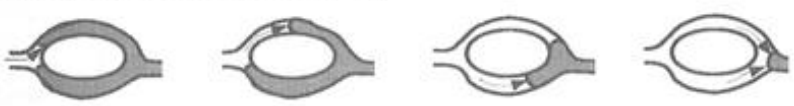

(b) trapping due to by-passing
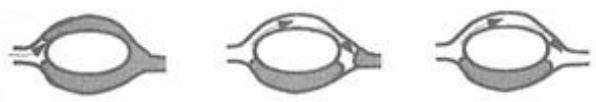

(c) trapping due to both by-passing and snap-off
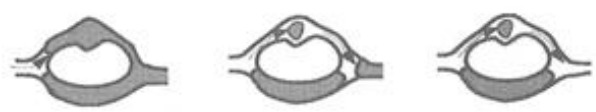

Figura 13 - Mecanismos que explicam a formação de uma saturação de óleo remanescente [4]. 
A partir dos fenômenos supracitados, pode-se afirmar que a redução da saturação de óleo remanescente em um reservatório envolve as seguintes ações no nível microscópico:

- Redução da tensão interfacial;

- Bloqueio de poros já lavados pela fase deslocante, forçando o redirecionamento do fluxo dessa fase no meio poroso.

\subsubsection{Número de Capilaridade (Nc)}

O número de capilaridade associado ao deslocamento de um fluido em um meio poroso é dado por:

$$
N_{c}=\frac{\mu_{d} \cdot U}{\sigma}
$$

Onde:

$\mu_{d}$ - viscosidade do fluido deslocante (água);

$U$ - velocidade de Darcy;

$\sigma$ - tensão interfacial entre as fases óleo e água.

O número de capilaridade representa a razão entre as forças viscosas associadas ao escoamento da fase deslocante e a força capilar entre as fases, que dificulta o deslocamento da outra fase. $O$ aumento de $N_{c}$ desloca o balanço para o lado das forças viscosas e, consequentemente, diminui a saturação da fase deslocada no poro.

Os valores do número de capilaridade variam tipicamente entre $10^{-7}$ e $10^{-6} \mathrm{em}$ projetos de injeção de água. A tensão interfacial óleo-água depende da composição do óleo, além da salinidade e temperatura da água de injeção. Os valores típicos são entre 20 e 30 dyn/cm [56], [57].

A correlação entre a saturação de óleo remanescente e o número de capilaridade é obtida em ensaios de deslocamento de óleo por água com diferentes valores de $\mathrm{N}_{c}$, construindo-se, dessa forma, a curva de dessaturação capilar do meio (CDC). Segundo Willhite [56], diversos 
pesquisadores avaliaram essa relação e construíram CDC para diferentes rochas e petróleos.

A Figura 14 é a compilação dos resultados de vários pesquisadores a partir de ensaios em amostras de arenitos Berea. Os aumentos de $\mathrm{N}_{c}$ foram obtidos através da alteração da tensão interfacial pelo uso de surfactantes ou pelo aumento da velocidade de fluxo.

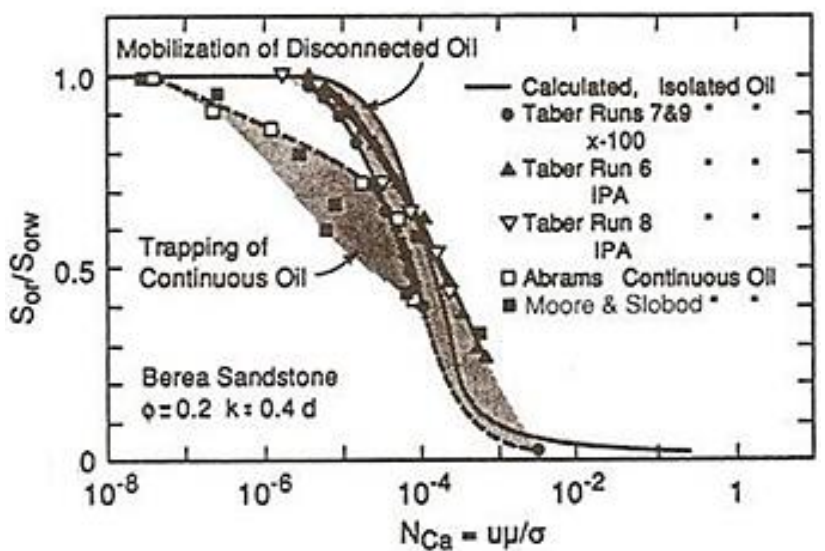

Figura 14 - Influência da variação do número de capilaridade na diminuição da saturação de óleo remanescente após a injeção de água [56].

Observando-se a curva da fase não-molhante (óleo) observa-se que existe um número de capilaridade crítico em que se observa que a saturação de óleo começa a sofrer sensível redução $\left(\mathrm{N}_{\mathrm{c}}>10^{-4}\right)$. Essa faixa de número de capilaridade pode ocorrer naturalmente nas proximidades dos poços devido ao aumento da velocidade de fluxo, mas não é atingida no interior do reservatório. Outra possibilidade de aumento do número de capilaridade é a redução da tensão interfacial pela adição de surfactantes. Surfactantes comerciais são capazes de reduzir a tensão interfacial óleo-água para valores menores que $10^{-3} \mathrm{dyn} / \mathrm{cm}$.

A melhoria de razão de mobilidade pode ser obtida através da adição de polímeros à água de injeção. Nesse caso, os problemas mais importantes são a ocorrência de adsorção parcial do produto pela rochareservatório, a perda de parte do poder de viscosificação pelo cisalhamento do polímero ao passar pelo sistema de injeção e o grande espaço requerido pelas plantas de mistura e depósitos de produto. 
Geralmente são projetos de alto custo que demandam grandes modificações nas instalações de produção.

A injeção de emulsões de óleo em água diluídas em reservatórios portadores de óleo viscoso pode contribuir significativamente para o bloqueio parcial de áreas já lavadas pela água de injeção (captura parcial das gotas de óleo emulsionadas). Além disso, a presença de um surfactante na fase contínua diminui a tensão interfacial causando a diminuição da saturação de óleo residual devido ao aumento do número de capilaridade. Essas emulsões podem ser obtidas, após tratamento adequado, a partir da água produzida pelo campo. Essa estratégia pode levar à obtenção de emulsões a baixo custo, além da redução do descarte de água oleosa no mar. Os desafios da separação e tratamento da água produzida em campos de petróleo são discutidos no próximo item. 


\subsubsection{Gerenciamento da água produzida}

\subsubsection{Introdução}

Água produzida é a água trazida até a superfície junto com a produção de óleo e gás. A água produzida por cada campo possui características físico-químicas únicas derivadas de seu contato com a rocha-reservatório e com os hidrocarbonetos da acumulação. Os componentes da água produzida geralmente incluem minerais dissolvidos oriundos da formação produtora, constituintes oleosos dissolvidos e dispersos, produtos químicos empregados durante o processo de produção, sólidos (incluindo produtos de corrosão, bactérias e asfaltenos) e gases dissolvidos (incluindo $\mathrm{CO}_{2}$ e $\mathrm{H}_{2} \mathrm{~S}$ ). A composição da água produzida por um campo de petróleo é variável ao longo do tempo devido a fatores como: a) injeção de água doce ou do mar como método de recuperação suplementar; b) influxo de aquíferos conectados à zona de óleo ou c) interações químicas entre os fluidos injetados e a rochareservatório (mais comum em reservatórios carbonáticos). Os constituintes mais importantes para a caracterização da água produzida são:

- Salinidade total;

- Teor de sólidos dissolvidos;

- Teor de óleos e graxas;

- Compostos orgânicos, inorgânicos e aditivos químicos utilizados na perfuração dos poços e nas operações de produção e

- Materiais naturais portadores de radioatividade (NORM);

Embora a primeira patente de injeção de água conhecida seja de 1865, seu largo emprego (e consequente produção de grandes volumes de água) é bem mais recente. A água é injetada no reservatório com o objetivo de manter a energia do reservatório e deslocar o óleo até aos poços produtores. 
Um fato curioso é que a injeção de água era proibida em alguns estados americanos, pois se pensava que a intenção do produtor era aumentar a produção ao vender como óleo parte da água emulsionada.

Até a primeira metade do século $\mathrm{XX}$, a produção de óleo se fazia basicamente utilizando a energia primária dos reservatórios (pressão estática, compressibilidade da rocha e expansão dos fluidos). Não se fazia a reposição dos fluidos retirados da rocha para compensar a queda de pressão que decorria da produção. O declínio de produção era, na maioria dos casos, compensado pelo adensamento da malha de drenagem dos campos. Já nessa época, o Bureau of Mines dos Estados Unidos iniciou a pesquisa nos métodos de injeção e monitoramento do deslocamento da água no meio poroso.

A descoberta do campo gigante East Texas associada à Grande Depressão iniciada em 1929, criaram superoferta de petróleo no mercado, desestimulando o investimento no aumento da produção. Na realidade, o governo criou regras que limitavam a produção dos poços a fim de manter um piso para o preço.

A eclosão da $2^{\text {a }}$ Guerra Mundial alterou dramaticamente essa situação. A produção americana foi elevada substancialmente para suprir o consumo dos exércitos aliados. Já em 1941, o American Petroleum Institute (API) manifestava sua preocupação com a disponibilidade de petróleo para o consumo doméstico no futuro. Em 1947, os Estados Unidos não mais eram autossuficientes em petróleo. O forte declínio da produção de óleo nos campos do Texas gerou um grande impulso para os estudos de viabilidade técnica de projetos de injeção de água.

Nos anos 50 entram em operação grandes projetos de injeção de água nos campos terrestres americanos. A injeção periférica foi, geralmente, a opção inicial, sendo posteriormente implantados projetos "infill drilling" nos esquemas de 5-spot, 7-spot entre outros.

Os anos 60 marcam a entrada dos primeiros simuladores de fluxo em reservatório e dos traçadores químicos e radioativos para melhor caracterização do reservatório.

A partir dos anos 70, a elevação dos preços do petróleo fez com que as companhias investissem fortemente em projetos de injeção de água 
visando auferirem grandes lucros com a antecipação da produção. Esse fenômeno ocorreu não só nos Estados Unidos, mas também em outras regiões produtoras como o Mar do Norte.

A prática atual consiste em iniciar a recuperação secundária praticamente junto com a produção dos campos, tendo em vista os benefícios em termos de gerenciamento do reservatório causados pela manutenção da pressão e o aumento do retorno econômico dos projetos de explotação.

A tendência moderna da indústria petrolífera é associar a reinjeção a um projeto integrado de gerenciamento de água. O gerenciamento integrado de água se ocupa do ciclo completo, incluindo a captação da água para injeção, sua adequação aos requisitos do campo, a coleta e tratamento da água produzida e sua destinação final (descarte ou reinjeção). O gerenciamento integrado contempla:

- Redução do volume de água produzida;

- Reuso;

- Disposição (descarte em corpos d'água ou reinjeção);

- Técnicas avançadas de tratamento;

- Uso de sísmica 4D.

Para a redução do volume de água produzida, deve-se considerar:

a) bloqueio mecânico ou químico das zonas com alta produção de água ("water shut-off");

b) Separação óleo-água em fundo de poço com reinjeção da água produzida;

c) Separação submarina com reinjeção da água produzida (SSAO) ;

d) Uso de poços com completação inteligente a fim de poder isolar as zonas com alto BSW.

O reuso da água produzida inclui a reinjeção e usos alternativos como emprego industrial (geração de vapor, uso em pavimentação de 
estradas, água industrial para limpeza, etc) e a irrigação de plantações não destinadas ao consumo humano.

A disposição inclui as alternativas do descarte em cursos de água, injeção em aquíferos superficiais, emprego de tanques de evaporação e a reinjeção para manutenção da pressão do reservatório produtor.

As técnicas avançadas de tratamento objetivam a redução dos teores de efluentes presentes na água produzida como, por exemplo, as tecnologias C-Tour e Epcon.

A sísmica 4D permite identificar as áreas do reservatório já lavadas pela injeção e o posicionamento otimizado dos poços de complemento da malha de drenagem do campo nas partes com maiores saturações de óleo remanescente.

A Figura 15 ilustra o ciclo de gerenciamento integrado de água na indústria do petróleo.

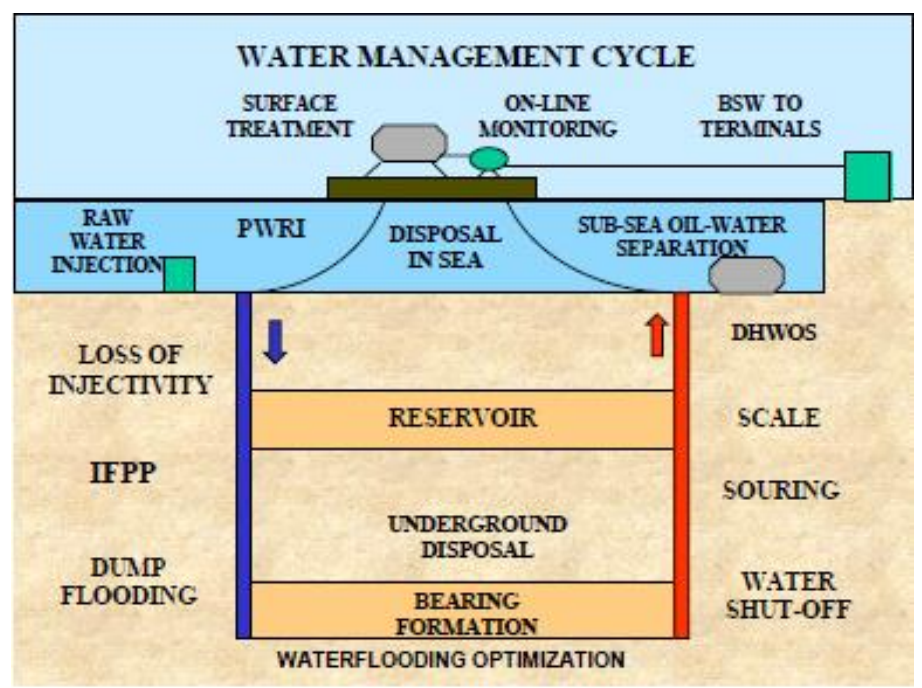

Figura 15 - Fatores críticos a serem considerados no gerenciamento de água [22].

\subsubsection{Visão geral sobre as normas para descarte da água produzida}

Os grandes projetos de injeção de água implantados nos anos 50 nos EUA utilizavam fontes de água superficiais. Entretanto, devido aos altos volumes de água necessários para repressurizar os campos, alguns especialistas já destacavam sua preocupação com a competição no uso desses recursos com o consumo humano e as atividades agrícolas. Ao mesmo tempo foram surgindo legislações mais restritivas quanto ao 
descarte da água produzida em superfície a fim de evitar a contaminação de fontes de águas superficiais, do solo e de aquíferos rasos. Esses fatores motivaram os primeiros estudos para a reinjeção da água produzida. Um dos primeiros campos a receberem PWRI foi o SACROC Complex no Texas [11]. Os principais problemas citados durante a operação desse projeto foram:

- Perda de injetividade nos poços por produtos de corrosão e formação de incrustações;

- Aumento da taxa de corrosão no sistema (bombas e filtros).

A produção offshore, em larga escala, no Golfo do México e no Mar do Norte foi iniciada no final dos anos 60. Nessa época o descarte da água produzida era feito no mar, pois a ideia corrente era de que a atmosfera e o mar eram meios "infinitos". Nos anos 70 surgiram os primeiros artigos científicos relatando a contaminação ambiental da flora e fauna marinha próximas de plataformas no Mar do Norte, gerando pressões por parte da sociedade para o estabelecimento de legislações que regulassem a descarga de efluentes no mar.

As convenções de Oslo (1972) e Paris (1974) resultaram na criação da Convenção OSPAR que regula as descargas de efluentes no Atlântico Norte. A indústria de petróleo tem suas atividades fortemente reguladas. A Comissão de Paris (PARCOM) estabeleceu os conceitos de "lista negra" e "lista verde" de efluentes. A "lista negra" inclui os compostos cuja presença em níveis detectáveis impede o descarte da água produzida no mar (basicamente Mercúrio, Cádmio e seus compostos). A "lista verde" inclui os compostos cuja concentração na água produzida deve ser mantida sempre abaixo do limite estabelecido, como metais pesados, rádionuclídeos e hidrocarbonetos.

Em relação ao descarte de óleo no mar, em 2001, o TOG médio mensal foi reduzido de $40 \mathrm{mg} / \mathrm{L}$ para $30 \mathrm{mg} / \mathrm{L}$ no Mar do Norte, além do estabelecimento de uma meta de redução de $15 \%$ na tonelagem total de óleo descartada (ano-base: 2000) a partir de 2006. Esses limites forçaram muitas operadoras a implantar sistemas de descarte da água produzida em subsuperfície para continuarem operando. Mais recentemente, foi 
proibido o descarte de efluentes no mar acima do paralelo $78 \mathrm{~N}$, afetando diretamente os projetos de explotação de óleo previstos para a região ártica. A Figura 16 mostra o aspecto da água produzida por um campo de óleo leve com diferentes teores de óleo e graxa.

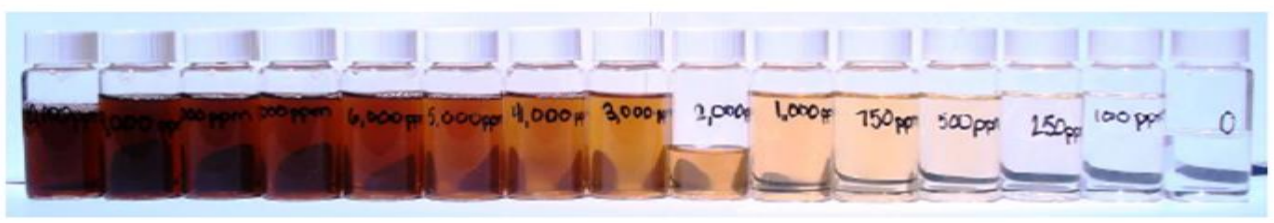

Figura 16 - Variação do aspecto da água produzida em função do teor de óleo e graxas. O TOG varia desde 10000 ppm (amostra no extremo esquerdo) até zero na extremidade direita [24].

No Brasil, a classificação dos corpos de água e as diretrizes ambientais para o seu enquadramento são reguladas pela resolução CONAMA 357/2005, enquanto as concentrações máximas de efluentes descartados pela indústria do petróleo são prescritas pelo CONAMA 393/2007. Essa legislação claramente se inspira nas resoluções OSPAR, embora não seja estabelecida uma "lista negra" de compostos ou limites de tonelagem máxima anual de óleo descartado. Cabe a crítica de que os limites deveriam levar em conta particularidades como a distância da costa onde é feito o descarte e fatores que impactam a dispersão, a evaporação e a absorção dos contaminantes como, por exemplo, a dinâmica oceânica de cada região e a incidência de radiação solar. Caso esses fatores fossem levados em consideração, os limites de concentração de alguns efluentes na água produzida pelas plataformas de águas profundas (mais distantes da costa) poderiam ser relaxados.

A moderna legislação americana estabelece os limites de concentração de efluentes considerando a capacidade de absorção do meio e as melhores tecnologias de tratamento disponíveis.

A Tabela 1 mostra os limites da concentração de óleos e graxas por região, além dos demais parâmetros monitorados. 
Tabela 1 - Comparativo das Normas para Enquadramento da Água de Descarte nos EUA, Mar do Norte e Brasil.

\begin{tabular}{|c|c|c|}
\hline Região/País & $\begin{array}{l}\text { Teores de óleos e graxas } \\
\text { admissíveis (TOG em mg/L) }\end{array}$ & Observações \\
\hline Estados Unidos & $\begin{array}{l}\text { EPA } \\
\text { Valores típicos: Média mensal }=29 \\
\text { Pico }=42 \\
\text { Valores mais reduzidos para áreas } \\
\text { costeiras, de altas latitudes e } \\
\text { adjacentes a unidades de conservação } \\
\text { ambiental. }\end{array}$ & $\begin{array}{l}\text { Monitoramento anual de } \\
\text { alguns compostos; } \\
\text { Consideração da capacidade } \\
\text { de absorção do meio para } \\
\text { determinação dos limites para } \\
\text { descarte. } \\
\text { Teores fixados utilizando o } \\
\text { conceito de Best Technology } \\
\text { Avaliable (atual = flotação a } \\
\text { gás). }\end{array}$ \\
\hline Canadá & $\begin{array}{l}\text { Média mensal = } 40 \\
\text { Pico }=80 \text { ( } 2 \text { dias } / \text { mês })\end{array}$ & $\begin{array}{l}\text { Monitoramento quadrimestral } \\
\text { de alguns compostos e } \\
\text { mensal do TOG. }\end{array}$ \\
\hline Mar do Norte & $\begin{array}{l}\text { OSPAR } \\
\text { Média mensal = } 30 \\
\text { Pico = } 100\end{array}$ & $\begin{array}{l}\text { Monitoramento anual de } \\
\text { alguns compostos (metais, } \\
\text { compostos orgânicos e } \\
\text { radioisótopos); } \\
\text { Lista verde e lista negra; } \\
\text { Meta de redução de } 15 \% \text { na } \\
\text { tonelagem total de óleo } \\
\text { descartada (ano-base: 2000) } \\
\text { já em 2007; } \\
\text { Vedado o descarte de } \\
\text { efluentes dos campos situados } \\
\text { acima do paralelo } 78 \mathrm{~N} \text {. }\end{array}$ \\
\hline Brasil & $\begin{array}{l}\text { CONAMA } 357 \text { e } 393 \\
\text { Média mensal }=29,7 / \text { Pico }=42\end{array}$ & $\begin{array}{l}\text { Monitoramento anual da } \\
\text { concentração de alguns } \\
\text { compostos; }\end{array}$ \\
\hline
\end{tabular}

Em algumas situações, é difícil o enquadramento do teor de óleos e graxas. A presença de sólidos finos suspensos, produtos de corrosão das linhas e colunas, além de aditivos utilizados na produção potencializa a formação de emulsões de óleo em água. As soluções mais comuns são o aumento do tempo de residência da água produzida no sistema de separação (com a consequente diminuição da capacidade de tratamento de fluido e diminuição do potencial de produção de óleo) ou a reinjeção da água produzida no próprio reservatório produtor ou em aquíferos profundos com características permoporosa adequadas ao descarte dessa água. 
$\mathrm{Na}$ Tabela 2 destacam-se algumas vantagens e desvantagens a serem consideradas na etapa de implantação de um projeto de reinjeção da água produzida.

Tabela 2 - Comparativo das vantagens e desvantagens da adoção da reinjeção da água produzida.

\begin{tabular}{|c|c|}
\hline Vantagens & Desvantagens \\
\hline $\begin{array}{l}\text { - Forte apelo ambiental: Transformação de } \\
\text { um efluente em um recurso; } \\
\text { - Permite o enquadramento de instalações de } \\
\text { produção antigas a normas ambientais mais } \\
\text { restritivas; } \\
\text { - Redução dos custos de tratamento da água } \\
\text { produzida; } \\
\text { - Permite o "desengargalamento" com o } \\
\text { consequente aumento da produção de água } \\
\text { em instalações "topadas" na capacidade de } \\
\text { produção de líquido. Pode ser fundamental } \\
\text { para garantir a economicidade em projetos de } \\
\text { explotação de óleos pesados e extrapesados } \\
\text { offshore; } \\
\text { - Liberação de águas superficiais para outros } \\
\text { usos; } \\
\text { - Possível aumento do fator de recuperação } \\
\text { de óleo. }\end{array}$ & $\begin{array}{l}\text { - Maior consumo de energia devido à maior } \\
\text { pressão de injeção requerida (especialmente } \\
\text { na reinjeção com propagação de fratura); } \\
\text { - Potencial de aumento na frequência de } \\
\text { intervenção nos poços para restauração do } \\
\text { índice de injetividade; } \\
\text { - Potencial de aumento da taxa de corrosão } \\
\text { das instalações de superfície e equipamentos } \\
\text { de poços; } \\
\text { - Possível aumento do potencial de geração } \\
\text { biogênica de } \mathrm{H}_{2} \mathrm{~S} ; \\
\text { - Possível aumento do potencial de } \\
\text { incrustações salinas; } \\
\text { - Possível aumento do impacto ambiental se } \\
\text { levadas em conta as emissões de } \mathrm{CO}_{2} \text { para a } \\
\text { atmosfera para geração de energia elétrica } \\
\text { (crítico nas formações de baixa } \\
\text { permeabilidade } \rightarrow \text { requerem reinjeção com } \\
\text { propagacão de fratura). }\end{array}$ \\
\hline
\end{tabular}

\subsection{Estado da Arte}

Atualmente são gerados cerca de 77 bilhões de barris anuais de água produzida nas instalações em operação no mundo [9] . Em termos mundiais, de cada 4 barris de fluido produzidos pelos campos de petróleo no mundo, 3 são de água produzida. Nas regiões produtoras mais antigas, essa proporção é significativamente maior. O DOE estimou, em 2007, que essa relação para os campos americanos maduros atingiu 9,5:1. A água produzida é o maior efluente gerado na indústria de petróleo. Segundo Sharma [2], em 2004, cerca de 98\% dos efluentes gerados pela indústria petrolífera americana eram água produzida. $\mathrm{O}$ tratamento e o descarte adequados desse efluente são o maior custo operacional dos campos maduros. Cerca de $90 \%$ da água produzida atualmente nos campos americanos é reinjetada $(71 \% \mathrm{em}$ projetos de recuperação melhorada de óleo). As demais opções de tratamento 
incluem o uso de lagoas de evaporação, o descarte em cursos de água e a filtração do óleo em membranas.

O maior projeto de reinjeção de água produzida operando nos EUA é o de Prudhoe Bay (Alasca - maior campo americano). Esse projeto foi iniciado em 1986. Em 2004, eram reinjetados 1.200 .000 bpd de água produzida e 850.000 bpd de água do mar através de 159 poços. Todos os poços injetores do campo são fraturados, sendo, dessa forma, possível injetar água com TOG's de até 2000 ppm. Outro projeto importante de reinjeção é o do East Texas Oilfield. No Golfo do México, projetos são operados em Thunder Horse e Na Kika.

Em 2004, havia mais de 20 projetos de reinjeção em operação no Mar do Norte, em campos como Forties, Ula, Gyda, Tordis, Ekofisk, Foinaven e Statfjord [14]. Devido às severas restrições ao descarte de efluentes no mar, a expectativa é atingir-se $100 \%$ de reinjeção por volta de 2020. Em geral, o fluido é produzido até as instalações de superfície, sendo a água separada e reinjetada no reservatório produtor ou em aquíferos rasos, geralmente com propagação de fratura.

Em alguns projetos mais recentes, a produção é enviada para separadores submarinos água/óleo (SSAO) antes de ser elevada até a plataforma. Esse é o caso dos projetos dos campos de Troll e Tordis. Nesses sistemas, a água é separada e reinjetada no alvo de descarte e o óleo é elevado até a superfície com BSW muito baixo. Como os TOG' s da água de reinjeção podem ser maiores que os da água para descarte, os tempos de residência do líquido no sistema são menores e a capacidade de processamento de líquido aumenta e, consequentemente, a produção de óleo e gás. $O$ aumento da capacidade de processamento de líquido ("desengargalamento") tem sido responsável pela postergação do abandono de alguns campos maduros.

No campo de Tordis, foi instalado em 2007, um sistema de separação submarina óleo-água (lâmina d'água de $220 \mathrm{~m}$ ). O sistema é capaz de processar 200.000 bpd de líquido, separando e reinjetando água com TOG de 500 ppm. O descarte não é feito no reservatório produtor, mas sim no aquífero Utsira, formação rasa que se entende por parte da plataforma continental norueguesa. A produção de óleo do campo $\left(36^{0}\right.$ 
API) é exportada por oleoduto até uma das plataformas centrais do campo de Gulfaks. Segundo o NPD, (Norwegian Petroleum Directorate), a instalação desse sistema permitiu ampliar o fator de recuperação de óleo do campo de $49 \%$ para $55 \%$. Outro campo que opera com separação submarina é o de Troll (inicio em 2001) com estimativa de ganhos de até 2.500.000 barris de óleo anuais. A Figura 17 é o layout do sistema de produção de Tordis.

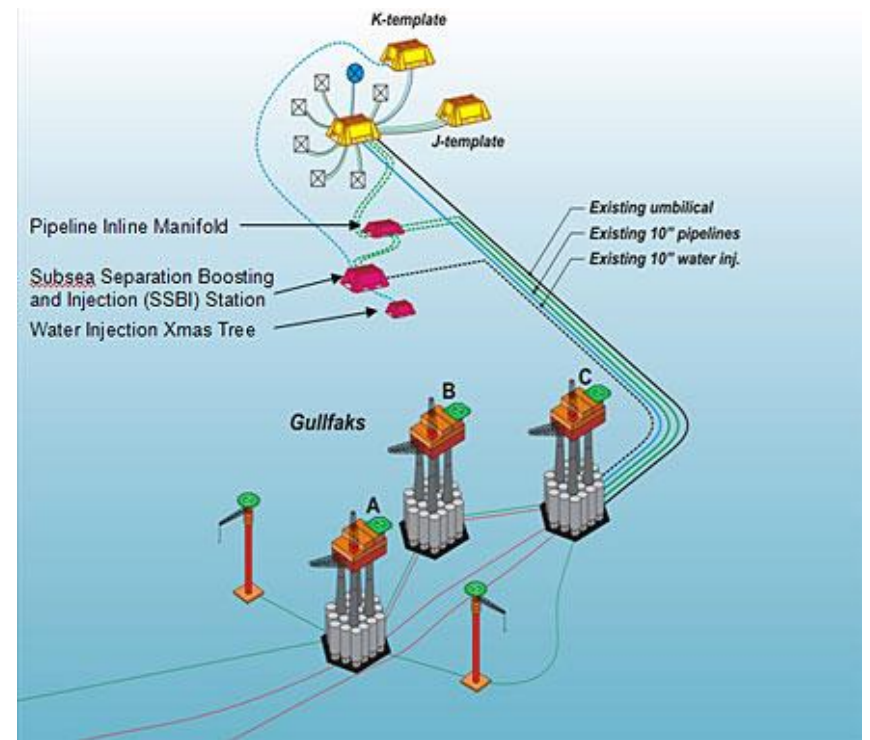

Figura 17 - Sistema de separação submarina do campo de Tordis (SSBI) (http://org.uib.no/cipr/Workshop/2009/CO2/Present/Mid/TordisIncident2008.pdf).

A crescente pressão das agências ambientais tem forçado as operadoras a investir fortemente em projetos de reinjeção. Em 2005, a Shell afirmou reinjetar cerca de $70 \%$ de sua produção de água no mundo e a BP $80 \%$. Essa tendência é observada em outros grandes operadores como a Statoil, a Total e a Conoco-Phillips, não só no Mar do Norte, mas em outras regiões produtoras como o Golfo do México e o Oeste da África.

No oeste da África, a Total opera grandes projetos no bloco 17 de Angola. Nessa região, está instalado o maior FPSO do mundo (Girassol capacidade de processamento de 450.000 bpd de líquido), drenando os campos de Girassol, Rosa e Jasmim. A água de injeção de Girassol e Jasmim é tratada em uma URS (Unidade de Remoção de Sulfato) para reduzir o potencial de incrustação dos poços de produção por Sulfato de 
Bário. Por conta da presença da URS no FPSO, a água produzida por Girassol e Jasmim contém baixos teores de sulfato em comparação com a água do mar (40-100 ppm x 2800 ppm) e será reinjetada no campo de Rosa para pressurização do reservatório. Dessa forma, Rosa terá acesso à água dessulfatada de baixo custo, melhorando a economicidade do projeto.

No Brasil, são reinjetados atualmente $80 \%$ da água produzida nos campos de terra e cerca de $10 \%$ da produzida offshore. Em ambiente offshore, há projetos operando em Pargo, Carapeba, Albacora e Marlim. Há projetos para implantação da reinjeção da água produzida nos campos de Jubarte, Cherne, Namorado, Pampo e Corvina, campos operados pela Petrobras na Bacia de Campos e do Espírito Santo. Esses projetos visam, principalmente, o desengargalamento das facilidades de produção de plataformas antigas, aumentando a capacidade de processamento de líquido e a produção de óleo. Particularmente importantes foram os projetos-pilotos de reinjeção feitos na plataforma P-35 e na P-37 (Marlim), pois coletaram dados para a implantação do separador submarino águaóleo (SSAO) no campo em 2013. Esse sistema tem capacidade de processamento de $3500 \mathrm{~m}^{3} / \mathrm{d}$ de líquido (Figura 18). O sistema recebe a produção do poço MRL-141, separa grande parte da água produzida para reinjeção no poço RJS-488. A produção de óleo e gás do MRL-141 é enviada para a plataforma P-37.

Diferenças importantes entre os sistemas de Tordis e Troll quando comparados ao projeto de Marlim são o grau API do óleo e a profundidade de instalação. O óleo de Marlim é mais pesado (Tordis, Troll $36^{\circ} \mathrm{API} \times$ Marlim $22^{\circ}$ ) e o sistema de Marlim irá operar em águas mais profundas $\left(\operatorname{LDA}_{\text {Tordis }}=200 \mathrm{~m}, \operatorname{LDA}_{\text {Troll }}=340 \mathrm{~m}\right.$ e $\left.\operatorname{LDA}_{\text {Marlim }}=950 \mathrm{~m}\right) .0$ sistema de Marlim irá processar um óleo muito mais viscoso e difícil de separar. 


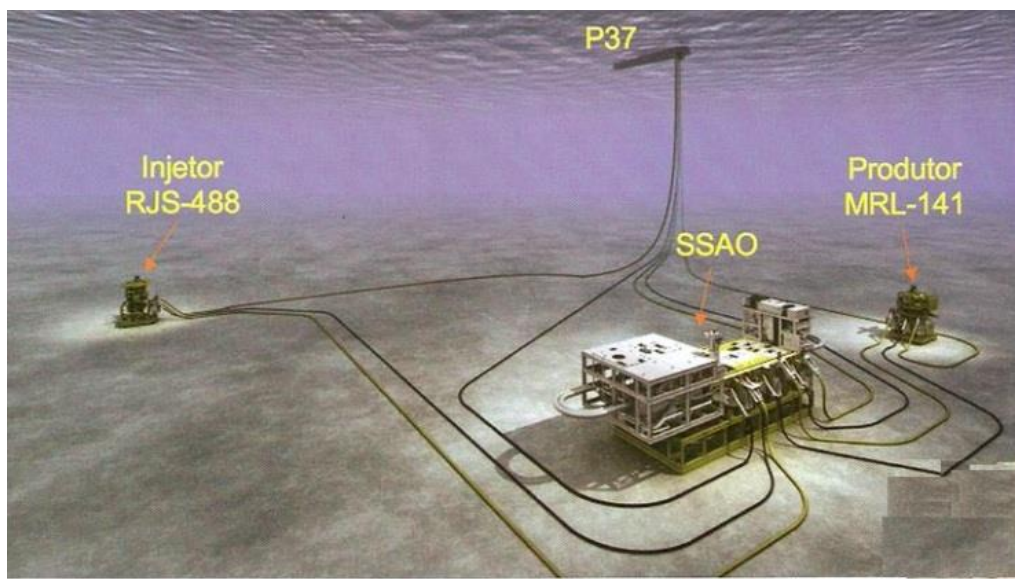

Figura 18 - Representação esquemática do sistema de separação submarina água-óleo a ser instalado no campo de Marlim [16].

A Figura 19 mostra o diagrama do sistema de reinjeção da água produzida na plataforma P-35 do campo de Marlim. Nesse sistema, parte da água é retirada no segundo estágio de separação (TO), filtrada e reinjetada no poço MRL-94. O restante da água segue no circuito "normal" de tratamento, passando por mais dois equipamentos antes do descarte no mar.

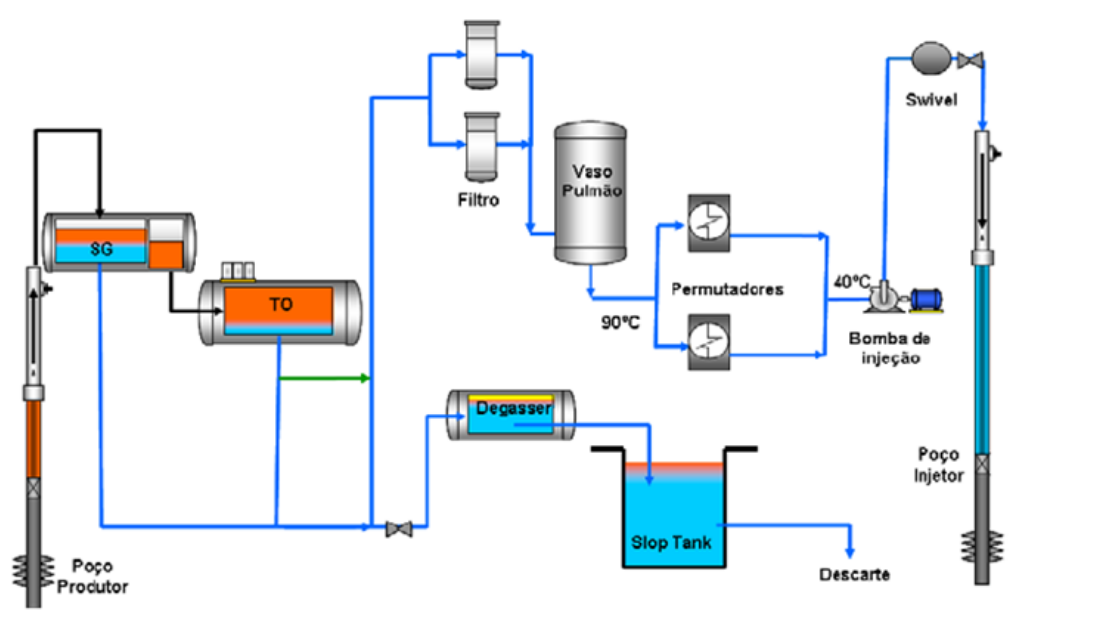

Figura 19 - Diagrama simplificado do sistema de reinjeção na plataforma P-35 do campo de Marlim [15].

Também estão previstas a reinjeção nos campos de Peregrino (operador Statoil) e Frade (operador Chevron), tendência que deverá ser 
seguida nos novos desenvolvimentos das operadoras privadas na Bacia de Campos.

\subsection{Especificação da Água de Relnjeção}

Do ponto de vista da Engenharia de Reservatórios, os dados necessários para um estudo de reinjeção da água produzida são:

- Teor de óleos e graxas da água a ser descartada e sua distribuição de diâmetros de gotas;

- Temperatura estimada de chegada da água produzida no fundo dos poços injetores;

- Teor de sólidos suspensos (TSS) e sua caracterização em termos de composição e distribuição de diâmetros de partículas;

- Dados do reservatório (mapas de permeabilidade, porosidade, razão net-to-gross, espessura, falhamentos, temperatura, distribuição de gargantas de poros e dados dos fluidos presentes);

- Pressão de fratura e orientação das tensões principais da rochareservatórios para os projetos com reinjeção acima da pressão de fratura.

A Tabela 3 é a especificação utilizada atualmente na Petrobras em projetos de injeção de água. 
Tabela 3 - Especificações da água de injeção e reinjeção utilizadas pela PETROBRAS [26].

\begin{tabular}{|c|c|c|c|c|}
\hline Tipo de rocha & Tipo de Injeção & TSS (mg/L) & TOG (mg/L) & $\begin{array}{c}\text { Tamanho } \\
\text { máximo de } \\
\text { partículas } \\
(\mu \mathrm{\mu m})\end{array}$ \\
\hline \multirow{4}{*}{$\begin{array}{c}\text { Arenito } \\
\text { Inconsolidado }\end{array}$} & AM s/IAPF & $5-20$ & - & $10-30$ \\
\cline { 2 - 5 } & AM c/IAPF & $20-50$ & - & $30-$ sem filtro \\
\cline { 2 - 5 } & AP s/IAPF & $5-20$ & $20-50$ & $10-30$ \\
\cline { 2 - 5 } & AP c/IAPF & $20-50$ & $50-200$ & $30-80$ \\
\hline \multirow{2}{*}{$\begin{array}{c}\text { Arenito } \\
\text { consolidado e } \\
\text { carbonato }\end{array}$} & AM s/IAPF & $2-10$ & - & $5-20$ \\
\cline { 2 - 5 } & AM c/IAPF & $10-30$ & $10-40$ & $5-20$ \\
\cline { 2 - 5 } & AP s/IAPF & $2-10$ & $40-100$ & $20-50$ \\
\cline { 2 - 5 }
\end{tabular}

OBS: $\mathrm{AM}$ = água do mar / AP = água produzida / IAPF = injeção de água acima da pressão de fratura.

A Tabela 4 contém os valores típicos de tamanhos de gotas de óleo presentes na água produzida na saída de diversos equipamentos da planta de processamento de plataformas de petróleo offshore. Esses valores devem ser utilizados apenas como uma aproximação inicial, pois é fundamental a determinação da distribuição de gotas de óleo na água produzida a ser reinjetada, pois ela depende de diversos fatores como o tempo de residência do fluido em cada equipamento, a temperatura de operação, da composição do óleo, além das concentrações produzidas dos diversos produtos presentes (inibidores de corrosão, desemulsificantes, biocidas, finos do reservatório, produtos da corrosão dos equipamentos, etc). 
Tabela 4 - Valores de referência para o tamanho máximo das gotas de óleo disperso na saída dos equipamentos de tratamento de água [21].

\begin{tabular}{|c|c|c|}
\hline Equipamento & Tecnologia & $\begin{array}{c}\text { Tamanho das gotas de } \\
\text { água separadas }\end{array}$ \\
\hline Separador gravitacional & Gravitacional & $>150 \mu \mathrm{m}$ \\
\hline TO & $\begin{array}{c}\text { Gravitacional + coalescência } \\
\text { das gotas de água }\end{array}$ & $>50 \mu \mathrm{m}$ \\
\hline Flotador & Flotação à gás & $>20 \mu \mathrm{m}$ \\
\hline Hidrociclones & Centrifugação & $>10 \mu \mathrm{m}$ \\
\hline Filtros de coalescência & Adsorção & $<2 \mu \mathrm{m}$ \\
\hline Filtros de absorção & Absorção & $<1 \mu \mathrm{m}$ \\
\hline Membranas & Barreira & $<$ \\
\hline
\end{tabular}

A Figura 20 mostra as tecnologias aplicáveis para atingir cada faixa de TOG e os custos atuais associados, segundo [21].

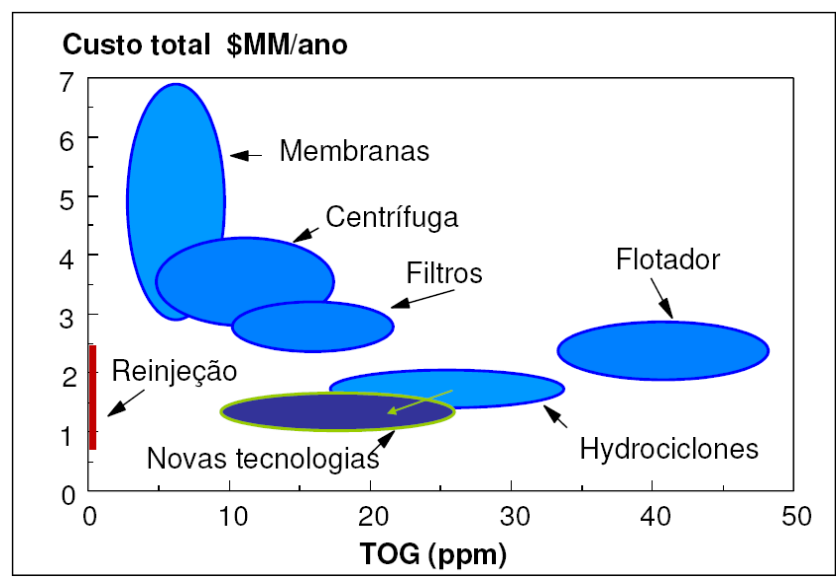

Figura 20 - Comparativo de custos das tecnologias disponíveis para tratamento da água produzida [21].

\subsection{Conclusões}

1. A reinjeção da água produzida é a tendência atual de todas as operadoras, não só pelo aspecto econômico, mas também pelo forte apelo ambiental; 
2. A reinjeção é a alternativa mais utilizada para ampliação da capacidade de produção de plataformas mais antigas limitadas pelos altos volumes de água produzida a processar;

3. A tendência atual é o aumento das restrições legais ao descarte da água produzida em superfície e, por conta disso, a implantação de projetos de reinjeção pode ser a única alternativa no futuro para que as instalações mais antigas continuem a operar;

4. Para a implantação de tecnologias emergentes na indústria de E\&P como a separação submarina, é fundamental a viabilização de projetos de reinjeção que operem com grandes intervalos entre intervenções nos poços. Por isso, é de fundamental importância o investimento na caracterização e entendimento do fluxo desse tipo de água em reservatórios de petróleo;

5. A modelagem da água produzida como uma emulsão muito diluída é uma abordagem adequada ao problema, particularmente para água com baixa concentração de partículas sólidas, cujo diâmetro médio seja pequeno em relação ao diâmetro da garganta de poro média do reservatório. Uma correlação prática estabelece que sólidos com tamanho entre 1/7 e 1/3 do diâmetro da garganta de poro tendem a ser transportados juntamente com fase contínua com menor tendência à formação de reboco no poço injetor. A deposição desses sólidos ocorre de forma distribuída na rocha (filtração profunda). Essa abordagem é a bastante simplificada, pois o efeito real da presença de sólidos e óleo emulsionado depende não só das suas concentrações e distribuição de tamanhos, mas também do tipo dos sólidos presentes [32]. 


\section{Surfactantes e Emulsões}

\subsection{Introdução}

Como discutido no capítulo anterior, a água produzida com baixo teor de sólidos pode ser considerada uma emulsão de óleo em água salina. Por conta disso, esse capítulo apresenta uma breve revisão dos conceitos fundamentais para o entendimento da formação e estabilidade de emulsões.

\subsection{Tensão Superficial e Energia Superficial Livre}

Considere um líquido e sua interface com um gás. As moléculas no interior da massa líquida são atraídas por forças iguais em todas as direções pelas outras moléculas (forças de Van der Walls no caso da água). $\mathrm{Na}$ interface isso muda, surgindo uma resultante apontada para dentro do líquido (Figura 21). Isso faz com que as moléculas da superfície estejam "desbalanceadas". Uma boa analogia para a interface é a de uma membrana esticada. A tensão superficial é a força por unidade de comprimento aplicada nessa interface. Como todo sistema mecânico tende a adotar espontaneamente a configuração de energia potencial mínima, a interface tende naturalmente a se contrair [44],[76]. Qualquer movimento do líquido que resulte no aumento da superfície (ex. a formação de uma gota na saída de um conta-gotas) resulta em um número maior de moléculas que devem ir para a superfície, impondo a necessidade da realização de um trabalho externo no sistema. 

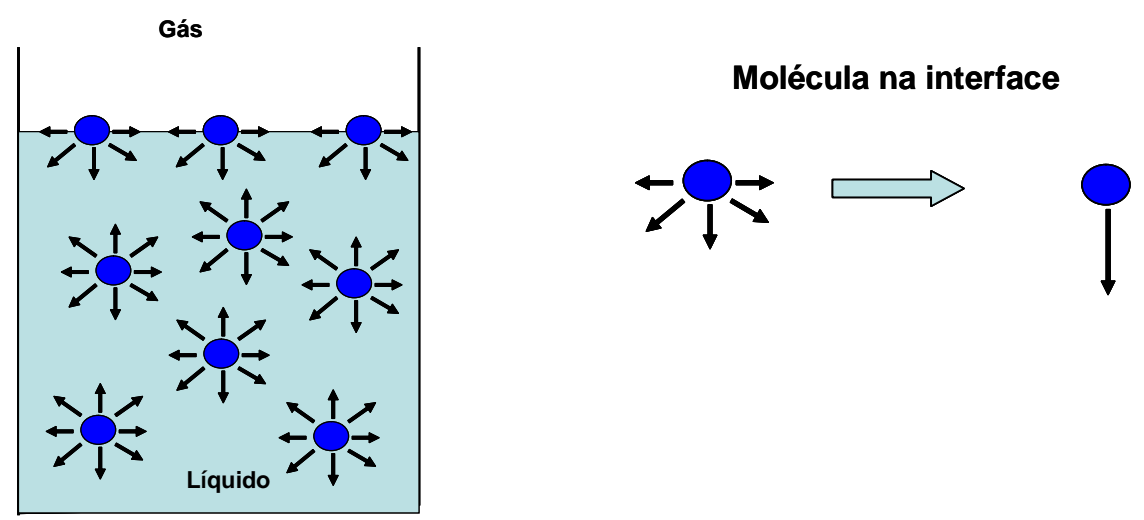

Figura 21 - Representação da tensão superficial e do balanço das forças nas moléculas na interface e no interior do líquido..

A Figura 22 representa a interface entre dois fluidos. Suponha uma força $\mathrm{F}$ aplicada para provocar um deslocamento infinitesimal $\mathrm{dx}$ dessa interface. $O$ aumento da área da interface implica, termodinamicamente, realização de um trabalho externo no sistema. A tensão interfacial $(\sigma)$ representa o trabalho necessário para acrescentar 1 unidade de área à interface (Figura 22). Esse termo é geralmente aplicado para sistemas compostos por 2 líquidos.

$$
d w=\sigma \cdot d A
$$

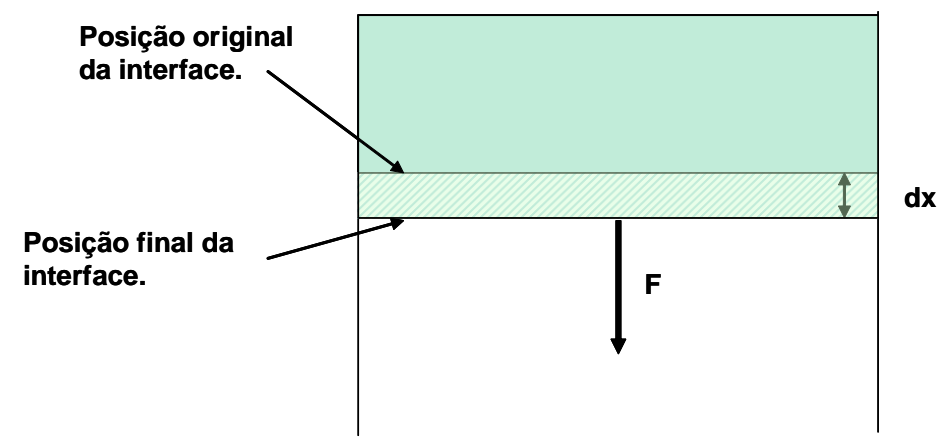

Figura 22 - Conceito de tensão interfacial.

A medida da tensão interfacial entre dois líquidos pode ser feita através de diversos tipos de ensaios como o método da placa de Wilhelmy, o método do anel de Du Nouy, o método da gota pendente, o método da gota girante, método da coluna capilar e método do peso da gota. A escolha do método mais adequado vai depender, principalmente, 
da natureza dos líquidos envolvidos e do grau de precisão requerido [44]. Nas medidas da tensão interfacial entre petróleos e soluções aquosas de surfactantes são mais utilizados os métodos da gota girante e da gota pendente.

\subsection{Molhabilidade}

O termo molhabilidade é utilizado para descrever a tendência de espalhamento ou aderência de um fluido sobre uma superfície sólida na presença de outro fluido imiscível [13].

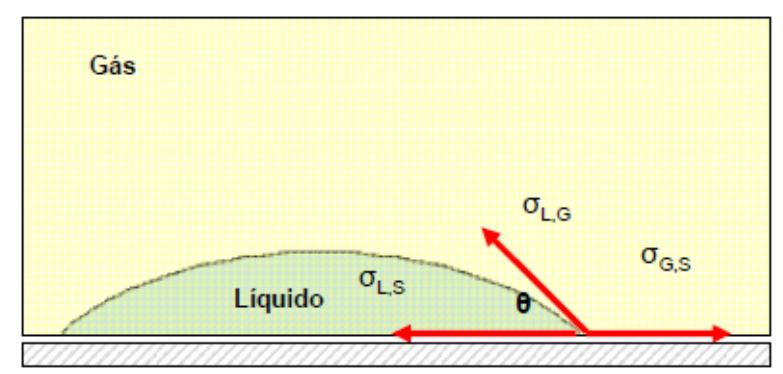

Figura 23 - Equilíbrio de uma gota de líquido em contato com um sólido.

O equilíbrio da gota é dado pela equação de Young:

$$
\sigma_{S, G}=\sigma_{L, S}+\sigma_{L, G} \cdot \cos \theta
$$

Existe uma relação forte entre a tensão superficial e a molhabilidade. As substâncias com elevada tensão superficial tendem a formar gotas praticamente esféricas sobre a superfície, molhando pouco. Isso se explica pela elevada força de atração entre as moléculas do líquido que faz com que elas tendam a se manter juntas.

Quando a tensão superficial é mais baixa, a molhabilidade é considerada intermediária $\left(0<\theta<90^{\circ}\right)$. Quando $\theta=180^{\circ}$, a molhabilidade é completa [13]. Em um reservatório de petróleo, a situação é semelhante. As fases presentes nesse caso são a rocha, o óleo, o gás e a água. A Figura 24 mostra o equilíbrio de uma gota de água em uma rocha molhável à água e ao óleo. 

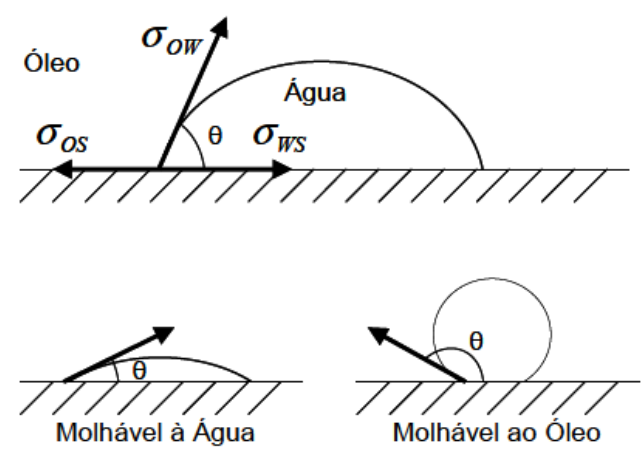

Figura 24 - Molhabilidade em rochas-reservatório [13]

Em rochas-reservatório reais, pode-se afirmar que, tipicamente reservatórios areníticos são predominantemente molháveis à água. Entre os carbonatos, a dispersão é maior, podendo-se encontrar rochas desde levemente molháveis a água até fortemente molháveis ao óleo. A Tabela 5 contém a faixa de valores do ângulo de contato tipicamente encontrados em rochas-reservatório.

Tabela 5 - Valores do ângulo de contato encontrados em rochas-reservatórios [13].

\begin{tabular}{|c|c|c|c|}
\hline Molhabilidade & Molhável à água & $\begin{array}{c}\text { Molhabilidade } \\
\text { Neutra }\end{array}$ & Molhável ao Óleo \\
\hline$\theta_{\text {mínimo }}$ & $0^{\circ}$ & $60^{\circ}$ a $75^{\circ}$ & $105^{\circ}$ a $120^{\circ}$ \\
\hline$\theta_{\text {máx }}$ & $60^{\circ}$ a $75^{\circ}$ & $105^{\circ}$ a $120^{\circ}$ & $180^{\circ}$ \\
\hline
\end{tabular}

Segundo Faerstein [13]: "Muitas vezes a molhabilidade é tratada como uma característica binária, isto é, o reservatório seria molhável à água ou ao óleo. Nessa abordagem, extremamente simplificada, despreza a complexidade dos fenômenos físicos envolvidos. A característica binária descreve apenas os casos extremos e, entre eles, há uma infinidade de graus de preferência do sólido por determinado fluido. Se o sólido não for molhável preferencialmente por nenhum dos fluidos presentes, o sistema é definido como de molhabilidade neutra ou intermediária." Também é preciso levar em conta que a alteração de parâmetros como a salinidade ou pH devido à injeção de um fluido no reservatório podem alterar o fluido que preferencialmente molha a rocha. Essa teoria é utilizada para, por 
exemplo, explicar o aumento do fator de recuperação de óleo provocado pela injeção de água de baixa salinidade.

\subsection{Surfactantes ou Tensoativos}

\subsubsection{Introdução}

A palavra surfactante é a contração do "surface active agent". Outro termo utilizado é tensoativo. O papel de um surfactante é alterar as propriedades da interface entre os fluidos, diminuindo a tensão superficial entre as fases. Dessa forma, é facilitada a formação de uma superfície de contato aumentada com menor quantidade de energia mecânica aplicada. Além disso, o surfactante forma uma barreira entre as fases que impede a coalescência entre as gotas da fase dispersa.

A representação de um surfactante é usualmente feita por uma longa cadeia carbônica de caráter oleofílica ("cauda") e uma extremidade ("cabeça") de característica hidrofílica. Os surfactantes mais utilizados em recuperação avançada de petróleo usualmente possuem uma cabeça composta por um íon $\left(\mathrm{Ca}^{++}, \mathrm{Na}^{+}, \mathrm{Cl}^{-}\right.$ou $\left.\mathrm{Br}^{-}\right)$.

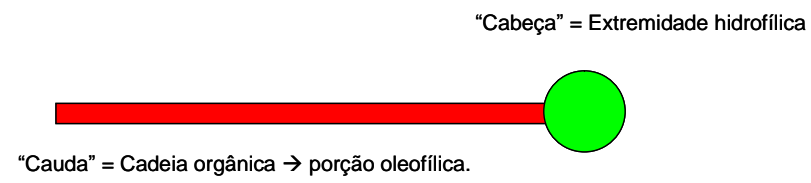

Figura 25 - Representação esquemática de uma molécula de surfactante.

\subsubsection{Classificação dos Surfactantes}

A classificação dos surfactantes é baseada na natureza química da cabeça hidrofílica.

Aniônicos: caracterizados pela carga positiva na extremidade hidrofílica quando em solução aquosa (geralmente $\mathrm{Na}+\mathrm{K}+$ e $\mathrm{Ca}++$ ). É a maior classe e a mais utilizada pela indústria. Os principais compostos dessa classe são sais de ácidos carboxílicos, sulfatos de alcoóis, sulfonatos e 
ésteres de ácido fosfórico. Esse grupo é bastante utilizado em projetos de recuperação avançada de petróleo. Sua solubilidade é bastante afetada pela presença de altas concentrações de íons na fase aquosa (principalmente água dura - altas concentrações de $\mathrm{Mg}^{++}$e $\mathrm{Ca}^{++}$) ou extremos de pH. A adição de 1 a 3 mols de óxido de eteno (EO) na molécula gera produtos com propriedades menos sensíveis à composição iônica da água. Alguns exemplos são o laureato de potássio $\left(\mathrm{CH}_{3}\left(\mathrm{CH}_{2}\right)_{10} \mathrm{COO}^{-} \mathrm{K}^{+}\right)$, o decil-sulfato de sódio $\left(\mathrm{CH}_{3}\left(\mathrm{CH}_{2}\right)_{9} \mathrm{SO}_{4}{ }^{-2} \mathrm{Na}^{+}\right)$e o hexadecilsulfonato de sódio $\left.\mathrm{CH}_{3}\left(\mathrm{CH}_{2}\right)_{15} \mathrm{SO}_{3}{ }^{-2} \mathrm{Na}^{+}\right)$.

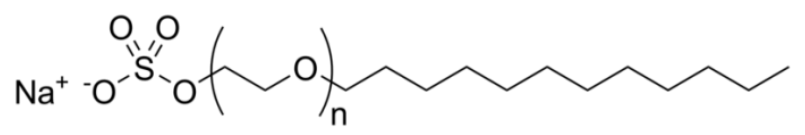

Figura 26 - Representação de uma molécula etoxilada de lauriletersulfato de sódio. O grupo eteno aparece destacado entre parênteses.

Catiônicos: caracterizados pela carga negativa da extremidade hidrofílica quando solução aquosa. Os principais compostos dessa classe são as poliaminas e seus sais, sais quartenários de amônia e óxidos de amina. De forma semelhante aos aniônicos, também são sensíveis à salinidade da água e a pH extremos. Outra característica importante é a tendência desses compostos de aderirem em superfícies sólidas sendo bastante utilizados como aditivos de óleos lubrificantes e anticorrosivos;<smiles>[R][N+]([R])([R])[R]</smiles>

Figura 27 - Representação esquemática de um surfactante baseado em sal quartenário de amônio. Os radicais $R$ podem ser ou não de um mesmo grupo funcional. Também é possível conexão entre eles.

Não-iônicos: são a segunda classe mais abundante de surfactantes. As moléculas dos surfactantes não-iônicos não se dissocia em partes "+" e "-“" em solução aquosa. São comumente sintetizados pela adição de grupos 
EO em cadeias orgânicas longas com grupos hidroxila $(\mathrm{OH}-)$ ou carboxila $(\mathrm{COOH}-)$. A adição de óxido de eteno (EO) na molécula tem por objetivo aumentar a área superficial da cabeça do tensoativo, separando fisicamente as cargas na interface e formar pontes de hidrogênio com as moléculas de água. A adição de EO também aumenta o balanço hidrofílico-lipofílico HLB do tensoativo. Esse tipo de surfactante é o mais adequado para emprego em águas duras (alta concentração de cátions $\mathrm{Ca}^{++}$e $\left.\mathrm{Mg}^{++}\right)$. Em algumas aplicações são empregados em combinação com surfactantes aniônicos, pois são geralmente compatíveis com surfactantes de outras classes, de forma a obter-se uma solução menos sensível à dureza da água do meio. Os principais compostos são alquilfenóis, alcoóis etoxilados, e alcanolamidas.

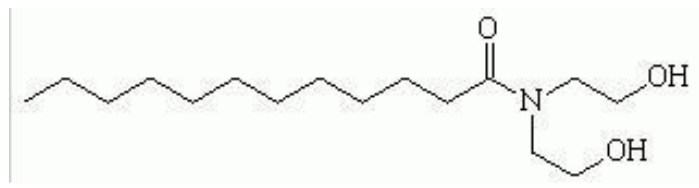

Figura 28 - Molécula da dietanolamida de ácido graxo de coco.

Anfotéricos ou zwitteriônicos: é uma classe de surfactantes que se comportam como aniônicos, catiônicos ou mesmo não-iônicos dependendo do $\mathrm{pH}$ da solução. Ainda são compostos pouco utilizados pela indústria principalmente devido ao seu alto custo. Esses compostos contêm na extremidade hidrofílica dois grupos com cargas elétricas opostas. O grupo de carga positiva é geralmente amônio, enquanto o grupo de carga negativa pode ser um carboxilato, sulfato ou sulfonato. Ex: Cocoamida - propilbetaína 2.

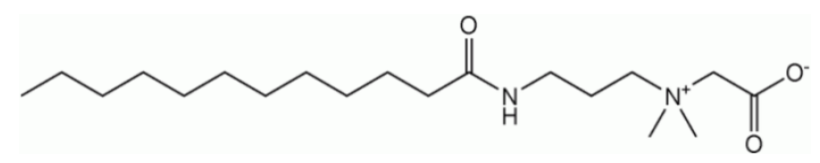

Figura 29 - Cocoamidapropil betaina 2 


\subsubsection{Regras Básicas para Seleção de Surfactantes}

Há duas regras básicas muito importantes em relação aos surfactantes:

Regra 1 (Regra de Bancroft): o líquido em que o surfactante é mais solúvel tende a se tornar a fase contínua. $O$ emulsificante é preferencialmente molhado por uma das fases. Então, ele se situa na interface entre elas com a direção convexa voltada para essa fase.

Regra 2: sabões de cátions metálicos monovalentes tendem a produzir emulsões de óleo em água, enquanto os sabões de íons polivalentes tendem a gerar emulsões de água em óleo ("Teoria da Cunha Orientada").
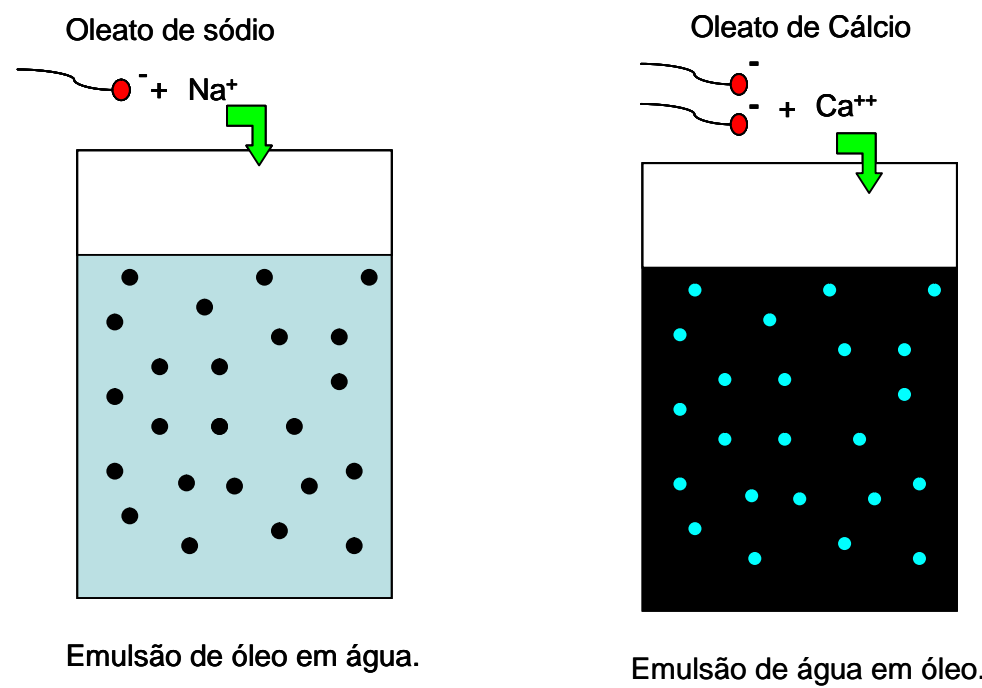

Figura 30 - Influência do cátion metálico no tipo da emulsão formada.

\subsubsection{Balanço Hidrofílico-Lipofílico (Escala HLB)}

A ação do surfactante é medida empiricamente pela escala HLB (balanço hidrofílico-lipofílico), proposta por Griffin em 1949 para surfactantes não-iônicos. Griffin construiu uma escala que vai de 1 (HLB do ácido oléico $\rightarrow$ molécula com forte caráter oleofílico) a 20 (HLB do oleato de potássio $\rightarrow$ sabão com forte caráter hidrofílico). Posteriormente, a escala foi redimensionada de 1 a 40 . O valor do HLB de um surfactante 
é calculado pela diferença entre o número hidrofílico da extremidade metálica da molécula menos o número oleofílico da sua cauda de natureza orgânica. Os valores dos números hidrofílicos e oleofílicos de cada grupo são determinados experimentalmente e existem tabelas na literatura com os valores dos grupos mais comumente encontrados nos surfactantes comerciais [44]. O HLB de um surfactante pode ser estimado por:

$H L B=7+\sum$ (grupos hidrofílicos) $-\sum$ grupos hidrofóbicos

Nas referências [44] e [45] podem ser encontradas expressões utilizadas para a determinação do balanço hidrofílico-lipofílico de algumas classes de surfactantes.

A Tabela 6 correlaciona a principal aplicação do surfactante para diversas faixas de HLB.

Tabela 6 - Relação entre o HLB e a aplicação do surfactante.

\begin{tabular}{|c|c|}
\hline Valor do HLB & Principal aplicação \\
\hline $3-6$ & Emulsões de água em óleo \\
\hline $7-9$ & Umectantes \\
\hline $8-14$ & Emulsões de óleo em água \\
\hline $9-13$ & Detergentes \\
\hline $10-13$ & Solubilizantes \\
\hline Acima de 12 & Dispersantes de sólidos em água \\
\hline
\end{tabular}

Para misturas de surfactantes, o HLB pode ser estimado pela média ponderada dos HLB's de cada composto:

$$
H L B=\sum_{i=1}^{n} w_{i} \cdot H L B_{i}
$$

Onde wi é a fração mássica de cada surfactante na mistura. Entretanto, deve-se destacar que a seleção de surfactantes é um procedimento 
eminentemente empírico. Existem situações em que misturas de dois surfactantes com o mesmo HLB possuem, paradoxalmente, melhor desempenho que o emprego de um único deles puro.

\subsection{Emulsões}

\subsubsection{Introdução}

Uma emulsão é uma dispersão em que um líquido é disperso em uma fase líquida contínua e imiscível com ele. A estabilização das gotas de líquido disperso é feita através de agentes denominados surfactantes. Os surfactantes têm função de diminuir a tensão interfacial na interface e estabilizar as gotículas da fase dispersa no interior da fase contínua. A Figura 31 mostra a classificação das emulsões baseada no tamanho das gotas da fase dispersa.

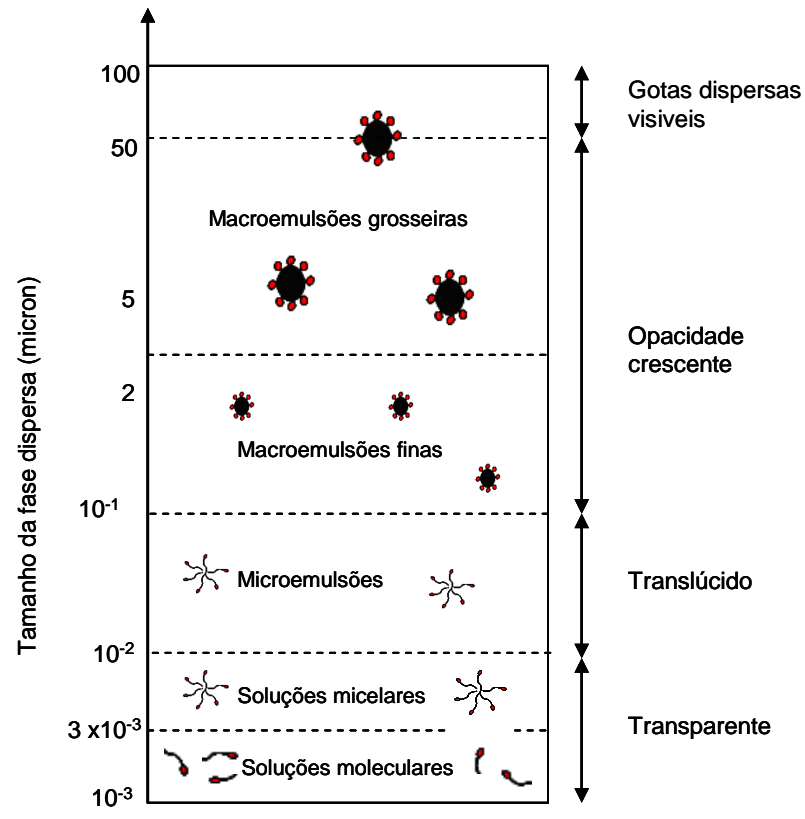

Figura 31 - Classificação das emulsões baseada no tamanho das gotas da fase dispersa.

A estabilização da fase dispersa pela ação do surfactante pode ser explicada de forma simples. As moléculas do surfactante se arranjam em torno da interface óleo-água, estabilizando-a (Figura 32). A partir daí, surge uma força de repulsão eletrostática entre as gotículas responsável pela sua dispersão no interior da fase contínua. A estabilização das gotas pode também ocorrer pela ação de outros agentes como alguns 
polímeros e sólidos finamente divididos. Existem petróleos com a presença de compostos que podem naturalmente causar o fenômeno da emulsificação.

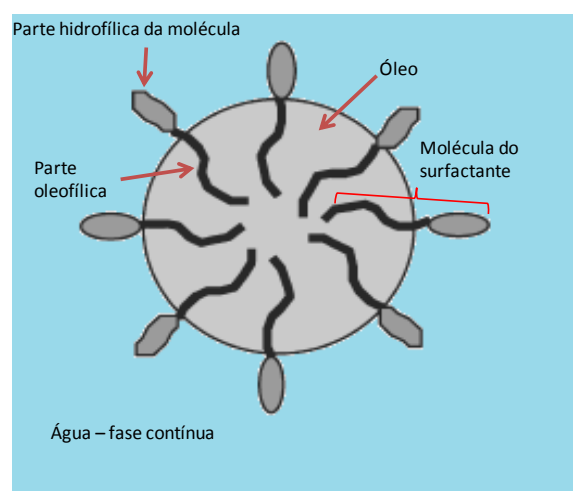

Figura 32 - Representação esquemática da ação dos surfactantes na estabilização de gotas.

$\mathrm{Na}$ indústria do petróleo, emulsões são comumente encontradas ao longo de todas as etapas da cadeia produtiva, conforme mostrado na

Tabela 7.

Tabela 7 - Tipos de emulsões encontradas na indústria de petróleo.

\begin{tabular}{|c|c|c|}
\hline Tipo/local de ocorrência & Tipo usual & Comentário \\
\hline Sistema de produção & Água-óleo & Indesejável \\
\hline $\begin{array}{l}\text { Emulsão de combustível na } \\
\text { água do mar }\end{array}$ & Água-óleo & Indesejável \\
\hline $\begin{array}{l}\text { Sistemas de separação bi } \\
\text { ou trifásicos }\end{array}$ & $\begin{array}{l}\text { Óleo-água ou água-óleo } \\
\text { (dependente da fração de } \\
\text { cada fase) }\end{array}$ & Indesejável \\
\hline $\begin{array}{l}\begin{array}{l}\text { Vazamentos de óleo em } \\
\text { ambiente } \\
\text { ("mousse") }\end{array} \\
\text { marinho }\end{array}$ & Água-óleo & Indesejável \\
\hline $\begin{array}{l}\text { Sistemas de flotação de oil } \\
\text { sands (espuma diluída). }\end{array}$ & Óleo-água-óleo & Indesejável \\
\hline $\begin{array}{l}\text { Resíduo de fundo dos } \\
\text { tanques de petroleiros }\end{array}$ & Água-óleo & Indesejável \\
\hline $\begin{array}{l}\text { Dutos de transporte de óleo } \\
\text { pesado }\end{array}$ & Óleo-água & Desejável \\
\hline $\begin{array}{l}\text { Fluido de perfuração base } \\
\text { óleo }\end{array}$ & Óleo-agua & Desejável \\
\hline $\begin{array}{l}\text { Emulsão para enhanced oil } \\
\text { recovery }\end{array}$ & Óleo-água & Desejável \\
\hline
\end{tabular}




\subsubsection{Estabilidade de Emulsões}

A estabilização de uma emulsão serve para retardar ou evitar a ocorrência dos fenômenos da agregação e coalescência.

a) Agregação $\rightarrow$ é a fusão de gotas pequenas formando um aglomerado cuja área superficial é praticamente a mesma (Figura 33).

b) Coalescência $\rightarrow$ é a fusão de gotas pequenas, provocada por choques mecânicos, para formar gotas maiores com diminuição da área superficial do sistema (Figura 34).

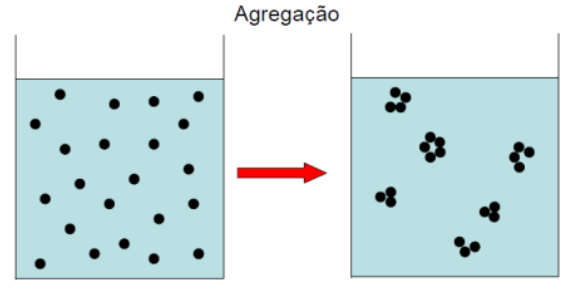

Figura 33 - Representação esquemática da agregação.

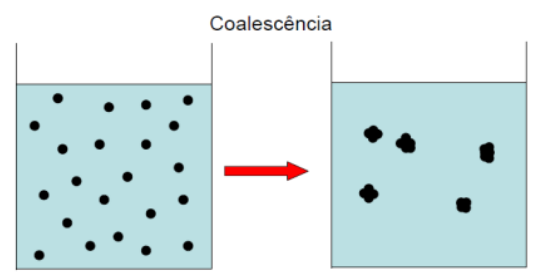

Figura 34 - Representação esquemática da coalescência.

A estabilidade de uma emulsão é aumentada pelos seguintes fatores:

- Baixos valores de tensão interfacial (energia livre) que facilitam a manutenção de uma área de contato grande;

- Filme interfacial mecanicamente forte para agir como uma barreira contra a coalescência. Esse filme é, geralmente, fortalecido pela presença de sólidos finos ou surfactantes;

- Repulsão eletrostática entre as gotas devido à presença do surfactante na superfície;

- Pequenos tamanhos de gotas da fase dispersa;

A estabilização de uma emulsão por um período de tempo adequado ao seu emprego depende de uma série de fatores de natureza física e 
química. A Figura 35 mostra as correlações entre os diversos parâmetros envolvidos.

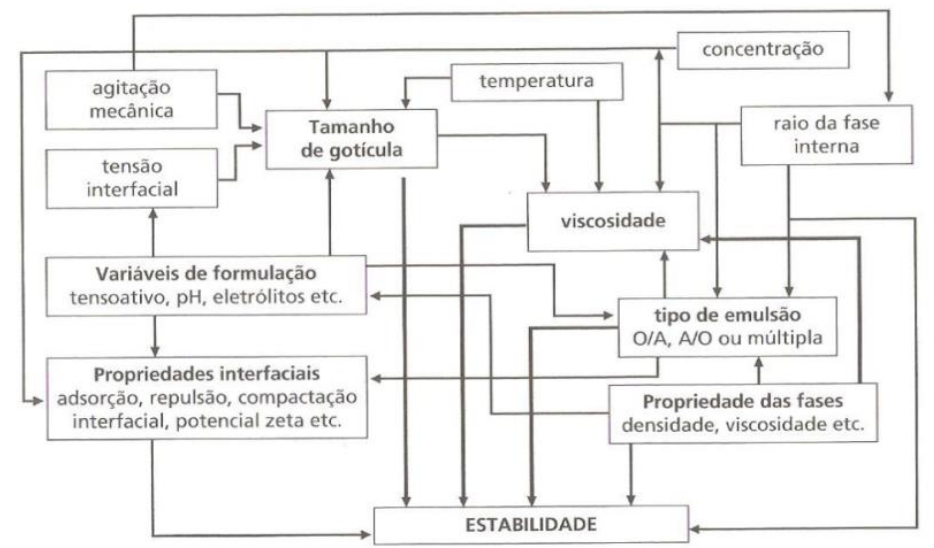

Figura 35 - Representação esquemática das correlações entre os parâmetros envolvidos no mecanismo de estabilização de emulsões [44].

\subsubsection{Concentração Micelar Crítica (CMC)}

Quando um surfactante é adicionado a um sistema bifásico, ele naturalmente tende a se concentrar na interface. Inicialmente, o aumento da concentração de surfactante é acompanhado pela diminuição da tensão interfacial. A interface aceita moléculas de surfactante até atingir uma concentração máxima. A partir daí, as moléculas de surfactante adicionadas vão se dispersando no interior da fase contínua em forma livre. O aumento da concentração de tensoativo tende a promover a formação de estruturas chamadas micelas em que as moléculas se agrupam pelas suas extremidades hidrofóbicas. Essa configuração se forma naturalmente por ser mais estável que a presença de moléculas livres na solução. A menor concentração de tensoativo em que se observa a formação de micelas é denominada concentração micelar crítica (CMC) que também corresponde ao mínimo da tensão interfacial. A determinação do $\mathrm{CMC}$ é feita experimentalmente medindo-se a tensão interfacial para diversas concentrações do surfactante até que se observe que essa atingiu um mínimo. A capacidade máxima de surfactante adicionável ao sistema depende da sua solubilidade na fase contínua. 


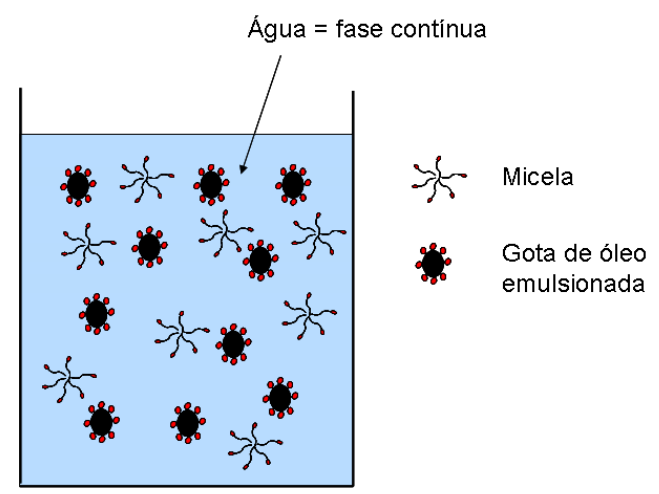

Figura 36 - Representação esquemática de uma emulsão de óleo em água com concentração de surfactante acima da CMC.

A partir da CMC, a tensão interfacial se mantém mínima e constante. Outras propriedades também podem ser utilizadas como, por exemplo, a resistividade elétrica da solução que decresce com o aumento da concentração de surfactante (o aumento da quantidade de íons dispersos no sistema provoca o aumento da condutância elétrica do sistema).

A Figura 37 mostra os diferentes formatos de micelas propostos tomando por base resultados experimentais.

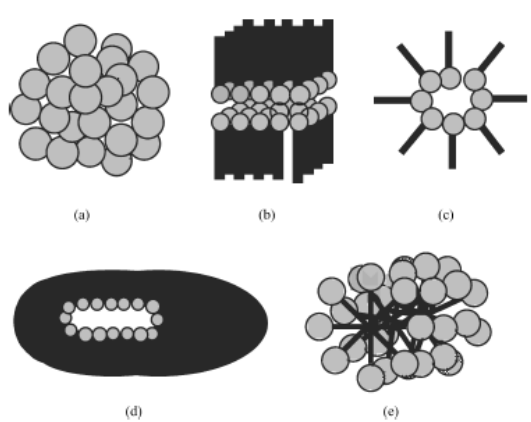

Figura 37 - Possíveis arranjos de micelas de acordo com a interpretação de dados experimentais. (a) esféricas, (b) lamelar, (c) inversa ou reversa, (d) disco e (e) cilíndrico ou barra [45].

\subsection{Microemulsões}

As microemulsões são compostas por dois líquidos imiscíveis em que uma das fases se dispersa espontaneamente na outra pela ação de um tensoativo. Em alguns casos, a ação do tensoativo é reforçada pela presença de um cotensoativo, geralmente um álcool.

É importante destacar que as microemulsões não são emulsões formadas por gotas pequenas. A aplicação de níveis crescentes de 
energia a uma emulsão é capaz de aumentar o grau de dispersão pela geração de gotas cada vez menores. O sistema formado dessa forma é denominado miniemulsão ou nanoemulsão, mas, ainda sim, é termodinamicamente instável.

A formação de uma microemulsão é espontânea, ou seja, não é necessário realizar nenhum trabalho adicional sobre o sistema. Esse fenômeno, então, está forçosamente ligado à diminuição da área interfacial, somente possível se uma das fases desaparece ou é substituída por outro tipo de estrutura.

O processo de formação de microemulsões de óleo em água começa com a existência de uma solução de surfactante em água (alto HLB) cuja concentração é bem acima da CMC. As moléculas de óleo adicionadas ao sistema espontaneamente tendem a se alojar entre os sítios lipofílicos do tensoativo. Se a quantidade de micelas presente for suficiente para microemulsionar todo o óleo adicionado ao sistema, não haverá a formação de uma fase de óleo livre no sistema. Caso contrário, o sistema formado terá as fases microemulsão e óleo livre. De forma análoga, uma solução contendo um surfactante de baixo HLB em óleo pode formar uma microemulsão de água em óleo. Esse arranjo é termodinamicamente estável, pois é atingido o mínimo de energia de Gibbs.

$\mathrm{Na}$ área de petróleo, as microemulsões têm sido empregadas com sucesso na área de EOR. A primeira aplicação de campo foi feita pela Marathon Oil em 1963 [56]. Outras aplicações em área correlatas abrangem a limpeza de solos e aquíferos contaminados por derramamentos de petróleo e derivados. Em todas essas situações, o principal mecanismo envolvido é a solubilização e transporte do óleo presente na rocha ou solo.

Para as microemulsões, Winsor propôs uma classificação baseada na natureza das fases envolvidas.

- Winsor I: quando a microemulsão está em equilíbrio com a fase orgânica (óleo) em excesso; 
- Winsor II: quando a microemulsão está em equilíbrio com excesso da fase aquosa;

- Winsor III: quando o sistema formado é trifásico, ou seja, há a presença das fases aquosa, orgânica e microemulsão;

- Winsor IV: quando o sistema é monofásico em escala macroscópica composto por uma única fase microemulsionada.
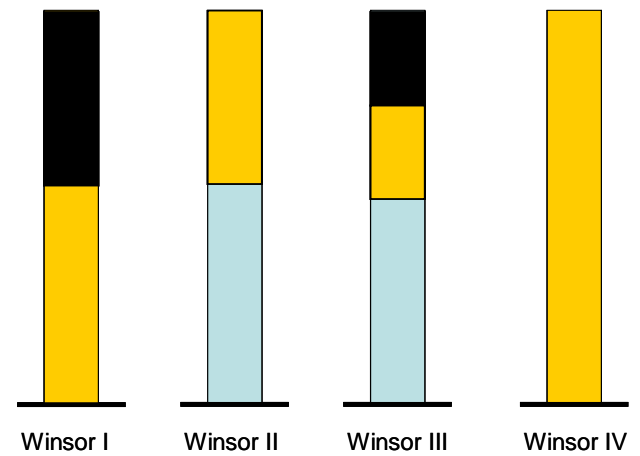

a Óleo

$\square$ Microemulsão
Água

Figura 38 - Classificação de Winsor.

Usualmente representa-se a faixa de proporções água-óleosurfactante capaz de promover o surgimento de microemulsões em um diagrama ternário como o representado na Figura 39.

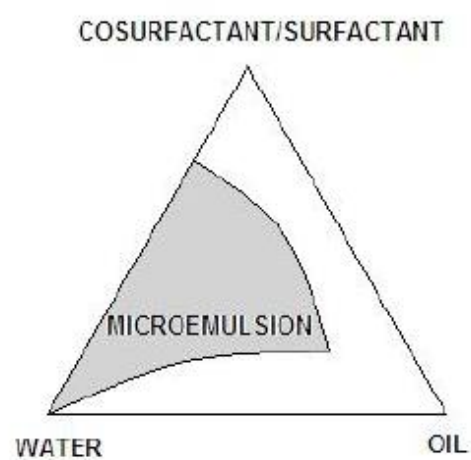

Figura 39 - Representação esquemática de um diagrama ternário óleo-água-surfactante indicando a região de formação de microemulsão [42].

A Tabela 8 mostra as diferenças fundamentais entre emulsões e microemulsões. 
Tabela 8 - Principais diferenças entre emulsões e microemulsões [43], [44]

\begin{tabular}{|c|c|}
\hline Emulsão & Microemulsão \\
\hline Termodinamicamente instável. & Termodinamicamente estável. \\
\hline $\begin{array}{l}\text { Ordem de grandeza do diâmetro de gotas da } \\
\text { fase dispersa }=10^{-6} \mathrm{~m} .\end{array}$ & $\begin{array}{l}\text { Ordem de grandeza dos agregados dispersos } \\
=10^{-9} \mathrm{~m} \text {. }\end{array}$ \\
\hline $\begin{array}{l}\text { Pequenas quantidades de surfactantes } \\
\text { requeridas para estabilização. }\end{array}$ & Grandes quantidades de surfactantes. \\
\hline Interfaces óleo-água com pequena curvatura. & Filme interfacial pode ter curvatura muito alta. \\
\hline $\begin{array}{l}\text { Necessária a agitação intensa. A distribuição } \\
\text { de diâmetros das gotas da fase dispersa } \\
\text { depende do processo de agitação empregado. }\end{array}$ & $\begin{array}{l}\text { É formada após uma ligeira agitação dos } \\
\text { ingredientes. }\end{array}$ \\
\hline Visualmente opaca. & Visualmente transparente. \\
\hline $\begin{array}{l}\text { Os tamanhos de gotas formam uma } \\
\text { distribuição polidispersa. }\end{array}$ & $\begin{array}{l}\text { Os tamanhos de gotas formam uma } \\
\text { distribuição praticamente monodispersa. }\end{array}$ \\
\hline
\end{tabular}




\section{Modelagem da Injeção de Emulsões em Meios Porosos}

\subsection{Introdução}

$\mathrm{Na}$ literatura, a descrição do escoamento de emulsões em meios porosos é feita a partir de quatro abordagens básicas:

- Modelos baseados na viscosidade ("bulk viscosity models") [50];

- Modelos de retardamento de gotas [48]

- Modelos adaptados a partir da teoria da filtração [53], [54];

- Modelos baseados no balanço de forças viscosas e capilares na escala dos poros [55], [59], [60].

O modelo de viscosidade aborda a emulsão como uma única fase e descreve seu fluxo no meio poroso de forma análoga ao de um fluido nãoNewtoniano como as soluções poliméricas. Nessa abordagem, a única diferença é a introdução de uma função material para descrever como a viscosidade da emulsão varia com a taxa de cisalhamento imposta pelo fluxo. Não se considera nenhum efeito do fluxo da emulsão sobre a permeabilidade do meio, influência da razão de diâmetros das gotas de óleo e das gargantas de poros e nem efeitos transientes ou em regime estacionário. Claramente, este modelo não é capaz de descrever os vários fenômenos observados no escoamento de emulsões através de meios porosos.

Os modelos de retardamento de gotas consideram que o fluxo é retardado pela restrição oferecida pelo meio poroso ao fluxo das gotas, principalmente, quando elas encontram gargantas de poros com diâmetros menores que os seus. A maior resistência oferecida pelo meio ao fluxo das gotas promove uma diminuição da permeabilidade local. $O$ 
regime estacionário é estabelecido no instante que as gotas eclodem na face oposta ao ponto de injeção.

Os modelos baseados na teoria clássica da filtração são adequados para descrição do fluxo de emulsões diluídas em meios porosos. A captura das gotas ocorre pelos mecanismos de bloqueio de poros (exclusão por tamanho) e por retenção pelas paredes do meio devido às interações com as paredes dos poros (semelhante ao mecanismo de filtração profunda). Um evento de retenção nas paredes reduz a área do poro disponível ao fluxo, podendo, dessa forma, ser a causa do bloqueio do poro por gotas que penetrem nele posteriormente. Os processos descritos diminuem a área aberta ao fluxo e, consequentemente, causam redução da permeabilidade local. De forma similar ao fluxo de suspensões sólidas em meios porosos, esses fenômenos acabam sendo considerados de forma indireta com o uso de modelos de transporte e funções de redução da permeabilidade local ("dano").

Os modelos baseados no balanço de forças viscosas e capilares buscam estabelecer uma relação entre o fluxo das gotas através das gargantas de poros e a redução da permeabilidade ao fluxo. A abordagem é feita da definição de uma lei de formação que estabelece a relação entre o número de capilaridade local e um fator de redução de permeabilidade local (ou fator de bloqueio). Para cada distribuição de garganta de poros e tamanho de gotas dispersas, existirá uma faixa de número de capilaridade máximo (número de capilaridade crítico) em que as gotas são capturadas pelo meio e a permeabilidade local é reduzida. Para números de capilaridade mais altos, o fluxo ocorre com algum aumento no diferencial de pressão, mas o bloqueio é muito pequeno ou inexistente. Esse tipo de modelagem é capaz de descrever fenômenos que não são bem descritos com modelos de filtração.

\subsection{Experimentos de McAuliffe}

McAuliffe [46] fez uma série de experimentos em arenitos Berea, Alhambra e Boise com objetivo de avaliar o potencial da injeção de emulsões óleo-água a fim de avaliar seu potencial de controle da 
digitação viscosa em campos de petróleo. Foram inicialmente preparadas emulsões com até $70 \%$ de óleo para determinação de suas propriedades. Entretanto, as emulsões efetivamente injetadas nos plugs tinham concentração de $0,5 \%$ a $3 \%$ de óleo. Os arenitos ensaiados eram de alta permeabilidade (1600 mD) e as emulsões tinham tamanhos de gotas variando entre $1 \mu \mathrm{m}$ e $12 \mu \mathrm{m}$. O gradiente de pressão aplicado (10 psi/ft = $0,023 \mathrm{kgf} / \mathrm{cm}^{2} / \mathrm{cm}$ ) foi muito grande em comparação ao gradiente aplicado em reservatórios reais $\left(0,005 \mathrm{kgf} / \mathrm{cm}^{2} / \mathrm{cm}\right)$, mas compatível com os níveis estimados nas proximidades de poços injetores. As principais conclusões desse estudo foram:

- As emulsões com concentrações de óleo acima de $60 \%$ exibiram um comportamento que ele denominou de "pseudo não-Newtoniano" no deslocamento nos meios porosos. Ele atribui esse comportamento principalmente às interações entre gotas. Particularmente cita que o aumento do gradiente de pressão entre as extremidades dos plugs provocou queda na taxa de redução da permeabilidade para os mesmos números de volumes porosos injetados nas amostras;

- As emulsões com gotas pequenas foram menos eficientes na diminuição de permeabilidade que as formadas por gotas intermediárias e grandes;

- A permeabilidade medida nos plugs sofreu uma grande redução inicial seguida de uma quase estabilização. As permeabilidades finais após a injeção de 10 volumes porosos de emulsão variaram entre $1 \%$ até $10 \%$ da inicial;

- Os arenitos de maiores permeabilidades originais sofreram menores reduções de permeabilidade;

- A redução da permeabilidade provocada pela passagem das emulsões nos plugs não foram revertidos mesmo após a posterior injeção de vários volumes porosos de água destilada; 
A Figura 40 ilustra o processo de bloqueio de poros pelas gotas de óleo de uma emulsão.

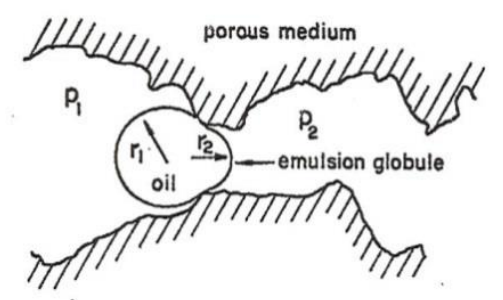

Figura 40 - Gota retida em uma garganta de poro [50].

Os resultados desse estudo motivaram um teste de injeção de emulsões no campo de Midway-Sunset nos EUA [47]. Nesse projeto foi injetado um volume de 33000 bbl de emulsão óleo-água a 14\% (3\% do volume poroso estimado da área). Os resultados foram monitorados através das vazões de óleo e água nos poços produtores próximos (Figura 41), salinidade da água produzida e uso de traçadores radioativos adicionados no banco de água injetado após o tratamento com a emulsão. Entre os resultados, destacam-se:

- Houve diminuição na vazão de água dos poços produtores monitorados, indicando que a emulsão atuou eficientemente no bloqueio das zonas com elevado grau de digitação viscosa. O ganho de óleo acumulado foi estimado em 55000 bbl calculado através da diferença entre a produção de óleo realizada e o modelo de declínio dos poços;

- O retorno dos traçadores indicou que a emulsão alterou o padrão de fluxo no reservatório, pois o traçador foi detectado em poços originalmente pouco afetados pela injeção dos poços onde a emulsão foi aplicada;

- Foram detectados aumentos nas salinidades das águas produzidas pelos produtores da área, indicando que a emulsão ampliou o varrido do reservatório. 


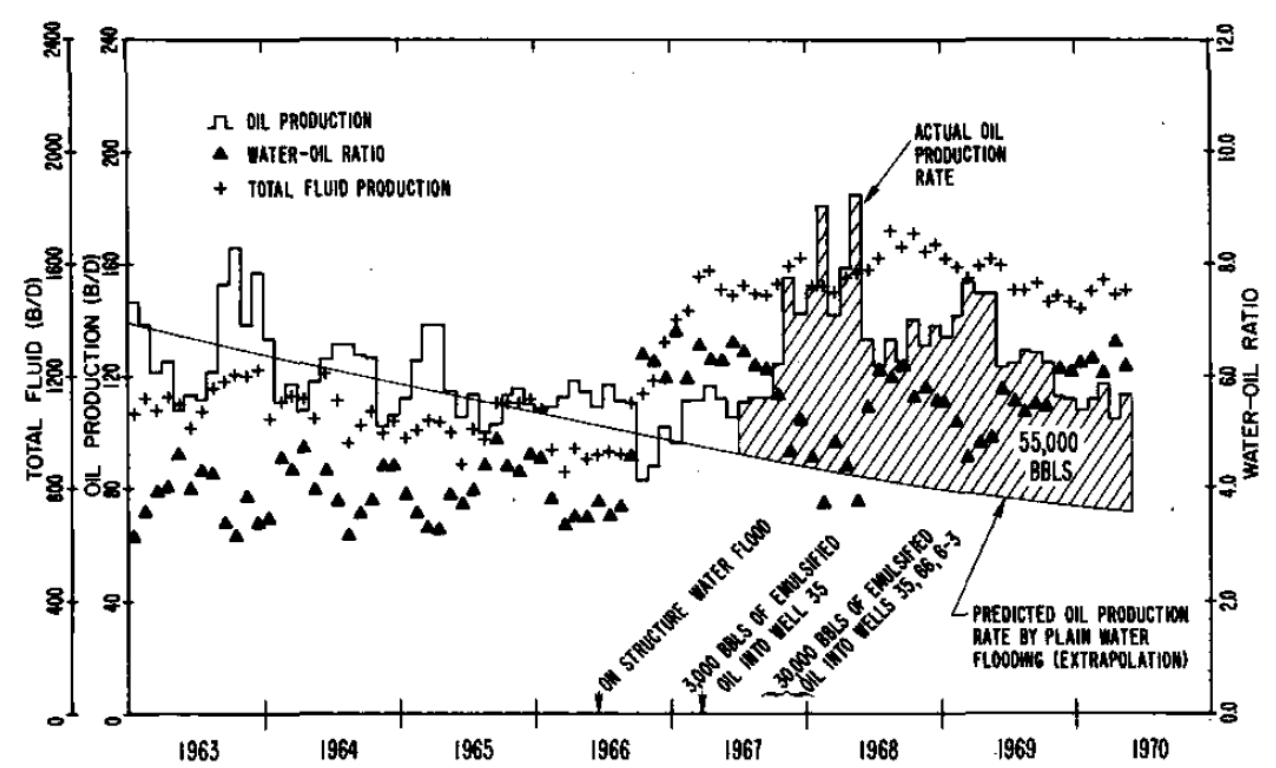

Figura 41 - Histórico da produção de líquido, óleo e da razão água-óleo (RAO) durante o piloto de injeção de emulsão no campo de Midway Sunset [47].

Apesar do aparente sucesso do piloto de injeção de emulsão, ele não foi estendido ao restante do campo.

\subsection{Modelo de Devereux}

O modelo de Devereux [48] buscou dar tratamento matemático aos resultados obtidos por McAuliffe [47]. A principal modificação consiste na inserção de um parâmetro chamado fator de retardamento capilar na teoria de Buckley e Leverett (1942) para modelar o deslocamento de emulsões em meios porosos. Nesse modelo, a redução de permeabilidade transiente provocada pelo deslocamento da emulsão no meio poroso é dada por:

$$
\frac{K}{K_{0}}=\left[\left(1-x_{f}\right)+\left(\frac{1+\frac{K_{0} \cdot k_{r d}}{u \cdot \mu_{d}} \cdot \gamma}{1+\frac{\mu_{d} \cdot k_{r w}}{\mu_{w} \cdot k_{r d}}}\right) \cdot \frac{\mu_{d} \cdot x_{f}}{\mu_{w} \cdot k_{r d}}\right]^{-1}
$$

Onde:

$K$ - permeabilidade do meio após a passagem da frente de avanço da emulsão; 
$K_{0}$ - Permeabilidade original do meio;

$x_{f}$ - posição adimensional da frente de avanço da emulsão;

$\mu_{d}$ - viscosidade das gotas dispersas;

$\mu_{w}$ - viscosidade da água;

$u$ - velocidade da emulsão no meio poroso;

$k_{r d}$ - permeabilidade relativa das gotas de óleo dispersas na emulsão;

$k_{r w}$ - permeabilidade relativa da água;

$\gamma$ - fator de retardamento capilar por unidade de volume no meio poroso;

A posição da frente de avanço da emulsão é dada por:

$$
\begin{gathered}
x_{f}=c_{i} \cdot \frac{\tau}{S_{d}} \leftrightarrow c_{i} \cdot \frac{\tau}{S_{d}} \leq 1 \\
x_{f}=1 \leftrightarrow c_{i} \cdot \frac{\tau}{S_{d}} \geq 1
\end{gathered}
$$

Onde:

$c_{i}$ - concentração de gotas na entrada do meio poroso;

$\tau$ - número de volumes porosos de emulsão injetados;

$S_{d}$ - Saturação de gotas da emulsão atrás da frente de avanço.

Os parâmetros $\gamma, S_{d}, \quad \mathrm{k}_{\mathrm{rd}} \quad \mathrm{e} \quad \mathrm{k}_{\mathrm{rw}}$ devem ser determinados experimentalmente.

O modelo estabelece relações entre os parâmetros coerentes com as observadas em laboratório como:

- A redução da permeabilidade do meio poroso é proporcional à posição da frente de avanço da emulsão;

- A redução da velocidade de fluxo $u$ aumenta a queda de permeabilidade

Em relação ao modelo de Devereux, cabem dois comentários:

- O modelo prevê que o breakthrough da emulsão ocorre como uma onda de choque, ou seja, a concentração de emulsão 
produzida varia subitamente de zero a $c_{i}$. Esse fato não é observado nos ensaios;

- O modelo indica que a permeabilidade do meio retorna ao valor original se houver a injeção de água após um banco de emulsão. Esse fato também não é verificado em laboratório.

\subsection{Modelo de Alvarado e Marsden}

O modelo de Alvarado e Marsden [50] foi desenvolvido para modelar o comportamento de emulsões concentradas entre $10 \%$ e $70 \%$. O objetivo principal foi determinar uma correlação entre o fluxo dessas emulsões em tubos capilares (escoamento de Hagen-Pouseille) e em meios porosos (Lei de Darcy). Foi proposto o emprego de uma permeabilidade modificada $\left(\mathrm{K}_{\mathrm{f}}\right)$ no lugar da permeabilidade do meio para aplicação direta da Lei de Darcy ao fluxo de emulsões. Nos ensaios realizados, foram ligados em série tubos capilares com diâmetros compreendidos na faixa 217-775 $\mu \mathrm{m}$ com plugs com permeabilidades entre $200 \mathrm{mD}$ e $847 \mathrm{mD}$. As emulsões continham óleo mineral estabilizado com surfactantes. As conclusões mais importantes do trabalho são:

- As emulsões com conteúdos de até $40 \%$ de óleo exibiram comportamento newtoniano;

- Emulsões com concentrações mais altas exibiram comportamento pseudoplástico;

A Tabela 9 mostra os valores obtidos nos ensaios para diferentes concentrações e óleo e permeabilidades. Pode-se verificar que a redução de permeabilidade é proporcional ao conteúdo de óleo e ao valor da permeabilidade inicial. 
Tabela 9 - Redução da permeabilidade em regime permanente observada nos experimentos de Alvarado e Marsden [50].

\begin{tabular}{|c|c|c|c|}
\hline $\begin{array}{c}\text { Concentração de óleo } \\
\text { na emulsão (\%) }\end{array}$ & $\begin{array}{l}\text { Permeabilidade da } \\
\text { rocha }(\mathrm{mD})\end{array}$ & $\begin{array}{l}\text { Permeabilidade } \\
\text { modificada }(\mathrm{mD})\end{array}$ & $\begin{array}{c}\text { Diferença entre } \\
K_{f} \text { e K (\%) }\end{array}$ \\
\hline 10 & 200 & 182 & -9 \\
\hline 20 & 653 & 434 & $-33,54$ \\
\hline 40 & 847 & 532 & $-38,25$ \\
\hline
\end{tabular}

Em relação ao modelo de Alvarado e Marsden, cabem os seguintes comentários:

- O modelo não considera as interações entre gotas e poros que dependem dos tamanhos médios de ambos;

- A permeabilidade modificada é apenas um artifício para permitir a aplicação direta da Lei de Darcy ao fluxo de emulsões em meios porosos. O modelo não considera a existência real de um dano à rocha causado pela passagem da emulsão.

- O modelo indica que a emulsão é produzida exatamente após a injeção de 1 volume poroso, fato que não é observado em laboratório.

Devido às altas concentrações de óleo utilizadas, o modelo não é adequado para modelagem da reinjeção da água produzida, pois os teores de óleo e graxas encontrados nessa água são bem menores.

\subsection{Modelo de Soo e Radke}

O modelo de Soo e Radke é uma adaptação da teoria clássica da filtração ao fluxo de emulsões muito diluídas. Esse modelo foi desenvolvido a partir dos resultados de uma série de experimentos de injeção de emulsões óleo-água em arenitos inconsolidados. As concentrações de óleo variaram na faixa 0,5-2,5\%, enquanto as permeabilidades das rochas variaram entre 580 e 2000 mD. 
A diferença mais importante entre o fluxo de suspensões de partículas sólidas e emulsões em meios porosos é em relação ao bloqueio de poros. Enquanto os poros, tipicamente, são bloqueados por partículas sólidas com tamanhos a partir de $1 / 3$ do seu diâmetro devido ao efeito de bridging, os pesquisadores observaram a possibilidade de gargantas de poros serem atravessadas por gotas de óleo com até 3 vezes seu diâmetro. As gotas de óleo da emulsão, dependendo do balanço de forças aplicadas, podem se deformar e atravessar os poros de tamanhos bem menores que os delas. As principais conclusões após os ensaios foram:

- Gotas de pequeno diâmetro se deslocam mais rápido no meio poroso. Em um arenito de $1170 \mathrm{mD}$, observou-se que as gotas de tamanho $2 \mu \mathrm{m}$ se deslocavam com velocidades entre 3 e 4 vezes maiores que as gotas de tamanho 4,5 $\mu \mathrm{m}$;

- Para um diâmetro de gota fixo, observou-se que a velocidade de percolação aumenta nos meios de maiores permeabilidades;

- O parâmetro de maior influência no comportamento de uma emulsão em certo meio poroso é a razão $\frac{D_{d}}{D_{p}}$, onde $D_{d}$ é o tamanho médio das gotas dispersas e $D_{p}$ é o tamanho médio dos poros do meio. Quanto maior for essa razão, mais rapidamente e maior deverá ser a redução de permeabilidade;

- A queda de permeabilidade provocada pela emulsão não é removida mesmo após a injeção de vários volumes porosos de água após sua passagem;

- Os resultados se mostraram independentes da viscosidade do óleo utilizado;

O modelo propõe a existência de 2 mecanismos de captura de gotas pelo meio poroso: a interceptação ("interception") e o bloqueio de poro (“straining"). 
O bloqueio de poro ocorre quando uma gota de emulsão encontra uma garganta de poro cujo diâmetro $D_{p}$ é da mesma ordem de grandeza que o diâmetro da gota de óleo $\mathrm{D}_{\mathrm{d}}$. É um mecanismo de exclusão pelo tamanho.

A interceptação de gotas ocorre devido às interações entre as gotas em suspensão e as paredes dos poros. O efeito local da retenção é a diminuição da área do poro aberta ao fluxo. A modelagem de fluxo deve levar em conta os efeitos de forma integrada. Por exemplo, poros com gotas retidas se tornam potenciais candidatos ao bloqueio por gotas de menores diâmetros que passem por eles posteriormente.

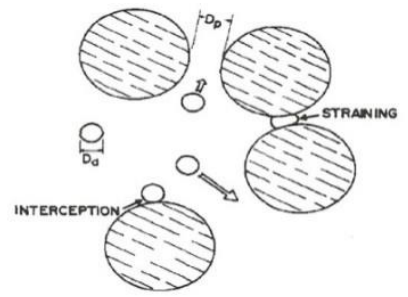

Figura 42 - Representação dos fenômenos de interceptação de gotas e bloqueio de poros [53].

O modelo proposto por Soo e Radke contém 3 parâmetros que devem ser determinados experimentalmente:

- Coeficiente de filtração do meio $(\lambda)$;

- Coeficiente de redistribuição de fluxo ou de dispersão ( $\alpha$ );

- Coeficiente de restrição de fluxo ou de dano $(\beta)$.

O coeficiente de filtração controla a taxa de captura das gotas emulsionadas. Os coeficientes de redistribuição e de restrição ao fluxo são fortemente correlacionados. O coeficiente $\alpha$ indica qual a parcela do fluxo que anteriormente fluía na classe de poros com diâmetros $D_{p}$ deverá ser redirecionada para as demais devido à queda de permeabilidade causada pela emulsão. O coeficiente de restrição indica a efetividade com que as gotas retidas diminuem a permeabilidade local. A Figura 43 representa esquematicamente os fenômenos de bloqueio e redistribuição de fluxo devido à injeção de emulsões em um reservatório de petróleo. 


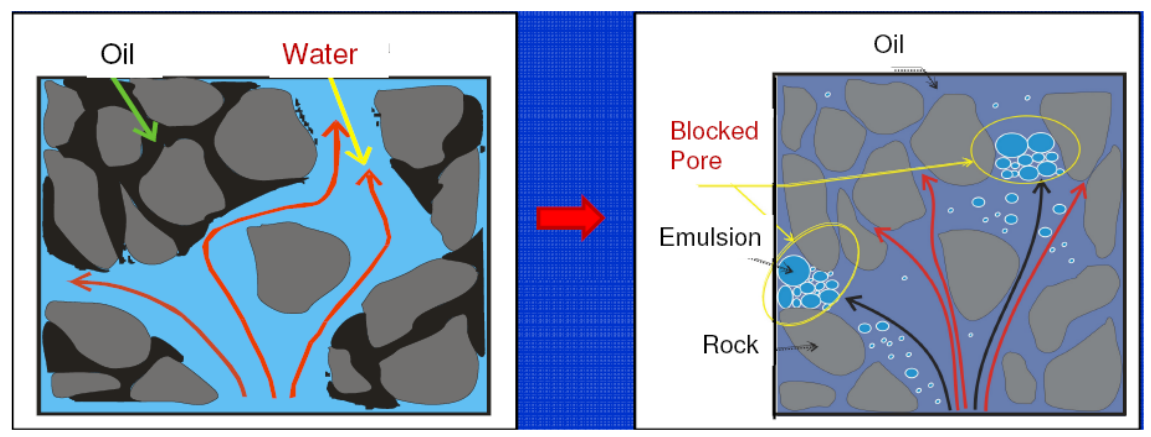

Figura 43 - Representação dos fenômenos de bloqueio de poros e redistribuição de fluxo [55].

Em situações reais, a emulsão e o meio poroso têm distribuições de tamanhos de gotas e poros caracterizados por médias e desvios-padrão. Nesse caso é necessário obter funções que calculem esses valores para cada diâmetro a fim de que seja possível calcular a perda de permeabilidade total e a parcela do fluxo que percorre cada classe de diâmetro de poro. Como os resultados não dependem da viscosidade do óleo, essas funções podem ser determinadas apenas 1 vez para cada par de distribuições.

A equação básica para o desenvolvimento da modelagem é a da filtração:

$$
\frac{\partial\left[\emptyset_{0} \cdot c+\sigma\right]}{\partial t}=\frac{\partial\left[\emptyset_{0} \cdot c+\int_{0}^{\infty} \sigma_{p} \cdot d D_{p}\right]}{\partial t}=-u \cdot \frac{\partial c}{\partial x}
$$

Onde:

$c(x, t)$ - Concentração de gotas de óleo que permanecem em suspensão na emulsão na posição x no tempo t;

$\mathrm{u}$ - velocidade de Darcy da emulsão no meio poroso;

$\emptyset_{0}-$ porosidade inicial do meio;

$\sigma$ - concentração de partículas retidas por unidade de volume $\sigma_{p} . D_{p}$ - volume de gotas de óleo retidas pelos poros com diâmetro compreendido entre $D_{p}$ e $D_{p}+d D_{p}$, isto é, $\int_{0}^{\infty} \sigma_{p} \cdot d D_{p}=\sigma$. 
Considerando que a emulsão é muito diluída, pode-se assumir que a porosidade do meio é pouco alterada pela captura de gotas, ou seja, $\emptyset \cong \emptyset_{0}$, escrevendo-se:

$$
\frac{\partial \sigma_{p}}{\partial t}=\lambda_{p} \cdot \theta_{p} \cdot u \cdot c
$$

Onde:

$\lambda_{p}$ - Coeficiente de filtração do meio para as gotas de diâmetro $D_{p}$;

$\theta_{p}$ - fração da emulsão que flui nos poros com diâmetro $D_{p}$.

O desenvolvimento continua assumindo duas hipóteses:

- As gotas de óleo estão adequadamente estabilizadas na emulsão, isto é, não há nenhuma coalescência de gotas no interior do meio poroso;

- O coeficiente de filtração é função do diâmetro $D_{p}$;

- Para emulsões muito diluídas, as gotas são capturadas individualmente, sem que a captura de uma gota interfira no processo das demais;

- Uma vez que uma gota de óleo é interceptada por um poro ele se torna inativo;

- O meio é considerado como um feixe de capilares paralelos com comprimentos diretamente proporcionais aos diâmetros.

A partir dessas hipóteses, pode-se considerar que:

- Para $D_{d} \geq D_{p}$ (gotas de tamanhos maiores ou de mesma ordem de grandeza que o diâmetro do poro) $\rightarrow$ a eficiência de captura é aproximadamente 1 e o coeficiente de filtração $\lambda_{p}=\frac{1}{L_{p}}$, onde $L_{p}$ é o comprimento do poro;

- Para $D_{d} \leq D_{p} \rightarrow$ a eficiência de captura é nula.

A fração da emulsão que flui através de cada classe de poro é dada por: 


$$
\theta_{p}=\frac{\left(\emptyset_{p}-\sigma_{p}\right)}{\left(\emptyset_{0}-\sigma\right)}
$$

Onde:

$\emptyset_{p}$ - fração da porosidade total devido aos poros de diâmetro $D_{p}$ no tempo $\mathrm{t}$;

$\sigma_{p}$ - concentração de gotas capturadas pelos poros com diâmetro $D_{p}$ no tempo t.

A cinética de captura de gotas pode ser escrita como:

$$
\frac{\partial \sigma}{\partial t}=\frac{u \cdot c}{\left(\emptyset_{0}-\sigma\right)} \cdot \int_{0}^{\infty} \lambda_{p} \cdot\left(\emptyset_{p}-\sigma_{p}\right) \cdot d D_{p}
$$

A redução da permeabilidade local é calculada a partir do parâmetro $\beta$ :

$$
\frac{K_{x}}{K_{0}}=1-\frac{1}{\emptyset_{0}} \int_{0}^{\infty} \beta_{p} \cdot \sigma_{p} \cdot d D_{p}
$$

O parâmetro $\beta_{p}$ dá a eficiência da classe de poros de diâmetro Dp na captura de gotas. É natural pensar que $\beta_{p}$ seja função da distribuição de diâmetros de gotas e poros do par emulsão-rocha.

A equação (17) indica que a captura de gotas feita pelos poros pequenos é rápida, pois o coeficiente de filtração desses poros é alto (hipótese do comprimento diretamente proporcional ao diâmetro do poro). Esse fato automaticamente obriga a redistribuição do fluxo para os poros maiores, modelada através do parâmetro $\alpha$.

Para meios com taxas de interceptação pequenas, o coeficiente de filtração para cada classe de tamanho de poro, no instante t, é calculado por: 


$$
\lambda_{p}=\lambda_{p, 0} \cdot \phi \cdot\left(1-\frac{\sigma_{p}}{\sigma_{p, \text { máx }}}\right)
$$

Onde:

$\sigma_{p, m a ́ x}$ - máxima concentração de partículas retidas pelos poros de tamanho $D_{p}$;

$\sigma_{p}$ - concentração de partículas retidas no tempo t;

$\lambda_{p, 0}$ - coeficiente de filtração do meio antes da passagem da emulsão.

A cinética da captura de gotas no meio poroso fica, então, descrita pela equação:

$$
\begin{aligned}
\frac{\partial \sigma}{\partial t}=\frac{u \cdot c}{\left(\emptyset_{0}-\sigma\right)} \cdot\left[\int_{0}^{D_{t}} \frac{1}{L_{p}} \cdot\left(\emptyset_{p}-\sigma_{p}\right) d D_{p}\right. \\
\left.+\int_{D_{t}}^{\infty} \lambda_{p, 0} \cdot\left(\emptyset_{p}-\sigma_{p}\right) \cdot\left(1-\frac{\sigma_{p}}{\sigma_{p, \text { máx }}}\right)\right] \cdot d D_{p}
\end{aligned}
$$

Onde:

$D_{t}$ - diâmetro de transição $\rightarrow$ representa o diâmetro de gota em que processo de interceptação dá lugar ao mecanismo de bloqueio de poro.

O primeiro termo de (19) dá a contribuição do fenômeno de interceptação na cinética da captura de gotas pelo meio poroso, enquanto o segundo termo expressa a parcela devido ao bloqueio de poros.

O modelo completo para o coeficiente de filtração, incluindo os efeitos de captura e retenção é da forma:

$$
\lambda_{S I}=\frac{1}{\emptyset_{0}} \cdot \int_{0}^{\infty} \lambda_{p, 0} \cdot \emptyset_{p} \cdot d D_{p}
$$

Onde: 
$\lambda_{S I}$ - parâmetro global de filtração $\rightarrow$ fixo para uma distribuição de tamanhos de gotas e de poros.

O parâmetro de redistribuição de fluxo (dispersão) $\alpha$ é dado por:

$$
\alpha=\frac{1}{\sigma \cdot \lambda_{S I}} \cdot \int_{0}^{\infty}\left(\lambda_{p, 0} \cdot \sigma_{p} \cdot \emptyset_{p} / \sigma_{p, \text { máx }}\right) d D_{p}
$$

A relação entre os fenômenos de filtração e dispersão fica:

$$
\frac{\partial \sigma}{\partial t}=\lambda_{S I} \cdot\left(1-\frac{\alpha \cdot \sigma}{\emptyset_{0}}\right) \cdot u \cdot c
$$

O parâmetro de efetividade do bloqueio $\beta$ é dado por:

$$
\beta=\frac{1}{\sigma} \cdot \int_{0}^{\infty} \beta_{p} \cdot \sigma_{p} \cdot d D_{p} \rightarrow \frac{K_{x}}{K}=1-\frac{\beta}{\emptyset_{0}}
$$

As equações (22) e (23) estabelecem a dependência entre os fenômenos de dispersão e bloqueio de gotas em função da concentração de gotas já retidas pelo meio no tempo t. Para os pares de emulsão e rocha em que o mecanismo de retenção de gotas é dominante, isto é, quando as gotas são de tamanho relativamente pequeno em relação aos poros da rocha, os valores de a e $\beta$ são aproximadamente constantes. Nas situações em que o bloqueio dos poros é o mecanismo dominante, $\alpha$ e $\beta$ variam significativamente na fase transiente.

Em [54], Soo e Radke desenvolveram expressões para o cálculos dos 3 parâmetros do modelo $\left(\alpha, \beta\right.$ e $\lambda_{\mathrm{sl}}$ ), baseadas nos seguintes parâmetros:

- Distribuições de tamanhos de gotas da emulsão (analisador de gotas); 
- Distribuição de tamanhos de poros do meio (ensaio de porosimetria por intrusão de $\mathrm{Hg}$ );

- Distribuição de tamanhos de grãos (peneiramento);

- Valores das pressões na entrada e saída da amostra;

- Concentrações de gotas no efluente coletado.

A análise da distribuição de tamanhos de poros das amostras analisadas (arenitos inconsolidados) indicou que ela é do tipo log-normal.

$O$ coeficiente de filtração global $\lambda_{S I}$, que engloba os efeitos de bloqueio de poros e interceptação de gotas, é dado por:

$$
\lambda_{S I}=\lambda_{S} \cdot\left(\frac{\phi_{S}}{\phi_{0}}\right)+\lambda_{I} \cdot\left(1-\frac{\phi_{S}}{\phi_{0}}\right)
$$

Onde:

$\lambda_{S I}$ - coeficiente global de filtração;

$\lambda_{S}$ - coeficiente de filtração devido ao bloqueio de poros;

$\lambda_{I}$ - coeficiente de filtração devido à interceptação de gotas;

$\phi_{0}, \phi_{s}$ - respectivamente as porosidades original e bloqueada do meio.

O coeficiente de filtração devido ao bloqueio dos poros é função do diâmetro dos grãos da rocha:

$$
\frac{1}{\lambda_{s}}=L=\left[\frac{\pi}{6 \cdot\left(1-\phi_{0}\right)} \cdot D_{g}^{3}\right]^{1 / 3}
$$

Onde:

$D_{g}$ - diâmetro médio dos grãos da rocha obtido através da distribuição granulométrica;

$\mathrm{L}$ - comprimento médio dos poros do meio;

O coeficiente de filtração por interceptação é estimado por Radke como:

$$
\lambda_{I}=0,01 . L
$$


A porosidade $\phi_{\mathrm{s}}$ dos poros bloqueáveis pela emulsão é determinada pela distribuição do tamanho de gotas e pelo valor assumido para o diâmetro de transição $D_{t}$

$$
\emptyset_{s}=\int_{0}^{D_{t}} \emptyset_{p} \cdot d D_{p}
$$

Os resultados experimentais indicam que o diâmetro de transição está entre 2 e 3 vezes o tamanho médio das gotas da emulsão.

O parâmetro de redistribuição de fluxo a no regime estacionário é calculado por:

$$
\alpha_{\infty}=\frac{\emptyset_{0}}{\sigma_{\infty}}=\frac{\emptyset_{0}}{\left(\phi_{S}+\sigma_{I, \text { máx }}\right)}
$$

Onde:

$\alpha_{\infty}$ - coeficiente de redistribuição de fluxo no regime estacionário;

$\sigma_{I, m a ́ x}$ - concentração de máxima de gotas no meio retidas por interceptação.

O parâmetro $\sigma_{I, m a ́ x}$ é avaliado pela seguinte expressão:

$$
\beta_{s}=\frac{2 \cdot \pi \cdot \emptyset_{0} \cdot\left(1-\emptyset_{0}\right) \cdot\left(1-\frac{\phi_{s}}{\phi_{0}}\right) \cdot D_{d}}{\sqrt{3} \cdot D_{g}} \cdot \omega
$$

O parâmetro $\omega$ varia entre 0.05 e 0.15 , sugerindo-se uma aproximação inicial de 0.10 .

O parâmetro de efetividade do bloqueio pelas gotas da emulsão no regime estacionário $\beta_{\infty}$ é calculado por:

$$
\beta_{\infty}=\frac{\beta_{S} \cdot \emptyset_{S}+\beta_{I, m a ́ x} \cdot \sigma_{I, m a ́ x}}{\left(\phi_{S}+\sigma_{I, m a ́ x}\right)}
$$


Os valores sugeridos pelo autor são $\beta_{\mathrm{s}}=1$ e $\beta_{\mathrm{I} \text {,máx }}$ na faixa $15-20 \mathrm{~m}$

1. Os resultados com os arenitos ensaiados indicaram $\beta_{\mathrm{I}, \mathrm{máx}}=18 \mathrm{~m}^{-1}$

As expressões propostas são baseadas nos resultados experimentais obtidos com os pares de emulsão e arenito ensaiados. Sugere-se utilizá-las como uma primeira aproximação dos parâmetros e ajustar os valores através de ensaios de fluxo com amostras da emulsão e da rocha que serão utilizadas no projeto.

Em relação ao modelo de Soo e Radke cabem alguns comentários:

- Os ensaios foram todos feitos com velocidade de fluxo constante de $0,07 \mathrm{~mm} / \mathrm{s}$. É natural esperar que os valores de $\lambda_{S I}$ dependam da velocidade de fluxo imposta para a emulsão. Maiores velocidades de fluxo devem resultar em menores coeficientes de filtração, pois a tendência de algumas gotas se deformarem e ultrapassarem gargantas de poros capazes de retê-las com velocidades de fluxo mais baixas aumenta;

- $\quad$ Para aplicação do modelo à reinjeção da água produzida devem ser realizados ensaios com a presença de sólidos de diferentes tipos e concentrações de forma a capturar os efeitos da presença de óleo e partículas ao mesmo tempo. Dessa forma, os parâmetros $\alpha, \beta$ e $\lambda_{S I}$ estarão adaptados para modelagem da RAP;

\subsection{Modelo de Mendez (1999)}

A tese de doutorado de Mendez [58] contém os resultados de uma série de ensaios de injeção de emulsões óleo-água muito diluídas. Foram empregados óleos e amostras de rocha dos campos de Brent (Mar do Norte) e Prudhoe Bay (Alasca). O interesse principal dos estudos foi a determinação da taxa de queda da injetividade no tempo em função da concentração de gotas, da permeabilidade inicial e da vazão de injeção. A principal diferença desse estudo em relação aos anteriores é a realização 
dos ensaios com presença de óleo residual. As concentrações de óleo utilizadas variaram entre 50 e 1000 ppm, enquanto as permeabilidades dos plugs de rocha variaram no intervalo 100-300 mD. Com objetivo de complementar o estudo, foram fabricados meios porosos artificiais entre os 400 e os $1200 \mathrm{mD}$. Entre as conclusões desse estudo, destacam-se:

- A taxa de declínio da permeabilidade foi proporcional à concentração de óleo na emulsão;

- A queda da permeabilidade é mais rápida nos meios de baixa permeabilidade;

- Quanto maior for a vazão de injeção de água, mais lentamente a permeabilidade do meio cai e maior a concentração de gotas de óleo no efluente produzido;

- A saturação de óleo residual influiu nos resultados;

- A concentração de gotas produzidas foi, em alguns casos, maior que a injetada. Esse fato indica que a emulsão foi capaz de mobilizar óleo adicional. O mecanismo principal dessa mobilização adicional de óleo não foi investigado;

- A água produzida deve ser preferencialmente reinjetada em meios de alta permeabilidade e com concentrações de óleo baixas.

\subsection{Modelo de Cobos (2009)}

Cobos [59] realizou uma série de experimentos de fluxo de emulsões de óleo em água em micromodelos de vidro. Foram utilizados 2 óleos lubrificantes sintéticos (Shell Tivela $\AA 160$ e 460), água deionizada, surfactante comercial (Triton X-100®) e agente viscosificante (Carbopol®) da fase contínua a fim de retardar a segregação gravitacional das gotas da emulsão. Foram preparadas cinco tipos de emulsões com diferentes concentrações de óleo $(30 \%$ e $60 \%$ ) com os dois óleos. Diferentes distribuições de tamanhos de gotas foram obtidas variando o procedimento de dispersão. Emulsões foram injetadas, utilizando uma bomba de seringa, nos micromodelos com diferentes vazões e o fluxo foi 
observado ao microscópio. Devido ao alto teor de óleo presente, as emulsões exibiram comportamento não-Newtoniano que foi descrito por uma função material tipo power-law.

As principais conclusões desse trabalho foram:

- As emulsões sempre escoaram pelas gargantas do capilar requerendo maior nível de pressão que o necessário para o escoamento da fase contínua pura;

- Quando as gotas emulsionadas são menores que a constrição, o acréscimo de pressão necessário é função apenas da viscosidade da emulsão;

- Quando as gotas emulsionadas são maiores que as gargantas de poros, o diferencial de pressão sofre um aumento devido ao bloqueio parcial da garganta pelas gotas;

- O fluxo de emulsões cujas gotas são maiores que as constrições não pode ser modelado apenas conhecendo-se a função material do fluido injetado. Observou-se que a pressão oscilou mesmo mantendo-se a vazão constante. Os picos de pressão estão associados aos eventos de passagem de gotas grandes pelas gargantas de poros.

O autor propôs um modelo da forma:

$$
q=f \cdot K_{C} \cdot \frac{\Delta p}{L}
$$

Onde:

q - vazão injetada no capilar;

$f$ - é um fator que indica o aumento da resistência ao escoamento provocada pela existência da emulsão;

$\Delta \mathrm{p}$ - diferencial de pressão necessário para o escoamento da emulsão;

$\mathrm{L}$ - comprimento do capilar. 
O fator f é calculado por:

$$
f=\frac{\Delta p_{c}}{\Delta p}
$$

onde $\Delta p$ é o diferencial de pressão necessário para promover o escoamento da fase contínua para a mesma vazão.

O fator f é aproximadamente constante para emulsões cujas gotas sejam muito menores que a constrição do capilar. Entretanto, para emulsões formadas por gotas relativamente grandes, o fator $f$ varia com o número de capilaridade associado ao escoamento. A Figura 44 mostra a sequência da passagem de uma gota grande pela constrição, enquanto a Figura 45 mostra a evolução da pressão de injeção. Os menores valores de pressão estão associados ao escoamento da fase contínua pela garganta (fotos A e B). O pico de pressão observado é provocado pela energia extra necessária para deformar a gota de óleo (fase dispersa) na passagem pela garganta do capilar (fotos C e D).

A

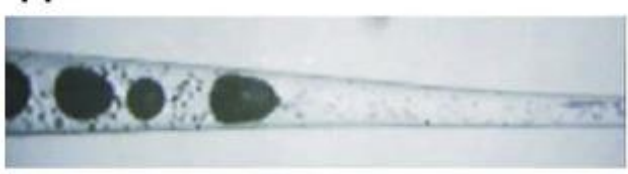

C

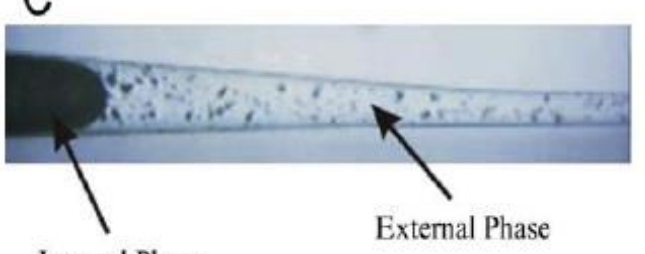

Internal Phase
B Internal Phase

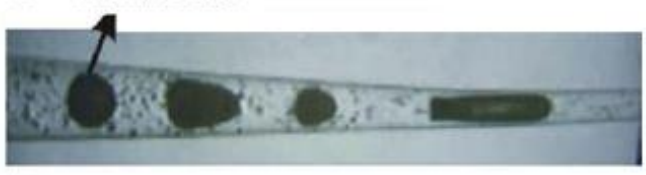

D

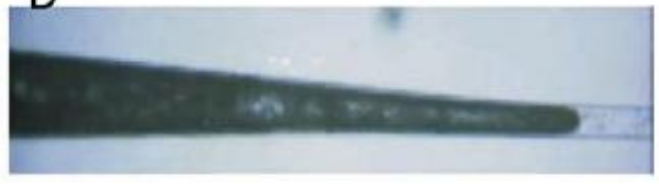

Figura 44 - Fotos ao microscópio do escoamento de uma emulsão através de uma garganta de poro [59]. 


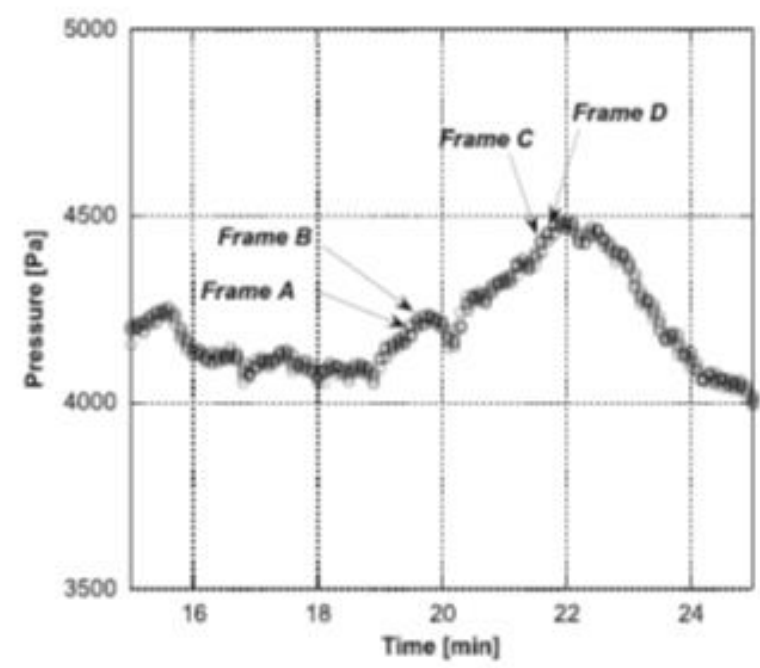

Figura 45 - Evolução da pressão de injeção relativa ao evento da passagem de uma gota grande através de uma garganta de poro [59].

Os resultados obtidos nesse trabalho sugerem que emulsões de óleo em água podem ser utilizadas como um método de controle de mobilidade em reservatórios de petróleo. $O$ tamanho das gotas pode ser controlado (com a utilização de um filtro, por exemplo) de forma a bloquear caminhos preferenciais da água, provocando, dessa forma, melhoria de varrido no reservatório.

\subsection{Experimentos de Guillen}

Guillen [60] conduziu um programa experimental em micromodelos preenchidos com esferas de vidro (foco principal: visualização do escoamento de emulsões em meios porosos) e plugs de rocha (investigação do uso de emulsões na recuperação melhorada de petróleo).

O micromodelo foi preenchido com esferas de vidro (100-200 $\mu \mathrm{m})$, gerando um meio poroso com permeabilidade 2.1 -D e porosidade $35 \%$, posteriormente saturado com água e, em seguida, com óleo mineral (Shell Talpa $30-\mu_{o}=410 \mathrm{cP} @ 23^{\circ} \mathrm{C}$ ). A emulsão foi preparada utilizando um óleo mais viscoso (Shell Tivela $460-\mu_{\circ}=1000$ cP @23 $3^{\circ} \mathrm{C}$ ) e estabilizada pelo surfactante Ultranex NT-110. Foi feita a injeção alternada de bancos de água e emulsão. A Figura 46 apresenta o gráfico 
do comportamento da pressão e do fator de recuperação de óleo obtido no experimento.

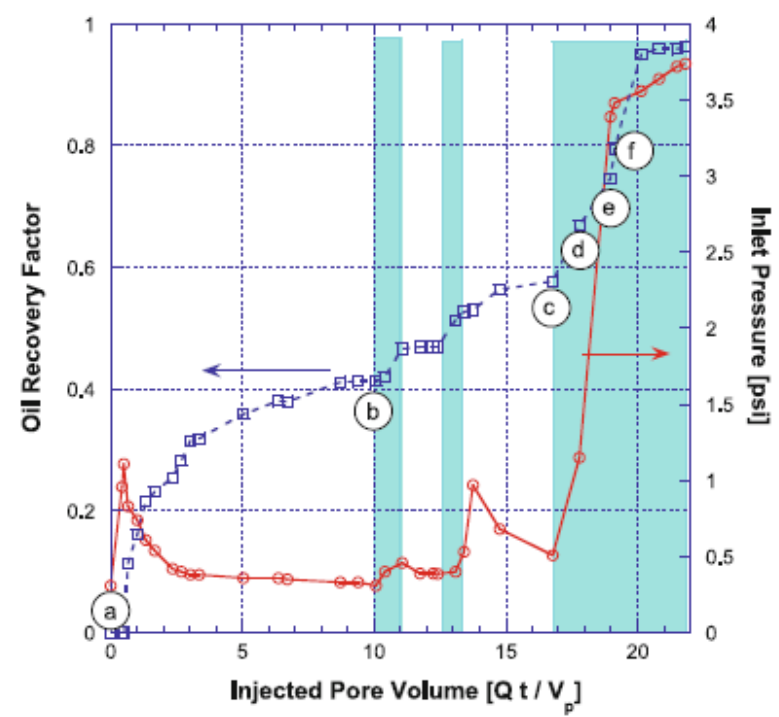

Figura 46 - Evolução do fator de recuperação de óleo (curva azul) e da pressão de injeção (curva vermelha). As áreas marcadas em azul claro correspondem aos períodos de injeção de emulsão [59].

Outro resultado interessante é a visualização do efeito da emulsão no controle da digitação viscosa. Na Figura 47, destacam-se a visualização da digitação viscosa oriunda da injeção de água inicial (quadro b) e a formação e deslocamento de um banco de óleo devido à injeção de emulsão (quadros c até f).
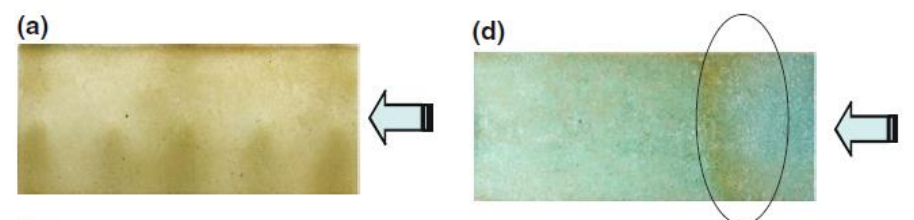

(b)
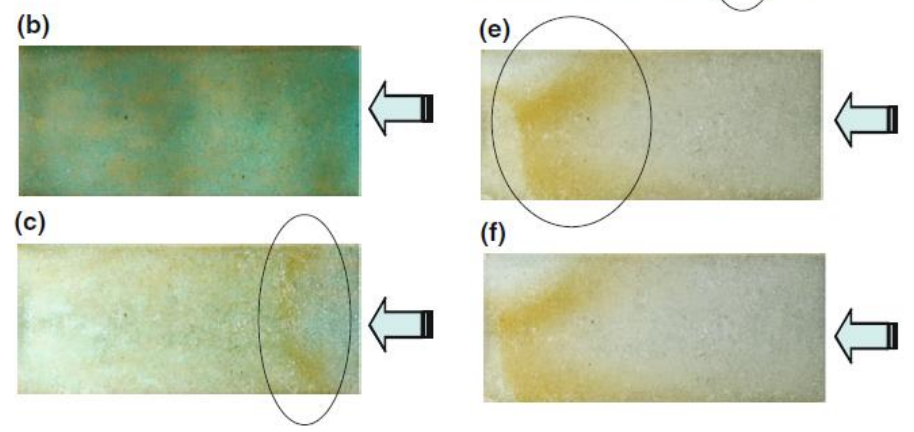

(f)

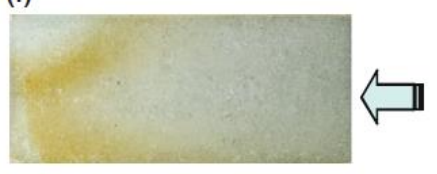

Figura 47 - Efeito da injeção da emulsão no controle da digitação viscosa. A fase aquosa (água injetada e a fase contínua da emulsão) aparece marcada em verde. Na sequência dos quadros está destacada a formação de um banco de óleo deslocado pela emulsão [60]. 
Os ensaios feitos nos micromodelos de vidro mostraram claramente a ação da emulsão no bloqueio de caminhos preferenciais criados pela água injetada e a melhoria do varrido resultante. A Figura 48 mostra a mesma região do micromodelo ensaiado antes (a) e depois (b) da injeção de um banco de emulsão. Foi possível enxergar claramente o bloqueio parcial do meio poroso e a mudança na trajetória da frente de injeção resultante.

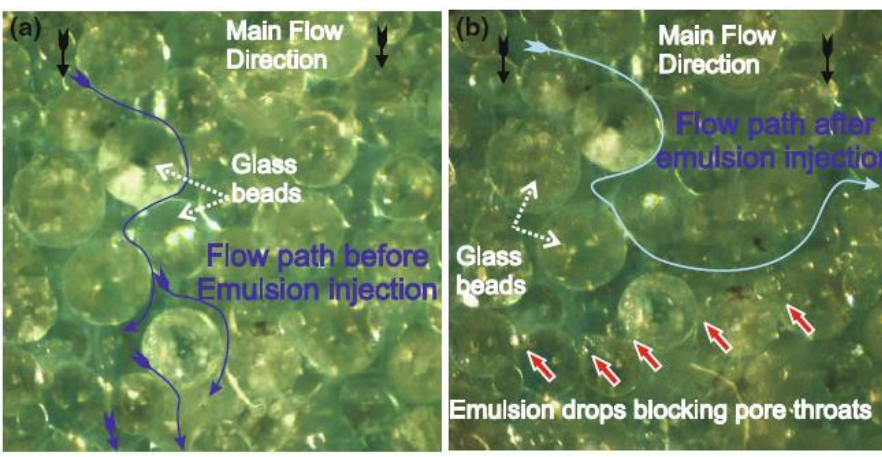

Figura 48 - Foto ao microscópio indicando a ação da emulsão ao nível de poros [60].

A segunda parte do programa experimental foi a injeção alternada de água e emulsão em dois plugs de arenito Botucatu com diferentes permeabilidades (1900 mD e $239 \mathrm{mD}$ ) arranjados em paralelo (Figura 49). Os plugs foram saturados com água e, em seguida, com o mesmo óleo mineral utilizado no experimento com o micromodelo. A injeção inicial de água fluiu quase integralmente pelo plug de alta permeabilidade, pois o fator de recuperação de óleo no plug de baixo $\mathrm{K}$ foi praticamente nulo. $\mathrm{A}$ injeção de emulsão subsequente provocou aumento na pressão de injeção devido ao bloqueio parcial dos poros pelas gotas dispersas na emulsão. Parte da injeção passou a varrer o plug de baixa permeabilidade, causando produção de óleo. O conjunto foi submetido a 3 ciclos de injeção alternada de água e emulsão levou a recuperações finais de óleo de $82 \%$ no plug de alta e $26 \%$ no de baixa permeabilidade. 


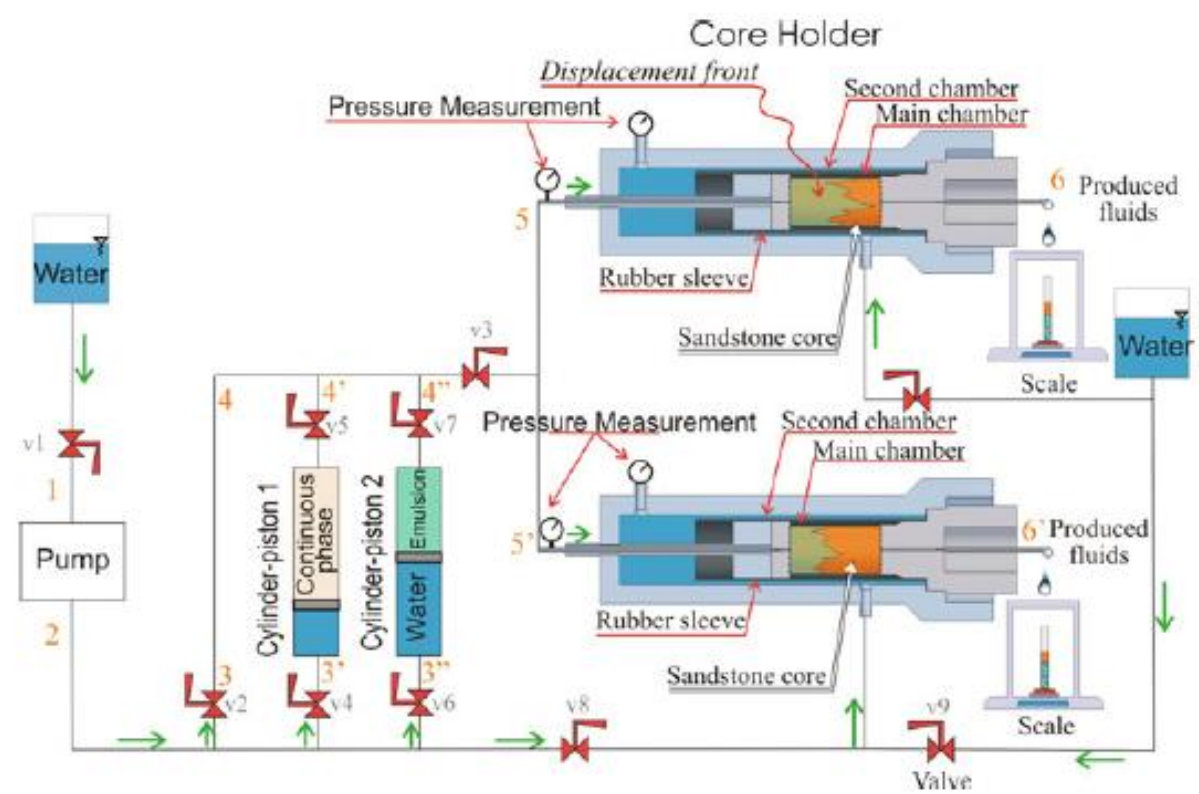

Figura 49 - Esquema do ensaio de injeção alternada de água e emulsão em plugs conectados em paralelo [60].

\subsection{Modelo de Romero (2011)}

Romero [61] realizou experimentos de injeção de emulsão de óleo em água em arenitos Botucatu inicialmente saturados apenas com água destilada. A fase contínua foi preparada utilizando uma solução de glicerina $(70 \%)$ e água $(30 \%)$ v/v. Posteriormente, essa solução recebeu a adição de $10 \%$ (v/v) de óleo sintético (Shell Tivela 460) e Dodecilsulfato de Sódio @ 6,9 g/L. A emulsão foi injetada em 2 plugs de diferentes permeabilidades e os resultados plotados de forma a obter uma curva vazão $x$ diferencial de pressão.

Os resultados foram utilizados para a validação qualitativa do modelo de rede de capilares desenvolvido a partir do originalmente gerado por Piri no Imperial College para um cubo de arenito Berea com aresta $3 \mathrm{~mm}$. Foi aplicado um fator de escala à essa rede de forma a respeitar os valores de permoporosidade observados nos plugs de arenito Botucatu. A rede gerada é bastante complexa com aproximadamente 12000 poros e 26000 capilares de diversas geometrias. Os números de coordenação dos poros variaram entre 1 e 19. Com esse modelo foi possível reproduzir apenas qualitativamente os resultados de laboratório. 
Uma série de simplificações foi introduzida na simulação como, por exemplo, a consideração de uma função de bloqueio de poros dependente apenas da razão entre os raios da gota e do capilar, além da consideração de uma emulsão monodispersa.

A partir dos resultados experimentais de Cobos [60], Romero [61] propôs a seguinte forma de cálculo para o fator de bloqueio capilar gerado pela emulsão:

a) Para $\mathrm{Ca}<\mathrm{Ca}^{*}$ :

$$
f=e^{-K_{A} \cdot\left(\frac{\alpha}{\alpha^{*}}-1\right)} \cdot\left(\frac{C a}{C a^{*}}\right)^{K_{B} \cdot\left(\frac{\alpha}{\alpha^{*}}-1\right)}
$$

b) Para $\mathrm{Ca}>\mathrm{Ca}^{*}$ :

$$
f=e^{-K_{A} \cdot\left(\frac{\alpha}{\alpha^{*}}-1\right)} .
$$

Onde:

$f$ - incremento no diferencial de pressão devido ao escoamento da emulsão em relação ao escoamento da fase contínua na mesma vazão; $\alpha$ - razão entre o raio típico das gotas dispersas na emulsão e o raio típico dos capilares do meio poroso.

$a^{*}$ - razão crítica entre raios;

$\mathrm{Ca}, \mathrm{Ca}^{*}$ - número de capilaridade associado ao fluxo no meio poroso e número de capilaridade crítico respectivamente;

$\mathrm{K}_{\mathrm{A}}$ e $\mathrm{K}_{\mathrm{B}}$ - parâmetros de ajuste do modelo.

\subsection{Conclusões}

1. Os resultados de McAuliffe [47] sugerem que a emulsão injetada foi efetiva no bloqueio de caminhos preferenciais da água de injeção no reservatório e alterou o varrido do reservatório e aumentou o volume de óleo recuperado; 
2. Os trabalhos de Cobos e Romero mostram, na escala de poro, a dependência entre o fluxo das gotas emulsionadas e o número de capilaridade local;

3. O modelo de Soo e Radke é uma adaptação da teoria da filtração bastante útil para o entendimento dos fenômenos da captura de gotas. Entretanto, os resultados foram obtidos para apenas uma velocidade de fluxo, ou seja, não foi desenvolvida nenhuma correlação entre os parâmetros de filtração e o número de capilaridade associado ao fluxo. O modelo não descreve todos os fenômenos observados no escoamento de emulsões em meios porosos;

4. Os experimentos de Guillen [60] mostram que a emulsão age em duas escalas. Na escala de poros, as gotas de emulsão alteram o caminho da fase aquosa e, desta forma, reduzem a saturação residual de óleo. Na escala macroscópica, a presença da fase dispersa altera a permeabilidade relativa da fase aquosa, levando a uma varreduda mais uniforme do meio poroso;

5. Não foram encontradas referências de estudos de injeção de emulsões diluídas de óleos pesados em meios de alta permeabilidade. O trabalho de Mendez [58] foi feito com óleos leves entre $35^{\circ}$ e $45^{\circ} \mathrm{API}$;

6. Os modelos na escala de reservatório para descrever o processo de injeção de emulsões como um método de recuperação melhorada de petróleo ainda apresentam limitações. 


\section{Programa Experimental Inicial - Ensaios de Fluxo 1-D}

\subsection{Objetivos do trabalho}

Os resultados experimentais obtidos em pesquisas anteriores motivaram o desenvolvimento de um programa experimental com foco na investigação do potencial emprego de emulsões como um agente na recuperação melhorada de óleos viscosos. Os objetivos principais desse programa são:

- Avaliar o potencial do emprego de emulsões diluídas de óleo em água como controle de mobilidade e método de recuperação avançada de petróleos viscosos;

- Estudar os mecanismos atuantes principais envolvidos e suas contribuições relativas;

- Avançar na modelagem do fenômeno utilizando um simulador de fluxo comercial (CMG STARS ${ }^{\circledR}$ );

- Visualização das alterações do padrão de fluxo no meio poroso geradas pela injeção da emulsão em 3D.

\subsection{Ensaios iniciais}

Os primeiros ensaios tiveram por objetivo um entendimento inicial do escoamento de emulsões através do meio poroso. Foram preparados sandpacks com areia de sílica 20/40 (diâmetro 1" x altura $1 \mathrm{ft}$ ) com permeabilidades entre 40 e $50 \mathrm{D}$. Os primeiros ensaios foram feitos injetando a emulsão em sandpacks saturados com uma fase aquosa de mesma composição que a fase contínua da emulsão. Esses ensaios tiveram os seguintes objetivos: 
- Verificar a estabilidade de emulsões formadas com água com mar sintética, surfactante Steol CS-330 e o petróleo utilizado nos ensaios;

- Análise qualitativa do potencial de retenção de gotas emulsionadas com diferentes tamanhos e velocidades de fluxo em sandpacks de areia de sílica 20/40.

Essa etapa foi desenvolvida no Laboratório de Fenômenos de Transporte da Rice University sob a orientação dos professores George Hirasaki e Clarence Miller.

\subsection{Materiais e Métodos}

Foram utilizados os seguintes equipamentos nos ensaios:

- Bomba HPLC isocrática (Series III® Scientific Systems);

- Transdutor de pressão Validyne modelo DP15-44;

- Filtros Swagelok com aberturas $5 \mu \mathrm{m}, 10 \mu \mathrm{m}, 25 \mu \mathrm{m}, 60 \mu \mathrm{m}$ e $90 \mu \mathrm{m}$

- Placa de aquisição de dados (Validyne modelo UPC 2100).

- Solução aquosa de $\mathrm{NaCl} @ 100 \mathrm{~g} / \mathrm{L}$ ("água de formação");

- Solução aquosa de $\mathrm{NaCl} @ 36.5$ g/L ("água do mar sintética");

- Surfactante Stepan Steol CS-330 @ 28\% de matéria ativa;

- Areias de Sílica F110 e 20/40 (U.S. Silica);

- Petróleo $20^{0} \mathrm{API}\left(\mu_{0}=30 \mathrm{cP}\right.$ ) oriundo da Bacia de Campos.

- Foram utilizados os mesmos equipamentos dos ensaios com meios saturados com água.

O procedimento de preparação desses meios porosos foi constituído pelos seguintes passos (Figura 50).

a) Compactação manual dos sandpacks por cerca de 20 minutos;

b) Saturação com $\mathrm{CO}_{2}$; 
c) Saturação, por bombeamento, do meio com solução aquosa de cloreto de sódio (@100.00 mg/L);

d) Saturação, por bombeamento, com petróleo oriundo da Bacia de Campos $\left(20^{\circ} \mathrm{API} / \mu=30 \mathrm{cP}\right)$;

Durante a preparação foram medidas a porosidade e permeabilidade de cada sandpack. $O$ procedimento utilizado está detalhado no apêndice 8.1.1 desse trabalho.

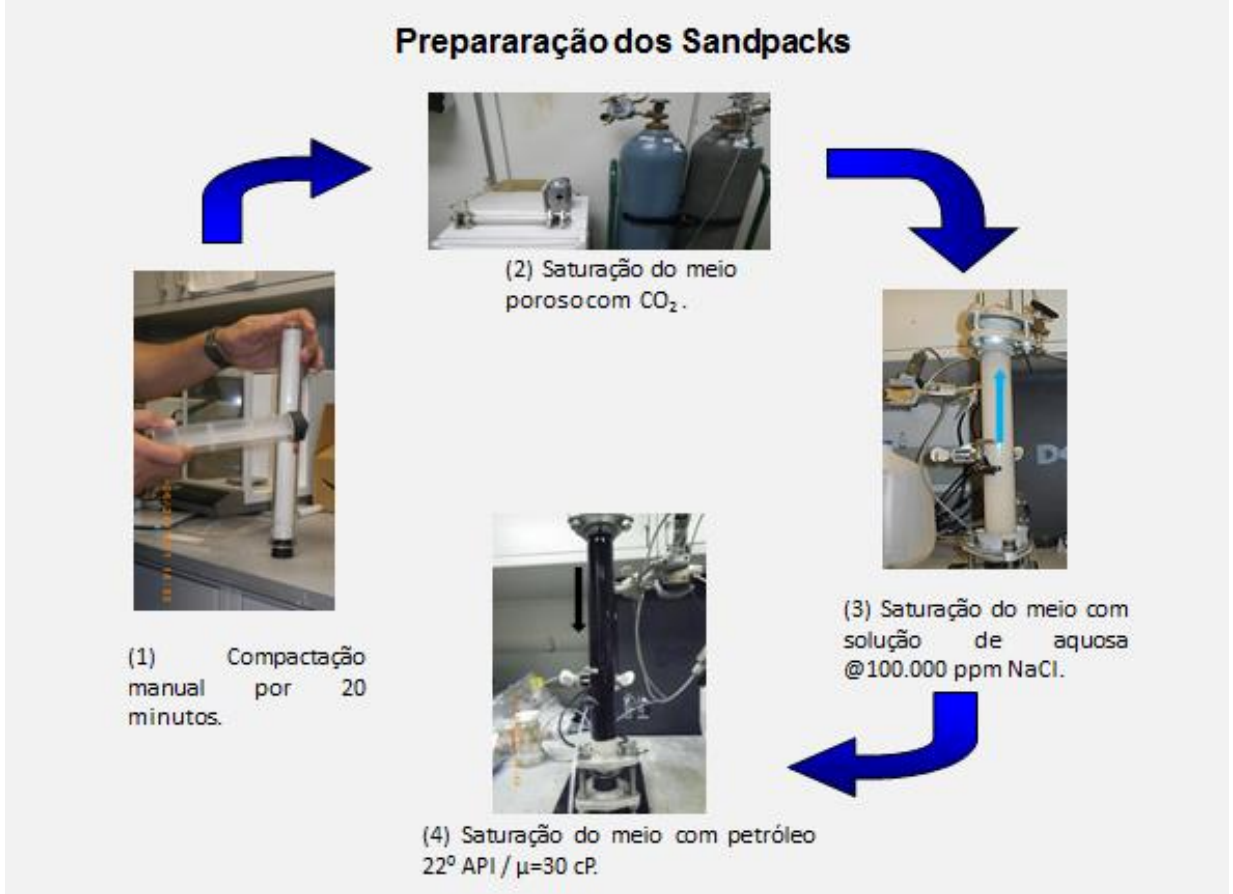

Figura 50 - Preparação dos sandpacks para avaliação do uso de emulsões na recuperação de petróleo - adaptado de [65].

Com os valores experimentais de porosidade e permeabilidade, pode-se calcular o diâmetro médio dos poros do sandpacks pela equação de Carman-Kozeny para efeito de comparação com o diâmetro médio das gotas emulsionadas injetadas.

\subsection{Ensaios em Meios Porosos Saturados apenas com a fase aquosa}

A preparação seguiu os passos de 1 a 3 descritos na Figura 50 . Foram injetadas emulsões de óleo em água utilizando filtros ("frit") com 
aberturas 5, 10 e $25 \mu \mathrm{m}$. Essas emulsões foram injetadas a diferentes vazões ( 1 , 3 e $9 \mathrm{ml} / \mathrm{min}$ ), coletando-se os efluentes produzidos para inspeção visual. O diferencial de pressão entre as extremidades dos sandpacks (posicionados na vertical e submetidos à injeção na base) foi monitorado. A Figura 51 mostra a configuração do experimento.

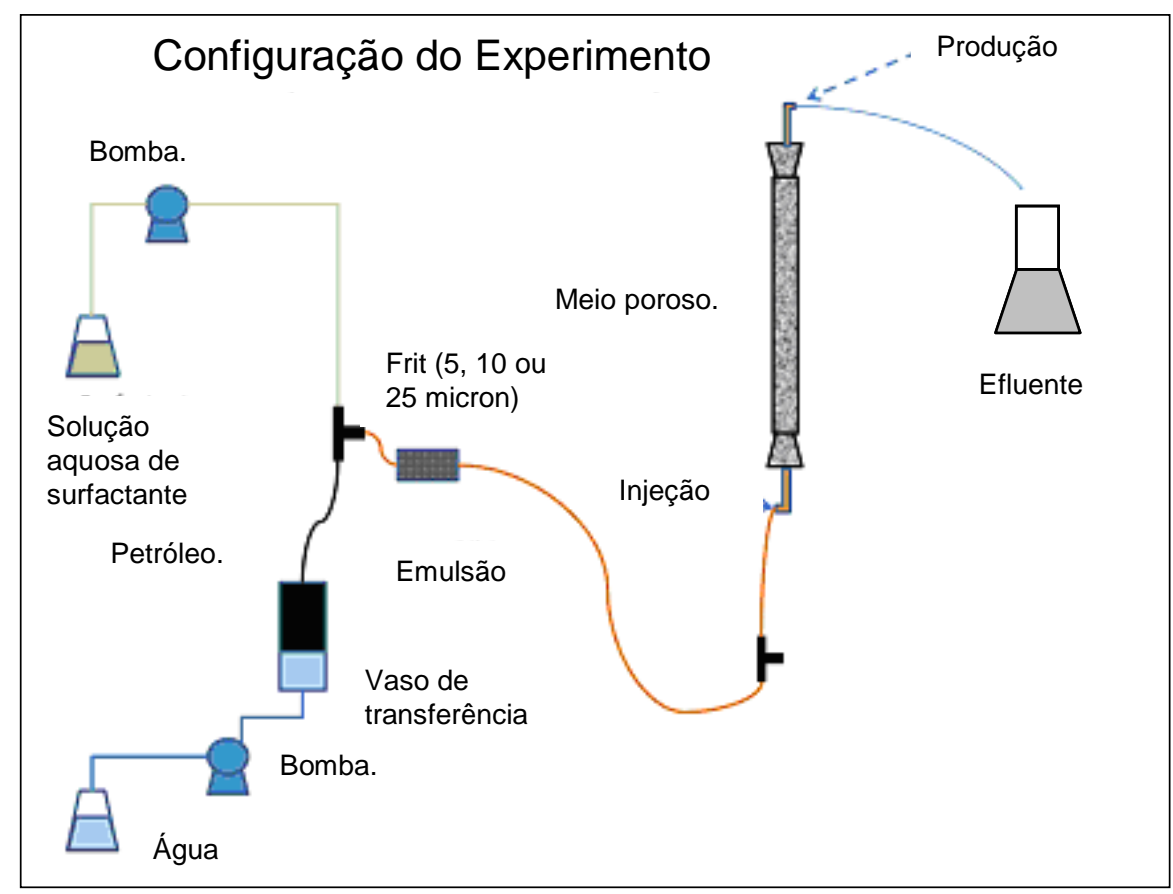

Figura 51 - Representação esquemática dos experimentos iniciais feitos em sandpacks $20 / 40$.

O efluente produzido nas 3 vazões tiveram praticamente a mesma coloração na injeção da emulsão preparada com o frit de $5 \mu \mathrm{m}$ (Figura 51). Entretanto, para as emulsões preparadas nos frits \#10 e \#25 $\mu \mathrm{m}$ (Figura 53 e Figura 54), pode-se perceber uma nítida diferença na coloração dos efluentes produzidos. A coloração foi se tornando mais clara à medida que a vazão vai diminuindo. Essa é uma indicação qualitativa de que ocorreu uma maior retenção de gotas no meio poroso para vazões mais baixas. Esses resultados mostraram a existência de uma forte dependência entre a vazão de injeção e a ocorrência de captura de gotas. 


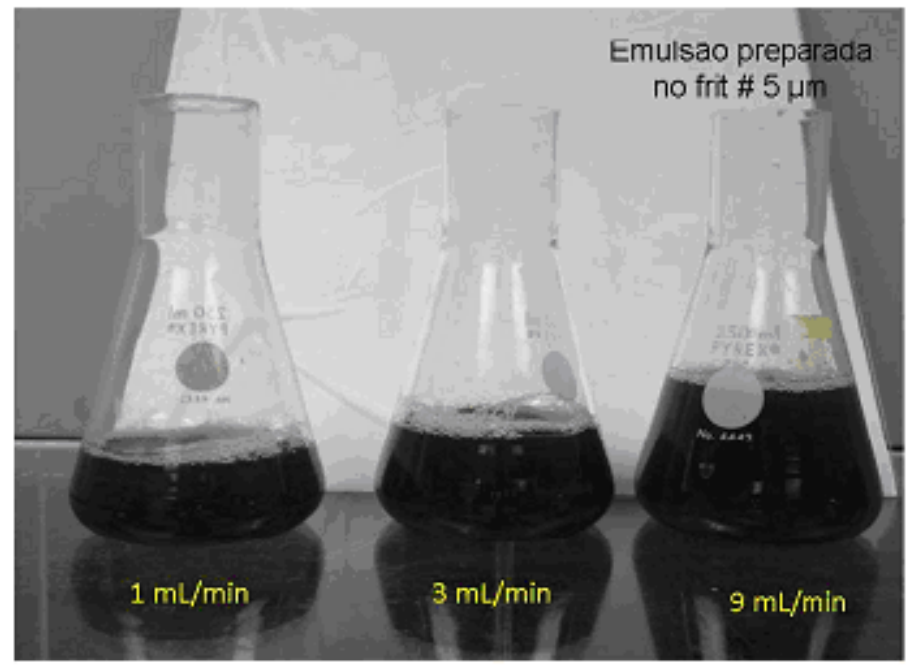

Figura 52 - aspecto visual dos efluentes coletadas na injeção de emulsão produzida no frit \# 5 m.

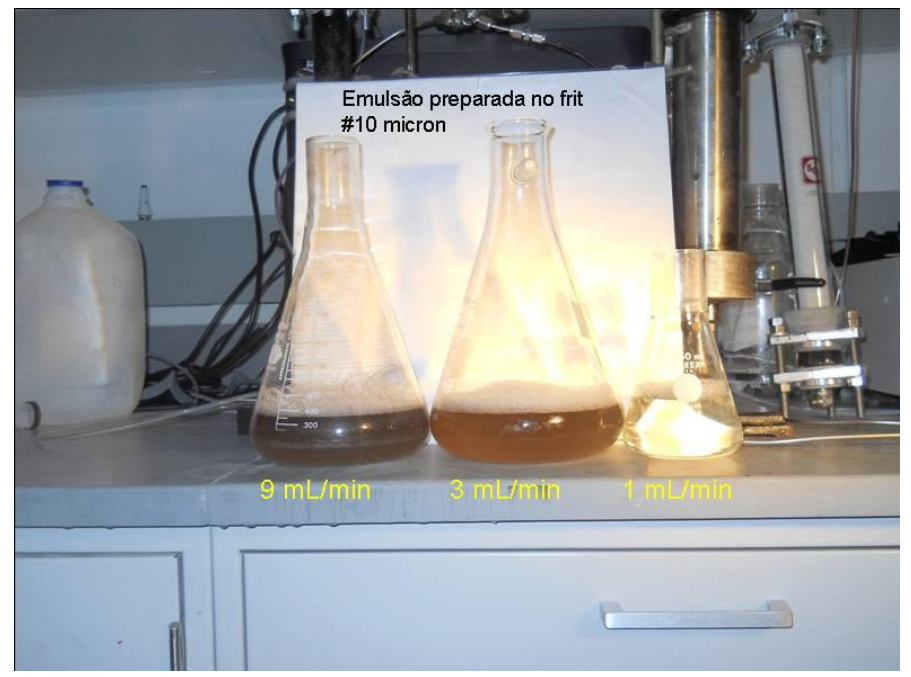

Figura 53 - aspecto visual dos efluentes coletadas na injeção de emulsão produzida no frit \#10 $\mu \mathrm{m}$.

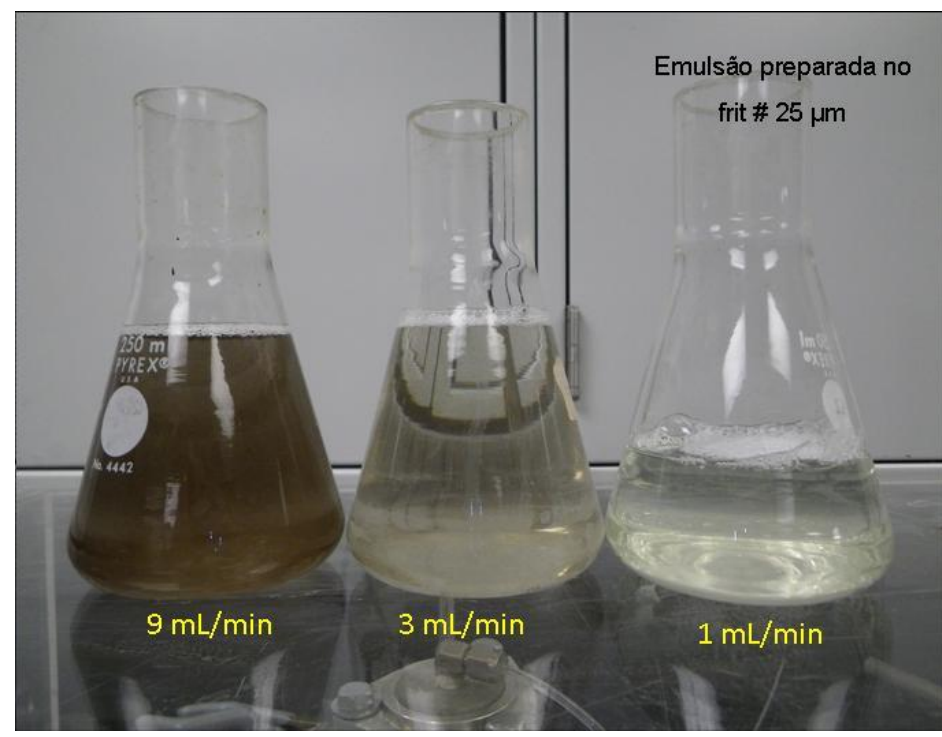

Figura 54 - aspecto visual dos efluentes coletadas na injeção de emulsão produzida no frit \#25 $\mu$ m. 
Uma avaliação quantitativa do efeito provocado pela retenção das gotas no meio poroso pode ser feita gráfico de Hall ("Hall Plot"). O gráfico de Hall é comumente utilizado na Engenharia de Reservatórios como um diagnóstico do comportamento de poços injetores, indicando a redução da injetividade ("dano") ou seu aumento ("estímulo") [63]. Em aplicações de campo, a causa mais comum de redução da injetividade é pelo acúmulo de sólidos em torno do injetor. Um exemplo de estímulo é o fraturamento do reservatório com o consequentemente aumento da área aberta ao fluxo em torno do poço. A construção desse gráfico é bastante simples:

a) No eixo das abscissas computa-se o volume acumulado de injeção;

b) A cada intervalo de tempo, calcula-se a razão $\frac{(\Delta \mathrm{P} . \Delta t)}{\Delta \mathrm{W}_{\mathrm{inj}}}$, onde $\Delta \mathrm{P}$ é o diferencial de pressão médio no intervalo de tempo $\Delta \mathrm{t}$ e $\Delta$ Winj é o volume injetado no intervalo de tempo considerado.

c) O somatório $\Sigma \frac{(\Delta \mathrm{P} . \Delta \mathrm{t})}{\Delta \mathrm{W}_{\mathrm{inj}}}$ é computado no eixo das ordenadas para construção de gráfico.

Essa técnica pode ser adaptada para analisar o que aconteceu aos sandpacks. Caso a razão calculada no passo (b) se mantiver constante, a passagem da emulsão pelo meio poroso não alterou sua permeabilidade média. O gráfico é uma linha reta. No caso de redução da permeabilidade do meio, são necessários diferenciais de pressão crescentes no tempo para manter-se a vazão de injeção. A curva resultante tende a se "verticalizar" com o aumento do volume injetado. Se a permeabilidade média do sandpack estiver crescendo com o volume injetado, o gráfico tende a se "horizontalizar" indicando que diferenciais de pressão menores são necessários para injetar-se o mesmo volume (Figura 55) 


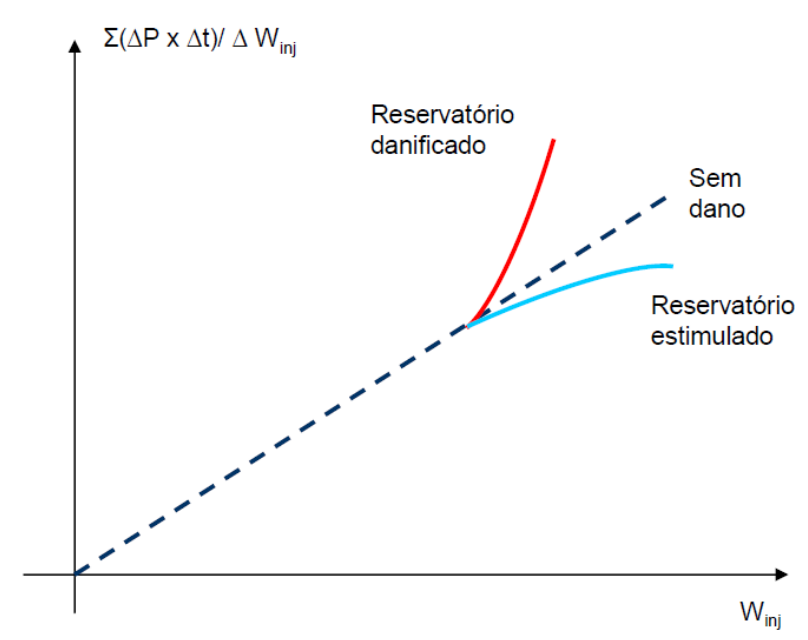

Figura 55 - Gráfico de Hall esquemático e sua interpretação.

A Figura 56 é o Gráfico de Hall para a injeção de uma emulsão produzida in line utilizando um filtro de abertura \#25 $\mu \mathrm{m}$ em um sandpack com $K=20.2$ D e $\varnothing=37.9 \%$. Nos ensaios impuseram-se vazões de 9 $\mathrm{ml} / \mathrm{min}$, $3 \mathrm{ml} / \mathrm{min}$ e $1 \mathrm{ml} / \mathrm{min}$. As concentrações de óleo nas emulsões foram, respectivamente, $0.23 \%, 0.29 \%$ e $1 \% \mathrm{v} / \mathrm{v}$. Na última etapa, a concentração de óleo foi maior por conta da impossibilidade de injetar-se óleo na mistura com vazão menor que $0.01 \mathrm{ml} / \mathrm{min}$. As pressões foram registradas a cada 15s. A análise do gráfico de Hall gerado, mostra claras mudanças nas declividades quando a vazão de injeção foi reduzida, mostrando que, para mesma emulsão, a captura de gotas se intensificou para as vazões mais baixas. Esse fato é confirmado pela inspeção visual dos efluentes produzidos (Figura 54). Outros ensaios feitos confirmaram esse comportamento. 


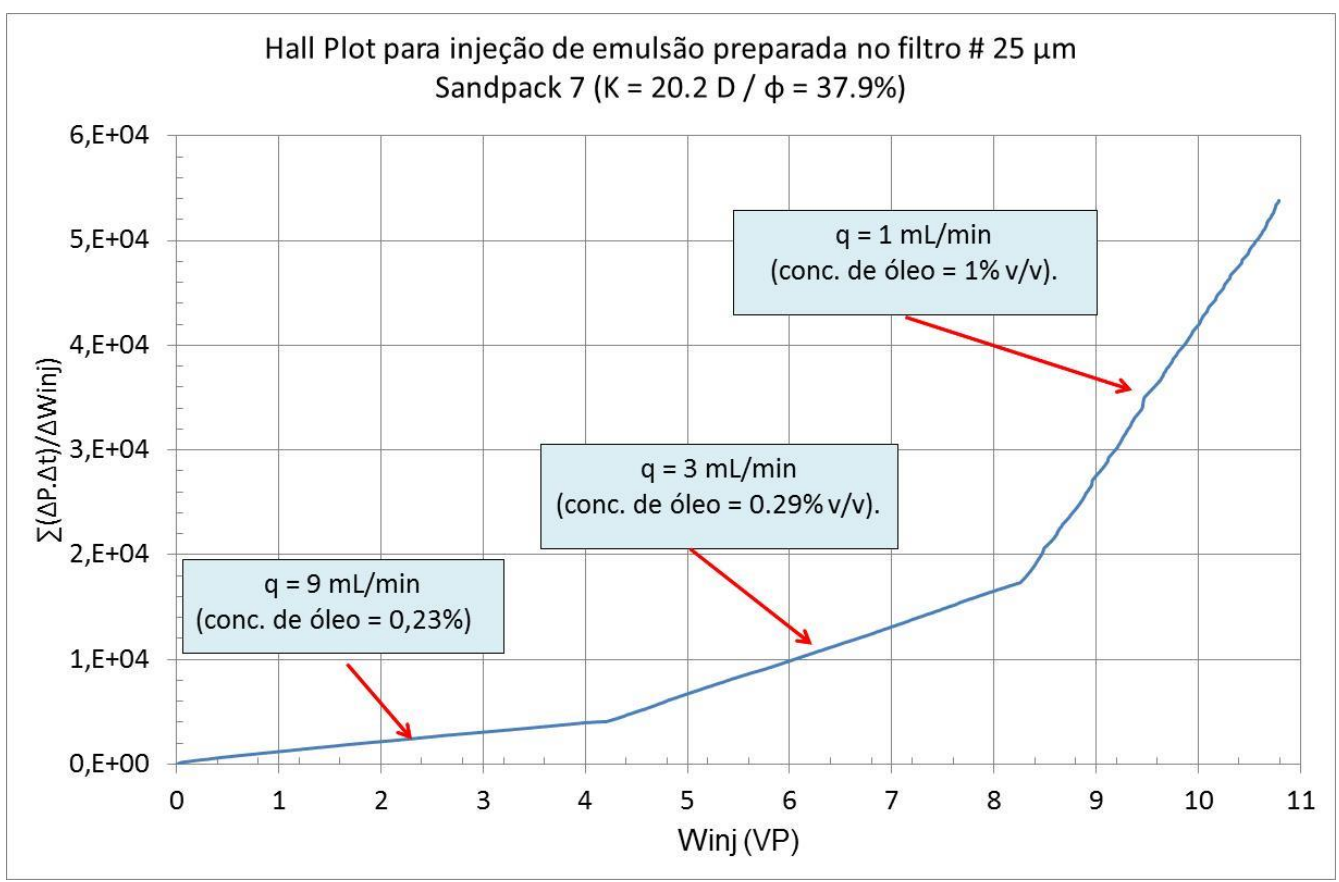

Figura 56 - Gráfico de Hall e para o mesmo experimento.

Os ensaios feitos com gotas menores mostraram maior penetração da emulsão no meio poroso, conforme pode ser verificado na comparação dos aspectos finais na Figura 57 e Figura 58. O sandpack ensaiado com a emulsão de gotas maiores ficou com o topo praticamente limpo.

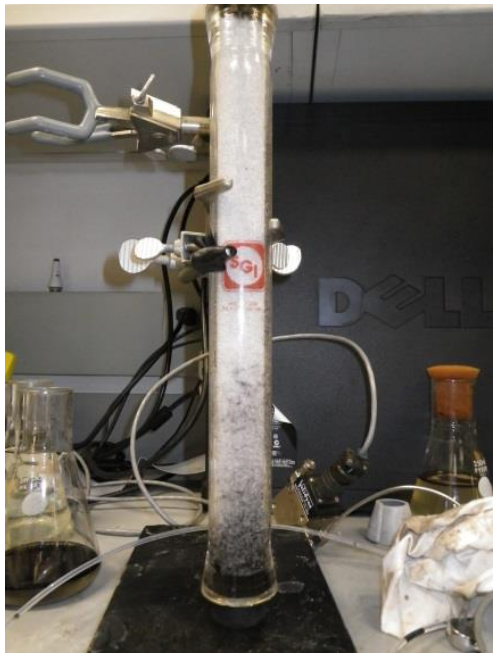

Figura 57 - aspecto final do sandpack após injeção de emulsão preparada no frit \#25 $\mu \mathrm{m}$.

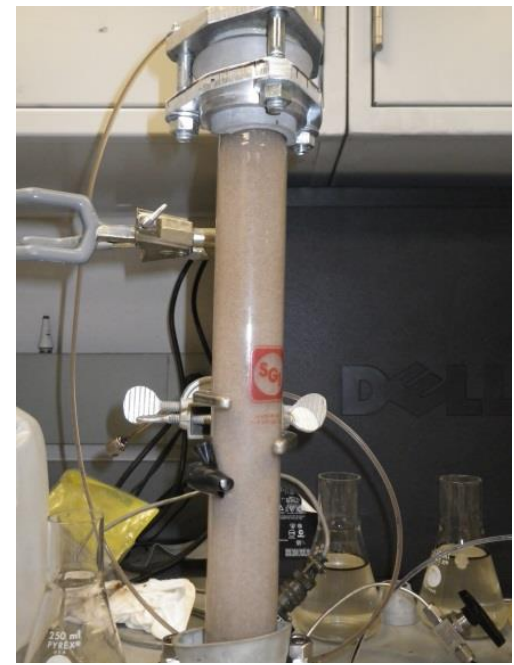

Figura 58 - aspecto final do sandpack após injeção de emulsão preparada no frit \#10 $\mu \mathrm{m}$.

As conclusões iniciais foram: 
a) A taxa de captura de gotas é um fenômeno mais complexo que a captura de sólidos. A captura de sólidos é basicamente um fenômeno de exclusão pelo tamanho, ou seja, as partículas são retidas caso encontrem uma garganta de poro menor que seu diâmetro. No caso do fluxo de gotículas emulsionadas, o efluente produzido claramente se alterou para diferentes níveis de vazão de injeção e tamanhos de gotas, conforme pode ser observado pela inspeção visual dos efluentes;

b) O processo de captura de gotas produziu redução da permeabilidade do meio. O Hall Plot pode ser utilizado para análise quantitativa do fenômeno;

\subsection{Ensaios 1-D de recuperação de óleo por emulsões}

\subsubsection{Introdução}

A próxima etapa do programa experimental foi avaliar o potencial uso de emulsões diluídas como agente de recuperação melhorada de petróleo. Essa etapa foi iniciada na Rice University e finalizada no laboratório de interação rocha-fluido do CENPES/PETROBRAS.

Nesses experimentos foram utilizados sandpacks preparados com areia de sílica F110 (US Sílica) que, após o empacotamento manual, produziram meios porosos com permeabilidades ao líquido (solução aquosa de $\mathrm{NaCl} @ 100 \mathrm{~g} / \mathrm{L})$ na faixa de 6 e 8 Darcy. As porosidades dos sandpacks preparados ficaram na faixa de $37.5 \%$ a $39 \%$. A saturação de óleo inicial média dos sandpacks foi de $90 \%$. Os equipamentos utilizados foram os mesmos do conjunto de ensaios anterior.

Após a preparação, os sandpacks foram submetidos aos diferentes esquemas de deslocamento do óleo, mantendo-se fixa a vazão de injeção de $0.3 \mathrm{ml} / \mathrm{min}$. Essa vazão corresponde a uma velocidade de Darcy de $2,47 \times 10^{-6} \mathrm{~m} / \mathrm{s}(=0,7 \mathrm{ft} /$ dia) que é compatível com a velocidade dos fluidos em um reservatório real. 
As emulsões mais utilizadas no programa experimental foram preparadas utilizando os filtros de aberturas \#10 $\mu \mathrm{m}$, \#25 $\mu \mathrm{m}$ e \#60 $\mu \mathrm{m}$. Essas emulsões foram caracterizadas em um analisador de tamanhos de partículas por difratometria laser (Malvern Mastersize Microplus ${ }^{\circledR}$ ). Foram feitos 2 ensaios para cada amostra com intervalos de 24h para avaliação da estabilidade das distribuições obtidas. A Tabela 10 mostra os diâmetros D10\% (menor que $90 \%$ das gotas), D50\% (menor que 50\% das gotas) e D90\% (menor que $90 \%$ das gotas). Uma discussão mais detalhada desse procedimento pode ser encontrada no apêndice 8.1.2.

Tabela 10 - Caracterização das emulsões utilizadas no programa experimental.

\begin{tabular}{|c|c|c|c|}
\hline Emulsão & $\mathrm{D} 10 \%(\mu \mathrm{m})$ & $\mathrm{D} 50 \%(\mu \mathrm{m})$ & $\mathrm{D90 \%}(\boldsymbol{\mu m})$ \\
\hline$\# 10 \mu \mathrm{m}$ & 10.04 & 23.32 & 44.30 \\
\hline$\# 25 \mu \mathrm{m}$ & 15.62 & 36.24 & 72.89 \\
\hline$\# 60 \mu \mathrm{m}$ & 19.94 & 41.32 & 74.93 \\
\hline
\end{tabular}

\subsubsection{Planejamento dos Experimentos}

Para efeito de comparação, todos os sandpacks foram submetidos à injeção de 3 volumes porosos de água nos ensaios. No deslocamento do óleo, foram utilizados diferentes esquemas, conforme a Tabela 11. 
Tabela 11 - Planejamento dos experimentos iniciais (vazão de injeção constante $=0.3 \mathrm{ml} / \mathrm{min}$ ).

\begin{tabular}{|c|c|c|c|c|c|}
\hline Experimento & $K(D)$ & $\varnothing(\%)$ & $\begin{array}{c}\text { AM/Em/A } \\
\text { M } \\
\text { (VP) }\end{array}$ & $\begin{array}{l}\text { Abertura } \\
\text { do filtro \# } \\
\quad(\mu \mathrm{m})\end{array}$ & Observação \\
\hline 1 & 6.38 & 38.75 & $3 / 0 / 0$ & 0 & $\begin{array}{l}\text { Caso-base: } 3 \text { VP de } \\
\text { água do mar sintética }\end{array}$ \\
\hline 2 & 7.00 & 41.09 & $0 / 3 / 0$ & 0 & $\begin{array}{l}3 \text { VP de solução de } \\
\text { surfactante }\end{array}$ \\
\hline 3 & 5.09 & 38.43 & $1 / 1 / 1$ & 60 & \\
\hline 4 & 6.38 & 41.06 & $1 / 1 / 1$ & 25 & \\
\hline 5 & 5.34 & 39.02 & $0.5 / 1.5 / 1$ & 90 & \\
\hline 6 & 4.50 & 39.34 & $0.5 / 1.5 / 1$ & 25 & \\
\hline 7 & 6.42 & 39.57 & $0.5 / 1.5 / 1$ & 60 & \\
\hline 8 & 8.70 & 40.0 & $0.5 / 1.5 / 1$ & 0 & $\begin{array}{c}\text { Apenas surfactante foi } \\
\text { adicionado ao segundo } \\
\text { banco injetado. }\end{array}$ \\
\hline 9 & 5.86 & 39.1 & $0 / 3 / 0$ & 60 & 3 VP de emulsão \\
\hline
\end{tabular}

Observações:

- $\quad$ Água do mar sintética $(A M)=$ solução aquosa deionizada + $\mathrm{NaCl} @ 36.5$ g/L;

- $\mathrm{AM} / \mathrm{Em} / \mathrm{AM}$ - tamanhos dos bancos de água inicial, emulsão e água final injetados.

- Solução aquosa de surfactante = água do mar sintética + $5 \mathrm{~mL} / \mathrm{L}$ de Steol CS-330 @ 28\% matéria ativa;

- $\quad$ Emulsão de óleo em água $(E m)$ = solução aquosa de surfactante + petróleo; 


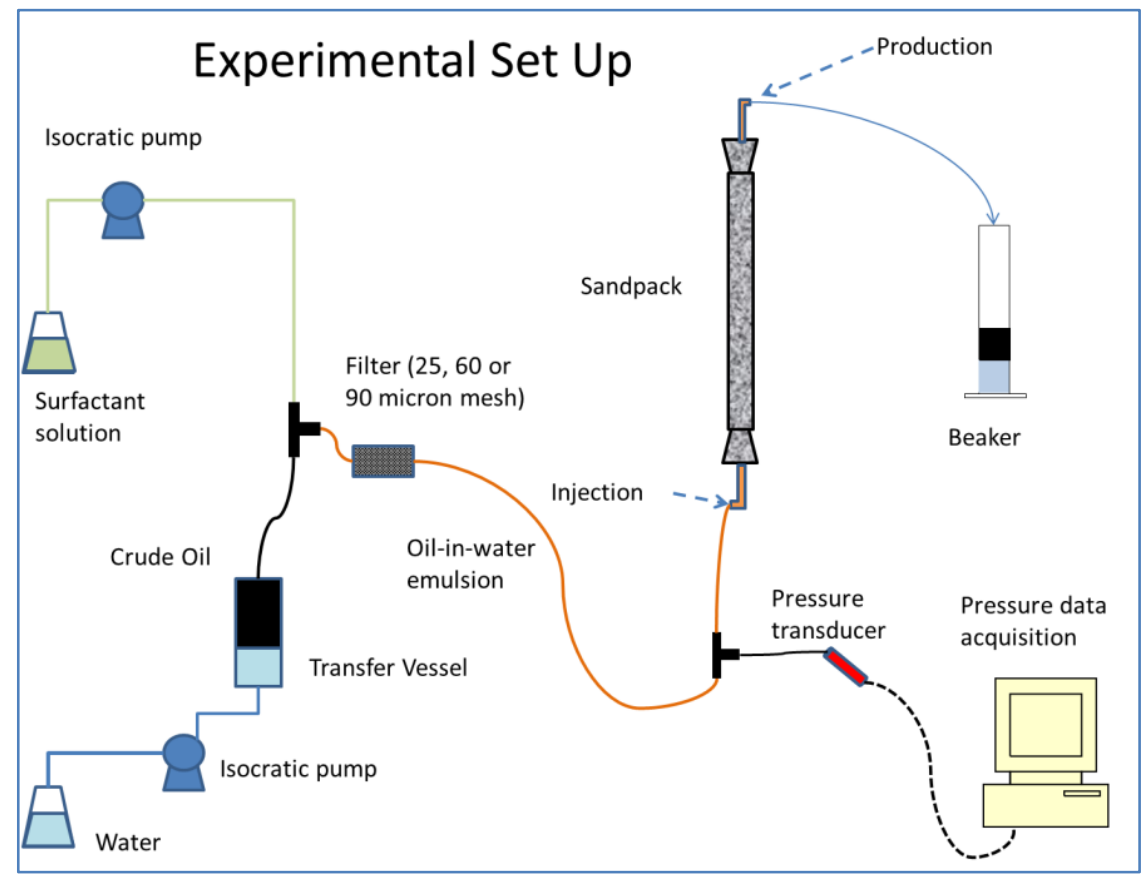

Figura 59 - Representação esquemática do ensaio de deslocamento de petróleo por diferentes métodos (injeção de água, emulsão e surfactante) [65].

A Tabela 12 contém os resultados do fator de recuperação final de óleo e a RAO (razão água-óleo) cumulativa em cada experimento.

Tabela 12 - Resultados dos experimentos iniciais (vazão de injeção constante $=0.3 \mathrm{ml} / \mathrm{min}$ ).

\begin{tabular}{|c|c|c|c|c|c|}
\hline $\begin{array}{c}\text { Experiment } \\
\mathbf{0}\end{array}$ & $\mathbf{K}(\mathrm{D})$ & $\varnothing(\%)$ & $\begin{array}{c}\text { Razão } \\
\text { (\#filtro) } \\
\left(\mathbf{D}_{\text {poros }}\right)\end{array}$ & $\begin{array}{c}\text { FR líquido } \\
\text { final de óleo } \\
(\%)\end{array}$ & $\begin{array}{c}\text { RAO } \\
\text { cumulativa } \\
\text { final }\end{array}$ \\
\hline 1 & 6.38 & 38.75 & 0.0 & 49.1 & 5.42 \\
\hline 2 & 7.00 & 41.09 & 0.0 & 55.3 & 5.20 \\
\hline 3 & 5.09 & 38.43 & 0.84 & 60.9 & 5.47 \\
\hline 4 & 6.38 & 41.06 & 0.53 & 57.5 & 4.76 \\
\hline 5 & 5.34 & 39.02 & 1.26 & 55.6 & 4.60 \\
\hline 6 & 4.50 & 39.34 & 0.41 & 65.2 & 4.10 \\
\hline 7 & 6.42 & 39.57 & 0.80 & 69.9 & 4.00 \\
\hline 8 & 8.70 & 40.0 & 0.0 & 65.6 & 4.14 \\
\hline 9 & 5.86 & 39.1 & 0.81 & 49.97 & 4.57 \\
\hline
\end{tabular}

Foram monitorados o comportamento da pressão de injeção e as produções de óleo e água em cada ensaio. 
A injeção de um banco de emulsão sempre aumentou o fator de recuperação líquido final de óleo, mesmo quando comparada com a injeção de 3 volumes porosos de solução de surfactante. A explicação é que a emulsão tem um efeito combinado de redução da saturação de óleo residual e modificação da trajetória da frente de injeção. Os resultados observados estão de acordo com os obtidos por Guillen et al [60].

O comportamento da pressão de injeção na injeção de emulsões tem um padrão característico. No início da injeção, a pressão tem um comportamento semelhante ao da injeção de água. Em seguida, a pressão começa a subir indicando o bloqueio parcial do meio poroso pelas gotas capturadas, o redirecionamento do fluxo para áreas ainda não varridas e a formação de um banco de óleo (fluido de maior viscosidade que a água que escoava predominantemente pelas áreas já varridas) que começa a se deslocar no meio. O comportamento da pressão é oscilante com alguns picos de pressão indicando, muito provavelmente, eventos de deslocamento de bolsões de óleo deixados para trás pela injeção de água inicial. A subida da pressão de injeção e a produção de óleo adicional ocorreram, tipicamente, para um volume acumulado de emulsão injetada entre 0.25 e 0.35 VP do sandpack.

A Figura 60 e a Figura 61 mostram, respectivamente, a evolução da fração recuperada de óleo e do diferencial de pressão (pressão de fluxo menos a pressão estática) no ponto de injeção para os experimentos 1, 2, 3, 4 e 9. O aumento da recuperação de óleo foi evidente nos sandpacks submetidos à injeção de emulsão após a injeção de água inicial. Os picos de pressão observados correspondem ao bloqueio mais intenso dos caminhos preferenciais formado na injeção de água inicial. O redirecionamento da frente de injeção leva à formação e deslocamento de pequenos bancos de óleo que são produzidos na extremidade oposta do sandpack algum tempo depois. O aumento da recuperação de óleo foi mais pronunciado para injeção com gotas maiores $(60 \mu \mathrm{m})$.

O experimento 9 consistiu na injeção de emulsão desde o início, ou seja, sem o banco de água inicial. A recuperação de óleo líquida foi ligeiramente maior que a obtida no ensaio de injeção de água. Entretanto, a curva desse ensaio fica praticamente o tempo todo abaixo da curva 3 
PV AM. Nesse caso, a emulsão deve ter bloqueado prematuramente alguns poros ainda saturados com óleo móvel. A curva de diferencial de pressão fica sempre acima das demais, indicando que essa não é a melhor estratégia de recuperação, pois aliou altas pressões necessárias com menores vazões de óleo. Nesse ensaio obteve-se uma fração recuperada de óleo "bruta" de 60\%, mas, descontando-se o óleo injetado, chega-se a uma fração líquida de $49.97 \%$, bem próxima da obtida na injeção de 3 VP de água do mar sintética (49.01\%).

Durante a injeção do terceiro volume poroso (água do mar sintética), houve produção de um fluido transparente amarelado nos sandpacks em que foram injetadas emulsão ou solução aquosa de surfactante na etapa anterior. A coloração dessa fase era mais intensa nos experimentos em que se utilizou emulsão. A concentração de óleo nessa fase foi medida utilizando um analisador de TOG por fluorescência de ultravioleta (Turner Designs TD-500 $D^{\circledR}$ ), obtendo-se valores entre 1\% e 1.5\%. A composição desse efluente é, provavelmente, a fração da emulsão que não foi capturada pelo meio poroso mais algum óleo mobilizado microemulsionado. Como as emulsões foram preparadas com o mesmo petróleo que saturava o meio poroso, não foi possível determinar a proporção gotas pequenas $x$ óleo remanescente mobilizado microemulsionado. 


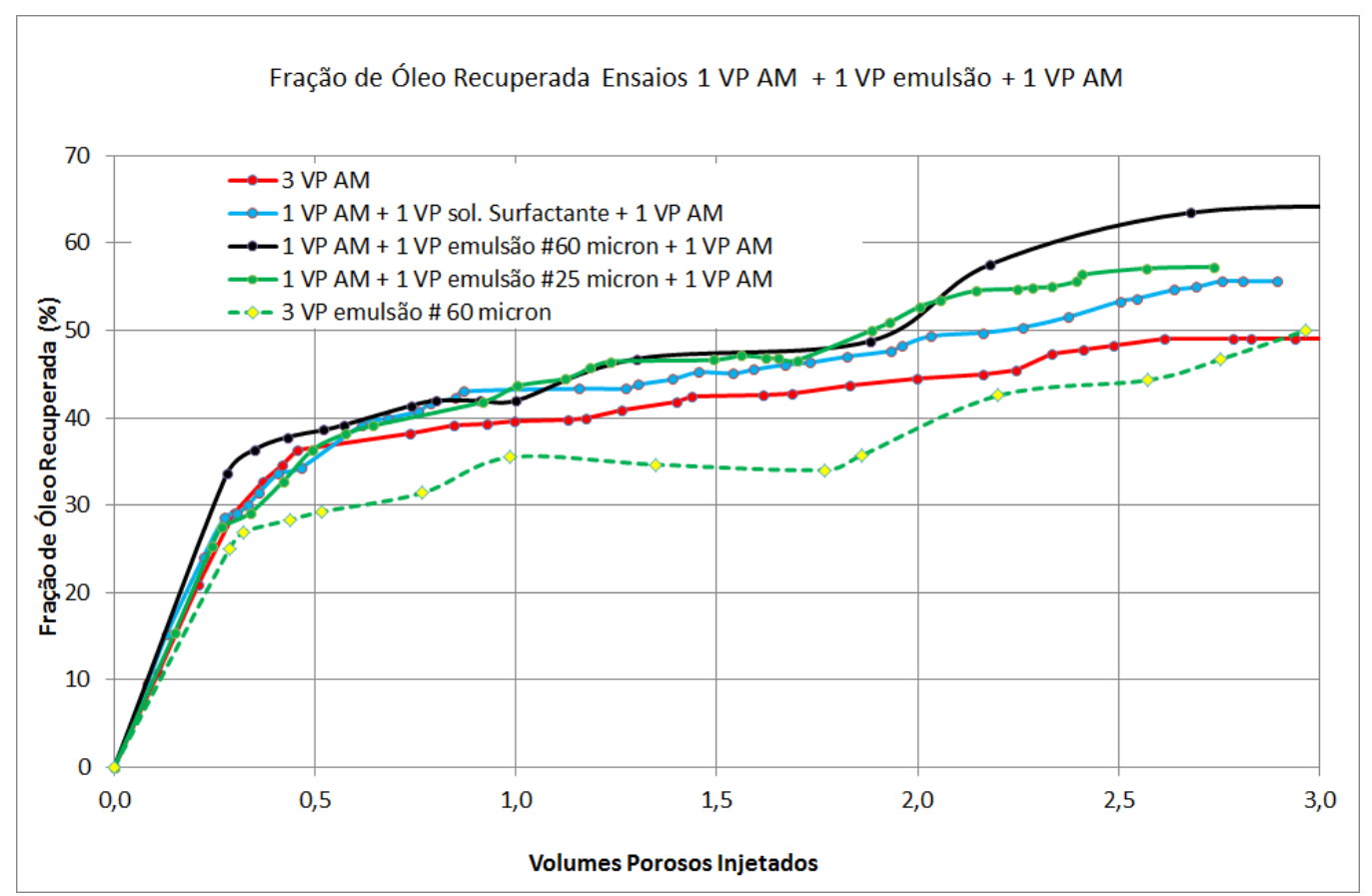

Figura 60 - Evolução da fração líquida de óleo recuperada nos experimentos de injeção alternada nos experimentos 1, 2, 3, 4 e 9 .

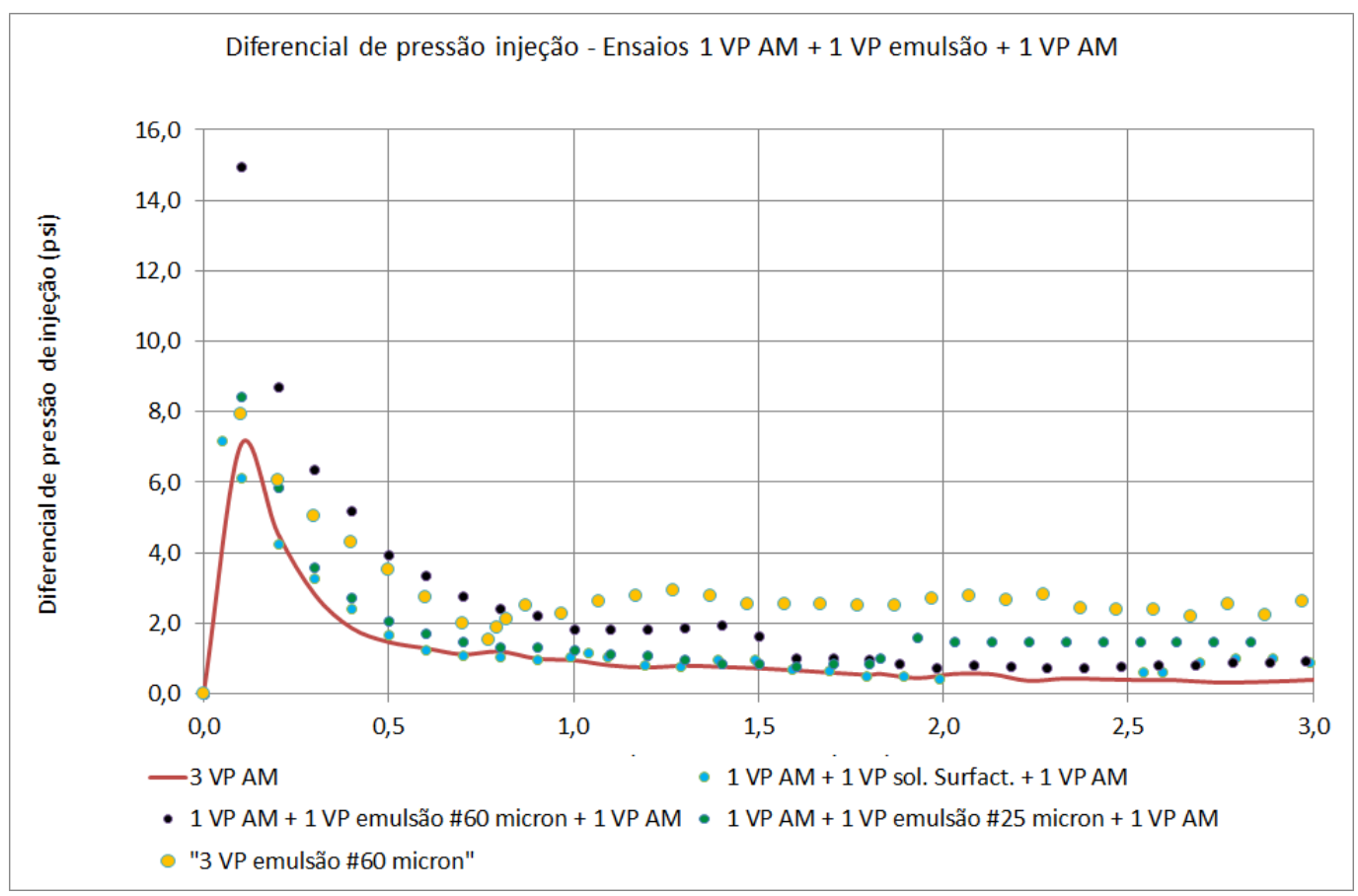

Figura 61 - Comportamento do diferencial de pressão de injeção experimentos 1, 2, 3,4 e 9. 


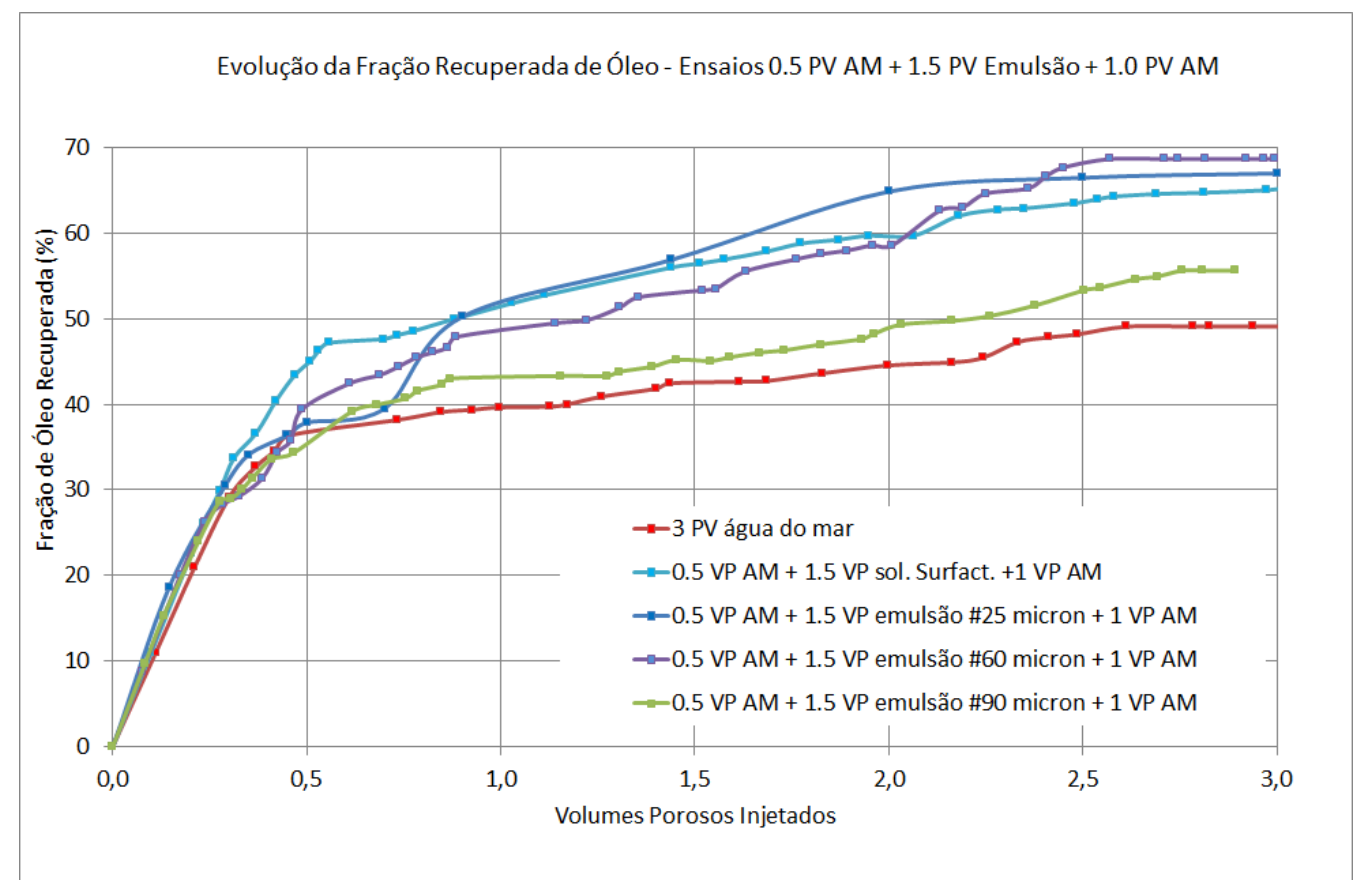

Figura 62 - Evolução da fração de óleo recuperada nos experimentos de injeção alternada nos experimentos $5,6,7$ e 8 .

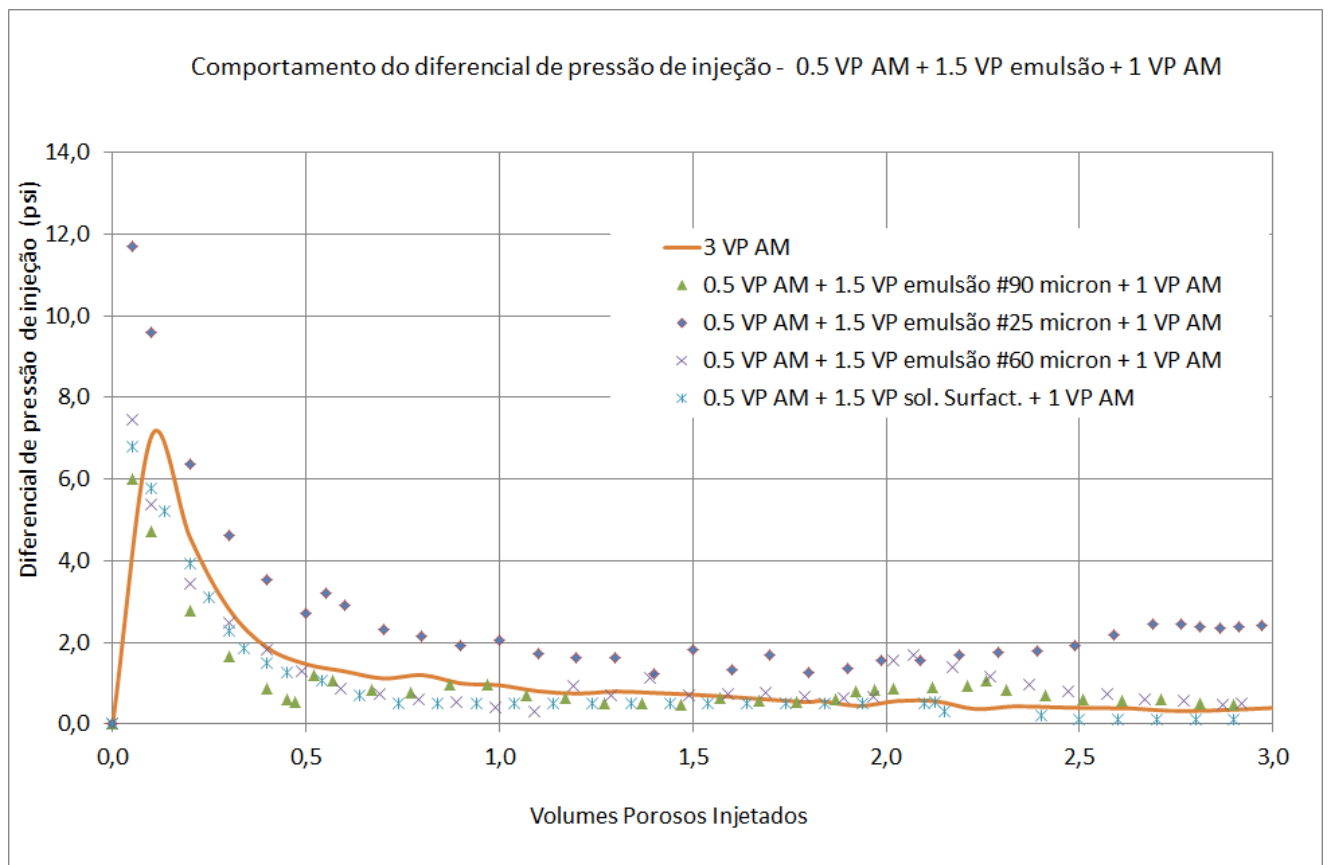

Figura 63 - - Comportamento de pressão nos experimentos 5, 6, 7 e. 8

A Figura 64 mostra os aspectos finais dos sandpacks próximos aos pontos de injeção. Pode-se observar que o processo de captura das gotículas de óleo foi mais intenso para as emulsões preparadas nos filtros/frit de maior abertura. 


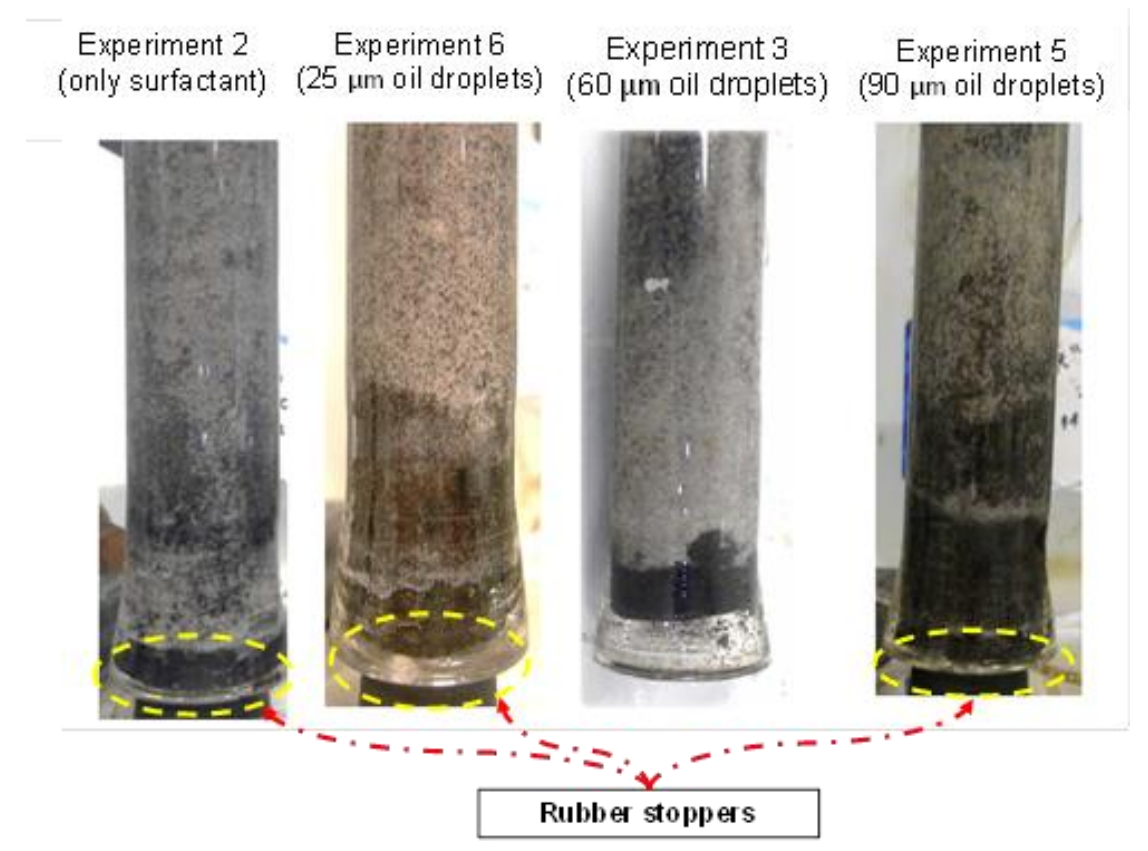

Figura 64 - Aspecto final dos sandpacks nas proximidades dos pontos de injeção.

\subsection{Estudo Paramétrico 1-D}

\subsubsection{Introdução}

A influência de alguns parâmetros no comportamento da pressão de injeção e no fator de recuperação final de óleo foi investigada. Foram estudadas as influências das seguintes variáveis:

- Concentração de óleo dispersa na emulsão;

- Vazão de injeção (velocidade ou número de capilaridade associado ao fluxo);

- Permeabilidade (variando a faixa com o uso de plugs de arenito Berea e Benthemer);

Os ensaios foram feitos no Laboratório de Interação Rocha-Fluido do CENPES/PETROBRAS. 


\subsubsection{Influência da Concentração de óleo presente na emulsão}

Foram feitos experimentos variando a concentração de óleo entre $0 \%$ e 3.3\%. Os sandpacks ensaiados foram submetidos à injeção de 1 PV de água do mar + 1 PV de emulsão produzida no filtro de \#60 $\mu \mathrm{m}+1$ PV de água do mar. A vazão de injeção foi mantida constante em $1 \mathrm{ml} / \mathrm{min}$. A Tabela 13 contém os experimentos executados e os valores finais da recuperação de óleo e razão água-óleo cumulativa.

Tabela 13 - Influência da concentração de óleo emulsionado na emulsão no fator de recuperação final de óleo.

\begin{tabular}{|c|c|c|c|c|}
\hline Amostra & $\begin{array}{c}\text { Fator de } \\
\text { recuperação } \\
\text { líquido final de } \\
\text { óleo (\%) }\end{array}$ & $\begin{array}{c}\text { Concentração } \\
\text { de óleo } \\
\text { emulsionado } \\
(\%)\end{array}$ & $\begin{array}{c}\text { Razão água } \\
\text { óleo } \\
\text { cumulativa } \\
\text { final }\end{array}$ & Observação \\
\hline 101 & 55.77 & 0 & 4.86 & $\begin{array}{c}3 \text { PV de água do mar } \\
\text { sintética - Caso-base. }\end{array}$ \\
\hline 102 & 56.84 & 0 & 4.92 & $\begin{array}{c}\text { 1 PV AM + 1 PV solução } \\
\text { de surfactante + 1 PV AM }\end{array}$ \\
\hline 105 & 80.20 & 3.3 & 3.13 & $\begin{array}{c}\text { 1 PV AM + 1 PV emulsão } \\
+1 \text { PV AM }\end{array}$ \\
\hline 111 & 54.65 & 1.0 & 3.64 & $\begin{array}{c}\text { 1 PV AM + 1 PV emulsão } \\
+1 \text { PV AM }\end{array}$ \\
\hline $112 / 113$ & 57.60 & 0.5 & 4.70 & $\begin{array}{c}1 \text { PV AM + 1 PV emulsão } \\
+1 \text { PV AM }\end{array}$ \\
\hline $114 / 115$ & 57.13 & 0.1 & 4.78 & 1 PV AM + 1 PV emulsão \\
+1 PV AM
\end{tabular}

A Figura 65 mostra a evolução da fração recuperada de óleo durante os ensaios. Nota-se que a fração recuperada de óleo líquida (óleo produzido menos óleo emulsionado injetado) cresceu com o aumento da concentração de óleo emulsionado. Além disso, a emulsão antecipou a produção do óleo. 


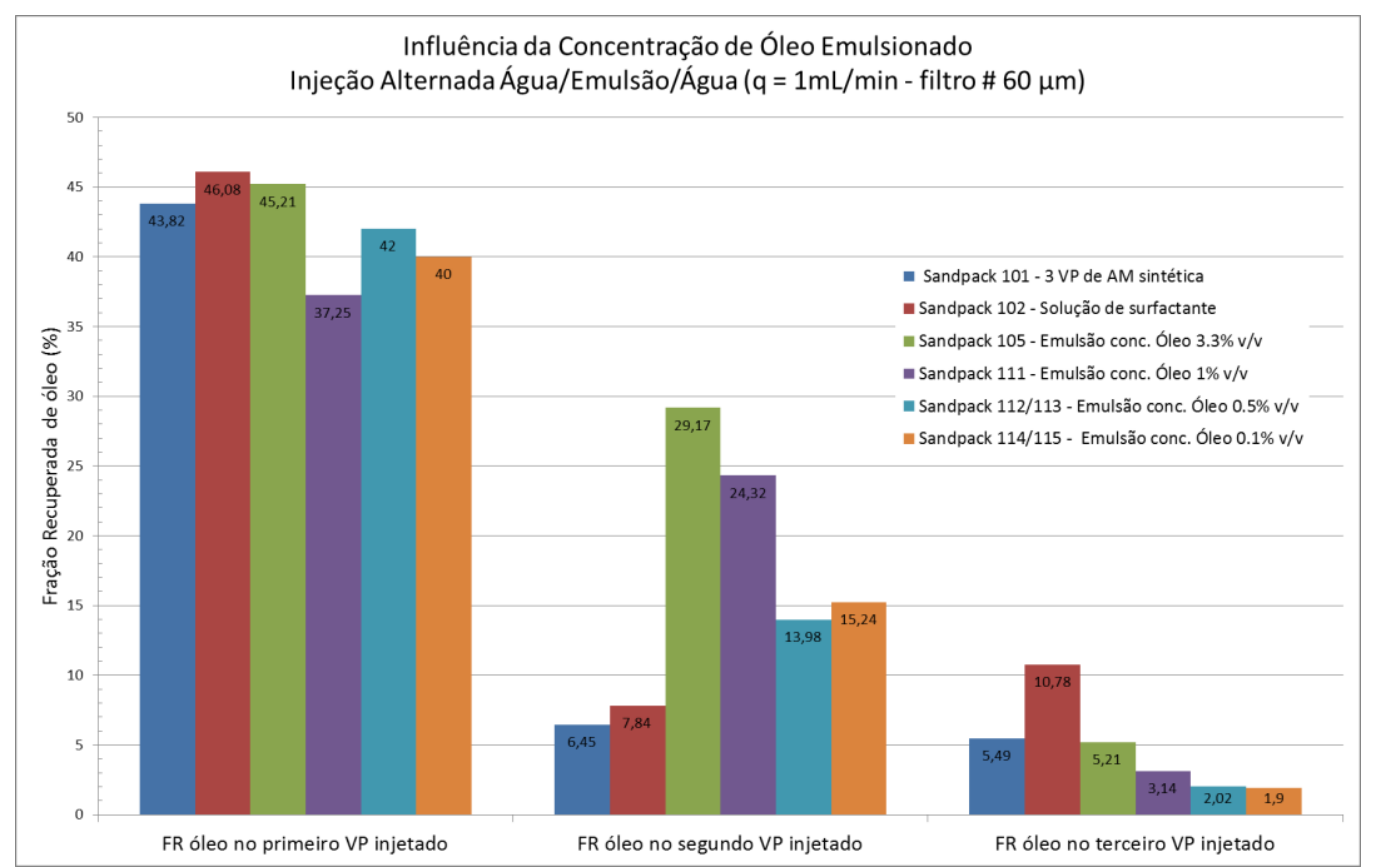

Figura 65 - Evolução da fração de óleo recuperada em cada experimento. A concentração de óleo na legenda se refere ao $2^{0}$ volume poroso injetado em cada amostra.

Os resultados mostram que o aumento da presença das gotículas suspensas promoveu aumento no fator de recuperação líquido de óleo, além da diminuição da razão água-óleo cumulativa. Esse efeito pode ser atribuído ao melhor bloqueio das áreas já lavadas na injeção de água inicial pela emulsão. A comparação dos sandpacks 101 e 102 é interessante. Ela mostra que a aplicação do surfactante promoveu um aumento discreto na recuperação final de óleo. Isso é explicável pelo fato de que o surfactante reduz a saturação de óleo residual nas áreas por ele lavadas, mas também promove um aumento da permeabilidade relativa da água nessas regiões. Dessa forma, a frente de injeção não sofre redirecionamento significativo e, consequentemente, regiões do meio poroso permanecem com alta saturação de óleo.

Outro parâmetro importante a ser considerado é o comportamento da pressão de injeção. O aumento da concentração de óleo promove um melhor bloqueio das áreas com canalização da água injetada, aumentando a pressão de injeção. Em uma aplicação de campo, esse aspecto é particularmente importante nos poços cuja pressão de injeção praticada é muito próxima da pressão de fratura da formação. A Figura 66 
mostra o comportamento do diferencial de pressão de injeção durante os ensaios.

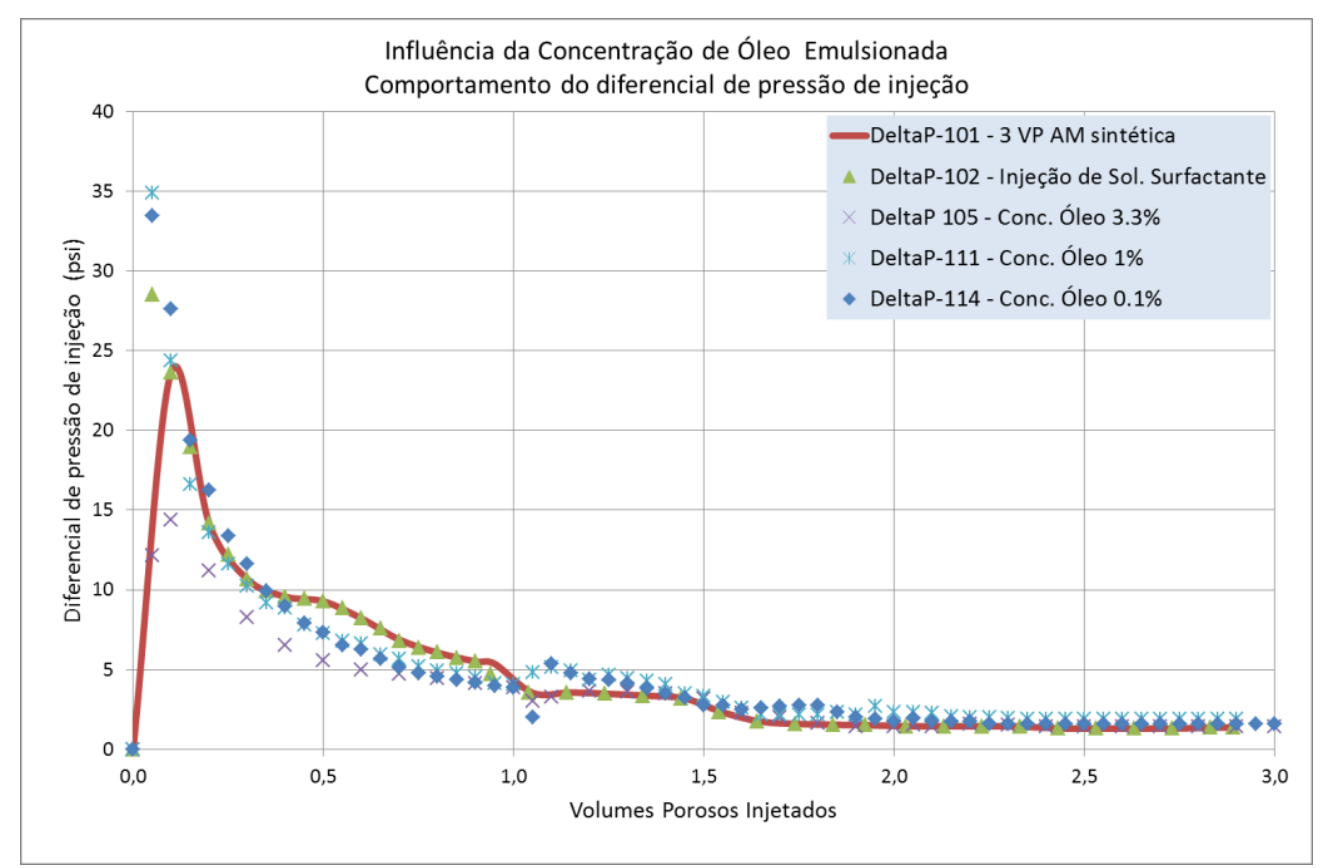

Figura 66 - Comportamento do diferencial de pressão nos ensaios realizados (a curva em linha cheia é do ensaio de injeção de água do mar).

\subsubsection{Influência da Vazão de Injeção}

A Tabela 14 compara os resultados obtidos na injeção de água do mar sintética com os obtidos na injeção de uma emulsão preparada no filtro de \# $60 \mu \mathrm{m}$ e concentração de óleo 3.3\% v/v. Em todos os ensaios seguiu-se o esquema 1 PV AM + 1 PV emulsão + 1 PV AM. 
Tabela 14- Ensaio para avaliar a influência da vazão de injeção.

\begin{tabular}{|c|c|c|c|c|}
\hline Sandpack & $\begin{array}{c}\text { Vazão de } \\
\text { injeção } \\
\text { (ml/min) }\end{array}$ & $\begin{array}{c}\text { Fator de } \\
\text { recuperação } \\
\text { final de óleo } \\
(\%)\end{array}$ & $\begin{array}{c}\text { Razão Água- } \\
\text { óleo } \\
\text { cumulativa } \\
\text { final }\end{array}$ & $\begin{array}{c}\text { Fluido } \\
\text { injetado no 2 } \\
\text { VP }\end{array}$ \\
\hline 25 & 0.3 & 60.9 & 4.86 & Emulsão \\
\hline 35 & 0.3 & 49.1 & 5.34 & AM \\
\hline 101 & 1.0 & 55.8 & 4.86 & AM \\
\hline 105 & 1.0 & 80.2 & 3.13 & Emulsão \\
\hline 103 & 3.0 & 73.2 & 3.74 & AM \\
\hline 106 & 3.0 & 70.0 & 3.71 & Emulsão \\
\hline
\end{tabular}

Observando os resultados, percebe-se que a injeção do banco de emulsão não foi efetiva na vazão mais alta. Nesse caso, a velocidade de fluxo ao nível dos poros foi suficiente para fazer com que as gotículas emulsionadas cruzassem o sandpack praticamente sem nenhuma captura significativa. Comparando os resultados obtidos pela injeção alternada água/emulsão/água (sandpack 106) com os da injeção de 3 PV de água (sandpack 103), percebe-se que são praticamente os mesmos. Outro fator que deve ser considerado é a que a permeabilidade do sandpack 103 é aproximadamente 15\% maior.

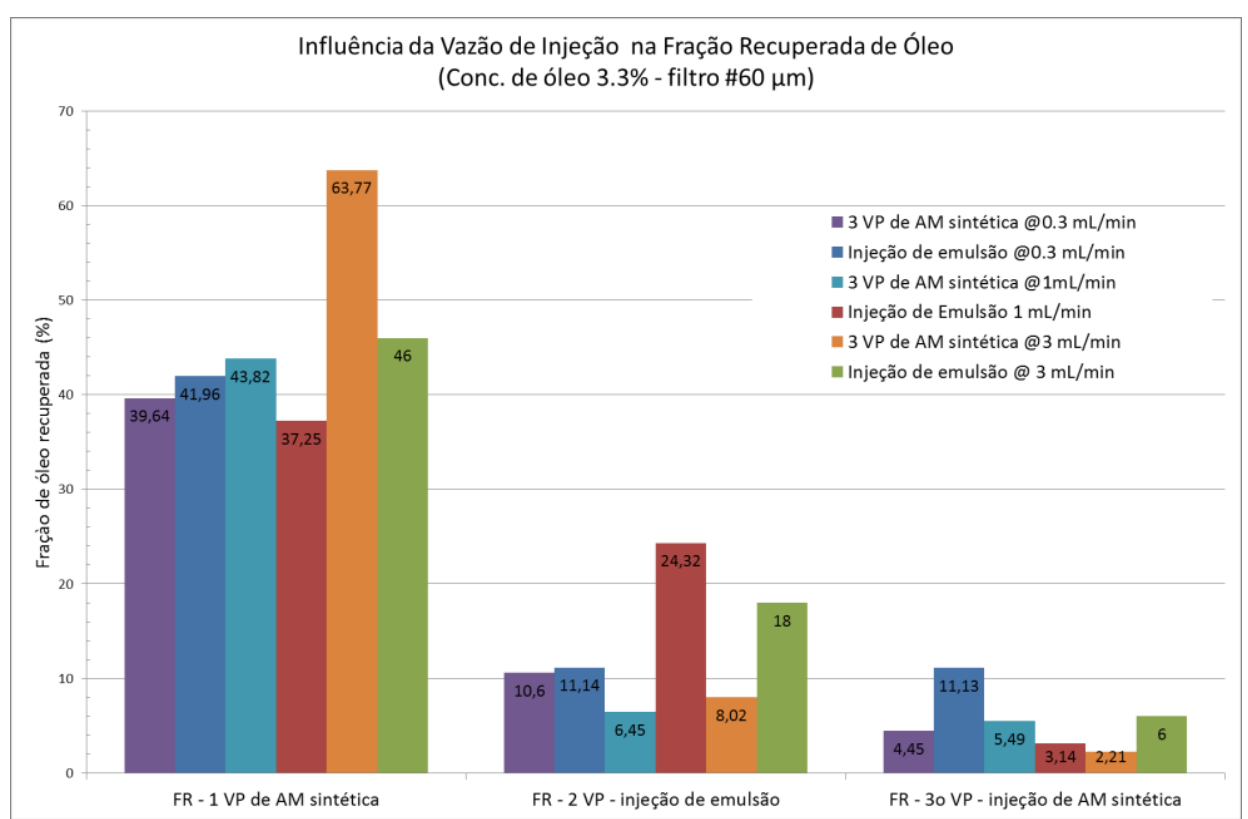

Figura 67 - Fatores de recuperação de óleo a cada volume poroso injetado nos ensaios para avaliar a influência da vazão de injeção nos resultados da injeção de emulsões. 


\subsubsection{Ensaios com Plugs de Arenito Berea e Bentheimer}

A validade dos resultados obtidos com sandpacks foi testada em plugs de arenito Berea $(\mathrm{K}=60 \mathrm{mD}$ e $\Phi=17.9 \%)$ e Bentheimer ( $\mathrm{K}=2320$ $\mathrm{mD} / \Phi=23.1 \%$ ). Dessa forma, pode-se investigar os efeitos da injeção de emulsão em rochas reais com diferentes níveis de permeabilidade. A preparação dos plugs seguiu a seguinte sequência:

- Pesagem a seco;

- Saturação com solução salina de NaCl@100.000 mg/L utilizando uma bomba de vácuo;

- Pesagem do sandpack saturado;

- Confinamento da amostra em um core holder @1000 psia $\left(6.89 \times 10^{3} \mathrm{KPa}\right)$;

- Saturação com petróleo por bombeamento.

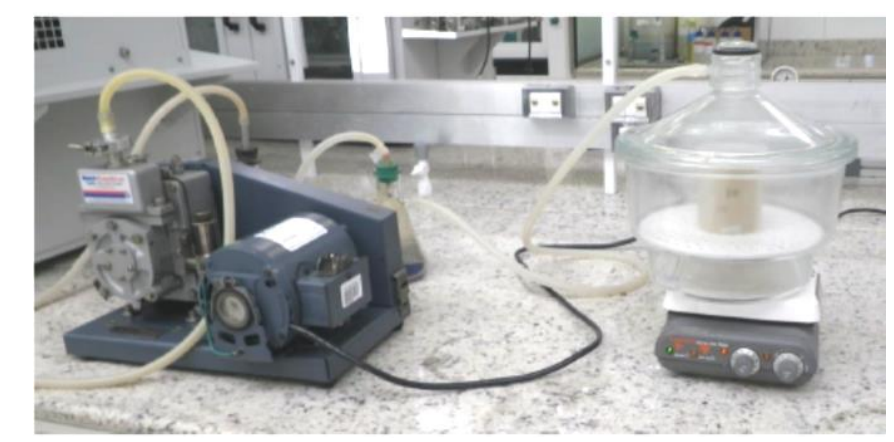

Figura 68 - Saturação dos plugs com água de formação desaerada em bomba de vácuo.

De forma a manter a velocidade de fluxo nos mesmos níveis dos experimentos nos sandpacks, a vazão de injeção foi ajustada para 0.18 $\mathrm{ml} / \mathrm{min}$. Os plugs de arenito Berea foram ensaiados com emulsões preparadas nos frits de aberturas \#10 e $25 \mu \mathrm{m}$. Essa modificação foi feita de forma a evitar-se o bloqueio muito forte nas proximidades do ponto de injeção e garantir o fluxo das gotas emulsionadas no meio poroso. A Tabela 15 mostra os resultados finais obtidos nos ensaios com arenitos 
Berea, enquanto a Figura 69, mostra a fração de óleo recuperada a cada volume poroso injetado para os esquemas de injeção utilizados.

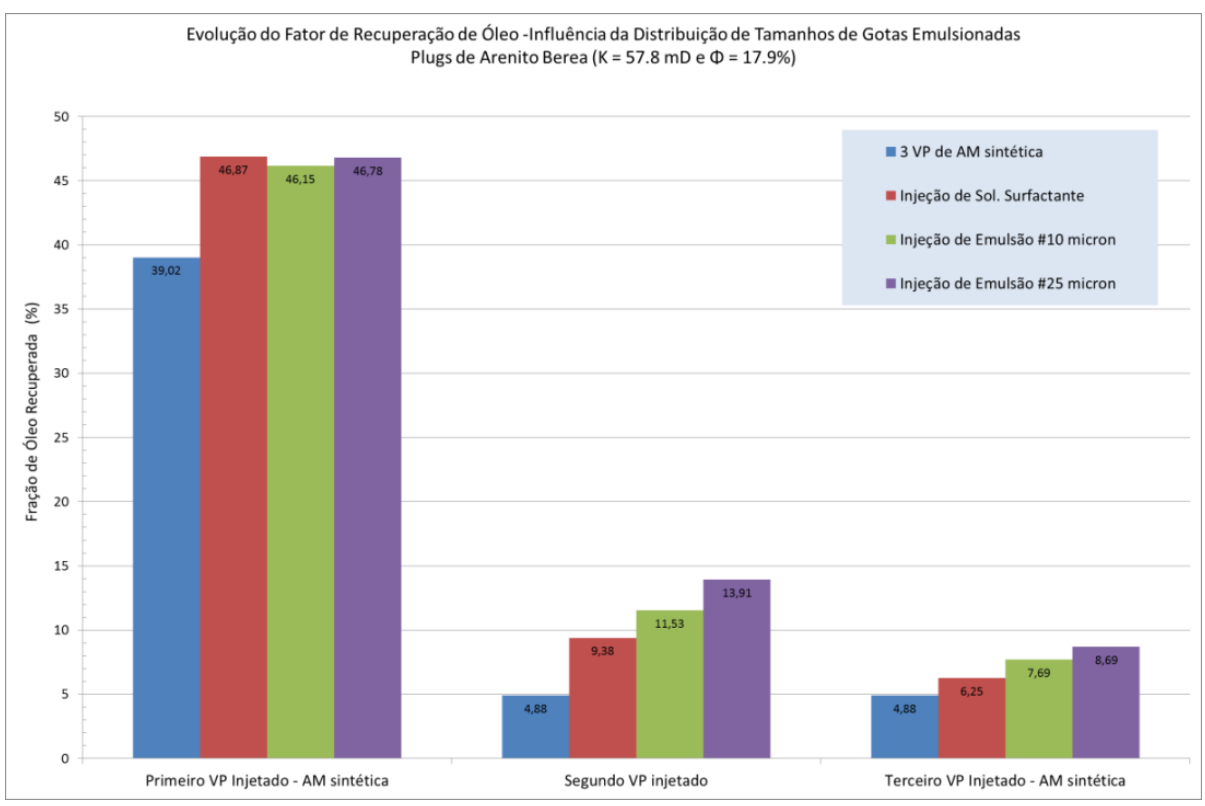

Figura 69 - Comparativo das frações recuperadas a cada volume poroso injetado para os plugs de arenito Berea ensaiados. A legenda se refere à fase injetada no segundo volume poroso.

Tabela 15 - Resultados dos ensaios com os plugs de arenito Berea ( $q=0.18 \mathrm{ml} / \mathrm{min}$ e conc. de óleo $3.3 \% \mathrm{v} / \mathrm{v})$.

\begin{tabular}{|c|c|c|c|}
\hline Amostra & Esquema de ensaio & $\begin{array}{c}\text { Fator de } \\
\text { recuperação final } \\
\text { de óleo (\%) }\end{array}$ & $\begin{array}{c}\text { Razão Água-óleo } \\
\text { cumulativa final }\end{array}$ \\
\hline $1 \mathrm{~A}$ & 3 PV AM & 48.78 & 6.81 \\
\hline $1 \mathrm{~B}$ & $\begin{array}{c}1 \text { PV AM + 1 PV solução } \\
\text { surfactante + 1 PV AM }\end{array}$ & 62.90 & 5.47 \\
\hline $1 \mathrm{C}$ & $\begin{array}{c}1 \mathrm{PV} \text { AM + 1 PV emulsão } \\
\text { \#10 } \mu \mathrm{m}+1 \text { PV AM }\end{array}$ & 65.37 & 4.82 \\
\hline $1 \mathrm{D}$ & $\begin{array}{c}1 \mathrm{PV} \mathrm{AM}+1 \text { PV emulsão } \\
\text { \#25 } \mu \mathrm{m}+1 \text { PV AM }\end{array}$ & 69.38 & \\
\hline
\end{tabular}

A Tabela 16 contém os resultados finais dos experimentos realizados com os plugs de arenito Bentheimer. Em função da permeabilidade média dessa rocha ser bem maior que a do arenito Berea ensaiado, optou-se pela injeção de emulsões preparadas nos frits de \#25 e $60 \mu \mathrm{m}$. 
Novamente foi claro o efeito de diminuição da razão água-óleo cumulativa e aumento do fator de recuperação final de óleo provocado pela injeção de emulsão nos meios porosos. Uma diferença em relação aos ensaios com os Berea foi em relação à dependência entre o tamanho de gotas emulsionadas e o fator de recuperação final de óleo. A recuperação diminuiu na injeção das gotas maiores (preparadas no frit \#60 $\mu \mathrm{m}$ ) quando comparada à média obtida para a injeção de emulsão preparada no frit \# $25 \mu \mathrm{m}$. A explicação mais provável é que as gotas menores encontraram maior facilidade em fluir no meio poroso. Como a concentração de óleo utilizada foi a mesma em ambas, a emulsão de preparada no frit \#25 $\mu \mathrm{m}$ possuía um número maior de gotas $/ \mathrm{mL}$ sendo, dessa forma, capaz de bloquear mais gargantas de poros. Essa observação reforça a necessidade de um programa experimental extenso antes da aplicação de campo dessa técnica para controle de mobilidade e EOR.

Tabela 16 - Resultados dos ensaios com os plugs de arenito Bentheimer $(q=1 \mathrm{ml} / \mathrm{min}$ e conc. de óleo $3.3 \% \mathrm{v} / \mathrm{v})$.

\begin{tabular}{|c|c|c|c|}
\hline Amostra & Esquema de ensaio & $\begin{array}{c}\text { Fator de } \\
\text { recuperação final de } \\
\text { óleo (\%) }\end{array}$ & RAO acumulada \\
\hline 2B & $\begin{array}{c}\text { 1 PV AM + 1 PV solução } \\
\text { surfactante + 1 PV AM }\end{array}$ & 45.45 & 7.11 \\
\hline $2 \mathrm{C} / 2 \mathrm{~F}$ & $\begin{array}{c}1 \mathrm{PV} \text { AM + 1 PV emulsão \#25 } \\
\mu \mathrm{m}+1 \text { PV AM }\end{array}$ & 54.91 & 6.74 \\
\hline $2 \mathrm{D}$ & 3 PV AM & 43.75 & 7.57 \\
\hline $2 \mathrm{E}$ & $\begin{array}{c}\text { 1 PV AM + 1 PV emulsão \#60 } \\
\mu \mathrm{m}+1 \text { PV AM }\end{array}$ & 48.39 & 6.38 \\
\hline
\end{tabular}

A Figura 70 mostra as frações de óleo recuperadas a cada volume poroso injetado nos ensaios realizados com os plugs de arenito Bentheimer, enquanto a Figura 71 é a evolução do diferencial de pressão de injeção para os experimentos. Um fato interessante foi que a recuperação final de óleo foi mais baixa para a injeção da emulsão preparada no filtro \#60 $\mu \mathrm{m}$. O gráfico da pressão de injeção nesse ensaio mostra valores bastante menores que os dos demais ensaios. Uma 
provável explicação para o fato é que essa amostra possuía algum caminho de alta permeabilidade (fratura?) que a emulsão não foi capaz de bloquear de maneira eficiente. Infelizmente, não havia mais amostras desse arenito disponíveis para ensaiar. É um fato amplamente conhecido que sempre que um método de recuperação melhorada estiver sendo efetiva, a pressão de injeção vai subir.

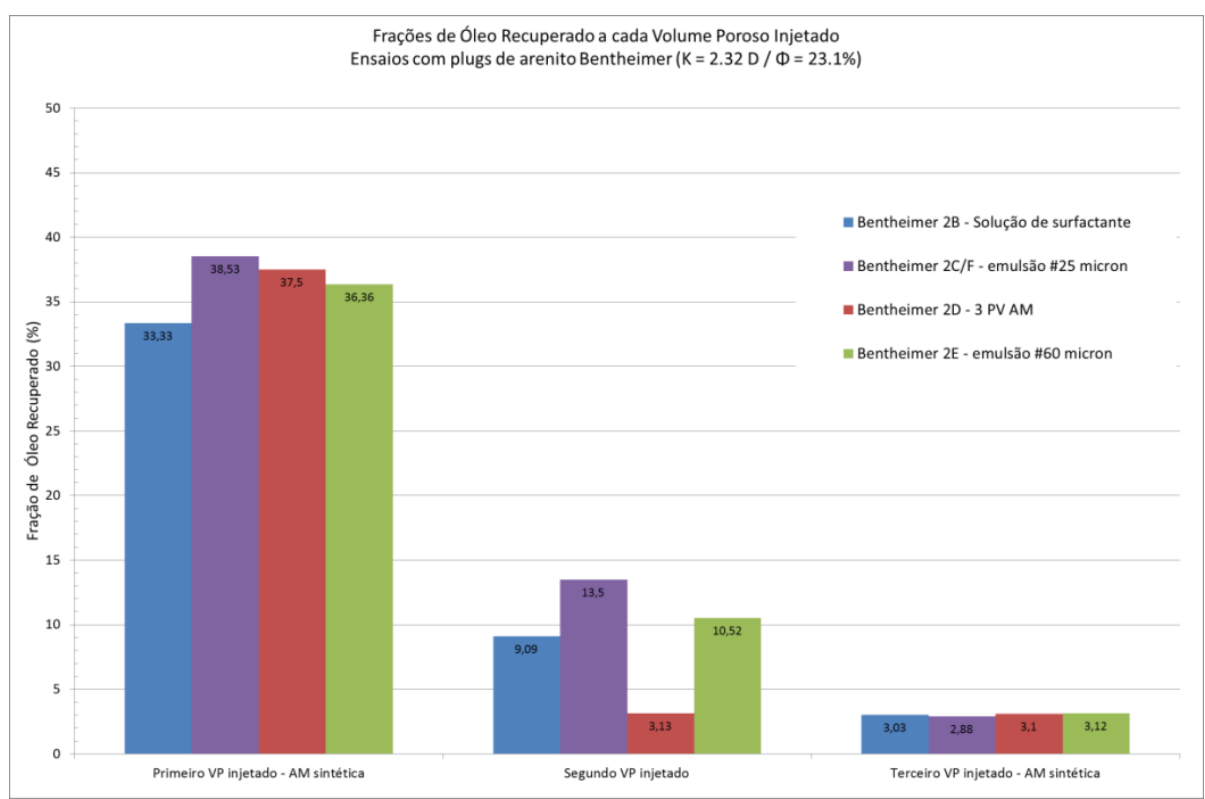

Figura 70 - Comparativo das frações recuperadas a cada volume poroso injetado para os plugs de arenito Bentheimer ensaiados.

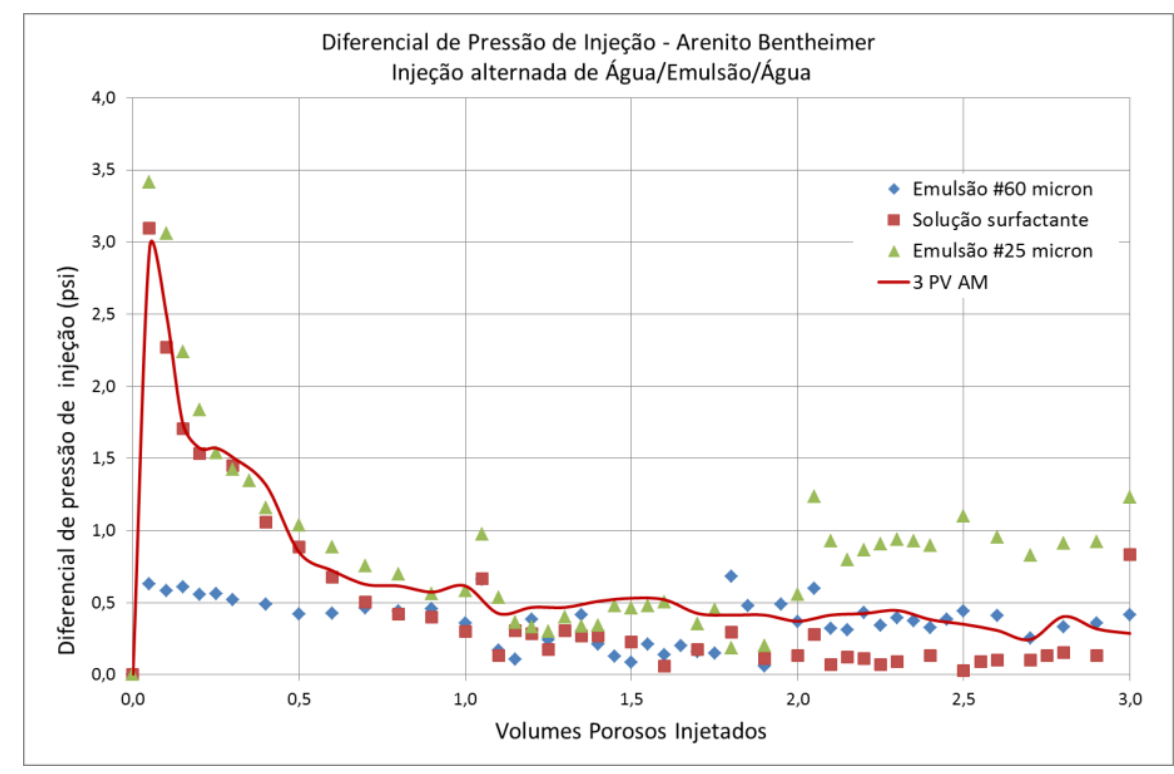

Figura 71 - Evolução do diferencial de pressão nos experimentos com arenito Bentheimer. A legenda se refere à fase injetada no segundo volume poroso. 


\subsubsection{Simulação Numérica de Fluxo de Emulsões}

Foram criados modelos de simulação para alguns dos ensaios. $O$ simulador de fluxo utilizado foi o STARS ("Steam Thermal and Advanced Process Reservoir Simulator) da CMG. O STARS é um simulador trifásico (óleo, água e gás), multicomponente com opções pré-configuradas para modelagem de diversos processos de recuperação avançada de petróleo, tais como injeção de vapor, polímeros, géis, emulsões e espumas.

Os modelos de simulação utilizados contêm 360 células distribuídas uniformemente em 20 camadas. $O$ grid tem geometria transversal radial. Para distribuir a produção e injeção, respectivamente nas extremidades superior e inferior do modelo, foram inseridos 7 poços injetores na entrada e 7 poços produtores na saída do sandpack. Em cada caso simulado, consideraram-se a porosidade, permeabilidade média, e saturações iniciais relativas ao sandpack ensaiado. A tensão interfacial para cada par de fluido foi medida em laboratório (Tabela 19) e considerada nas simulações. A Figura 72 é o modelo 3D gerado.

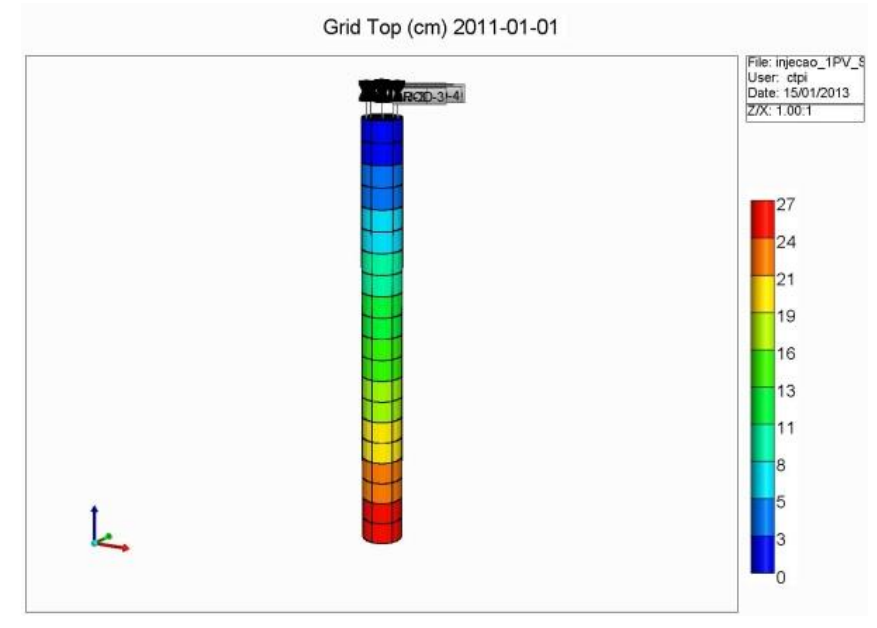

Figura 72 - Modelo 3D de simulação CMG STARS ${ }^{\circledast}$ composto por 360 células distribuídas uniformemente em 20 camadas. A figura foi gerada no CMG ModelBuider ${ }^{\circledR}$.

Os modelos foram simulados no STARS e os resultados pósprocessados nos aplicativos Results 3D e Results Graph.

Utilizando os históricos de produção dos casos-base (injeção 3 VP de AM e 3 VP de solução de surfactante) foram determinadas as curvas de permeabilidades relativas óleo-água. $\mathrm{O}$ ajuste da injeção de água 
inicial se deu com uma curva típica de arenitos inconsolidados (Kro@S $\mathrm{S}_{w i}=0.70 ; \mathrm{Krw} @ \mathrm{~S}_{\mathrm{or}}=0.70 ; \mathrm{S}_{\mathrm{or}}=0.38 ; \mathrm{S}_{\mathrm{wi}}=0.10$; expoentes de Corey $\mathrm{n}_{\mathrm{o}}=4.5$ e $\mathrm{n}_{\mathrm{w}}=2.5$ ). A Figura 73 mostra curvas de permeabilidade relativas ajustadas para a injeção de água inicial.

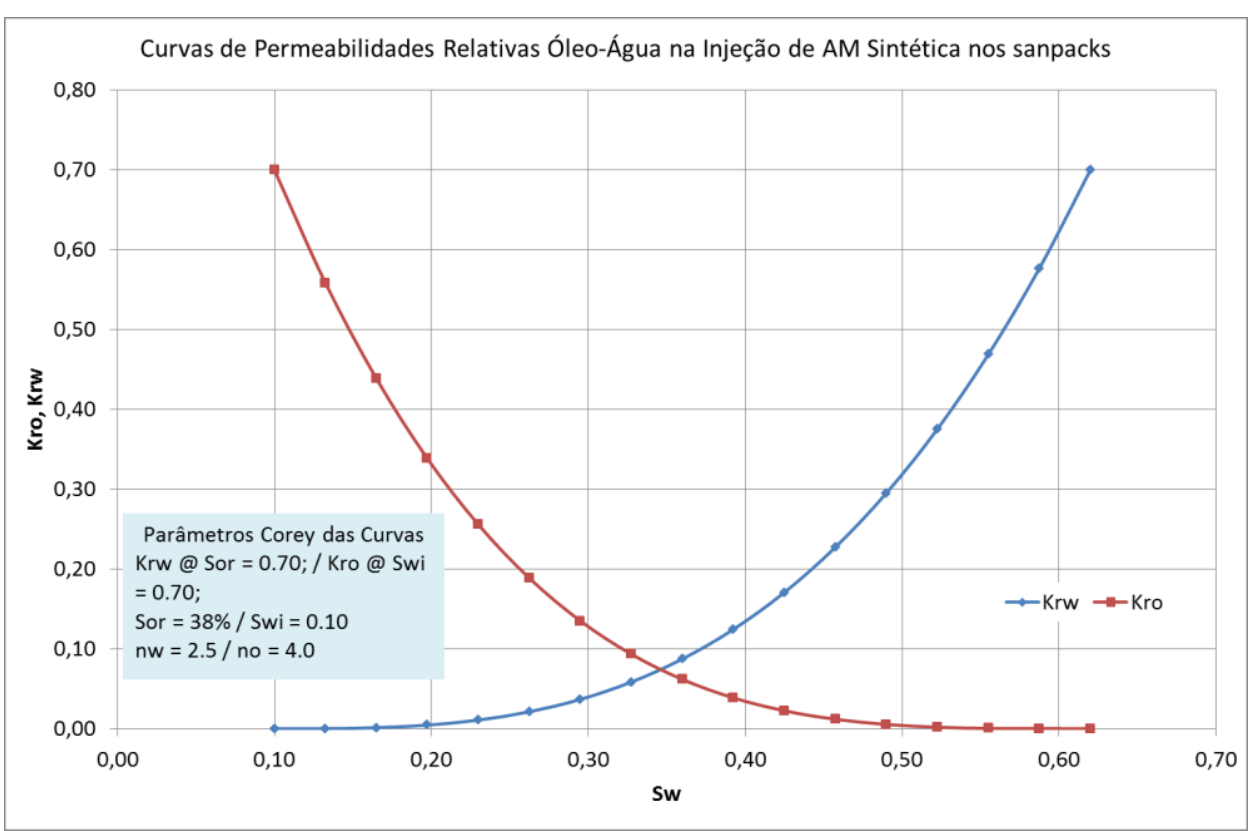

Figura 73 - Curva de permeabilidades relativas do óleo e da água utilizada no ajuste das produções observadas na injeção do banco inicial de água do mar sintética (ensaio realizado com vazão constante de $0.3 \mathrm{~mL} / \mathrm{min}$ ).

A Figura 74 mostra o ajuste obtido para injeção de 3 volumes porosos de água do mar sintética com vazão $0.3 \mathrm{ml} / \mathrm{min}$. Essas rodadas serviram para ajustar as curvas de permeabilidade relativas óleo-água (pontos terminais, saturação de óleo residual e expoentes de Corey). Ajustes de boa qualidade também foram alcançados para os casos de 3 VP de injeção de água nas vazões 1 e $3 \mathrm{ml} / \mathrm{min}$. 


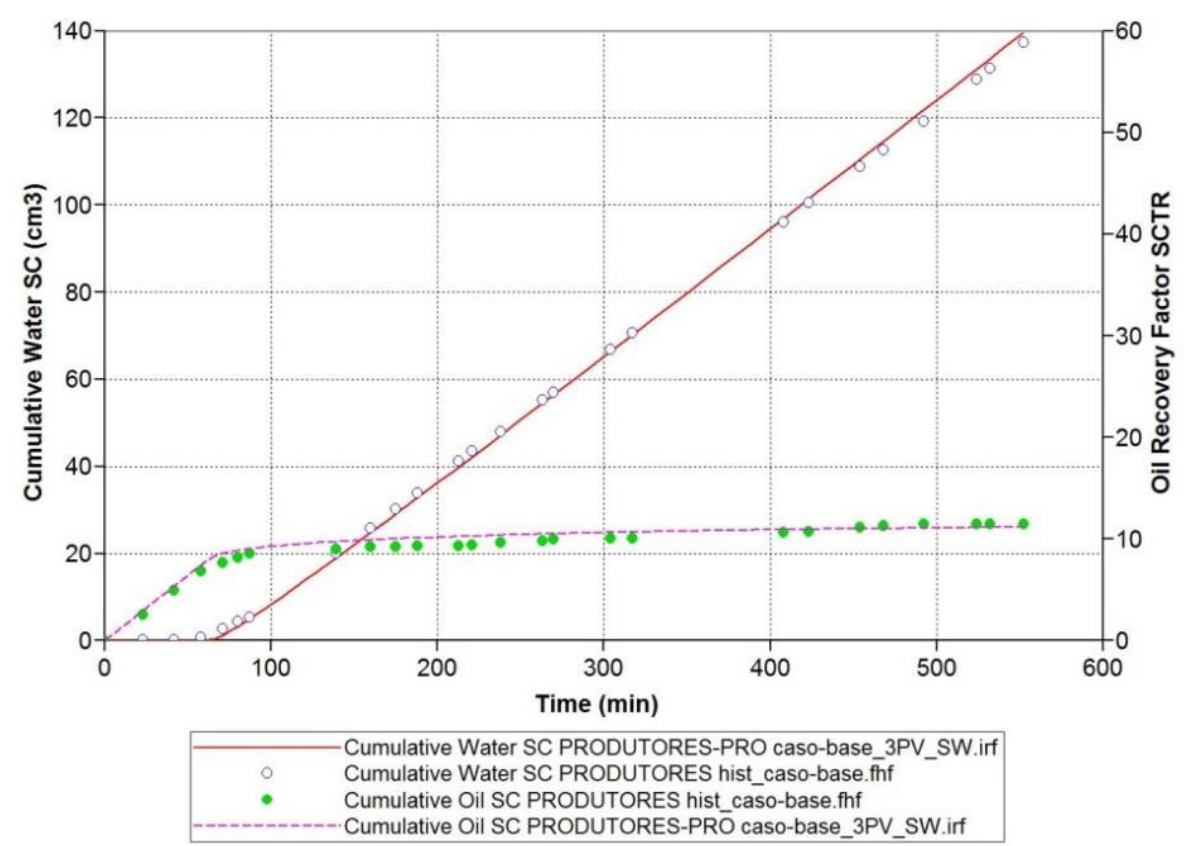

Figura 74 - Ajuste do histórico de produção de óleo e água - injeção de 3 volumes porosos de água do mar sintética com vazão $q=0.3 \mathrm{ml} / \mathrm{min}$. As curvas contínuas são a saída do modelo STARS e os pontos são os dados experimentais.

Nos experimentos em que o surfactante está presente na fase aquosa, foram inseridos dois conjuntos de curvas de permeabilidades relativas óleo-água, correspondentes ao valor máximo (na injeção de água do mar sintética $-\sigma_{0, a}=22.85 \mathrm{dyn} / \mathrm{cm}$ ) e mínimo da tensão interfacial (concentração máxima de surfactante na fase aquosa de $\left.1.37 \times 10^{-5} \mathrm{~mol} / \mathrm{l} \rightarrow \sigma_{0, a}=0.67 \mathrm{dyn} / \mathrm{cm}\right)$. Na condição de tensão interfacial mínima, as curvas de permeabilidades relativas assumem expoentes de Corey $n_{0}=n_{w}=1$ (Figura 75). A cada time step, o simulador calcula a tensão interfacial através da concentração de surfactante presente nas células e determina as permeabilidades relativas do óleo e da água por interpolação linear. 


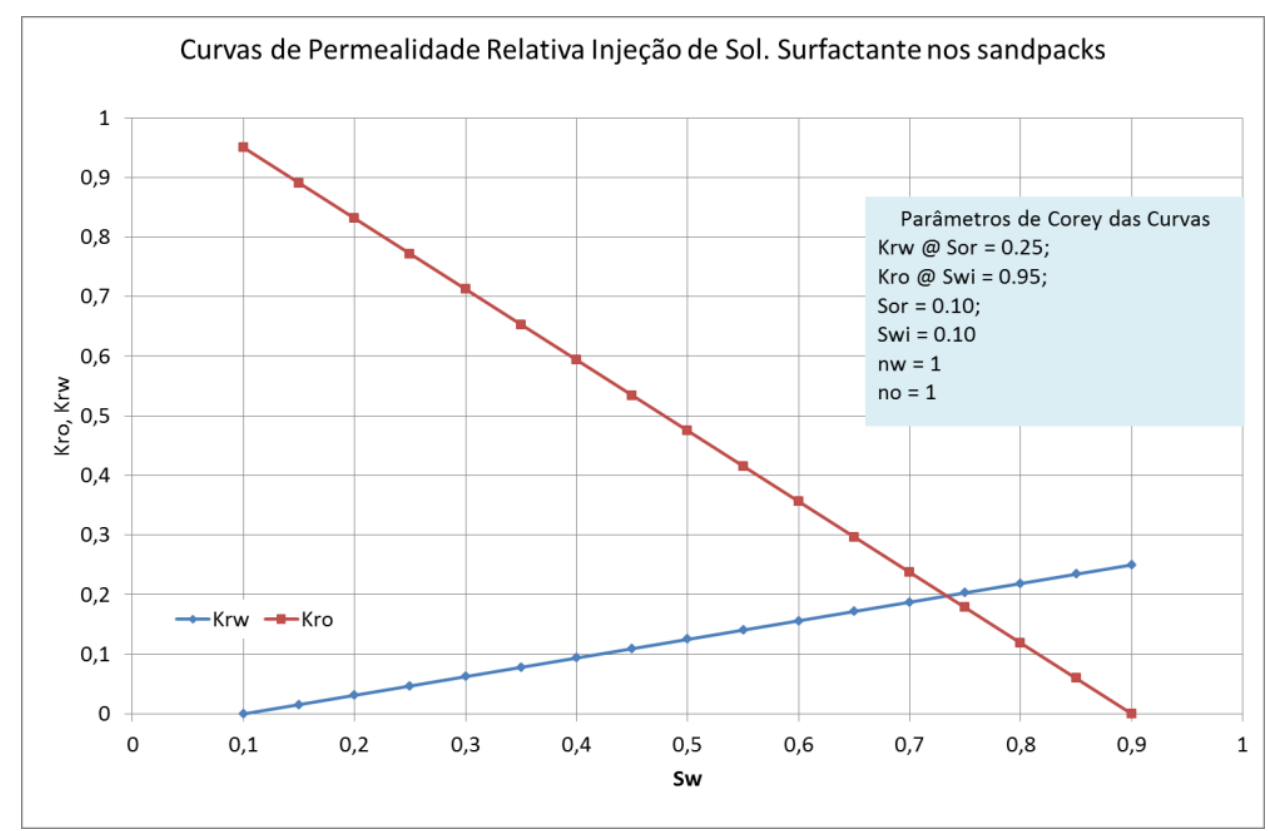

Figura 75 - Curvas de permeabilidade relativa correspondentes à tensão interfacial mínima.

Outro parâmetro ajustado, por tentativas, nessa etapa foi a adsorção do surfactante pela rocha (Figura 76). O valor ajustado foi baixo, como era de se esperar em um sandpack de sílica pura. Em rochas reais, os valores são mais altos devido à presença, principalmente, de minerais argilosos dispersos.

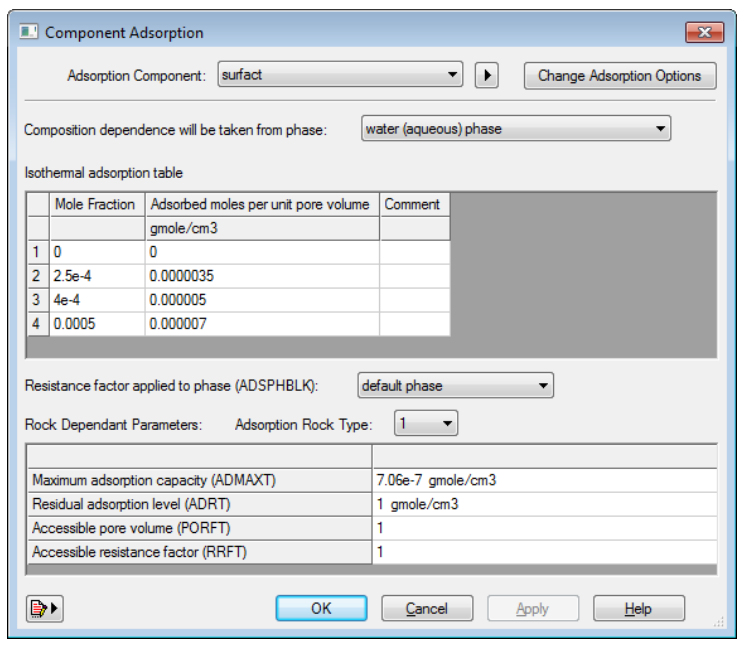

Figura 76 - Parâmetros de adsorção do surfactante ajustados para os sandpacks de sílica.

A Figura 77 e a Figura 78 mostram os ajustes obtidos na simulação dos experimentos de injeção de surfactante com vazão $0.3 \mathrm{ml} / \mathrm{min}$. 


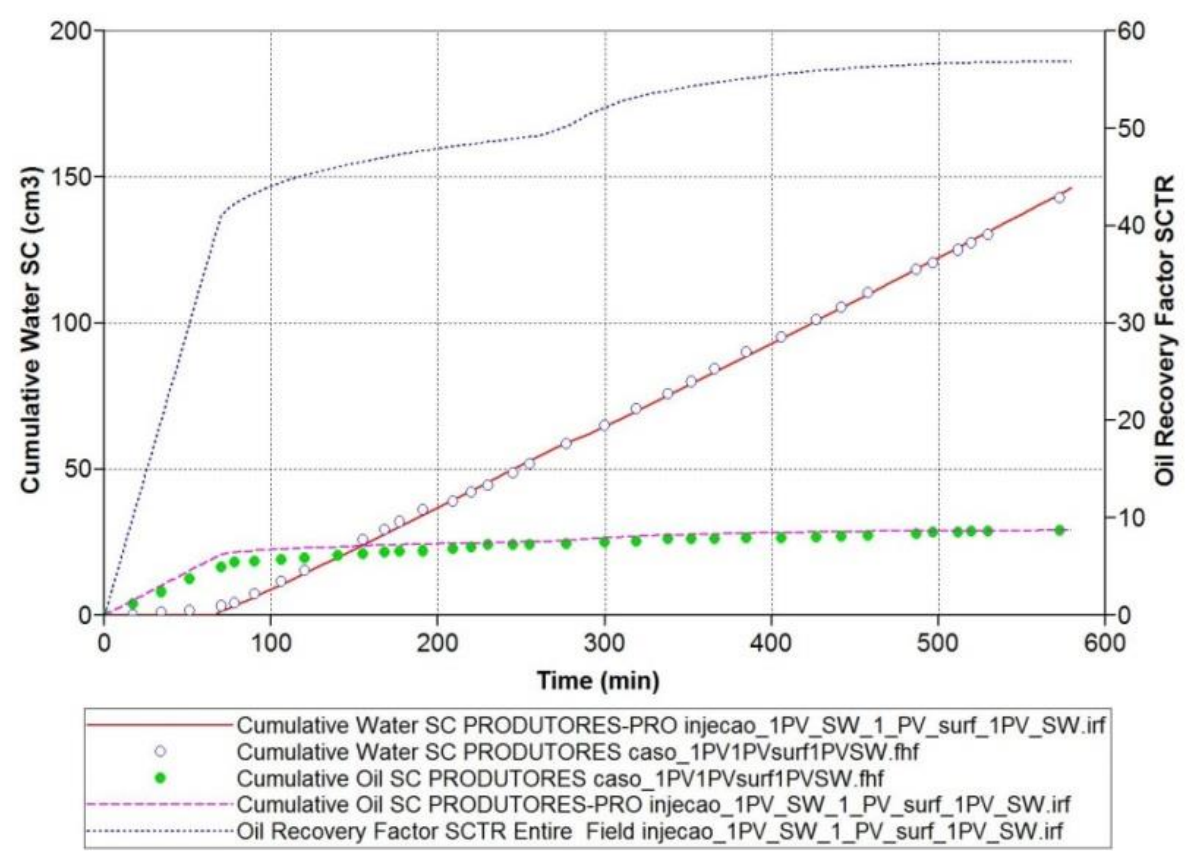

Figura $77-$ Ajuste de histórico - $1 \mathrm{VP} A M+1 \mathrm{VP}$ sol. Surfactante $+1 \mathrm{VP} A M-\mathrm{q}=0.30 \mathrm{ml} / \mathrm{min}$.

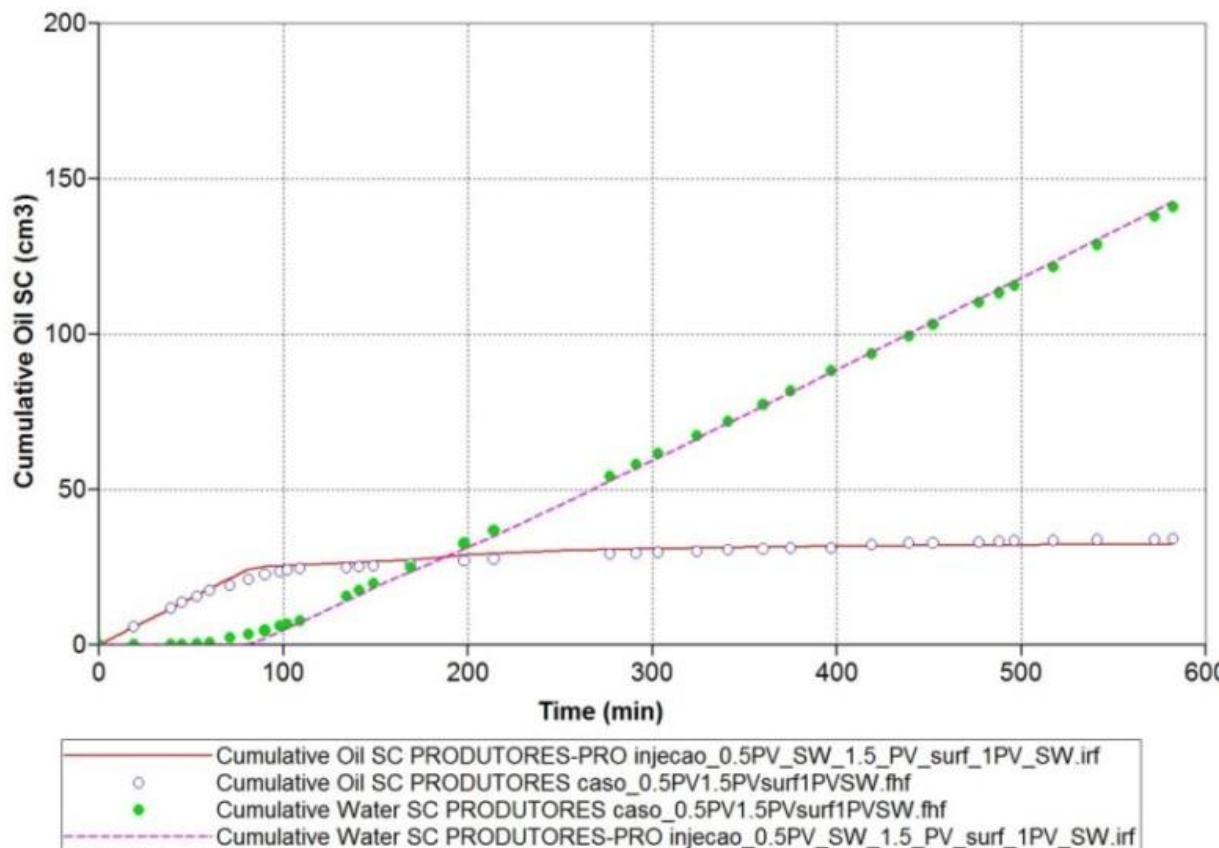

Figura 78 - Ajuste de histórico - 0.5 VP AM + 1.5 VP sol. Surfactante $+1 \mathrm{VP} A M-\mathrm{q}=0.30 \mathrm{ml} / \mathrm{min}$

O ajuste do modelo de injeção alternada de água e emulsão foi feito considerando 2 efeitos:

- Bloqueio parcial do meio poroso devido à captura das gotas emulsionadas; 
- Modificação das curvas de permeabilidade relativa (pontos teminais e expoentes de Corey).

A emulsão é caracterizada no simulador através da sua composição em fração molar. Considerando as quantidades adicionadas de água, óleo e surfactante, chegou-se à seguinte composição molar injetada (Tabela 17).

Tabela 17 - Composição molar da emulsão injetada (concentração de óleo 1\% v/v).

\begin{tabular}{|l|c|}
\hline \multicolumn{1}{|c|}{ Fase } & Fração molar (\%) \\
\hline Água do mar sintética & 99.99 \\
\hline Gotas de óleo & $4.24 \times 10^{-5}$ \\
\hline Surfactante & $2.50 \times 10^{-5}$ \\
\hline
\end{tabular}

O bloqueio parcial do meio poroso foi modelado utilizando a opção de adsorção do simulador. O processo de captura das gotas emulsionadas pelo meio poroso é um fenômeno mecânico, função da relação de tamanhos e do balanço entre forças capilares e viscosas. Esse parâmetro foi inicialmente ajustado de forma a considerar uma adsorção máxima de até $80 \%$ das gotas, ou seja, considerou-se que parte das gotas emulsionadas era pequena a ponto para atravessar o meio poroso sem serem capturadas. Essa hipótese se sustentou na observação da presença de gotas de óleo emulsionadas no fluido produzido quando se injetou água após um banco de emulsão.

Outro fator de ajuste importante é o fator de resistência residual RRFT. Ele dá a taxa de redução da permeabilidade de cada fase devido ao processo de adsorção por:

$$
R K_{o, w, g}=1+(R R F T-1) * A D(C, T) / A D(T)_{\text {máx }}
$$

Onde:

$\mathrm{RK}_{\mathrm{o}, \mathrm{w}, \mathrm{g}}$ - fator de redução da permeabilidade da fase óleo, água ou gás; RRFT - fator de resistência residual para a temperatura T;

$A D(C, T)$ - quantidade de gotas adsorvidas (função da temperatura e concentração presente na emulsão). 
$\mathrm{AD}(\mathrm{T})_{\text {máx }}$ - capacidade máxima de adsorção das gotas $\left(\mathrm{gmol} / \mathrm{cm}^{3}\right.$ de rocha) na temperatura da célula.

No ajuste, assumiu-se que apenas a fase aquosa era afetada pelo bloqueio da emulsão. A Figura 79 mostra a tela de entrada dos parâmetros de adsorção no ModelBuider ${ }^{\circledR}$.

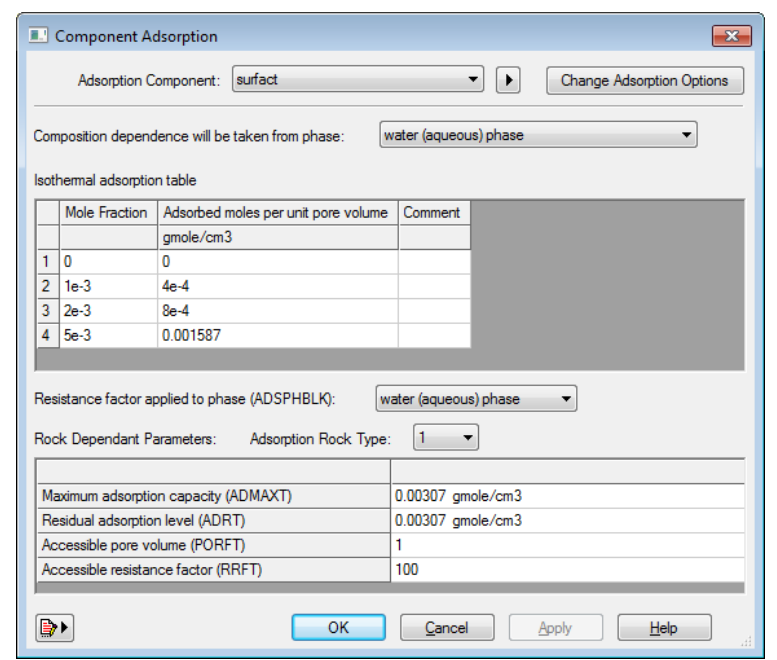

Figura 79 - Parâmetros de adsorção do processo de captura de gotas emulsionadas (concentração de óleo 1\% v/v e \#frit $60 \mu \mathrm{m}$ ). Os valores são os obtidos no ajuste ótimo.

Os dois processos foram considerados irreversíveis na modelagem adotada (adsorção residual ADRT=1). Essa hipótese é válida apenas para o caso do número de capilaridade local na célula se manter constante ao longo da simulação.

Foram rodados dois ajustes de histórico. A primeira estratégia foi considerar a atuação conjunta dos mecanismos de adsorção de gotas e alteração das permeabilidades relativas. A segunda estratégia é o ajuste do histórico apenas modificando as curvas de permeabilidades relativas. Inicialmente foi feito um ajuste de histórico por tentativas. Os ajustes iniciais foram melhorados com o uso do software $\mathrm{CMOST}^{\circledR}$. Foram consideradas as seguintes variáveis de incerteza:

a) capacidade máxima de adsorção de gotas emulsionadas pela rocha e fator de bloqueio (RRFT); 
b) pontos terminais e expoentes de Corey para a curva de permeabilidade relativa na tensão interfacial mínima $\left(\mathrm{K}_{\mathrm{ro}} @ \mathrm{~S}_{\mathrm{wi}}, \mathrm{K}_{\mathrm{rw}} @ \mathrm{~S}_{\mathrm{or}} ; \mathrm{n}_{\mathrm{o}}\right.$ e $\left.n_{w}\right) e$

c) saturação de óleo residual $S_{\text {or }}$ durante a injeção de emulsão.

A Figura 80 mostra as curvas de permeabilidades relativas óleoágua que ajustam as produções observadas nas duas estratégias.

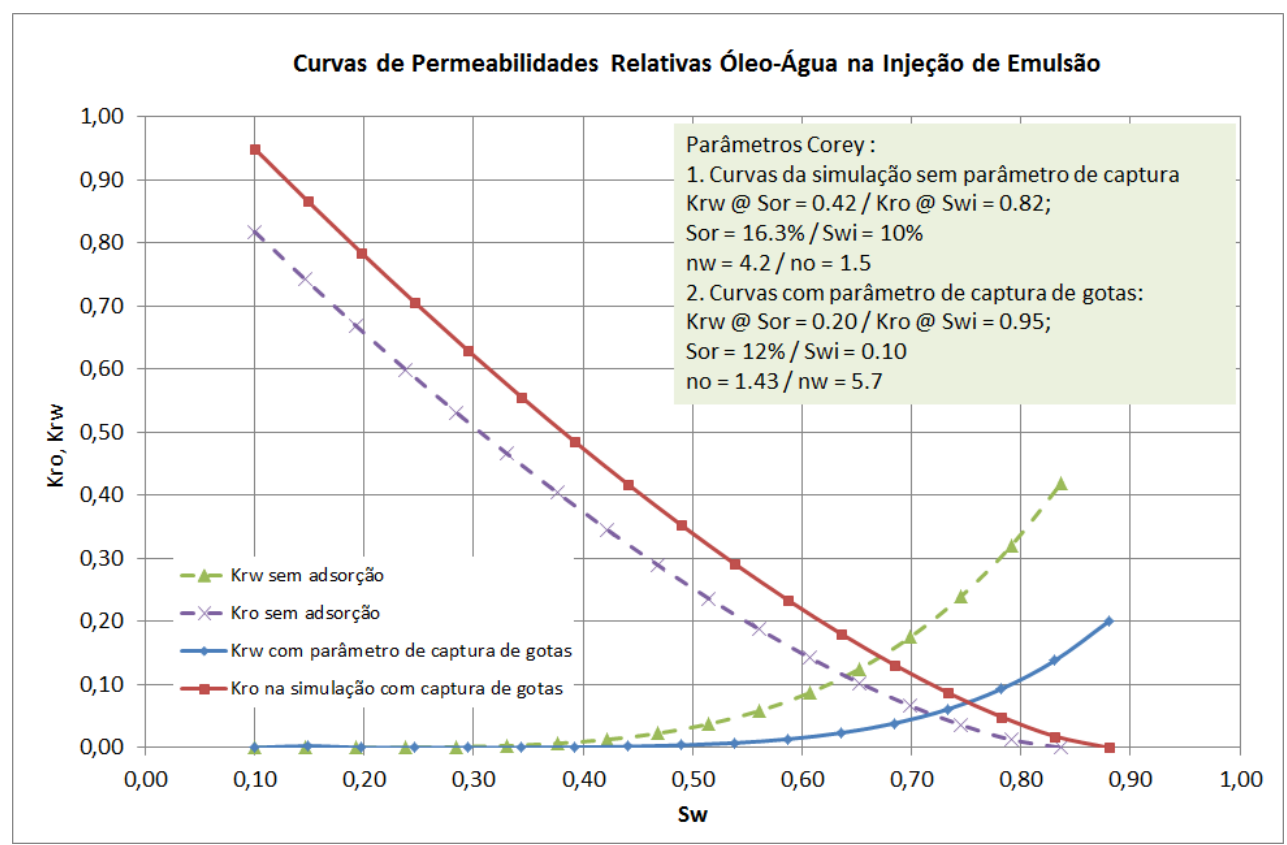

Figura 80 - Curvas de permeabilidade relativa utilizadas no ajuste do modelo de injeção alternada de água-emulsão-água (1 VP AM: 1 VP emulsão: 1 VP AM).

As duas estratégias conduziram a bons ajustes de histórico, conforme mostrado na Figura 81 e na Figura 82. 
Injeção alternada de água/emulsão/água - sandpack 111

Vazão de injeção de $1 \mathrm{~mL} / \mathrm{min} @ 1 \%$ óleo (\# 60 micron)

PRODUTORES-PRO

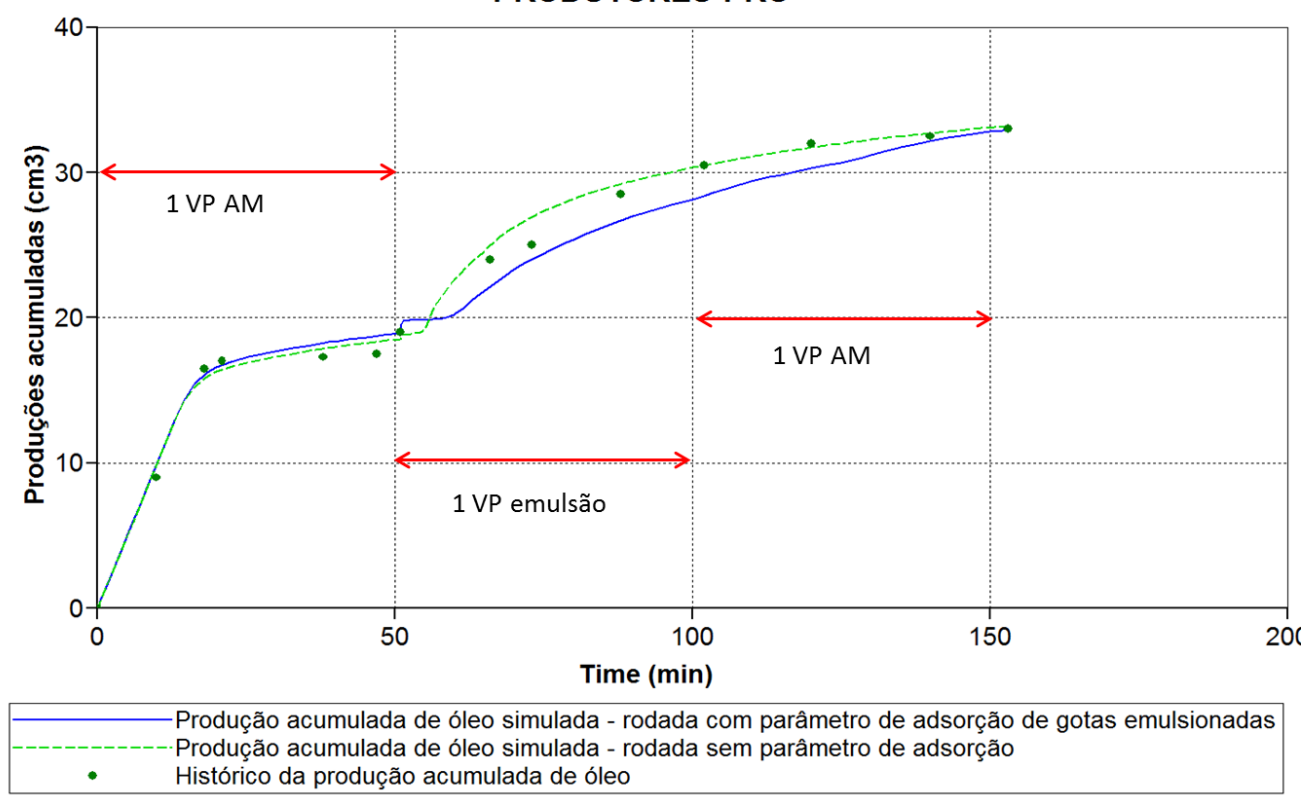

Figura 81 - Ajuste do histórico de produção de óleo no ensaio de injeção alternada água/emulsão/água no (sandpack 111).

Injeção alternada de água/emulsão/água - sandpack 111 Vazão de injeção de $1 \mathrm{~mL} / \mathrm{min} @ 1 \%$ óleo (\# 60 micron)

PRODUTORES-PRO

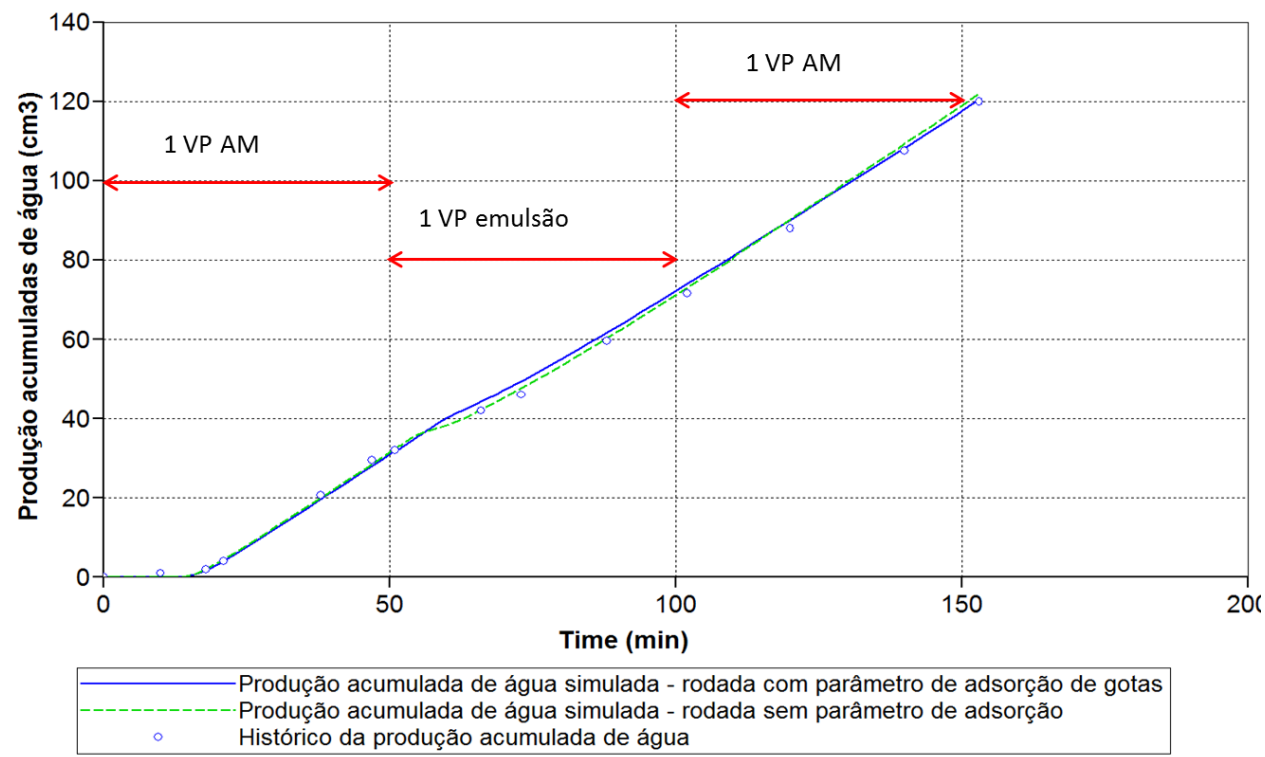

Figura 82 - Ajuste da produção de água no ensaio de injeção alternada água/emulsão (sandpack 111).

\section{A Tabela 18 compara os ajustes obtidos.}


Tabela 18 - Comparação dos ajustes obtidos (produções observadas: $\mathrm{N}_{\mathrm{p}}=33 \mathrm{~mL}$ e $\mathrm{W}_{\mathrm{p}}=120 \mathrm{~mL}$ ).

\begin{tabular}{|l|c|c|c|c|}
\hline \multicolumn{1}{|c|}{ Estratégia de ajuste } & Np simulado & $\begin{array}{c}\text { Wp } \\
\text { simulado }\end{array}$ & Erro Np (\%) & Erro Wp (\%) \\
\hline $\begin{array}{l}\text { Captura de gotas + alteração } \\
\text { de Kr }\end{array}$ & 32.92 & 119.68 & -0.25 & -0.25 \\
\hline Alteração de Kr & 33.20 & 121.5 & $+0.60 \%$ & $+1.25 \%$ \\
\hline
\end{tabular}

Um ponto a ser destacado é a própria dificuldade da medida das produções acumuladas durante o ensaio. A separação de fases não é instantânea, ou seja, existe uma incerteza nas medidas feitas durante o teste. A produção acumulada final de cada fase do ensaio (injeção de água / emulsão / água) sempre foi medida $24 \mathrm{~h}$ após o ensaio para garantir a total separação óleo-água.

A observação das curvas de vazão de óleo também traz informações importantes. A simulação considerando apenas a modificação da curva de permeabilidades relativas óleo-água gera um pico "instantâneo" na vazão de óleo (Figura 83) não observado nos experimentos. Tipicamente, observou-se que a vazão de óleo começa a subir após algum tempo de injeção de emulsão. A produção do banco de óleo mobilizado pela emulsão não ocorre de maneira contínua. O óleo mobilizado chega de maneira descontínua, refletindo diferentes trajetórias descritas no meio poroso. Esse é um efeito causado pela redistribuição de fluxo provocada pelo bloqueio parcial e disperso do meio poroso. A alteração pura e simples da curva de permeabilidades não reproduz a Física do problema. A opção de adsorção utilizada foi um artifício para representar a captura de gotas e o bloqueio de parte do meio poroso. Para modelar corretamente o processo, o simulador deveria ter uma opção de bloqueio mecânico dependente da distribuição de tamanhos de gotas e poros, além do número de capilaridade local. 


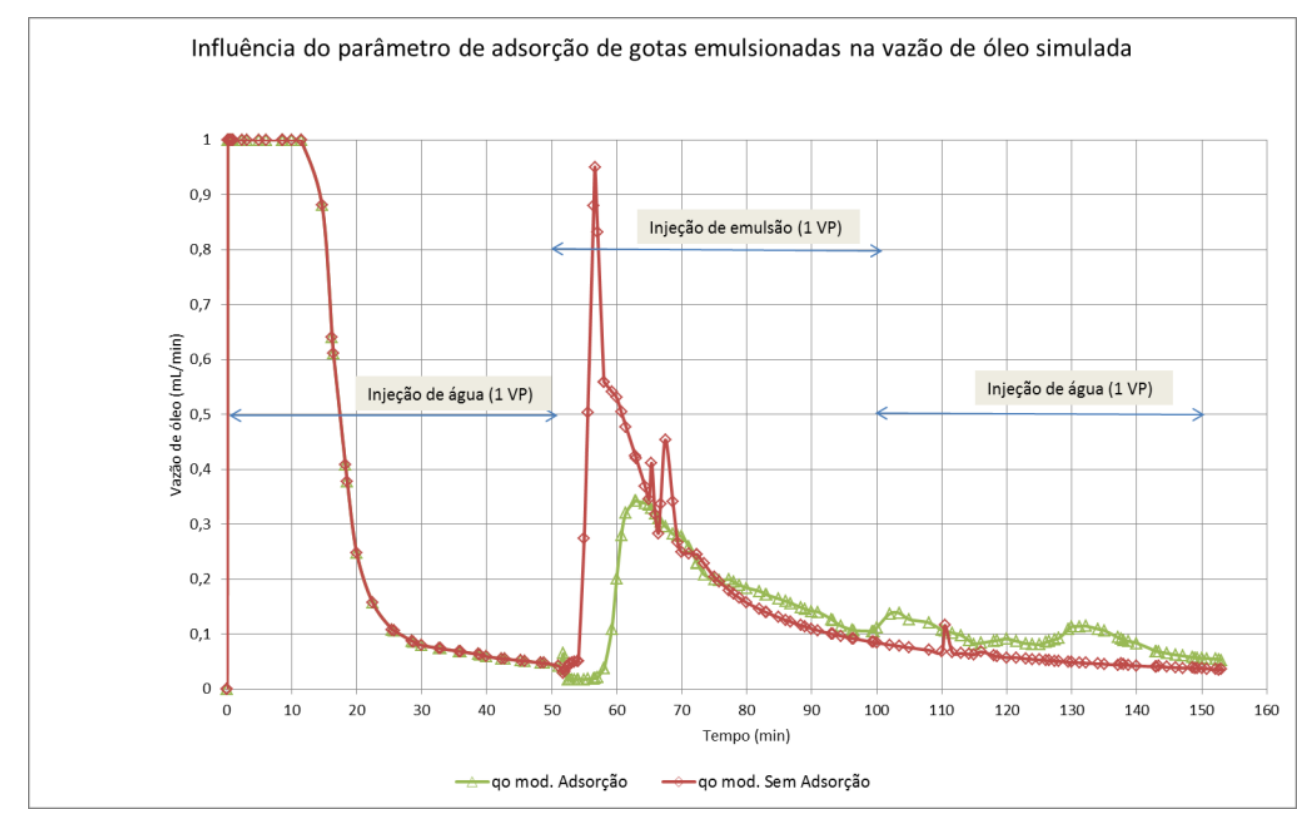

Figura 83 - Vazões de óleo simuladas no STARS para o ensaio de injeção alternada água/emulsão/água no sandpack 111 .

A Figura 84 é uma estimativa do perfil de distribuição de gotas de óleo capturadas estimada pelo modelo. A simulação indicou que a maioria das gotas emulsionadas foi capturada na metade inferior do sandpack (mais próxima do ponto de injeção). Esse resultado é coerente com a observação dos experimentos.

Global Mole Fraction(gotemuls) 2011-01-01.1062499993

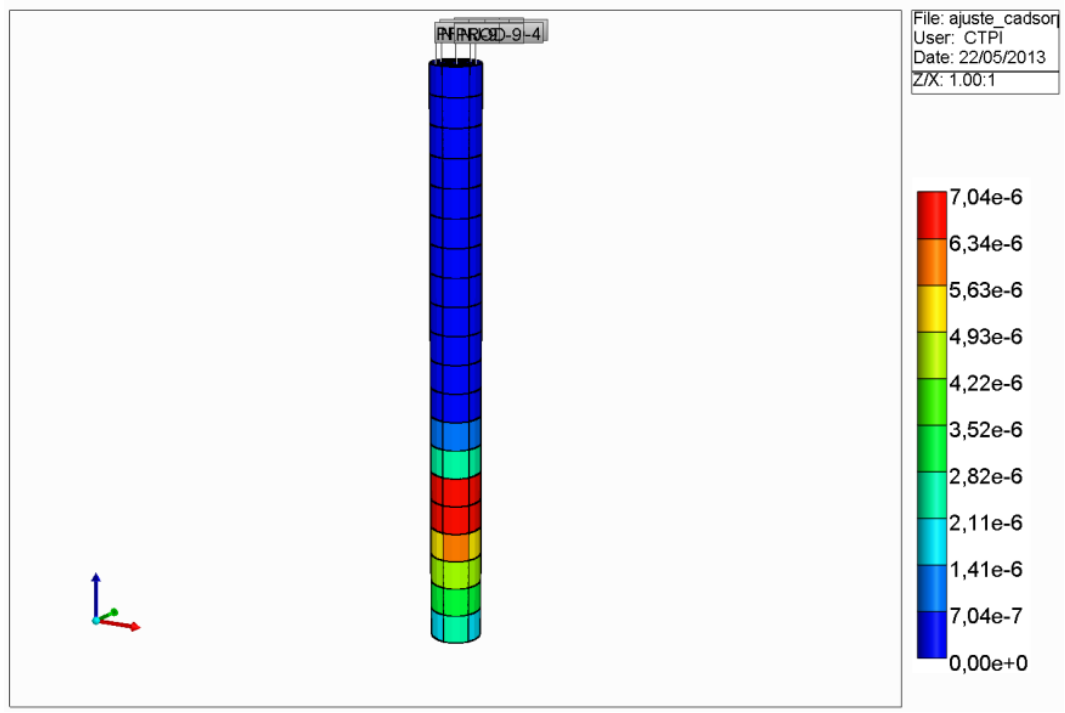

Figura 84 - Distribuição de gotas emulsionadas estimada pelo STARS. 


\subsection{Conclusões}

a) Tanto a injeção de emulsão quanto a de solução aquosa de surfactante foram capazes de incrementar o fator de recuperação final de óleo;

b) $O$ fator de recuperação final de óleo nos experimentos em que se injetou um banco de emulsão foi sempre maior, inclusive quando comparado ao obtido na injeção de 3 volumes porosos de solução de surfactante;

c) A injeção de emulsão foi capaz de provocar redução perceptível na razão água-óleo cumulativa quando comparada à injeção de água do mar sintética;

d) A injeção da emulsão se dá com maior perda de carga quando comparada com a injeção de água. Esse efeito pode ser atribuído à mobilização de óleo adicional provocada pela redistribuição de fluxo que surge devido ao bloqueio parcial do meio poroso causado pela captura parcial das gotas de óleo emulsionadas;

e) Os melhores resultados foram obtidos na injeção de emulsões com razão (abertura de frit)/(diâmetro médio dos poros) próxima de 1 . Uma relação muito pequena faz com que a emulsão atravesse o meio poroso praticamente sem retenção, enquanto valores muito altos dessa relação acabam por bloquear a entrada do meio poroso. A frente de injeção resultante avança praticamente sem gotas suspensas e capacidade de redistribuição de fluxo microscópico fica prejudicada. Outro efeito danoso é a redução da permeabilidade do meio poroso próximo do ponto de injeção. Em uma aplicação de campo, seria causado uma perda de injetividade sem nenhuma contrapartida em termos de melhoria de recuperação de óleo;

f) Os melhores resultados foram obtidos quando foi injetado um banco de água inicial, seguido da injeção de emulsão. A injeção de emulsão logo de início pode bloquear áreas com saturação de óleo ainda alta e, por conta disso, prejudicar a recuperação final; 
g) O dano induzido pelo bloqueio parcial do meio poroso não foi removido pela injeção subsequente de água, pois o diferencial de pressão permaneceu mais alto que o observado ao final da injeção de água.

h) Os efeitos de bloqueio por emulsão das áreas já lavadas pela injeção de água e a consequente redistribuição de fluxo nos meios porosos são influenciados pela velocidade da frente de injeção, distribuição de tamanhos das gotas emulsionadas, concentração de gotas e permoporosidade da rocha. Isso implica que é possível "projetar" emulsões com objetivo de bloquear áreas do reservatório com caminhos preferenciais ligando injetores e produtores. 


\section{Ensaio 3D Monitorado em Tomógrafo de Raios $X$}

\subsection{Introdução}

O programa experimental foi complementado com um ensaio de injeção de emulsão 3D. Dois blocos de arenito Castlegate $(K=440 \mathrm{mD}$ e $\Phi=22.35 \%$ ) foram preparados na configuração de $1 / 4$ de five-spot para execução de um ensaio de fluxo monitorando produções, pressão de injeção e padrão de fluxo no meio poroso através da aplicação de tomografia de raios $\mathrm{X}$. Os fluidos injetados foram dopados com lodeto de Potássio (KI) para permitir a visualização da evolução das regiões no meio poroso ocupadas pela fase injetada ao longo do tempo.

A principal diferença entre esse ensaio e os feitos anteriormente é a existência de um campo de velocidade variável no meio poroso. Dessa forma foi possível observar mais claramente a formação de instabilidades na frente inicial de injeção de água e os efeitos da injeção de emulsão em termos de controle de mobilidade. Outra diferença importante é que a adição de KI modificou a tensão interfacial entre os fluidos (alteração de salinidade total da solução). Dessa forma, os resultados 1D e 3D não devem ser comparados diretamente.

\subsection{Objetivos}

- Estudo da injeção de emulsões em 3D, e9999m termos de aumento do fator de recuperação final de petróleo, em um padrão de drenagem largamente utilizado na indústria de petróleo;

- Visualização da modificação do padrão de fluxo da frente de injeção provocado pela injeção de emulsão no meio poroso. 


\subsection{Materiais e Métodos}

Foram utilizados os seguintes fluidos:

- Petróleo cru $19.5^{\circ} \mathrm{API}\left(\mu_{o}=30 \mathrm{cP}\right)$;

- Solução aquosa de $\mathrm{NaCl} @ 100 \mathrm{~g} / \mathrm{L}$ ("água de formação);

- Solução aquosa de água de $\mathrm{NaCl}(36.5 \mathrm{~g} / \mathrm{L})+\mathrm{KI}(100 \mathrm{~g} / \mathrm{L}) \rightarrow$ salinidade equivalente de $84 \mathrm{~g} / \mathrm{L}$ de $\mathrm{NaCl}$ ("água de injeção");

- Emulsão óleo-água (concentração de óleo $1 \%$ v/v) preparada com a água de injeção mais $5 \mathrm{~mL} / \mathrm{L}$ de surfactante Stepan Steol CS-330 @ 28\% matéria ativa;

Os equipamentos utilizados foram:

- Tomógrafo médico G\&E BrightSpeed 16 canais;

- Transdutor de pressão Yogokawa modelo EJA130A;

- Bomba Jasco (HPLC) modelo PU-2086i;

- Microcomputador IBM PC.

Os blocos de arenito tinham dimensões originais de $30.48 \times 30.48 \times$ $10.16 \mathrm{~cm}^{3}$ (12" x 12"x 4"). Entretanto, na preparação para o ensaio, optouse reduzir sua. dimensões para $14 \times 14 \times 3.5 \mathrm{~cm}^{3}$ de forma a reduzir o volume poroso da amostra para facilitar os procedimentos de saturação do meio poroso com diferentes fluidos. Após a montagem, mediu-se a distância de $17.5 \mathrm{~cm}$ entre os poços. A Figura 85 mostra os detalhes da geometria do bloco de forma esquemática. 


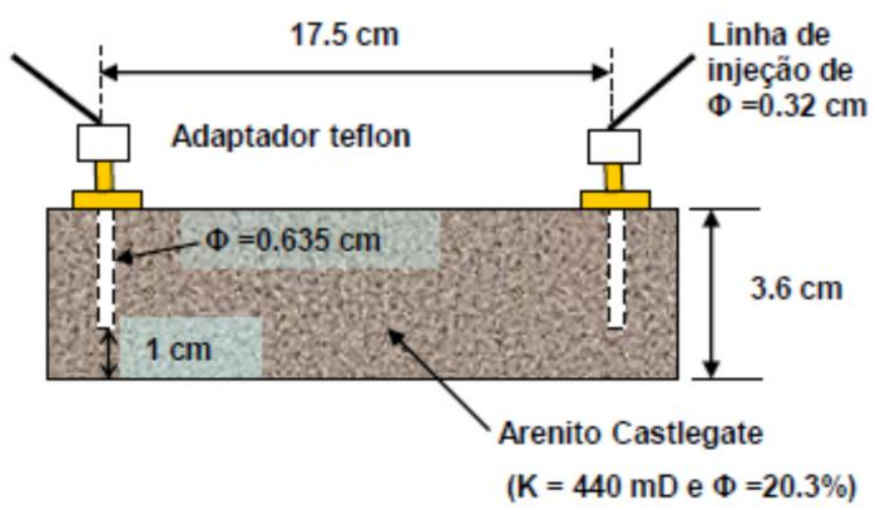

Figura 85 - Seção transversal esquemática (diagonal que une os poços) do bloco de arenito Castlegate ensaiado. Os detalhes da preparação não estão representados em escala.

A preparação dos blocos foi feita seguindo os seguintes passos (Figura 86 e Figura 87):

a) Serragem do bloco à meia-altura;

b) Extração de um plug para medida da permeabilidade e porosidade;

c) Perfuração dos poços até $2,6 \mathrm{~cm}$ de profundidade. Os poços foram perfurados longe da borda do bloco e deixando $1 \mathrm{~cm}$ de rocha preservada no fundo para evitar-se sua desagregação (arenito bastante inconsolidado);

d) Colagem dos adaptadores de teflon nas cabeças de poço e selagem inicial dos blocos com resina epóxi. Todos os adaptadores e linhas utilizados no experimento são plásticos (meio transparente aos raios $\mathrm{X}$ ) para evitar interferências nas leituras do tomógrafo ao longo do experimento;

e) Resinagem do bloco com resina epóxi (cobrimento de $2 \mathrm{~cm}$ );

f) Deslocamento do ar presente no meio poroso pela injeção de $\mathrm{CO}_{2}$ com baixa vazão;

g) Saturação com salmoura desaerada (NaCl@100.000 mg/L);

h) Saturação com petróleo cru $\left(20^{\circ} \mathrm{API}\right)$ por injeção em um poço e coleta do fluido deslocado no outro (4 VP). No último VP de petróleo injetado, a pressão de injeção se manteve constante e nenhuma água adicional foi produzida outro poço. 
Após a saturação do bloco com petróleo, obteve-se uma saturação média inicial de óleo $S_{\mathrm{oi}}=65 \%$ e uma saturação inicial de água $S_{w i}=35 \%$.

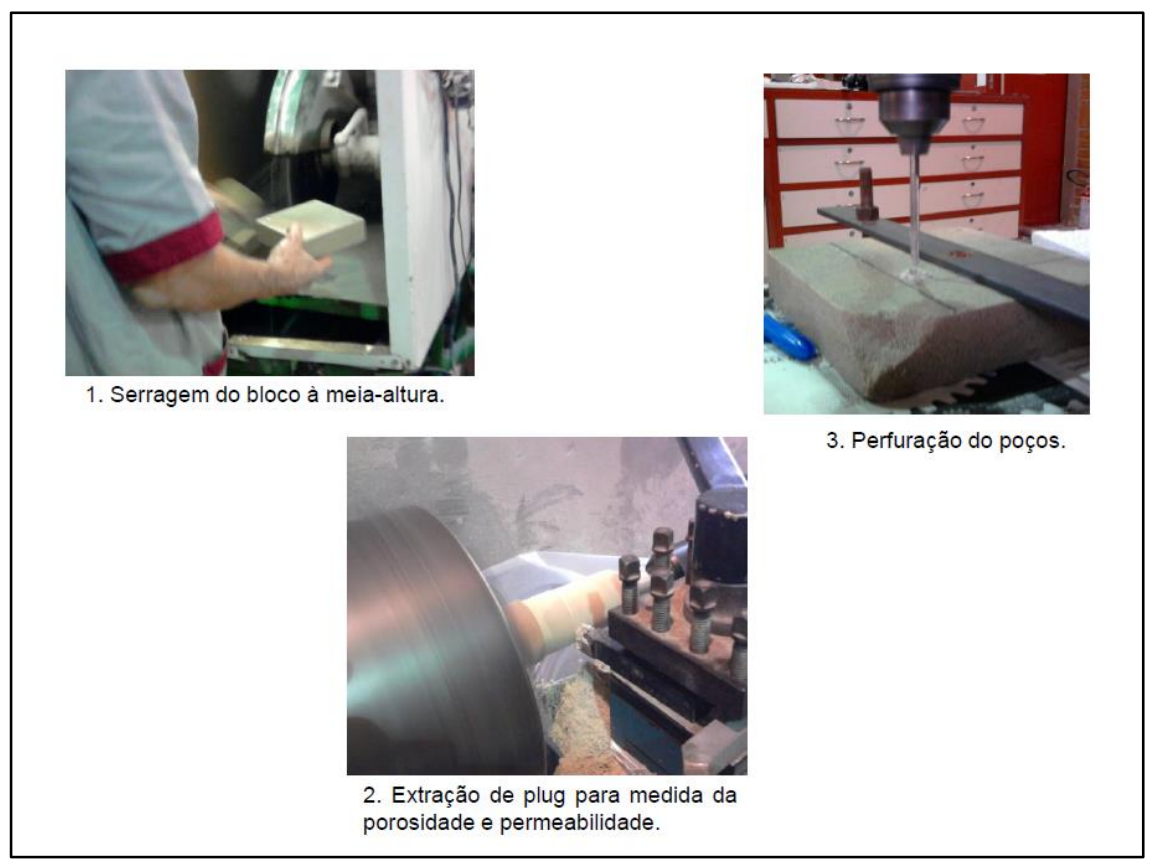

Figura 86 - Primeira etapa da preparação dos blocos de arenito Castlegate feita no Laboratório de Estruturas do Programa de Engenharia Civil da COPPE/UFRJ.

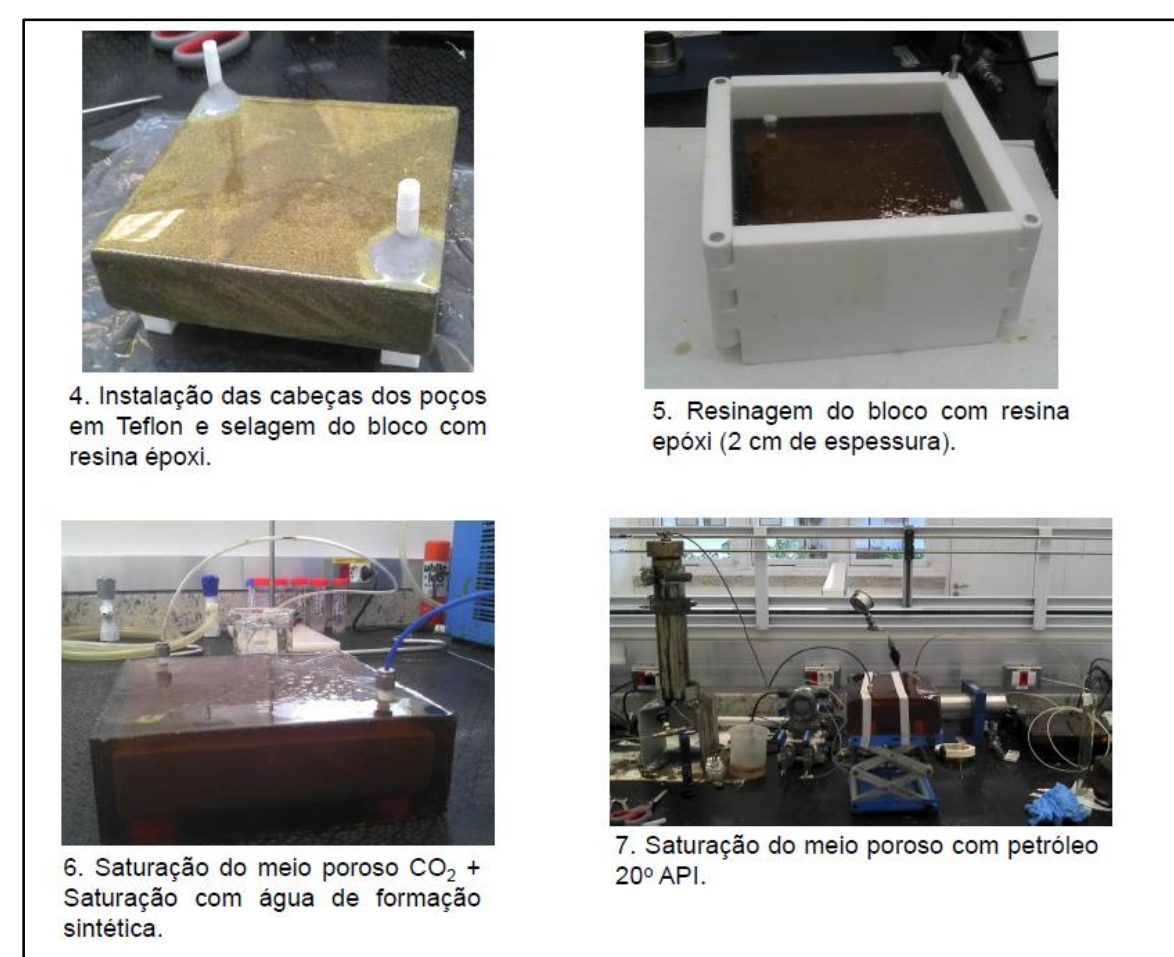

Figura 87 - Etapa final da preparação dos blocos de arenito Castlegate na configuração 1/4 de 5 spot feita no Laboratório de Interação Rocha-Fluido do CENPES/PETROBRAS. 


\subsection{Revisão Teórica}

\subsubsection{Raios $X$}

Os raios X foram descobertos por Wilhelm C. Roentgen em 1895 ao investigar o fenômeno da luminescência produzido em tubos de raios catódicos (tubos de Crookes). A primeira radiografia aconteceu nesse mesmo ano (exposição da mão da esposa de Roentgen aos raios $\mathrm{X}$ por 15 minutos). No tubo de raios catódicos, elétrons são acelerados pela alta diferença de potencial existente entre suas placas. Esses elétrons são violentamente desacelerados na chegado ao anodo do tubo e, como resultado, ocorre a emissão de uma onda eletromagnética (fótons) de comprimento de onda invisível ao olho humano. Os fótons emitidos em um equipamento moderno de raios $X$ são forçados a passar pelas aberturas de placas metálicas internas do equipamento, gerando um feixe contínuo e colimado para incidência no paciente ou amostra examinada.

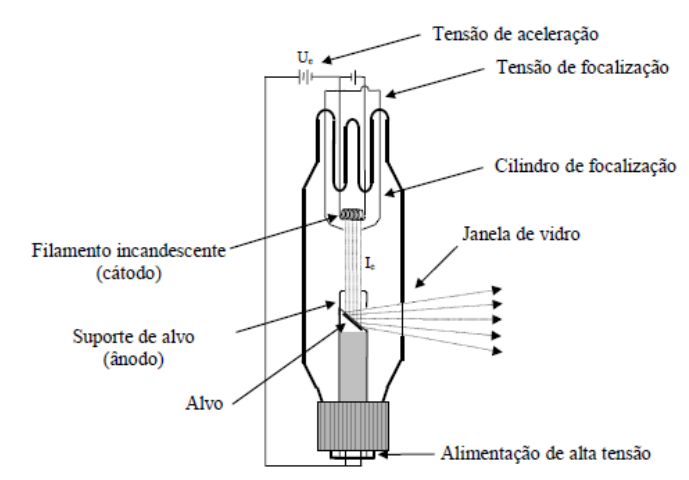

Figura 88 - Representação esquemática de um tubo de raios catódicos [75]

\subsubsection{Tomografia Computadorizada de Raios $X$}

A tomografia computadorizada (CT) de raios $X$ (tomo é a palavra em Grego para corte ou seção) surgiu nos anos 70 como uma técnica de exame não invasivo na área médica. $O$ método foi patenteado por $\mathrm{G}$. $\mathrm{N}$. Hounsfield em 1968. Os primeiros tomógrafos médicos chegaram ao mercado em 1972 [74]. 
Atualmente, a CT é uma técnica de análise não destrutiva aplicada em diversas áreas como avaliação de integridade de soldas, estudos de inibidores de corrosão e monitoramento de trincas por fadiga, entre outras.

$\mathrm{Na}$ indústria de petróleo, a CT é utilizada com sucesso em várias aplicações, destacando-se:

- Caracterização de amostras de rochas (campos de porosidade e densidade, modelagem de redes de fraturas e caracterização mineralógica),

- Visualização de fluxo em meios porosos para avaliação da efetividade de técnicas de EOR,

- Determinação de campos de saturações de óleo, água e gás em plugs de rocha;

- Avaliação do dano provocado pela invasão de fluidos de perfuração

A passagem dos Raios $\mathrm{X}$ por um meio produz dois efeitos: a) absorção e b) espalhamento dos raios incidentes (efeito Compton). Os raios espalhados têm comprimento de onda maior que os incidentes, ou seja, são de menor energia. Esse fenômeno é chamado atenuação. Esse fenômeno é regido pela Lei de Beer. Para um feixe cruzando um material homogêneo, escreve-se [68]:

$$
\frac{I}{I_{0}}=e^{-\mu \cdot x}=e^{-\rho . x \cdot(\mu / \rho)}
$$

Onde:

$\mathrm{I}_{0}$ - intensidade do raio incidente;

I - intensidade do raio após a atenuação causada pela passagem pelo meio;

$\mu$ - coeficiente de atenuação do material;

$\rho$ - densidade do material; 
$x$ - distância percorrida pelo feixe no interior do material.

Para feixes de raios $X$ atravessando camadas de materiais diferentes, escreve-se:

$$
\frac{I}{I_{0}}=e^{-\Sigma\left(\frac{\mu_{i}}{\rho_{i}}\right) \cdot \rho_{i} \cdot \Delta x_{i}}
$$

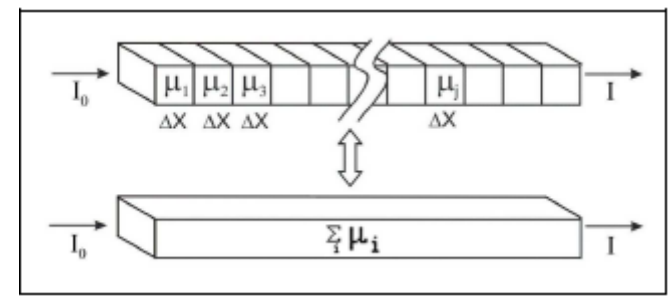

Figura 89- Atenuação de um feixe de raios $X$ incidente em uma amostra [69].

O coeficiente de atenuação do material depende do nível de energia do feixe de raios $X$, da sua densidade e sua composição química. $O$ coeficiente de atenuação para fótons de na faixa de $100 \mathrm{KeV}(1 \mathrm{eV}=1,6 \mathrm{x}$ $\left.10^{-19} \mathrm{~J}\right)$ é proporcional ao número atômico do elemento, ou seja, elementos químicos mais pesados atenuam mais a energia do feixe incidente que os mais leves. Utilizando esse princípio, são elaboradas as soluções dopadas para visualização de trajetórias de fluidos injetados em meios porosos.

Em um tomógrafo 3D, a fonte ou a amostra são giradas durante a incidência do feixe de raios $X$. As respostas coletadas nos vários ângulos de incidência precisam ser decompostas nas componentes relativas a cada região (deconvolução). O resultado desse processamento é a matriz de coeficientes de atenuação. No tomógrafo utilizado nesse ensaio, a fonte de raios $X$ é montada em um dispositivo móvel chamado "gantry" que permite que a fonte gire em torno da amostra mantida fixa (Figura 90). Dessa forma, são feitas aquisições com diferentes ângulos para processamento posterior. 


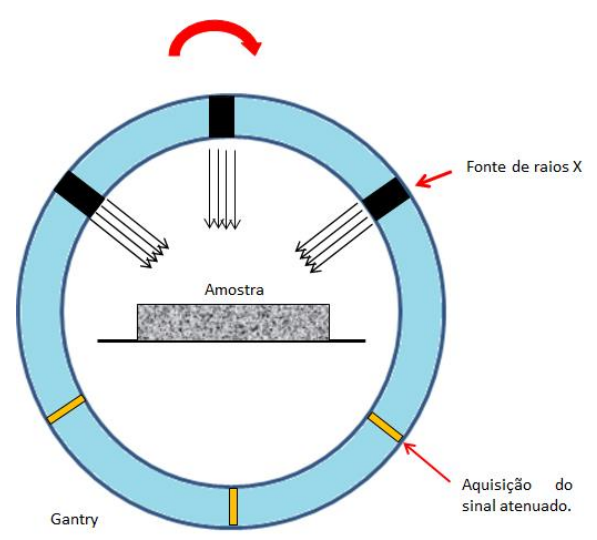

Figura 90 - Representação esquemática do movimento do gantry.

A saída do tomógrafo não é o coeficiente de atenuação de cada região da amostra. Convencionou-se exibir os resultados em uma unidade denominada Hounsfield (HU), definida por (38):

$$
H U_{(x, y)}=\frac{\mu_{(x, y)}-\mu_{w}}{\mu_{w}} .1000
$$

Onde:

$\mu_{(x, y)}$ - coeficiente de atenuação do material na coordenada $(x, y)$; $\mu_{w}$ - coeficiente de atenuação dos raios $X$ na água.

Por convenção: $\mathrm{HU}_{\mathrm{ar}}=-1000$ e $\mathrm{HU}_{\text {água }}=0$. Essa é a calibração utilizada em todos os tomógrafos médicos.

Uma imagem tomográfica é comumente chamada fatia ("slice"). O termo serve para reforçar o conceito de que a imagem não a uma seção da amostra, mas sim a um volume, ou seja, existe uma espessura associada a ela (Figura 91). Outra analogia é aplicável: enquanto uma fotografia digital é composta por pixels, uma slice tomográfica é um conjunto de elementos de volume denominados voxels. 


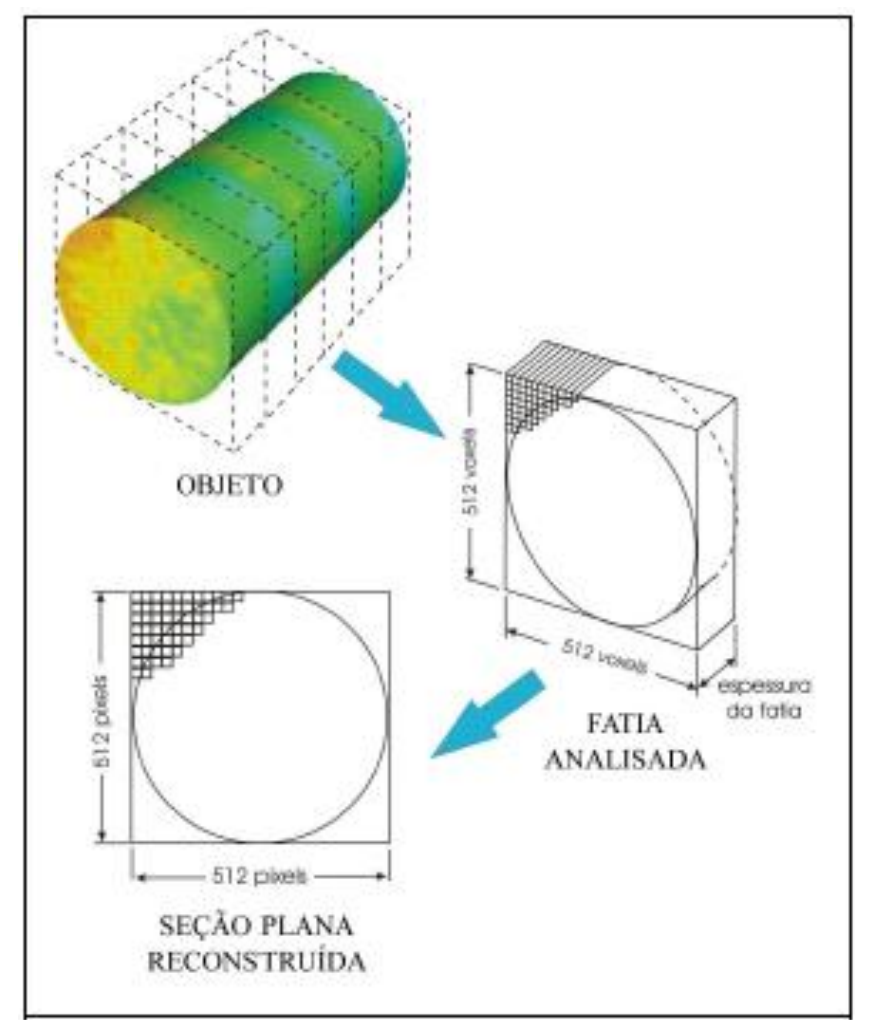

Figura 91 - Processo de reconstrução das imagens tomográficas [69].

\subsection{Descrição do Ensaio}

O ensaio foi composto das seguintes fases:

- Injeção de 0.5 volumes porosos de água de injeção - 1ำ fluxo $(q=0.5 \mathrm{ml} / \mathrm{min})$;

- Injeção de 1 VP de emulsão óleo-água passada em um frit \#25 $\mu \mathrm{m}-2^{\circ}$ fluxo ( $\left.\mathrm{q}=1 \mathrm{ml} / \mathrm{min}\right)$;

- Injeção de 1 VP de água de injeção - 3ํำ fluxo ( $q=1 \mathrm{ml} / \mathrm{min})$.

Durante os ensaios, foram feitas aquisições de imagens tomográficas a cada 10 minutos $(0.07 \mathrm{VP})$. Toda água injetada recebeu a adição de lodeto de Potássio (KI @100 g/L) de forma que fosse possível monitorar a movimentação de fluidos no meio poroso. O lodo é um átomo de número atômico elevado, ou seja, sua presença no fluido injetado vai realçar a trajetória seguida por ele no meio poroso. A Figura 92 mostra a 
montagem do ensaio feito no laboratório de tomografia de raios $\mathrm{X}$ do CENPES.

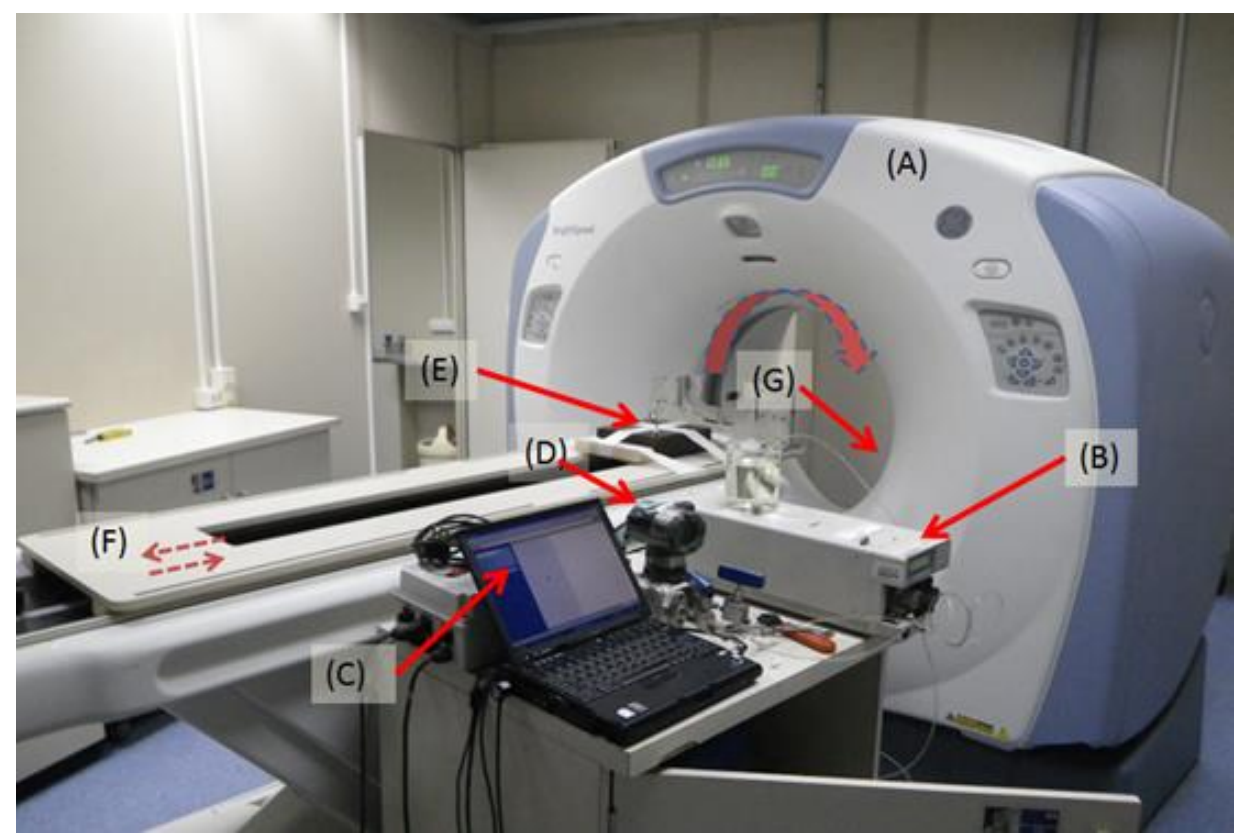

Figura 92 - Montagem do ensaio. (A) Tomógrafo médico G\&E BrightSpeed 16 canais; (B) Bomba HPLC Jasco modelo PU-2086i; (C) Aquisição de dados em microcomputador PC; (D) Transdutor de pressão Yokogawa modelo EJA130A ; (E) Bloco de arenito Castlegate; (F) Mesa deslizante do tomógrafo; (G) Gantry do tomógrafo. Os graus de liberdade da mesa e do gantry estão indicados.

\subsection{Resultados}

\subsubsection{Ajuste do histórico da injeção de água inicial}

De forma a permitir um ajuste de histórico dos dados de produção do primeiro banco de água injetada (0.5 VP na vazão de $0,5 \mathrm{~mL} / \mathrm{min}$ ) e extrapolar os resultados para efeito de comparação com a recuperação final do experimento, foi gerado um modelo de simulação numérica no STARS. Esse modelo é composto de 20 camadas com 49 células cada. As propriedades de rocha e fluidos medidas em laboratório foram inseridas no modelo, de forma que a curva de permeabilidade relativa óleo-água foi o único parâmetro de ajuste. A Figura 93 é a visualização do modelo gerado no CMG ModelBuilder ${ }^{\circledR}$ enquanto a Figura 95 é o pósprocessamento da simulação no aplicativo CMG Results Graph $\AA$. 


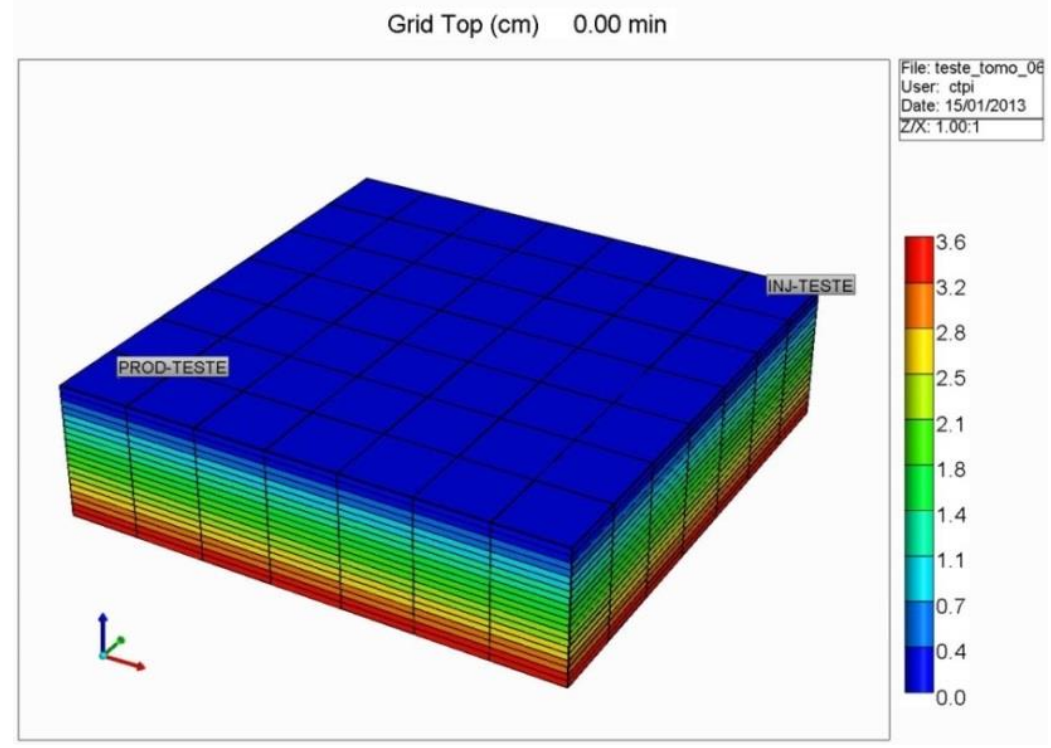

Figura 93 - Modelo de simulação STARS utilizado no ajuste da injeção inicial de água e extrapolação da produção.

A Figura 94 apresenta as curvas de permeabilidade relativa óleoágua obtida no ajuste do histórico da injeção inicial de água.

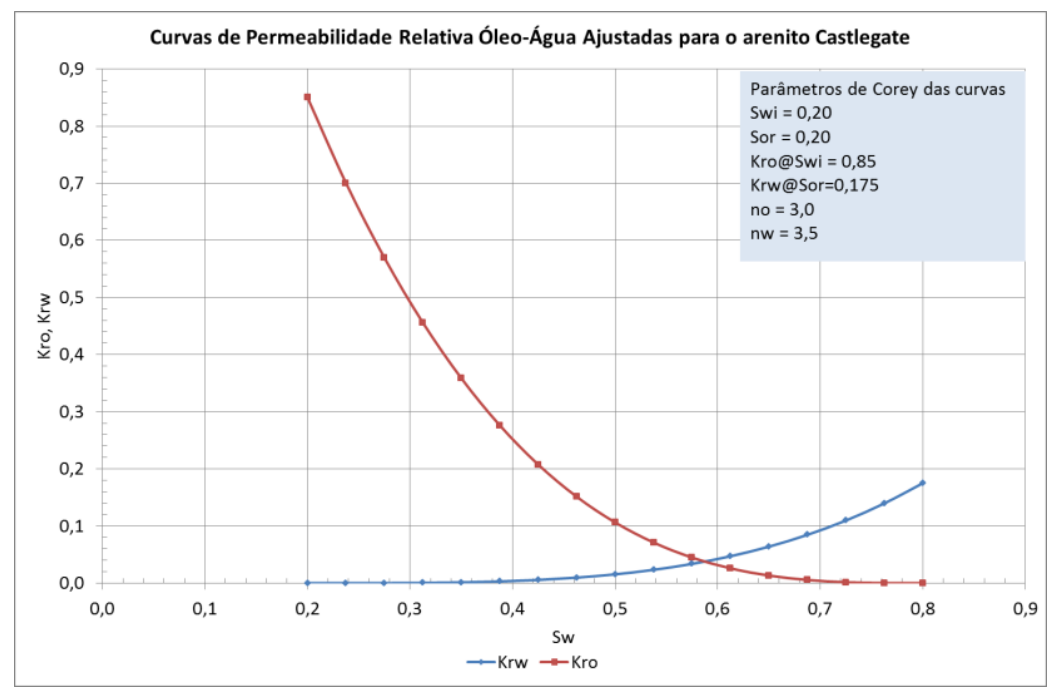

Figura 94 - Curva de permeabilidade relativa obtida no ajuste do modelo.

A Figura 95 e a Figura 96 são, respectivamente, os ajustes dos históricos de produção de óleo e água, além das extrapolações. 


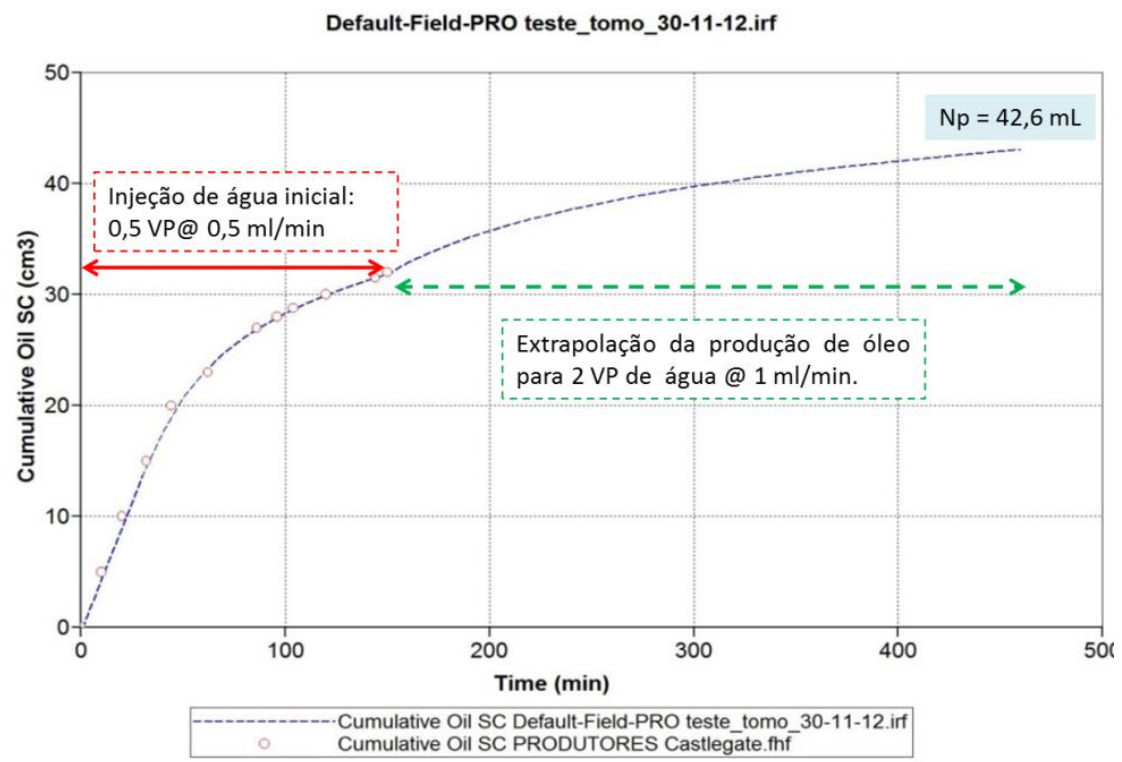

Figura 95 - Ajuste de histórico de produção de óleo com os dados da injeção de água inicial (0.5 VP) e extrapolação da produção de óleo, caso apenas água fosse injetada no sistema.

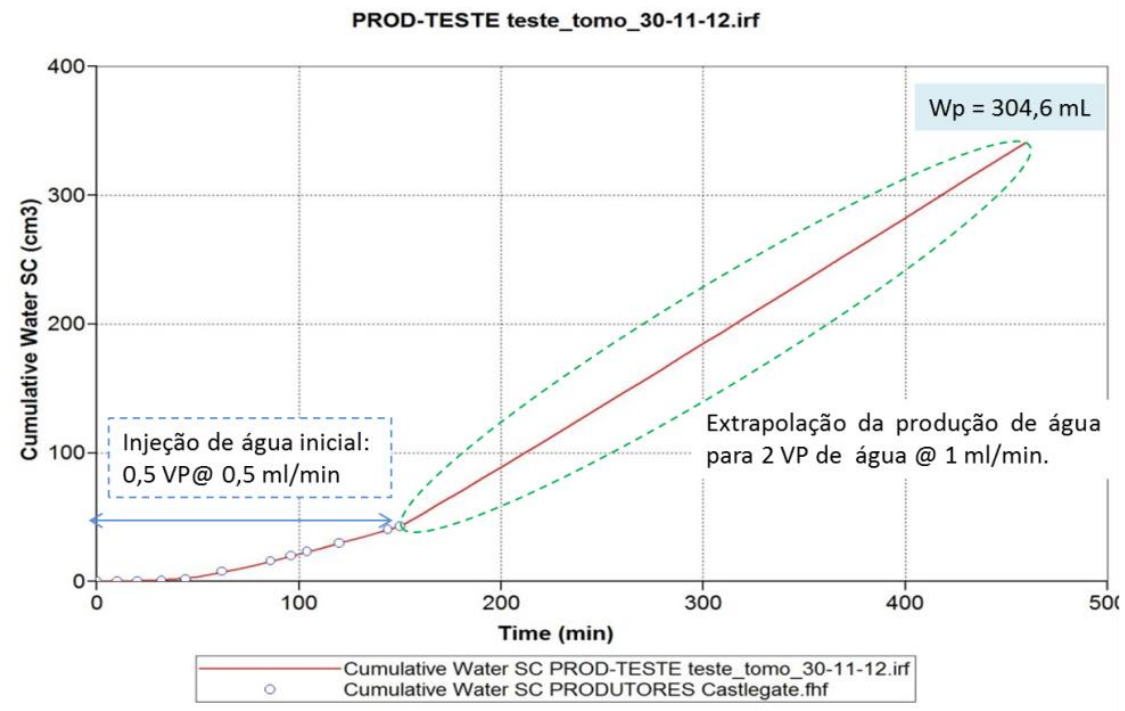

Figura 96 - Ajuste de histórico da produção de água e extrapolação dos resultados.

Os resultados da simulação indicam uma produção acumulada final de óleo de $42.6 \mathrm{~mL}$, correspondente a um fator de recuperação de $42.6 \%$.

\subsubsection{Resultados dos Ensaios}

A Figura 97 mostra a evolução da pressão de injeção e do fator de recuperação de óleo no bloco em relação ao volume de fluido injetado. Os efeitos da injeção de emulsão ficam claros tanto na pressão de injeção 
quanto no fator de recuperação de óleo. No início da injeção da emulsão, as gotículas se deslocam com altas velocidades e sua quantidade no meio poroso ainda é baixa. Entretanto, após aproximadamente 0.3 VP de emulsão injetada, a frente de avanço provavelmente encontrou uma região do reservatório cuja distribuição de tamanhos de poros e a sua velocidade de fluxo permitiram o início de um processo de captura de gotas mais intenso. A pressão de injeção reflete esse processo exibindo picos. Além disso, a oscilação de valores observada na fase deve indicar o redirecionamento do fluxo para poros menores (ainda saturados com óleo) e, talvez, algum processo de escorregamento de parte das gotas emulsionadas pelas gargantas de poros.

A produção seguiu um comportamento bastante semelhante ao observado nos ensaios 1-D. Os efeitos não são imediatos na produção. $O$ redirecionamento de fluxo da frente de injeção provocado pelo bloqueio parcial das áreas já lavadas faz com que seja mobilizado um óleo adicional de regiões com maiores restrições ao fluxo. Novamente ficou claro que o bloqueio parcial do meio poroso permaneceu durante a injeção de água feita depois do banco de emulsão. A pressão de injeção é maior do que a necessária para injetar a água se somente esse fluido houvesse sido utilizado para deslocar o petróleo. No ensaio atingiu-se um fator de recuperação final de óleo igual a 47\% (Figura 99). Esse resultado indica um ganho de $10.3 \%$ em relação à produção acumulada extrapolada com o simulador STARS. 


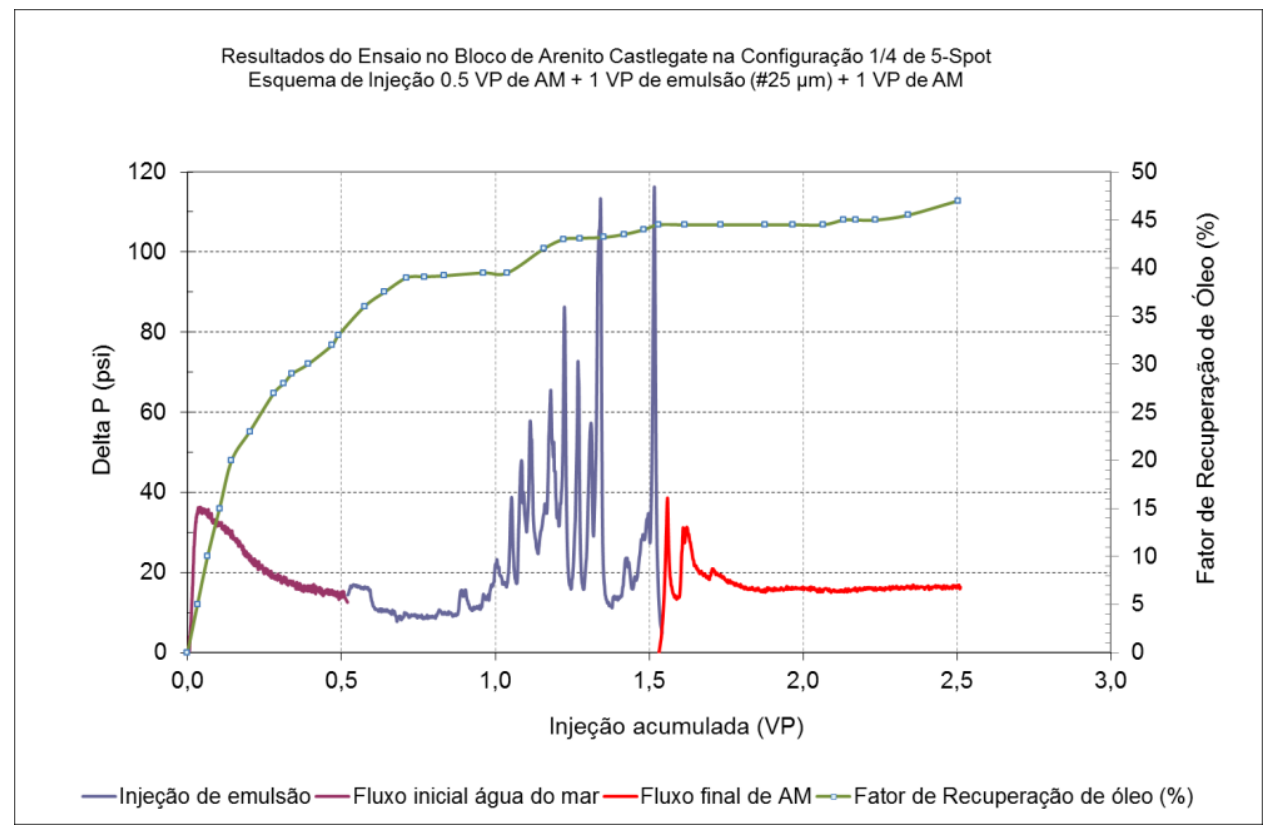

Figura 97 - Evolução da pressão de fluxo e fração de óleo recuperada no ensaio 3D.

A Figura 98 compara a evolução da razão água-óleo acumulada com a prevista pela extrapolação no modelo de simulação STARS. Pode-se observar que a RAO acumulada medida foi sempre menor que a simulada, comprovando a eficácia da injeção do banco de emulsão como controle de mobilidade.

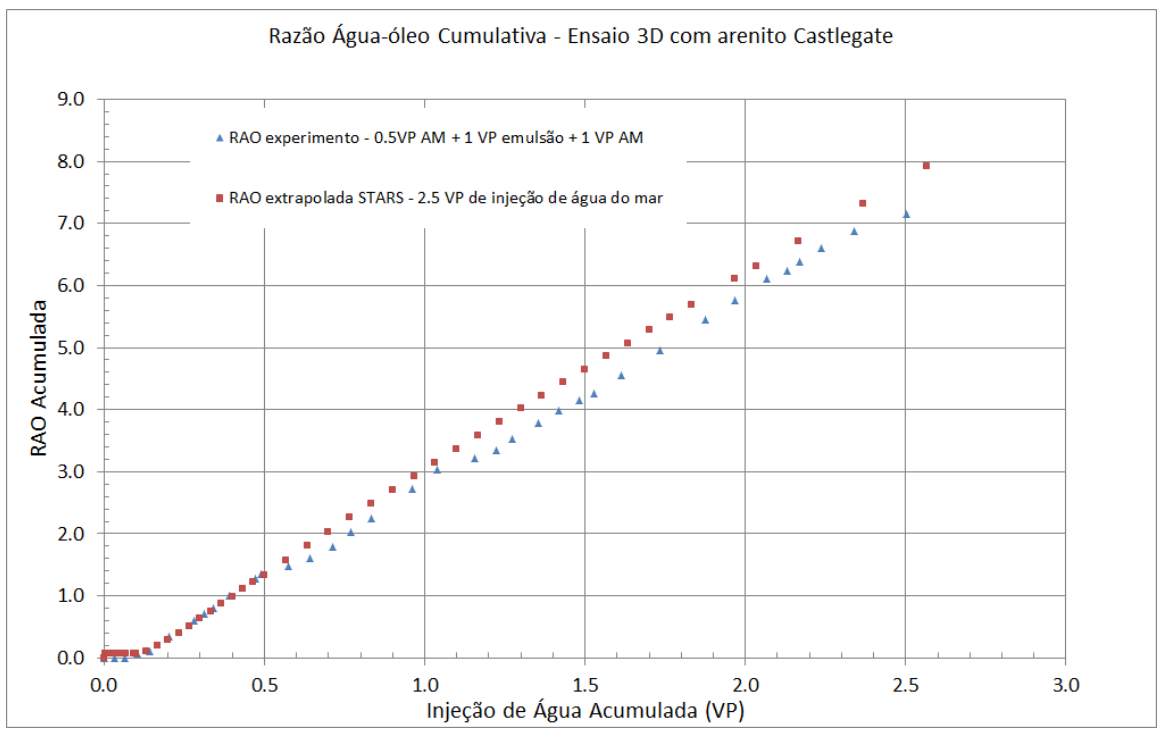

Figura 98 - Evolução da razão água-óleo cumulativa.

A Figura 99 mostra as produções de óleo e água ao longo do ensaio. As provetas estão ordenadas da esquerda para a direita. 


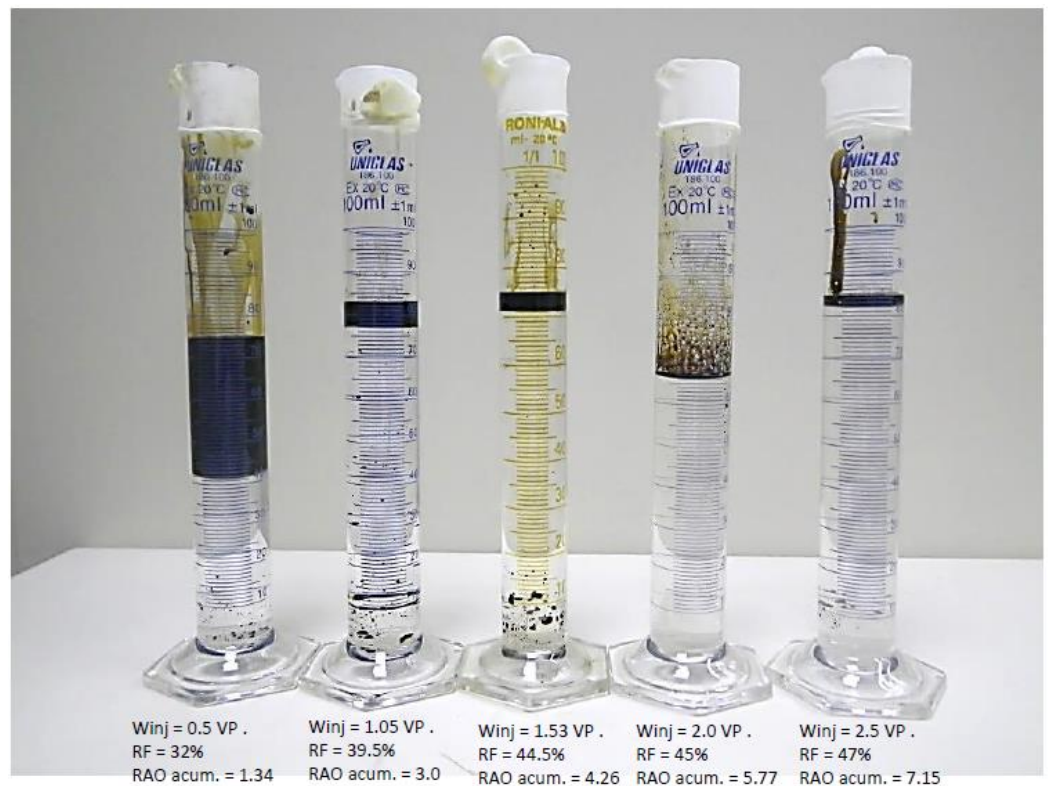

Figura 99 - Evolução da produção de óleo e água durante o ensaio.

\subsection{Imagens Tomográficas}

\subsubsection{Procedimento adotado}

Durante o ensaio, as imagens tomográficas foram adquiridas a cada 10 min (0.07 VP injetados). Todos os fluidos injetados (água do mar sintética e emulsão) foram dopado com lodeto de Potássio (conc. $100 \mathrm{~g} / \mathrm{L}$ ) para possibilitar a visualização da frente de avanço no meio poroso. $\mathrm{Na}$ etapa de processamento dos dados obtidos, foram gerados mapas de diferença de $\mathrm{HU}$, ou seja, destacando as regiões (voxels) que tiveram sua resposta aos raios $X$ alterada ao longo do ensaio. A cada etapa do ensaio foi feita a aquisição de um novo "zero", visando eliminar as influências da segregação gravitacional dos fluidos e de pequenas movimentações do bloco entre as etapas do ensaio. Dessa forma, foi possível inferir o efeito da movimentação do fluido no meio poroso em cada etapa do ensaio (injeções do banco de água inicial, do banco de emulsão e do banco de água final).

Uma observação importante é que a presença de partes metálicas na amostra ou nas proximidades produz forte interferência nas imagens tomográficas ("artefatos"). Por conta desse fato, todas as conexões 
utilizadas nesse ensaio são de Teflon (material transparente aos raios X). Outra limitação importante em relação ao uso de tomógrafos médicos nesse tipo de análise é que a aquisição e processamento das imagens foram otimizados para objetos de formato cilíndrico. Por conta disso, alguns artefatos podem se formar no processamento das imagens de um bloco, principalmente nas proximidades das bordas.

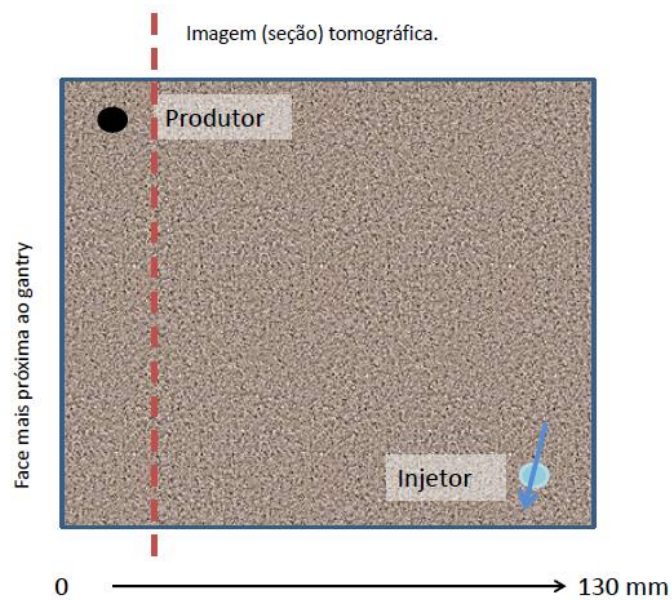

Figura 100 - Convenção para geração das imagens transversais.

\subsubsection{Resultados}

As imagens tomográficas "brutas", isto é, sem o processamento antes do procedimento para geração dos mapas de diferença, seguem a convenção esquematizada na Figura 100. O software utilizado para geração dessas imagens é o Imago XRay ${ }^{\circledR}$ (desenvolvimento ESSS). Nas imagens "brutas", a água injetada aparece em tom mais claro devido à resposta do lodo presente no fluido. A Figura 101 mostra algumas dessas imagens obtidas na injeção do banco de água do mar sintética inicial. 


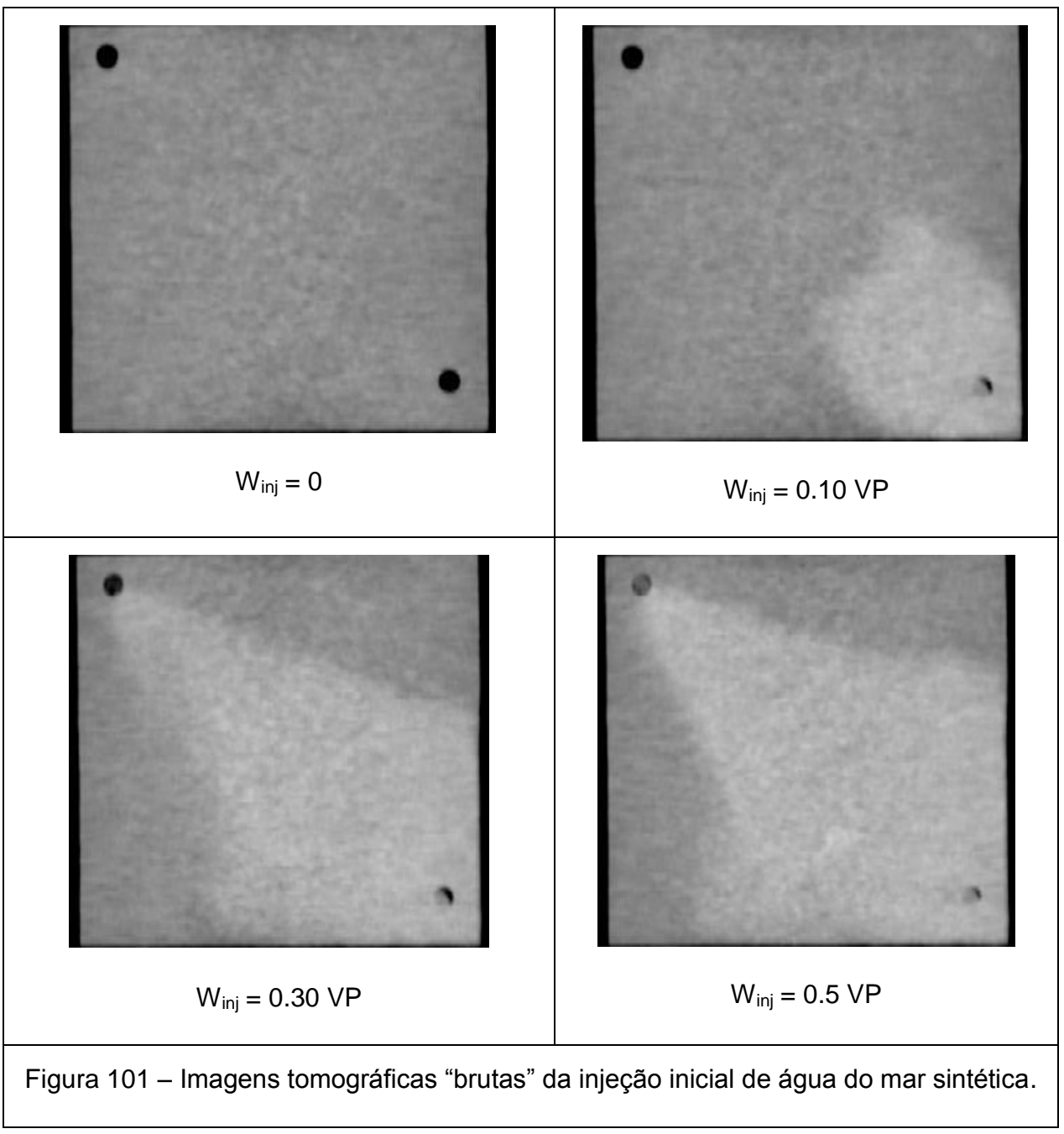

A Figura 101 mostra a evolução da imagem tomográfica bruta de uma seção a $75 \mathrm{~mm}$ da face mais próxima ao gantry. É possível claramente perceber o avanço "lateral" do fluido injetado se deslocando do poço injetor para o produtor. 


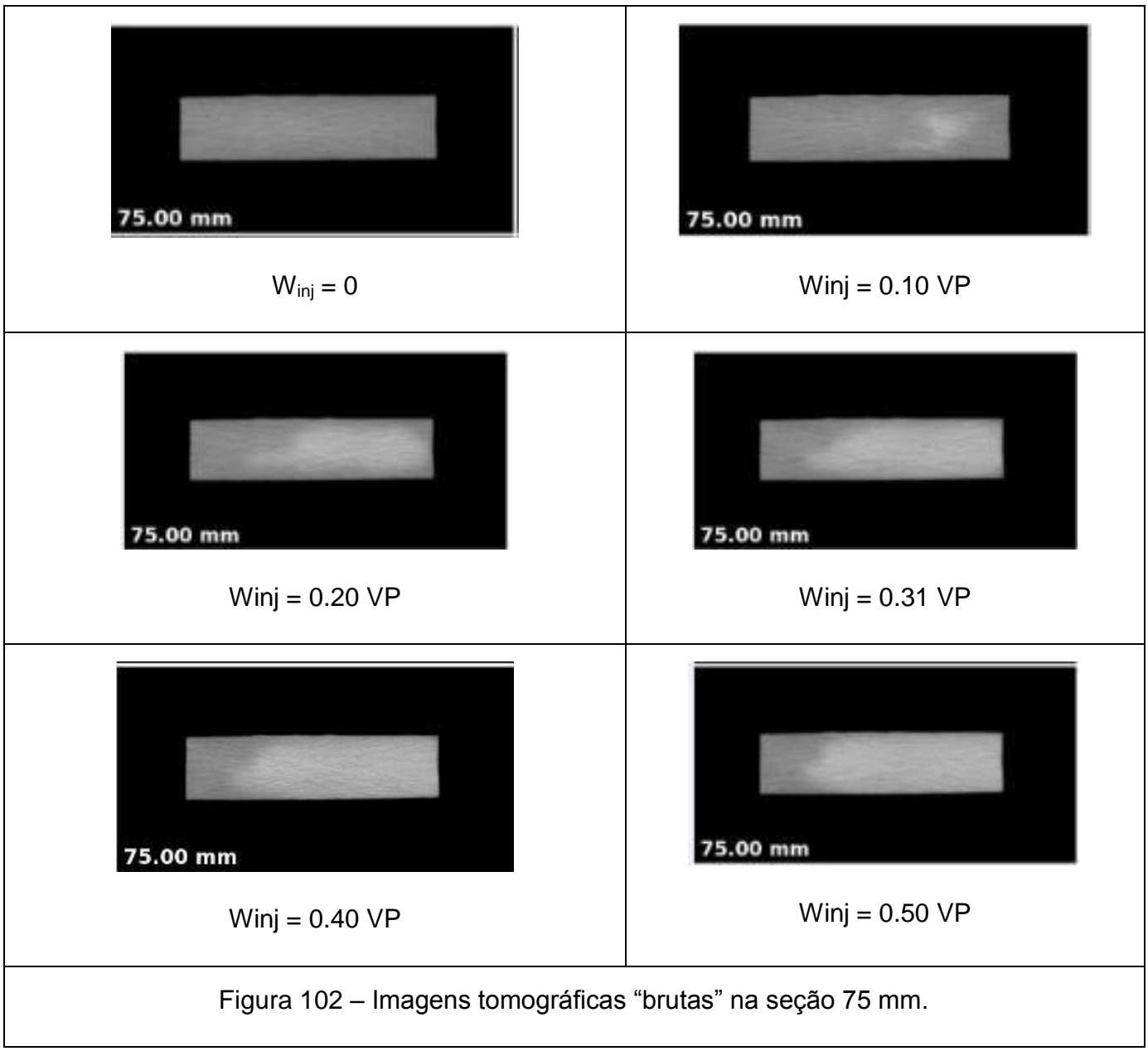

As imagens "brutas" mostraram de forma inequívoca que a solução de lodeto de Potássio produziu um contraste suficiente para a visualização, mas a análise dos resultados somente fica completa gerando e interpretando os "mapas diferença". Esses mapas são feitos subtraindo a imagem tomográfica a um tempo qualquer da imagem gerada no tempo zero. Essa técnica segue o mesmo conceito da sísmica 4D.

\subsubsection{Imagens Processadas (“Mapas Diferença 3D”) - Injeção do Banco de Água Inicial}

Os mapas diferença mostram a resposta aos raios $X$ do mesmo voxel em tempos diferentes. A diferença na resposta indica a substituição do fluido original do meio, ou seja, mobilização do óleo existente. As etapas do ensaio (injeções alternadas $A M / E m / A M$ ) ocorreram com 
intervalos de até 3 dias entre si. Por conta disso, certamente houve segregação gravitacional de parte do fluido injetado, obrigando que fosse feito uma aquisição de novo "zero".

Considerando a calibração do equipamento com $\mathrm{HU}_{\mathrm{ar}}=-1000$ e $\mathrm{HU}_{\text {água }}=0$, obteve-se os seguintes valores de resposta do meio poroso:

- Rocha com saturações médias $\mathrm{S}_{\mathrm{oi}}=65 \%$ e $\mathrm{S}_{\mathrm{wi}}=35 \%$ (a água de formação não foi dopada) $\rightarrow$ HU =1500 a 1600;

- Rocha invadida pelo fluido injetado (fase aquosa dopada com lodeto de Potássio) $\rightarrow \mathrm{HU}=1700$ a 1800.

\section{Desse modo, foram mapeadas as diferenças entre 100 e $300 \mathrm{HU}$.}

Para efeito de análise, foram feitas aquisições a cada início de ensaio e a cada intervalo de 10 minutos. A geração das imagens em 3D foi feita com o software EnSight ${ }^{\circledR}$ (desenvolvimento CEI).

A sequência a seguir (Figura 103 a Figura 106) mostra o processamento dos resultados na injeção do banco de água do mar sintética inicial. As áreas em azul mais escuro têm diferença HU igual a zero, ou seja, permaneceram com as mesmas saturações de fluidos originais. Os tons azuis mais claros são valores-diferença de HU próximos a 200, indicando a substituição parcial do fluido original pelo injetado (dopado com KI). Os pontos azulados dispersos no meio poroso e longe do ponto de injeção são interferências geradas na aquisição tomográfica ("artefatos"). Essas interferências ocorrem, principalmente, nas proximidades das faces do bloco (laterais, superior e inferior). É relativamente simples identificá-los nas imagens, pois são pontos claramente separados da frente de injeção.

$\mathrm{Na}$ primeira etapa do experimento, o mapa diferença indica a trajetória da frente de injeção no meio poroso. É importante destacar que essa é a única situação em que se pode fazer essa associação direta. 


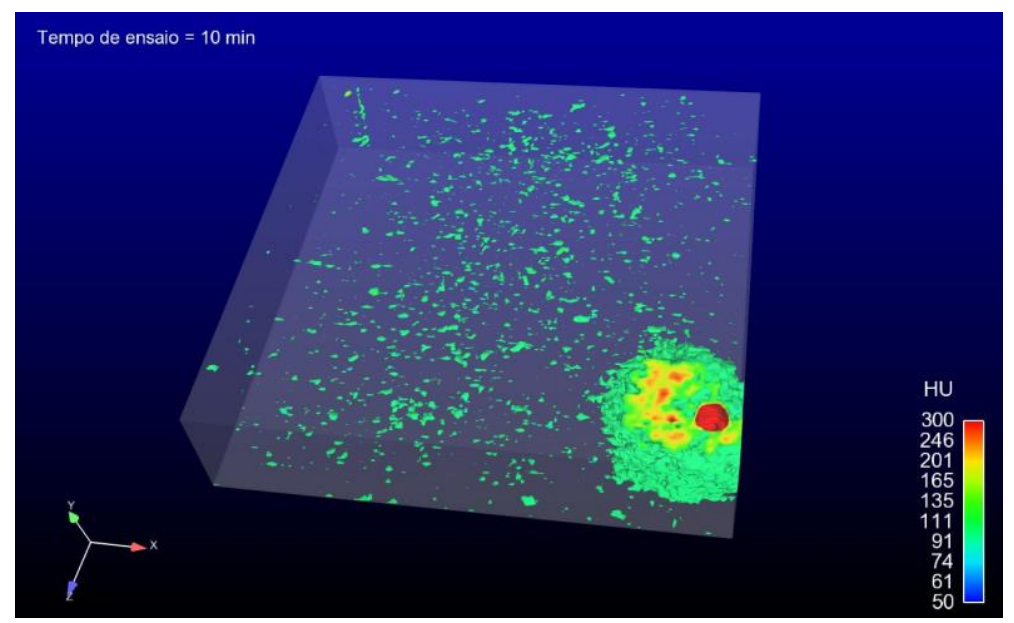

Figura 103 - Mapa diferença 3D obtido na injeção do banco de água inicial $\left(W_{\text {inj }}=0.03\right.$ VP). A área invadida pelo fluido injetado aparece destacada.

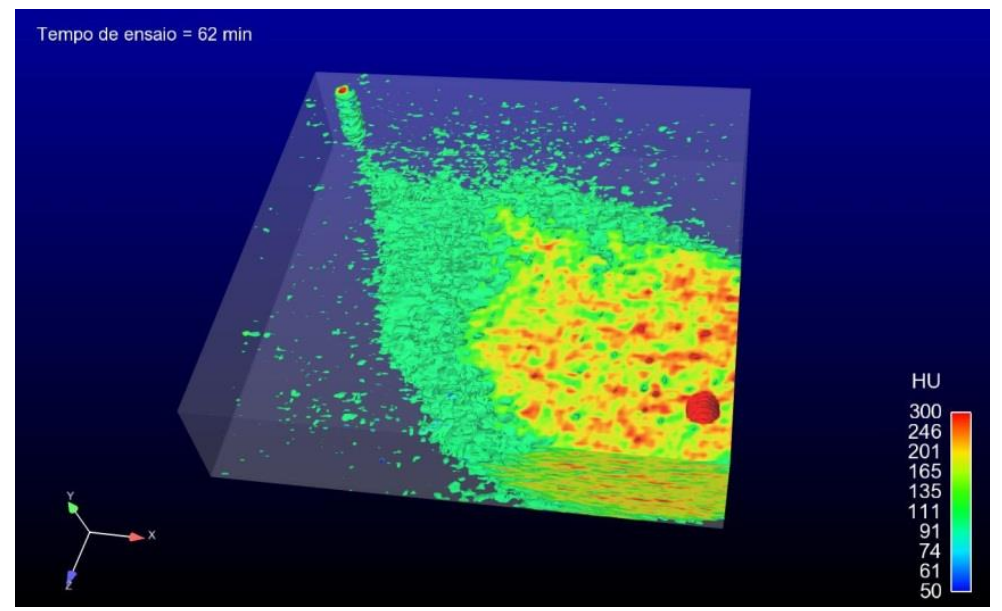

Figura 104 - Mapa diferença 3D obtido na injeção do banco de água inicial $\left(W_{\text {inj }}=0.20\right.$ VP). É possível observar que o breakthrough da água de injeção no poço produtor é iminente.

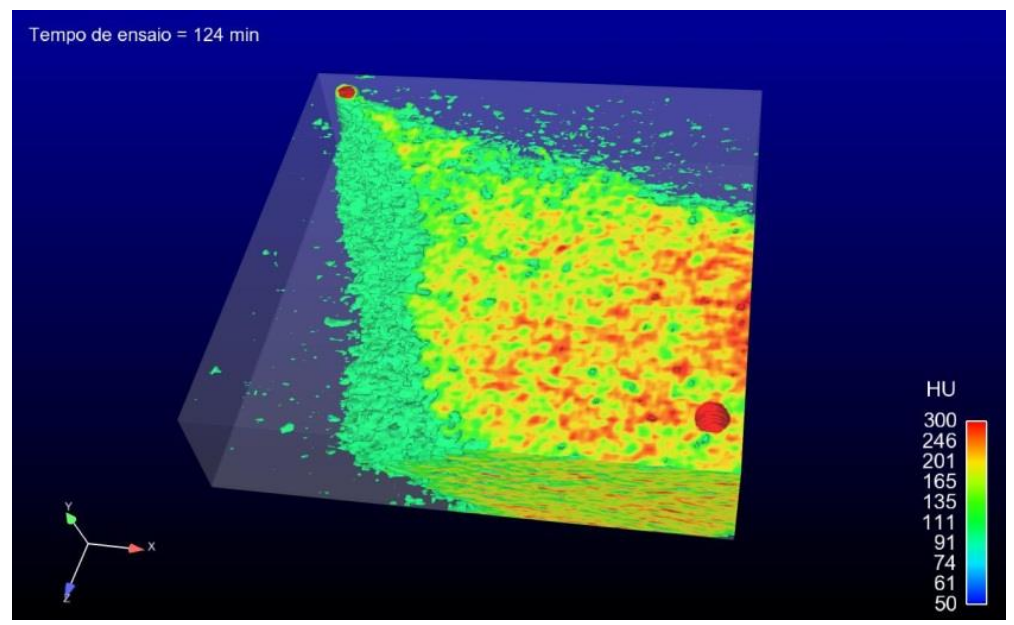

Figura 105 - Mapa diferença 3D obtido na injeção do banco de água inicial ( $\left.\mathrm{W}_{\mathrm{inj}}=0.41 \mathrm{VP}\right)$. Observa-se que a água de injeção está sendo produzida em todo intervalo completado do poço produtor. 


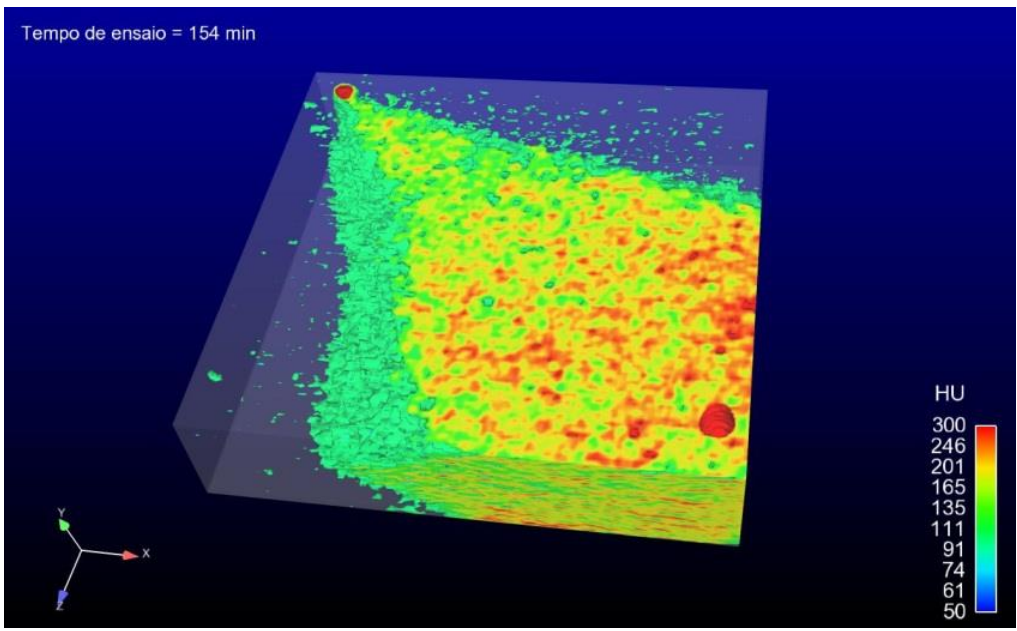

Figura 106 - Mapa diferença 3D obtido na injeção do banco de água inicial $\left(\mathrm{W}_{\mathrm{inj}}=0.50 \mathrm{VP}\right)$.

\subsubsection{Imagens Processadas (“Mapas Diferença 3D”) - Injeção do Banco de Emulsão}

Após a injeção desse banco de água, o tomógrafo somente poderia ser utilizado 3 dias depois. Dessa forma, parte da água injetada sofreu segregação gravitacional. Dessa forma a distribuição volumétrica dos fluidos no início da injeção do banco de emulsão era diferente da distribuição ao final da injeção do banco de água inicial. Por conta disso, o "zero" relativo a esse ensaio é diferente do inicial. $\mathrm{Na}$ análise das imagens a seguir é importante lembrar que as regiões em destaque não são as únicas porções do reservatório varridas pelo fluido, mas sim aquelas em que houve modificação do fluido presente na aquisição inicial.

A Figura 107 mostra regiões do reservatório destacadas ao raio $X$ (escala da resposta incluída nas figuras). Essas são as regiões em que o fludo original foi substituído pelo injetado. Respostas em tons azulados são próximas de zero. Isso apenas indica que essa área já estava lavada pela injeção inicial (a saturação de óleo não se modificou). Isso não quer dizer que não há mais fluxo, por exemplo, no plano que une os poços. $\mathrm{O}$ que está em destaque nas figuras é a divergência do fluido de injeção para novas áreas do reservatório. 


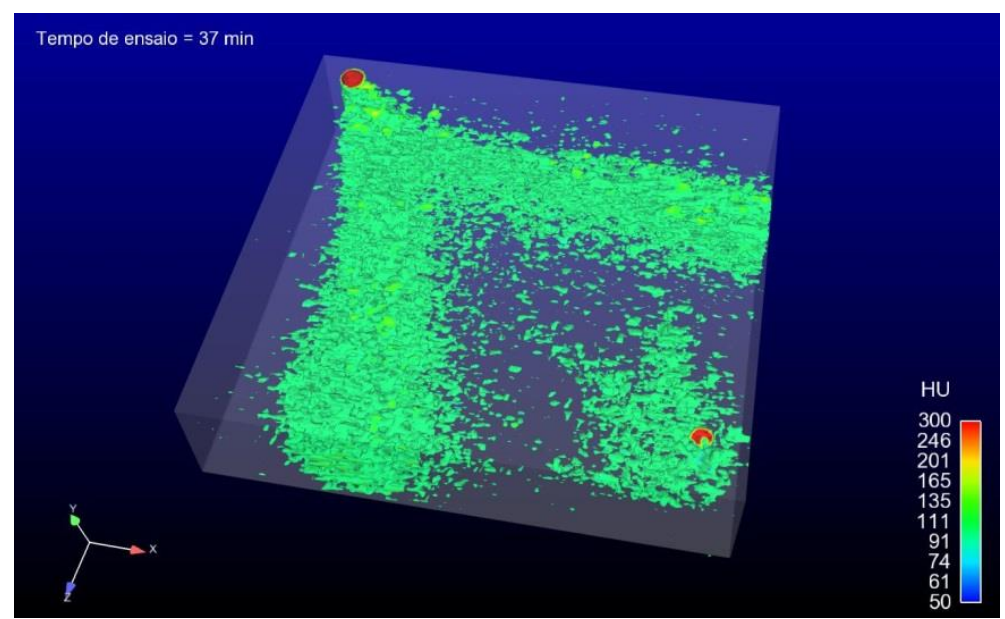

Figura 107 - Mapa diferença 3D obtido na injeção do banco de emulsão (0.25 VP injetados).

A Figura 108 e a Figura 109 mostram que esse efeito se intensificou com o aumento do volume injetado acumulado. Esse fato veio acompanhado de um expressivo aumento da pressão de injeção, indicando que o meio poroso está sendo parcialmente bloqueado pela emulsão. Esse fenômeno seria menos evidente na injeção de água ou de solução de surfactante que tenderiam se deslocar preferencialmente pelas áreas já lavadas pelo banco inicial de água.

Outro efeito importante é que a resposta de áreas já varridas pela injeção de água também foi modificada. Isso fica evidente ao ser observar a região em torno da diagonal que une os poços. A coloração vai gradativamente saindo do azul (volume sem substituição de fluidos) para tons esverdeados (substituição do fluido original pela emulsão injetada). Esse efeito é consequência direta do redirecionamento do fluxo microscópico causada pelo bloqueio parcial do meio poroso pela captura de gotas emulsionadas. Na injeção de água, uma vez estabelecidos, os caminhos preferenciais, a frente de injeção tende a caminhar por eles com quase nenhuma alteração de varrido adicional. 


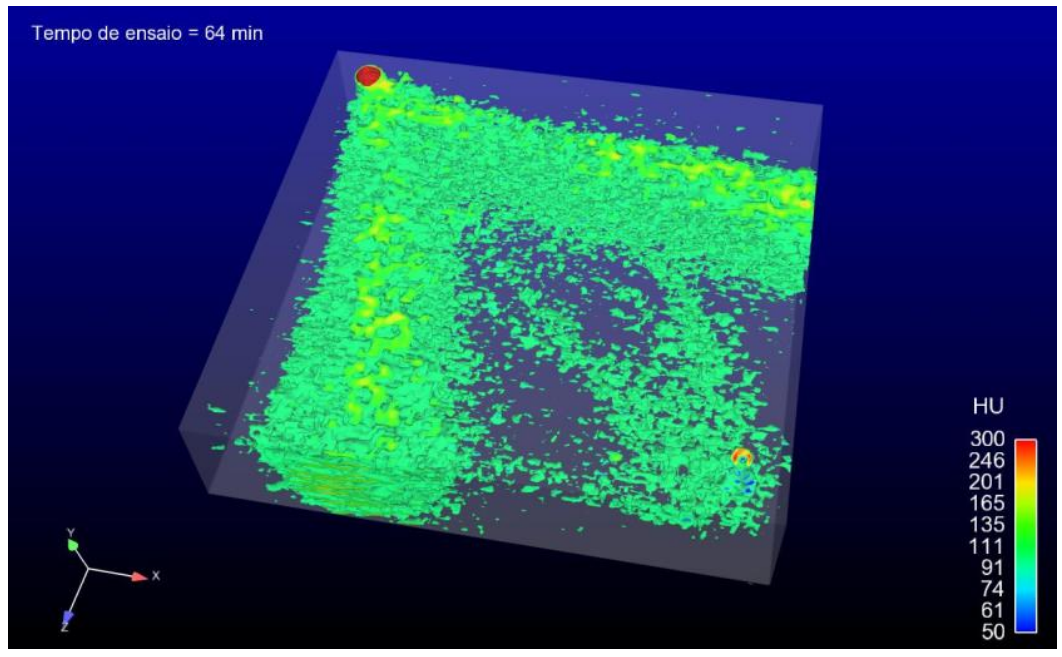

Figura 108 - Mapa diferença 3D obtido na injeção do banco de emulsão (0.43 VP injetados).

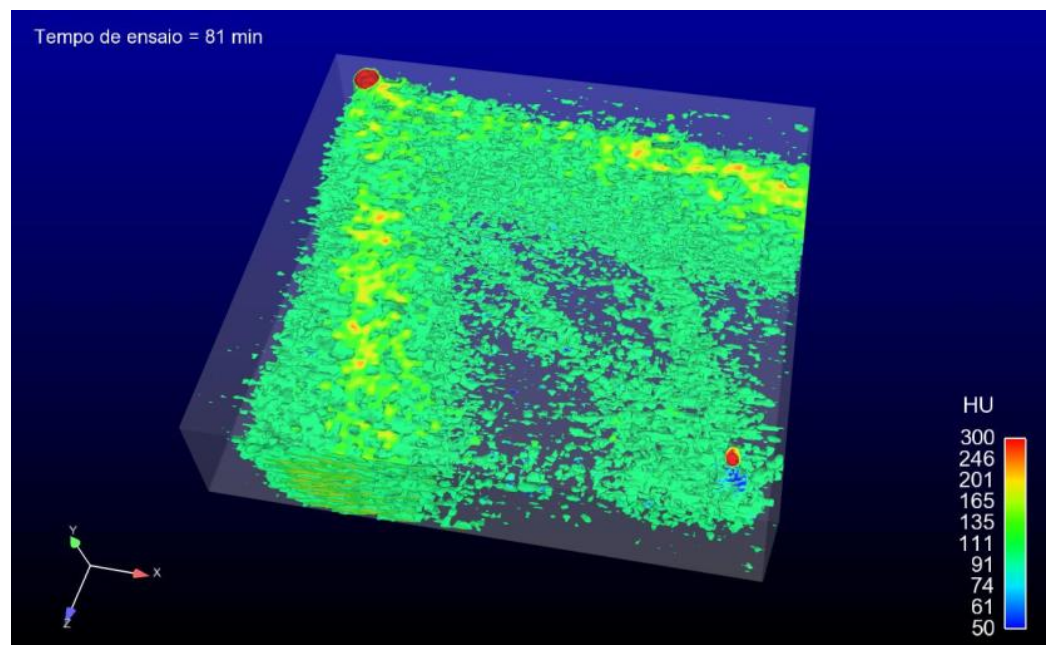

Figura 109 - Mapa diferença 3D obtido na injeção do banco de emulsão (0.54 VP injetados).

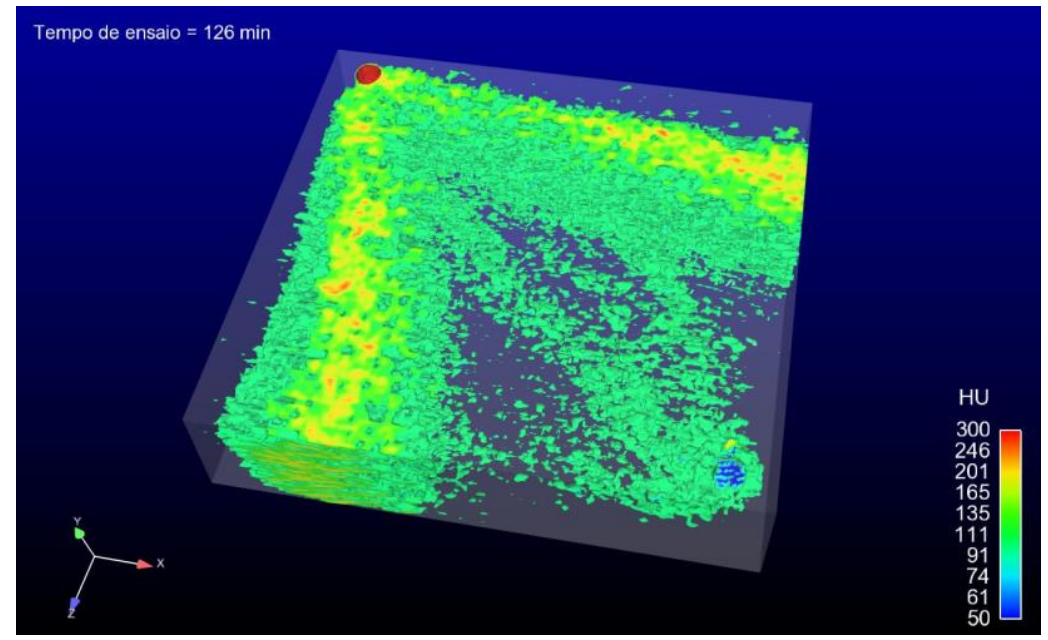

Figura 110 - Mapa diferença 3D obtido na injeção do banco de emulsão (0.84 VP). 


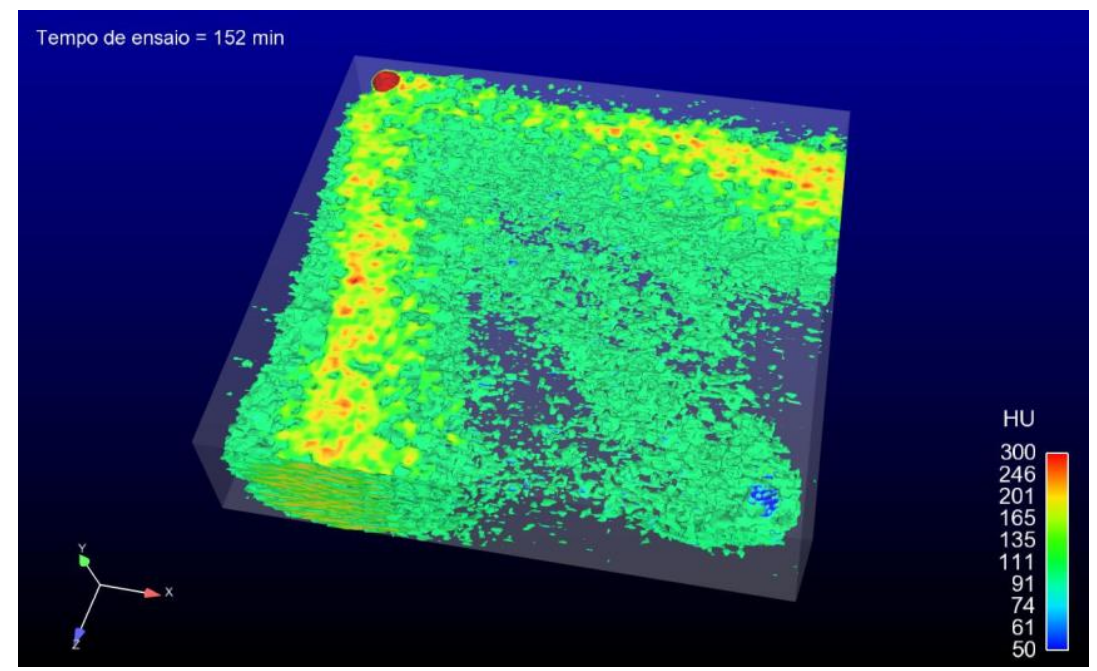

Figura 111 - Mapa diferença 3D obtido na injeção do banco de emulsão (1 VP).

A Figura 112 mostra o detalhe de um volume selecionado na diagonal que une os poços. O poço produtor é o círculo esbranquiçado na extremidade esquerda da figura. As áreas enegrecidas são diferenças negativas (substituição por um fluido de menor densidade $\rightarrow$ óleo). A hipótese mais provável é que elas indicam as regiões onde a captura de gotículas emulsionadas foi mais intensa. Notar que se formou um bloqueio mais intenso nas proximidades do injetor, mas houve alguma penetração para dentro do reservatório.

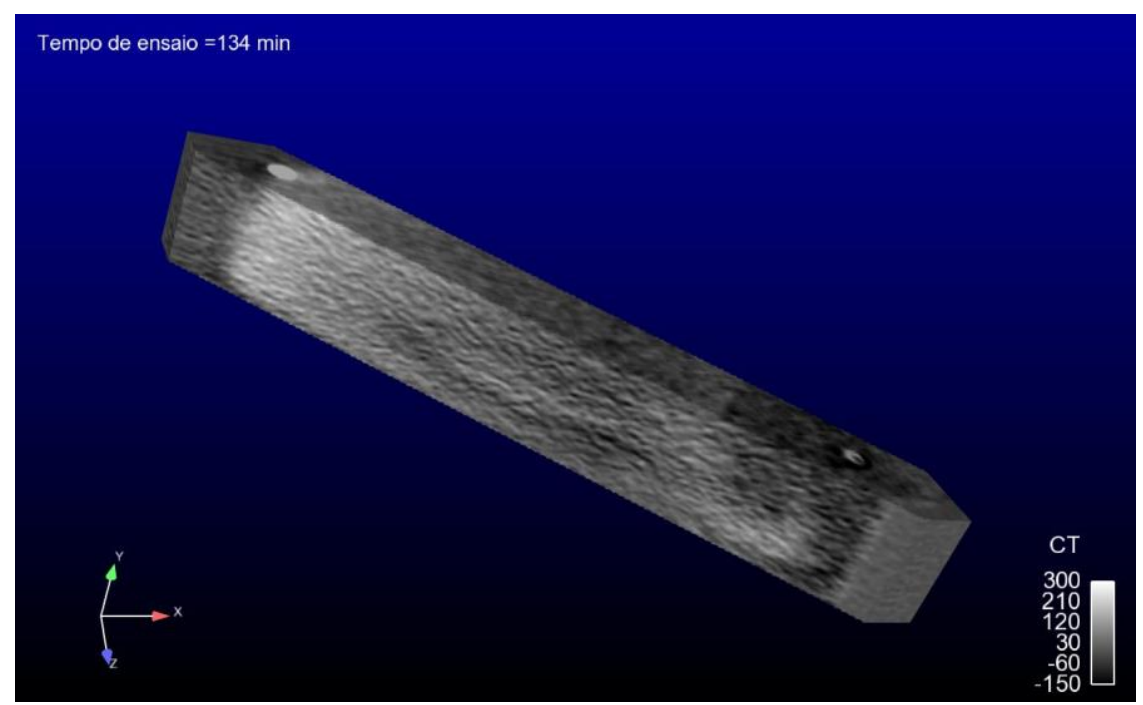

Figura 112 - Mapa de diferença 3D, após a injeção de 0.89 VP de emulsão, na diagonal que o poço injetor e o poço produtor. 


\subsubsection{Imagens Processadas (“Mapas Diferença 3D”) - Injeção do Banco de Água Final}

Para complementar o ensaio, foi injetado mais 1 volume poroso de água no reservatório, cujo principal objetivo era confirmar que a pressão de injeção de água se daria com pressão mais alta que a necessária para injetar o primeiro banco. Isso confirmaria a hipótese de que bloqueio induzido no meio poroso pelas gotas emulsionadas somente pode ser revertido com o aumento do número da capilaridade local.

Foi feita uma nova aquisição tomográfica ("zero") antes do ensaio para servir de base para os mapas de diferença gerados ao longo do ensaio.

A série de imagens tomográficas mostra que a substituição de fluidos nessa etapa do ensaio foi mais discreta que a que ocorreu na injeção do banco de emulsão. A frente de injeção provavelmente foi redirecionada para os poros menores dessa região, deslocando algum óleo adicional. Como o volume poroso extra que foi varrido é comparativamente menor, as diferenças nas imagens tomográficas refletem isso. Essa hipótese é baseada no fato de que um pequeno banco de óleo adicional foi produzido no último $0.5 \mathrm{VP}$ injetado, aumentado a fração recuperada de óleo de $45 \%$ para $47 \%$.

Outra diferença ocorreu perto do injetor. Nesse caso, provavelmente, houve uma associação do redirecionamento da frente de injeção para os poros menores mais algum arraste de gotículas emulsionadas pequenas. Essas gotículas não chegaram a ser produzidas em quantidade observável a olho nu. Entretanto, esse fenômeno foi observado durante a série de ensaios nos sandpacks (produção de gotículas de óleo emulsionado durante a injeção do banco de água final). O número de capilaridade em torno do injetor é mais alto que nas laterais, aumentando a possibilidade de algum arraste de gotículas menores. 


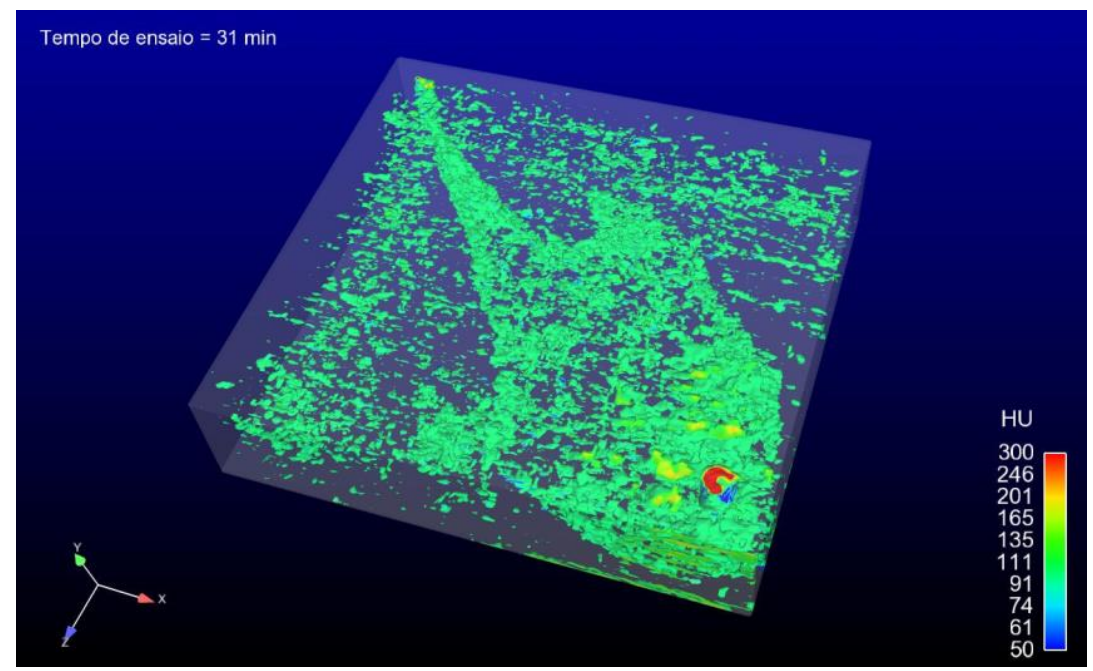

Figura 113 - Mapa diferença 3D na injeção do banco de água final (0.21 VP injetados).

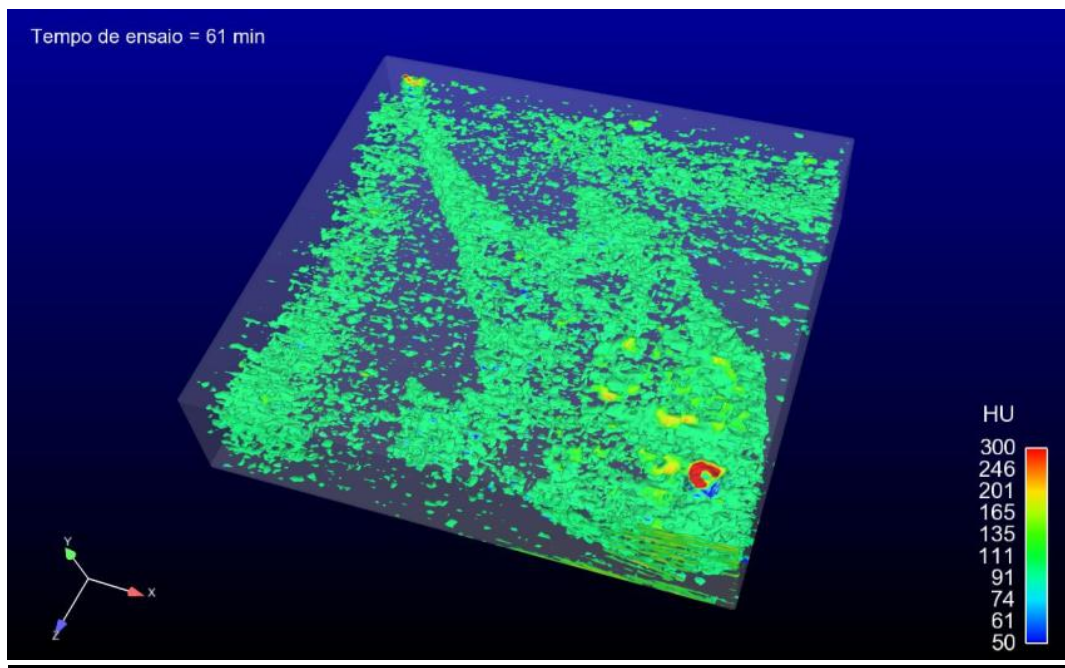

Figura 114 - Mapa diferença 3D na injeção do banco de água final (0.41 VP injetados).

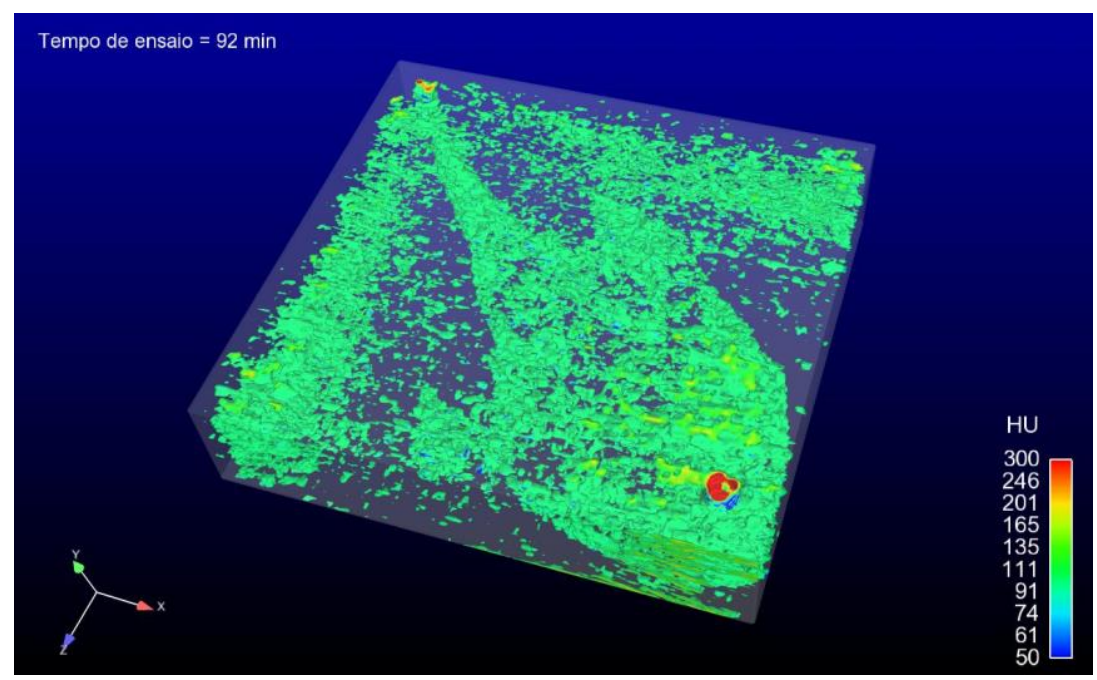

Figura 115 - Mapa diferença 3D na injeção do banco de água final (0.61 VP injetados). 


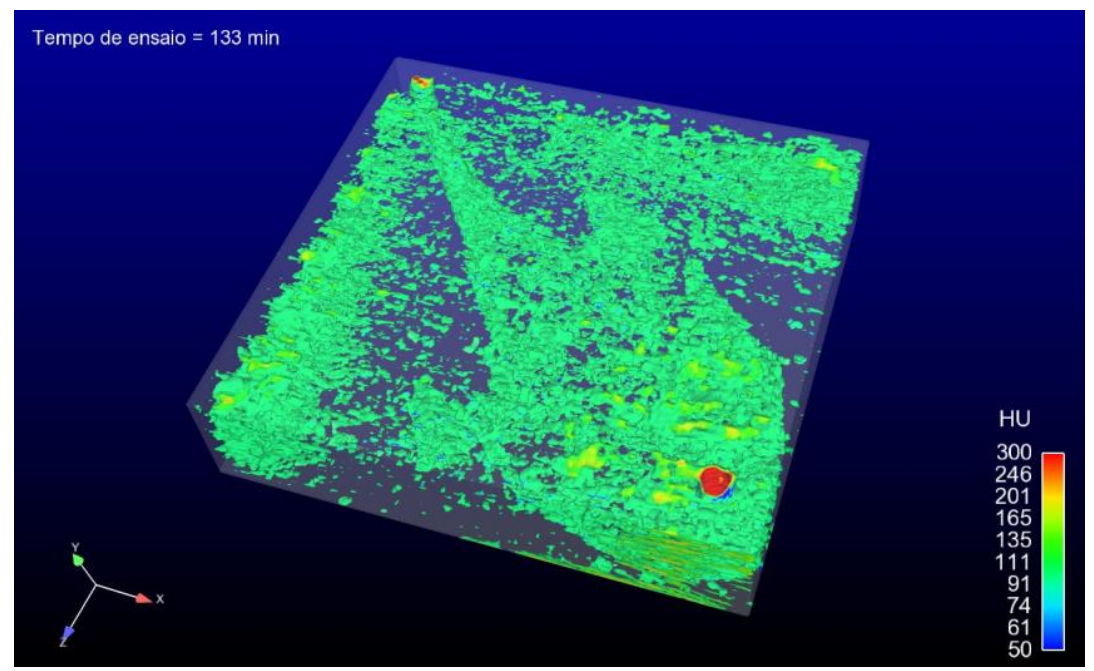

Figura 116 - Mapa diferença 3D na injeção do banco de água final (0.89 VP injetados).

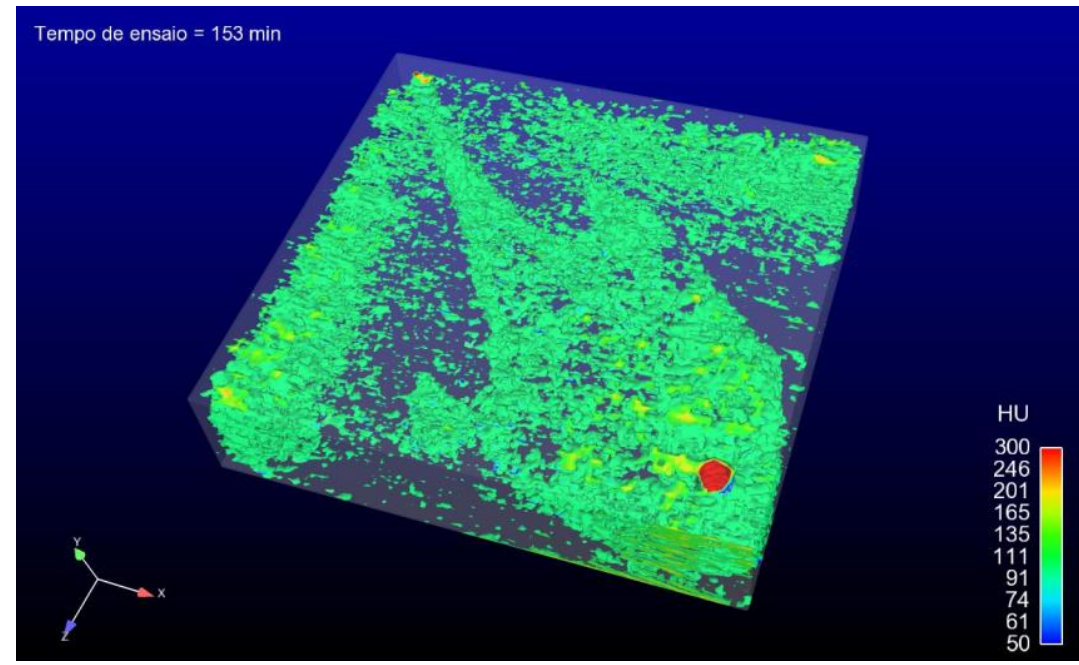

Figura 117 - Mapa diferença 3D na injeção do banco de água final (1.0 VP injetado). 


\section{Conclusões, Recomendações e Sugestões para Trabalhos Futuros.}

\subsection{Conclusões}

A produção de óleos viscosos em ambiente offshore tem como grande desafio o processamento da água produzida. A reinjeção é atualmente considerada por todas as operadoras, não só pelo aspecto econômico, mas também pelo forte apelo ambiental.

Para a implantação de tecnologias emergentes na indústria de E\&P como a separação submarina, é fundamental a viabilização de projetos de reinjeção que operem com grandes intervalos entre intervenções nos poços. Por isso, é de fundamental importância o investimento na caracterização e entendimento do fluxo desse tipo de água em reservatórios de petróleo. Para tal, é fundamental o uso de ferramentas como sensores de pressão de fundo de poço, injeção de traçadores interwell e aquisições sísmicas 4D.

O presente trabalho cobre uma lacuna existente na literatura relativa à injeção de emulsões feitas com petróleo viscoso em meios porosos.

A água produzida pode ser considerada, em muitos casos, uma emulsão de óleo em água diluída. Os resultados experimentais indicaram que, após tratamento adequado, a reinjeção pode aumentar o fator de recuperação final de petróleo, principalmente pelos mecanismos de bloqueio de áreas já lavadas pela injeção de água e redistribuição do fluido injetado para áreas ainda saturadas com óleo móvel. O tratamento deve ser o controle da quantidade e distribuição de tamanhos das partículas suspensas de forma a evitar-se perda de injetividade precocemente.

Outra possibilidade que se apresenta é de "projetar" emulsões, isto é, com distribuições de tamanhos de gotas controladas para bloqueio de 
área do reservatório com caminhos preferenciais formados entre produtores e injetores. Nessas situações a água injetada acaba por recircular no reservatório gerando pouca ou nenhuma recuperação de óleo adicional. Quando o número de capilaridade local é mantido, as gotas capturadas permanecem imóveis, gerando redução permanente da permeabilidade local. Como as gotas emulsionadas são capturadas em presença do surfactante, uma injeção de água no mesmo nível de vazão não conseguirá movê-las, pois o número de capilaridade local estará necessariamente menor. A explicação reside no fato de que a tensão interfacial óleo-água é maior que a verificada no evento de captura da gota pela garganta de poro (em presença de surfactante na fase contínua).

O experimento 3-D de injeção alternada de água do mar e emulsão comprovou que houve mobilização de óleo de áreas previamente ultrapassadas pela injeção de água inicial. A tomografia permitiu visualizar o deslocamento adicional de fluidos originais do meio poroso devido ao efeito de divergência de fluxo causado pelas gotas capturadas.

Foi possível ajustar os resultados de alguns experimentos 1-D em um simulador de fluxo comercial. Para tal, modificaram-se as curvas de permeabilidade relativa óleo-água (pontos terminais e expoentes de Corey) e introduziu-se um parâmetro de captura de gotas e consequente redução da permeabilidade relativa à água. Esse ajuste foi possível porque a velocidade era constante ao longo do meio poroso. Dessa forma foi possível determinar um parâmetro de captura de gotas único para modelar o problema. Em problemas 2-D e 3-D, tem-se um campo de velocidades no meio poroso. Nesses casos, obrigatoriamente será necessário desenvolver-se opções no simulador que permitam estabelecer uma dependência entre a taxa de captura de gotas, o diâmetro médio das gotas emulsionadas e a permoposoridade local com o número de capilaridade local.

O ganho econômico de implantar projetos de reinjeção deve ser subdividido em três aspectos: a) a água para reinjeção exige um tratamento menos rigoroso que o para descarte em superfície. Os tempos de residência requeridos são menores, aumentando a capacidade de 
processamento de líquido das instalações e a produção de óleo; b) redução da produção de água futura pelo bloqueio de áreas com canalizações no reservatório; c) redução de custos operacionais;

\subsection{Recomendações para trabalhos futuros}

Como sugestões de trabalhos futuros, poder-se-ia mencionar:

a) o desenvolvimento de um simulador numérico 1-D para modelar o processo de captura de gotas e redistribuição de fluxo provocado pela injeção de emulsões. Como dado de entrada deve-se ter as curvas de distribuição de gargantas de poros do meio e a distribuição de tamanhos de gotas emulsionadas. O processo de captura de gotas deve ser modelado como dependente do número de capilaridade local e razão entre os tamanhos da garganta de poro e da gota;

b) desenvolvimento de um programa experimental para avaliar a influência da presença conjunta de sólidos suspensos e óleo emulsionado no processo de captura e redistribuição de fluxo no meio poroso;

c) desenvolvimento de programa experimental para avaliar o potencial do uso de outros efluentes emulsionáveis em água como agentes de controle de mobilidade. Alguns exemplos seriam a glicerina e óleo lubrificante usado;

d) Realização de experimentos com limitação de pressão de injeção. Em rochas menos permeáveis, pode haver uma sensível redução na vazão de injeção capaz de reduzir a produção acumulada de óleo na comparação com o caso da injeção de água. 


\section{Referências Bibliográficas}

[1] Schollnberger, Wolfgang E. - "The Role of Oil and Gas in the Energy Mix of next 100 Years - Shifts in Demand, Supply and Utilization of Energy"- SPE Distinguished Lecture - Society of Petroleum Engineers 2010;

[2] Milani, E. J. et ali - "Petróleo na margem continental brasileira: geologia, exploração, resultados e perspectivas" - Revista Brasileira de Geofísica, vol. 18, $\mathrm{n}^{0} 3-2000-$ disponível em http://www.scielo.br/pdf/rbg/v18n3/a12v18n3.pdf.

[3] Petroleum Communication Foundation - "Canada's Oil Sands and Heavy Oil" - PCF - Canada - 2000.

[4] Pinder, George F.; Gray, William G. - "Essential of Multiphase Flow and Transport in Porous Media" - Wiley - ISBN 978-0-470-31762-4 2008.

[5] - Szklo, Alexandre S. - "Fundamentos do Refino do Petróleo" Editora Interciência - ISBN 85-7193-129-1 - 2005.

[6] Sydansk, Robert D.; Romero-Zerón, Laura - "Reservoir Conformance Improvement" - Society of Petroleum Engineers - ISBN 978-1-55563-3028 -- 2011.

[7] Skauge, Arne at ali - "2-D Visualisation of Unstable Waterflood and Polymer Flood for Displacement of Heavy Oil" - SPE Paper 154292 Eighteenth SPE Improved Oil Recovery Symposium - Tulsa - 2012.

[8] Greenkorn, R. A. - "Unstable Flow in Heterogeneous Porous Media" SPE Publication 17114 - Society of Petroleum Engineers - 1988.

[9] Veil, John A.; Puder, Markus G.; Elcok, Deborah e Redwick Jr, Robert J - "A White Paper describing Produced Water from Production of Crude Oil, Natural Gas and Coal Bed Methane" - U. S. Department of Energy 2004. 
[10] Sharma, Mukul - "Produced Water Management: Opportunities and Challenges" - SPE Distinguished Lecture http://www.pge.utexas.edu/pdf/SPEdislect.pdf

[11] Dixon, Bryan P., Newton Jr, L. E. - "Reinjection of Large Volumes of Produced Water in Secondary Operations" - SPE 1147 - Society of Petroleum Engineers - 1965.

[12] Svalheim, S. -"Zero Discharge - Opportunities and Challenges" FORCE Seminar - Stavanger - 2004.

[13] Faerstein, Marcos - "Impactos da Molhabilidade da Rocha na Produção e Recuperação de Petróleo" - Dissertação de Mestrado COPPE/UFRJ - 2010.

[14] Paige, R.W.; Murray, L. R. - "Re-injection of Produced Water - Field Experience and Current Understanding" - SPE Paper 28121 - SPE/ISRM Rock Mechanics in Petroleum Engineering Conference - Delft - 1994.

[15] Mendes, Roberta A.; Furtado, Claudio J. A. e Luz Jr, Eurípides B. "Reinjeção da Água Produzida na Bacia de Campos" - IBP2516-08 - Rio Oil \& Gas Expo and Conference 2008 - Rio de Janeiro - 2008.

[16] Vigliano, Ricardo - "Mais Espaço no Topside" - Revista Brasil Energia - Número 348 - pp 32-34 - 2009

[17] StatoilHydro - "Peregrino - Statoil's largest heavy crude oilfield" disponível em www.statoil.com - 2010.

[18] Offshore Technology - "Tordis IOR Project, Norway" - disponível em http://www.offshore-technology.com/projects/tordis/tordis1.html

[19] Svalheim, S. - "Zero Discharge - Opportunities and Challenges" FORCE Seminar - Stavanger - 2004.

[20] Vik, Eilen A. - "Reducing the Impact of Discharges to Sea" - OG21 TTA1 Seminar - 2008.

[21] Sweeney, Frank - "Changing the mindset: Produced Water as an opportunity rather than a problem" - Tekna Produced Water Conference Stavanger - 2007.

[22] Sousa, A. L. S.; Figueiredo, M. W.; Kupchil, C.; Bezerra, M.C.; Siqueira, A.G.; Furtado, C.J.A. - "Water Management in Petrobras: Developments and Challenges" - Offshore Technology Conference 2005 - Houston - 2005. 
[23] Ramis, Marcelo E. S. - "Tratamento da Água Produzida" - Material Interno Petrobras - 2008.

[24] Brost, Dale F. - "Understanding Oil-in-Water Instrument Specifications" - disponível em www.turnerdesigns.com - 2011.

[25] Robinson, James C. - "An Overview of Produced Water Treatment Technologies" - 2007.

[26] PETROBRAS - "Manual de Injeção de Água" - PETROBRAS - 2005.

[27] Furtado, Cláudio J. A., Souza, Antônio L. S., Siqueira, Alexandre G. de - "INJECT - Modelagem da Perda de Injetividade" - Relatório Interno Petrobras - 2006.

[28] Silva, M. F. da, Bedrikovetsky, P., Van de Broek, W. M. G. T.; Siqueira, A.; Serra, A. L. - "A New Method for Injectivity Impairment Characterization From Well and Coreflood Data" - Paper SPE 89885 SPE Annual Technical Conference and Exhibition - Houston - 2004.

[29] Silva, Maylton F. da - "Caracterização do Reboco Externo Durante a Injeção de Água do Mar - Aplicação para Descarte da água produzida em aquífero" - Dissertação de Mestrado - UENF - 2003.

[30] Barkmann, J. H.; Davidson, D. H. - "Measuring Water Quality and Predicting Well Impairment" - Paper SPE 3543 - 1972.

[31] van Oort, E.; van Velzen, J.F.G.; Leerlooljer, K. - "Impairment by Suspended Solids Invasion: Testing and Prediction" - SPE Paper 23822 SPE Formation Damage Symposium - Lafayette - 1992.

[32] Khatib, Z. I. - "Prediction of Formation Damage Due to Suspended Solids: Modeling Approach of Filter Cake Buildup in Injectors" - Paper SPE 28488 - SPE Annual Technical Conference and Exhibition - New Orleans - 1994 .

[33] Bedrikovestski, P. et alli - "Well-History-Based Prediction of Injectivity Decline During Seawater Flooding" - Paper SPE 93886 - SPE European Formation Damage Conference - Scheveningen - 2005.

[34] Pang, S.; Sharma, M. M. - "A Model for Predicting Injectivity Decline in Water-Injection Wells" - Paper SPE 24489 - SPE Technical Conference and Exhibition - New Orleans - 2004. 
[35] Siqueira, Alexandre G. da - "Modelagem em Rede 3D do Escoamento de Fluidos Particulados em Meio Poroso" - Dissertação de Mestrado - UNICAMP - 2000.

[36] Dullien, F.A.L. - "Porous Media: Fluid Transport and Pore Structure" Academic Press - 1992.

[37] Hofsaess, T.; Kleinitz, W. - "30 Years of Predicting Injectivity After Barkmann \& Davidson: Where are We today?" - Paper SPE 82231 - SPE European Formation Damage Conference - The Hague - 2003.

[38] Bai, M.; McLennan, J. e Standfird, W. - "An Alternative Method for Predicting Decline in Produced Water Re-Injection" - Paper SPE 120829 - SPE European Formation Damage Conference - Scheveningen - 2009. [39] Détienne, J.; Ochi, J.; Rivet, P. -“Internal Formation Damage Properties and Oil-Deposition Profile Within Reservoirs During PWRI Operations" - Paper SPE 108010 - SPE European Formation Damage Conference - Scheveningen - 2009.

[40] Bedrikovetsky, P. et alli - "Taking Advantage of Injectivity Decline for Sweep Enhancing during Waterflood with Horizontal Wells" - Paper SPE 122844 - SPE European Formation Damage Conference - Scheveningen -2009 .

[41] Mojarad, R. Salehi e Settari, A. - "Velocity-based Formation Damage Characterization Method for Produced Water Re-injection: Application on Masila Block Core Flood Tests" - Petroleum Science and Technology, 26 - pp. 937-954 - 2008.

[42] Santanna, Vanessa C.; Dantas, Tereza N. De C.; Neto, Afonso A. D "Microemulsions - An Introduction to Properties and Applications" disponível em http://www.intechopen.com/books/microemulsions-anintroduction-to-properties-and-applications.

[43] Somasundaran, P.; Wines, T.H; Mehta, S. C.; Gartin, Nissim; Farinato, R. - "Surfactants in Personal Care Products and Decorative Cosmetics" - Third Edition - Chapter 8 - CRC Press - ISBN 978$1574445312-2006$.

[44] Daltin, Decio - "Tensoativos - Química, propriedades e aplicações" Editora Edgar Blucher - ISBN 978-85-212-0585-2 - 2011. 
[45] Myers, Drew - "Surfactant Science and Technology"- Third Edition Wiley-Interscience - ISBN 13 978-0-471-68024-6 - 2006.

[46] McAuliffe, Clayton D. - "Oil-in-Water Emulsions and Their Flow Properties in Porous Media" - Paper SPE 4369 - Symposium of Improved Oil Recovery - Tulsa - 1972.

[47] McAuliffe, Clayton D. - "Crude-Oil-in-Water Emulsions To Improve Fluid Flow in an Oil Reservoir" - Paper SPE 4370 - Symposium of Improved Oil Recovery - Tulsa - 1972.

[48] Devereux, Owen F. - "Emulsion Flow in Porous Solids - I. A Flow Model" - The Chemical Engineering Journal - vol. 7 - pp. 121-128" 1974.

[49] Devereux, Owen F. - "Emulsion Flow in Porous Solids - II. Experiments with Crude Oil-in-Water Emulsion in Porous Sandstone" The Chemical Engineering Journal - vol. 7 - pp. 129-136" - 1974.

[50] Alvarado, D.A.; Marsden, S.S. - "Flow of Oil-in-Water Emulsions Through Tubes and Porous Media" - Paper SPE 5859 - SPE $46^{\text {th }}$ Annual California Regional Meeting - Long Beach - 1975.

[51] Schmidt, D. P.; Soo, H.; Radke, C.J. - "Linear Oil Displacement by the Emulsion Entrapment Process" - Paper SPE 11333-PA - SPE Journal 1984.

[52] Soo, H.; Radke, C.J. - "The Flow Mechanism of Dilute, Stable Emulsions in Porous Media" - Ind. Eng. Chem Fund. - vol. 23 - 1984.

[53] Soo, H.; Radke, C.J. - "A Filtration Model for the Flow of Dilute, Stable Emulsions in Porous Media - I. Theory" - Chemical Engineering Science - Vol. 41 - No 2 - pp. 263-272 - 1986.

[54] Soo, H.; Radke, C.J. - "A Filtration Model for the Flow of Dilute, Stable Emulsions in Porous Media - II Parameter Evaluation and Estimation" - Chemical Engineering Science - Vol. 41 - No 2 - pp. 273-281 $-1986$.

[55] Velásquez, Mao I. R. - "Capillary Network Model of Flow of Emulsion in Porous Media" - SPE Contest PUC-RJ 2008 - Rio de Janeiro - 2008. [56] Green, Don W. e Willhite, G. Paul - "Enhanced Oil Recovery" - SPE Textbook Series vol. 6 - 1998. 
[57] Rosa, Adalberto J.; Carvalho, Renato de S.; Xavier, José A. D. "Engenharia de Reservatórios de Petróleo" - 1a Edição - Editora Interciência - 2006.

[58] Mendez, Zuleyka Del C. - "Flow of Dilute Oil-in-Water Emulsions in Porous Media" - PhD Thesis - University of Texas at Austin - 1999.

[59] Cobos, S.; Carvalho, M. S.; Alvarado, V. - "Flow of oil-water emulsions through a constricted capillary" - International Journal of Multifase Flow (35) - pp. 507-515 - Elsevier - 2009.

[60] Guillen, V. R.; Carvalho, M. S.; Alvarado, V. - "Pore Scale and Macroscopic Displacement Mechanism in Emulsion Flooding" - Transport in Porous Media - Volume 86 - Springer - 2011.

[61] Romero, Mao I; Carvalho, M.S.; Alvarado, V. - "Experiments and network model of flow of oil-water emulsion in porous media" - Physical Review E. 00.006300 - American Physical Society - 2001

[62] Singh, K. K.; Mahajani, S. M.; Shenoy, K. T.; Ghosh, S. K. "Representative drop sizes and drop size distributions in A/O dispersions in continuous flow stirred tank" - Hydrometallurgy - vol 90 - issues 2-4 Elsevier - 2008.

[63] Hawe, Daniel E. - "Direct Approach Through Hall Plot Evaluation Improves the Accuracy of Formation Damage Calculations and Eliminates Pressure Fall-off Testing" - SPE 5989-MS - 1976.

[64] Sztukowski, Danuta W.; Yarraton, Harvey W. - "Oilfield Solids and Water-in-Oil Emulsion Stability" - Journal of Colloids and Interface Science 285 - pp.821-822 - 2005.

[65] Farias, Manoel L. R. de; Hirasaki, George; Miller, Clarence; Souza, Antônio L. S. de; Carvalho, Márcio da S. - "A Comparative Study of Emulsion Flooding and other IOR Methods for Heavy Oil" - SPE 152290 Latin American and Caribbean Petroleum Engineering Conference Cidade do México - 2012;

[66] Farias, Manoel L. R. de; Salinas, Jose Luiz - "Interfacial Tension Measurement Using Reverse Pendant Drop Method" - Internship Report \#2 - Rice University - 2011.

[67] Demarquette, Nicole R.; Kamal, Musa R. - "Comparação entre o Método da Gota Pendente e o Método da Gota Girante para Medida da 
Tensão Interfacial entre Polímeros" - Polímeros: Ciência e Tecnologia in www.scielo.br- Jul/Set - 1997.

[68] Castanier, Louis M. - "An Introduction to Computerized X-Ray Tomography for Petroleum Research" - Supri TR 66 - Stanford University Petroleum Research Institute - disponível em http://www.netl.doe.gov/kmd/cds/disk27/TR-66\%20X-ray\%20CT.pdf 1989.

[69] Campos, Elisabete F. - "Fundamentos Teóricos da Tomografia Computadorizada de Raios X" - Documento Interno CENPES/PETROBRAS - 2012.

[70] Gilliand R. E.; Coles, M. E. - "Use of CT Scanning in the Investigation of Damage to Unconsolidated Cores - Paper SPE 19408 - SPE Formation Damage Control Symposium - Lafayette - 1990.

[71] Whitjack, E.M - "Computed Tomography for Rock-Property Determination and Fluid-Flow Visualization" - SPE Formation Evaluation, December 1988 - pp. 696-704 - Society of Petroleum Engineers - 1988. [72] Feali, M. Et ali - "Qualitative and Quantitative Analysis of ThreePhase Distributions of Oil, Water and Gas in Bentheimer Sandstone Using Micro-CT Imaging - Paper SPE 151609 - SPE Latin American and Caribbean Petroleum Engineering Conference - Mexico City - 2012.

[73] Chen, H. L. et alli - "Laboratory Monitoring of Surfactant Imbibition Using Computerized Tomography" - Paper SPE 59006 - SPE International Petroleum Conference and Exhibition - México - 2000.

[74] Campos, E. F; Lopes, R. T. - "Aplicações da Tomografia Computadorizada de Raios X na Recuperação de Petróleo" - VI ENAN 2002.

[75] Ribeiro, J. L. B. - "Estudo das Interações Rocha-Fluido em Arenitos Inconsolidados Utilizando Simuladores Físicos com Tomografia Computadorizada e Microfluorescência de Raios X por Luz Síncrotron" Tese de Doutorado - Programa de Engenharia Nuclear - COPPE/UFRJ 2006.

[76] Braga Filho, Washington - "Fenômenos de transporte para engenharia" - Editora LTC - Rio de Janeiro - 2006. 
[77] Horiba Scientific - "Guidebook to Particle Analysis" - disponível em http://www.horiba.com/fileadmin/uploads/Scientific/eMag/PSA/Guidebook/ pdf/PSA_Guidebook.pdf. 


\section{Apêndices}

\subsection{Medidas das propriedades das rochas e fluidos.}

\subsubsection{Determinação da viscosidade absoluta do óleo}

A segunda amostra de petróleo morto, utilizada no programa experimental feito no CENPES, foi ensaiada no Laboratório de Reologia da PUC-Rio utilizando um reômetro Anton-Parr modelo MCR 501. A temperatura de ensaio foi $25^{\circ} \mathrm{C}$. A densidade do petróleo (0.92) corresponde a um grau API 19.5.

Os resultados obtidos indicaram um forte comportamento nãoNewtoniano para taxas de cisalhamento menores que $10 \mathrm{~s}^{-1}$. A partir dessa taxa, observa-se que a viscosidade fica praticamente constante (Figura 118).

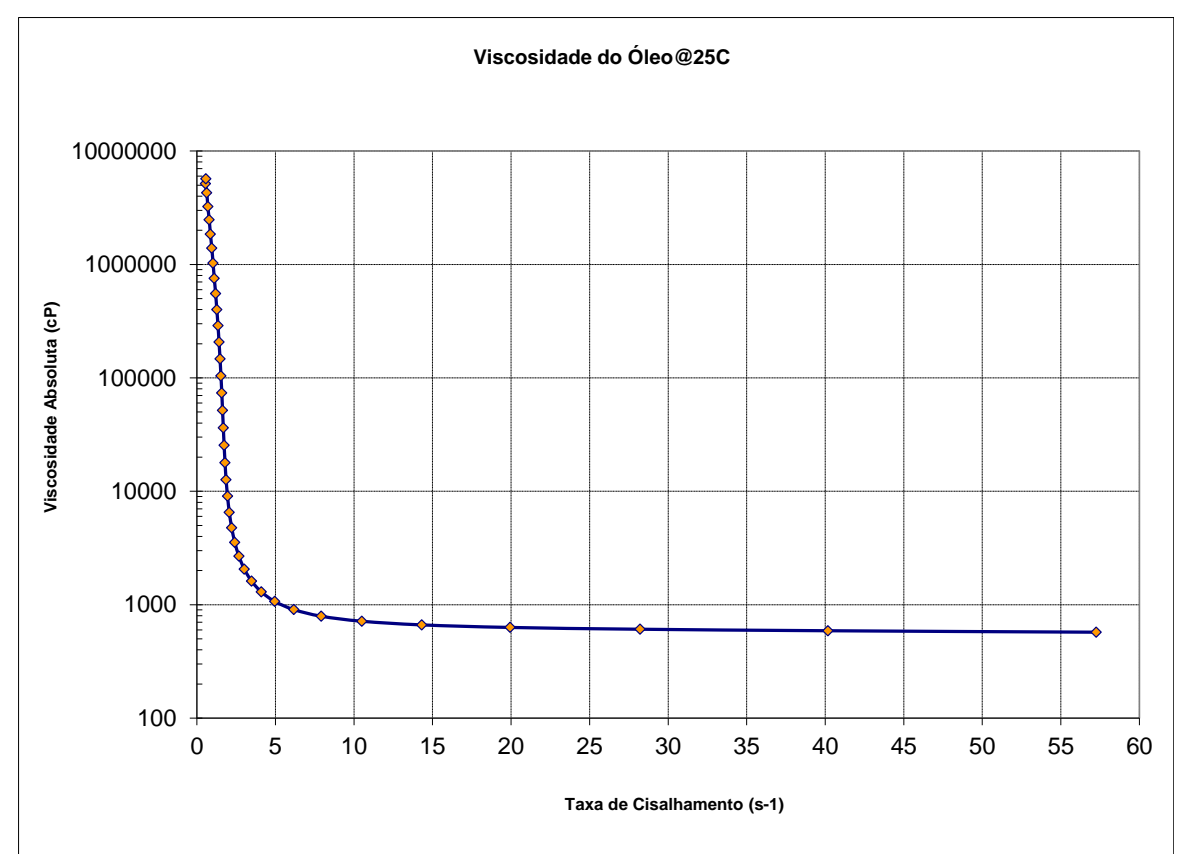

Figura 118 - Gráfico semi-log de variação da viscosidade do óleo com a taxa de cisalhamento. 
Para conseguir-se um bom ajuste, optou-se por modelar o fluido utilizando uma Lei de Potência para $\dot{\gamma}<10 \mathrm{~s}^{-1}$. Esse modelo é da forma:

$$
\tau=K \cdot(\dot{\gamma})^{n-1}
$$

Onde:

T - tensão de cisalhamento;

K - índice de consistência do fluido;

$\dot{\gamma}$ - taxa de cisalhamento;

$\mathrm{n}$ - expoente do modelo de potência.

O ajuste obtido está na Figura 119.

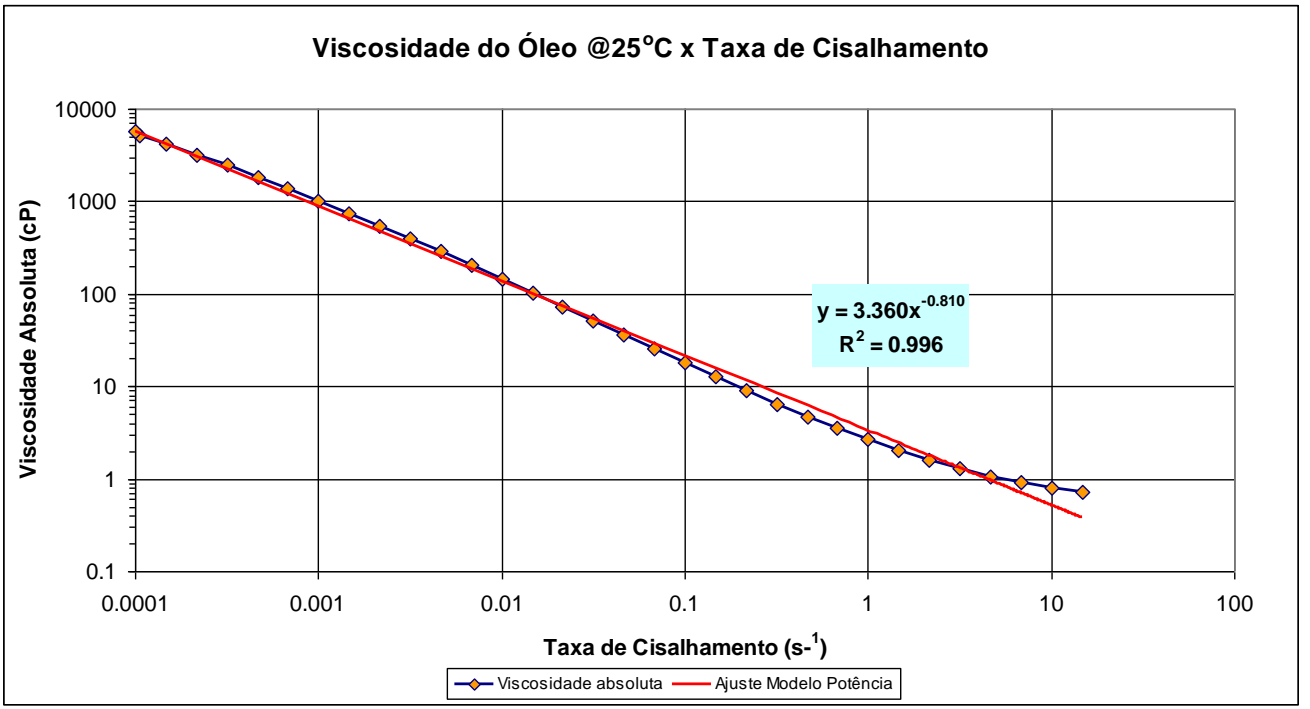

Figura 119 - Ajuste dos parâmetros do modelo Power-law para o óleo do MLL-10 (K=3.36 e $n=-$ $0.19)$.

A ordem de grandeza da viscosidade do óleo durante o fluxo pode ser calculada modelando o meio poroso como um feixe de capilares paralelos de mesmo diâmetro. No final do processo de saturação, a saturação de água se torna irredutível e a única fase móvel é o óleo. Nesse caso, a pode-se aplicar a Lei de Pouseille para o fluxo de óleo em 1 capilar: 
Lei de Pouseille:

$$
\frac{\Delta p}{L}=\frac{8 \cdot \mu_{\text {óleo }} \cdot q}{\pi \cdot r^{4}}
$$

Onde:

$\Delta \mathrm{p} / \mathrm{L}$ - gradiente de pressão médio $(\mathrm{kPa} / \mathrm{m})$;

Hóleo - viscosidade absoluta do óleo (Pa.s);

$q$ - vazão de óleo em no capilar $\left(\mathrm{m}^{3} / \mathrm{s}\right)$;

$r$ - raio médio do capilar $(m)$.

Considerando-se os seguintes valores médios para os sandpacks:

- Permeabilidade: $\mathrm{K}=6.5 \mathrm{D}=6,5 \times 10^{-12} \mathrm{~m}^{2}$;

- Vazão de injeção de óleo: $q=0,8 \mathrm{ml} / \mathrm{min}=1,33 \times 10^{-8} \mathrm{~m}^{3} / \mathrm{s}$;

- Gradiente médio de pressão: $\Delta \mathrm{p} / \mathrm{L} @ S_{\text {wirr }}=23 \mathrm{psi} / \mathrm{ft}=522 \mathrm{kPa} / \mathrm{m}$;

- Porosidade: $\varphi=37 \%$;

- Swirr $=0.10$

O raio médio dos capilares é relacionado com a permoporosidade pela equação de Carman-Kozeny:

$$
D_{p}=\sqrt{\frac{150 .(1-\emptyset)^{2} . K}{\emptyset^{3}}}=7.8 \times 10^{-5} \mathrm{~m} \therefore A_{\text {poro }} \cong 10^{-8} \mathrm{~m}^{2}
$$

A área total do sandpack aberta ao fluxo é calculada por:

$$
A_{\text {porosa,total }}=\emptyset \cdot \pi \cdot\left(1.27 \times 10^{-2}\right)^{2}=1.9 \times 10^{-4} \mathrm{~m}^{2} \cong 10^{-4} \mathrm{~m}^{2}
$$

A ordem de grandeza do número de capilares e a vazão por capilar são da ordem:

$$
n=\frac{10^{-4}}{10^{-8}}=10^{4} \text { capilares } \therefore q_{\text {poro }}=10^{-12} \mathrm{~m}^{3} / \mathrm{s}
$$

Substituindo os valores estimados em na equação de Pouseille, obtém-se: $\mu_{\text {óleo }}=10^{-2}$ Pa.s $=10^{1} \mathrm{cP}$. 
Na curva de viscosidade, taxa de cisalhamento é da ordem de 0,02 a $0,05 \mathrm{~s}^{-1}$.

O regime de fluxo ao nível dos capilares é dado pelo número de Reynolds:

$$
R e=\frac{q \cdot D \cdot \rho}{\mu \cdot A}=\frac{10^{-12} \cdot 10^{-4} \cdot 10^{3}}{10^{-2} \cdot 10^{-8}}=10^{-3} \rightarrow \text { Fluxo laminar }
$$

Onde:

q - vazão;

D - diâmetro do capilar;

$\rho$ - densidade do fluido;

$\mu$ - viscosidade;

A - área da seção transversal do poro.

\subsubsection{Caracterização das emulsões}

As emulsões foram caracterizadas no CENPES utilizando a técnica de difração de laser ("Teoria da Esfera Equivalente") com frequências calculadas em base volumétrica. Foi utilizado um analisador de tamanho de partículas Malvern Mastersize Microplus. Foram preparadas duas amostras de emulsão por abertura de filtro. Como forma de avaliar a estabilidade das emulsões produzidas, a segunda amostra de cada emulsão foi ensaiada $24 \mathrm{~h}$ depois.

A caracterização da distribuição de tamanho de gotas de uma emulsão é usualmente feita com os parâmetros D10, D50 e D90 que representam, respectivamente, o diâmetro que é maior que 10\%, 50\% e $90 \%$ das gotas. O diâmetro médio de uma distribuição qualquer de partículas é calculado por:

$$
D[p, q]=\frac{\sum d_{i}^{p} \cdot f_{i}}{\sum d_{i}^{q} \cdot f_{i}}
$$


Onde:

$D[p, q]$ - diâmetro médio da distribuição ( $p, q>0$ e $p-q=1)$;

$\mathrm{d}_{\mathrm{i}}$ - diâmetro médio da classe $\mathrm{i}$;

$f_{i}-$ frequência da classe $\mathrm{i}$.

Os valores de p,q são escolhidos de forma que a média calculada seja representativa para o fenômeno considerado [77]. Para emulsões, o valor mais comumente utilizado como a média da distribuição é a média de Sauter $\mathrm{D}[3,2]$ porque pode ser diretamente associado ao valor da área interfacial específica. Os valores são sempre calculados em base volumétrica.

A Figura 120, a Figura 121 e a Figura 122 mostram, respectivamente, a distribuição do tamanho de gotas das emulsões

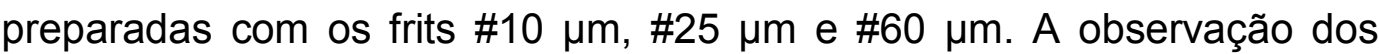
gráficos gerados a partir dos dados mostra boa concordância entre as curvas de distribuição das duas amostras ensaiadas por abertura de filtro, indicando que o processo utilizado na preparação gerou emulsões estáveis.

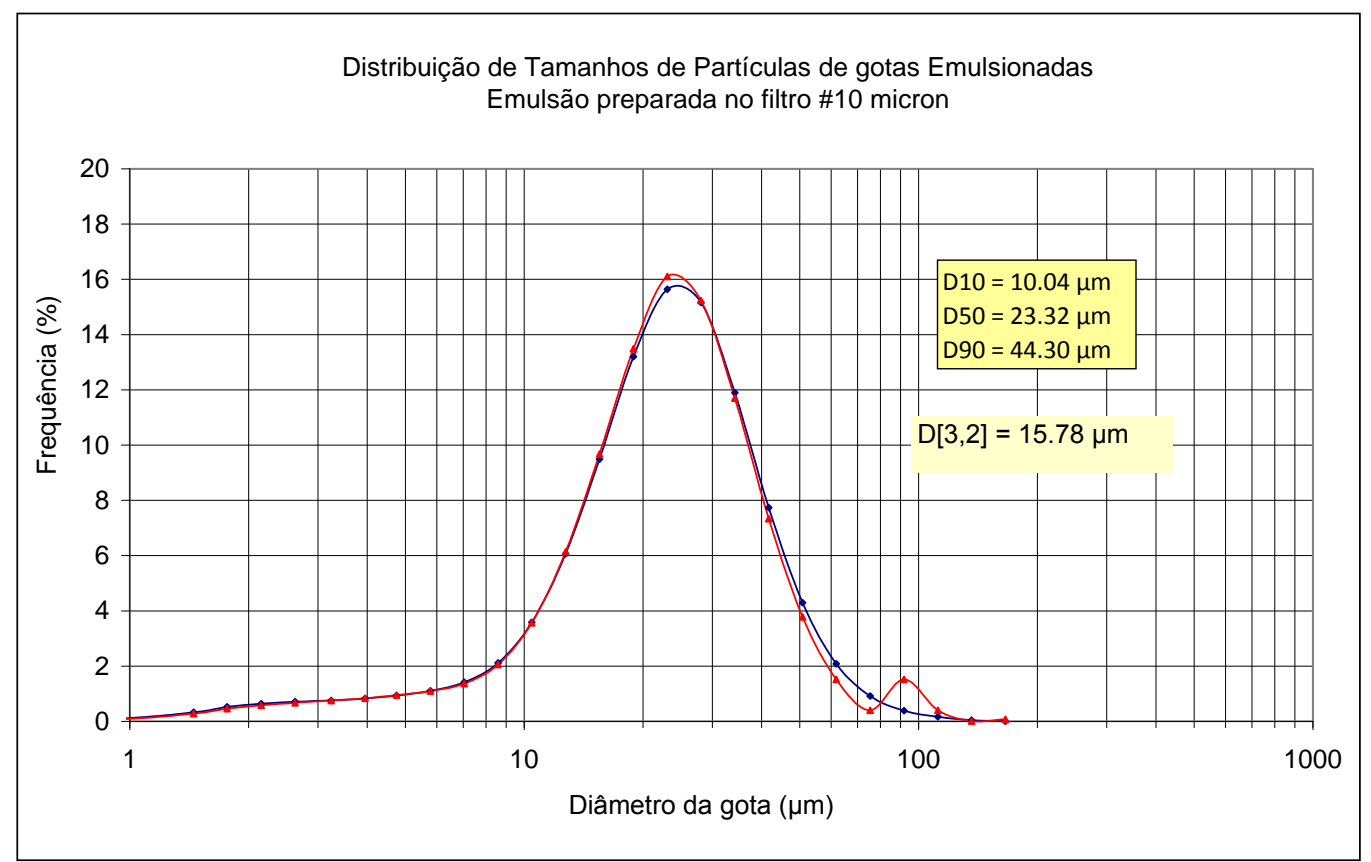

Figura 120 - Distribuição dos tamanhos de gotas da emulsão preparada no frit de abertura nominal $10 \mu \mathrm{m}$. 


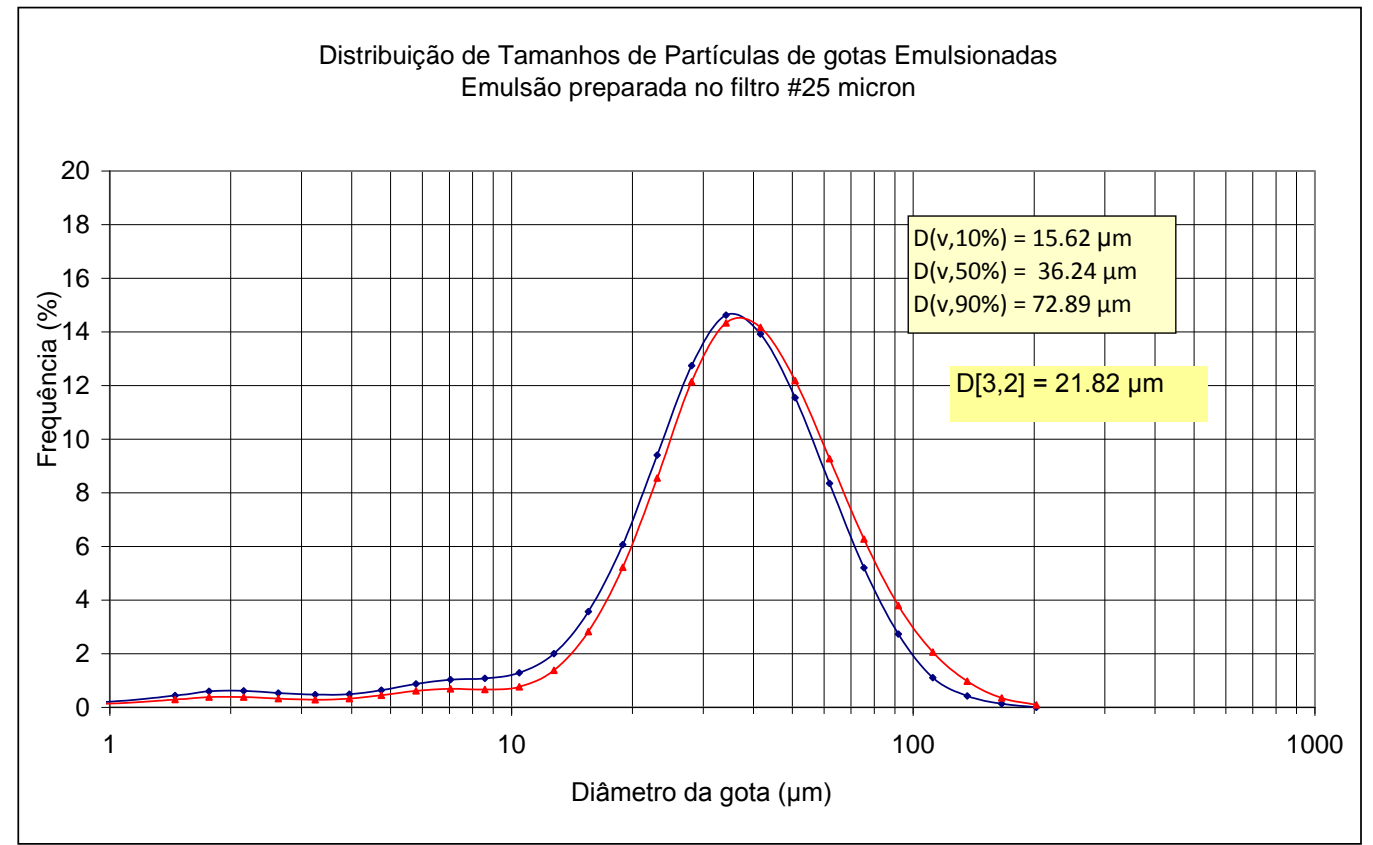

Figura 121 - Distribuição dos tamanhos de gotas da emulsão preparada no frit de abertura nominal $25 \mu \mathrm{m}$.

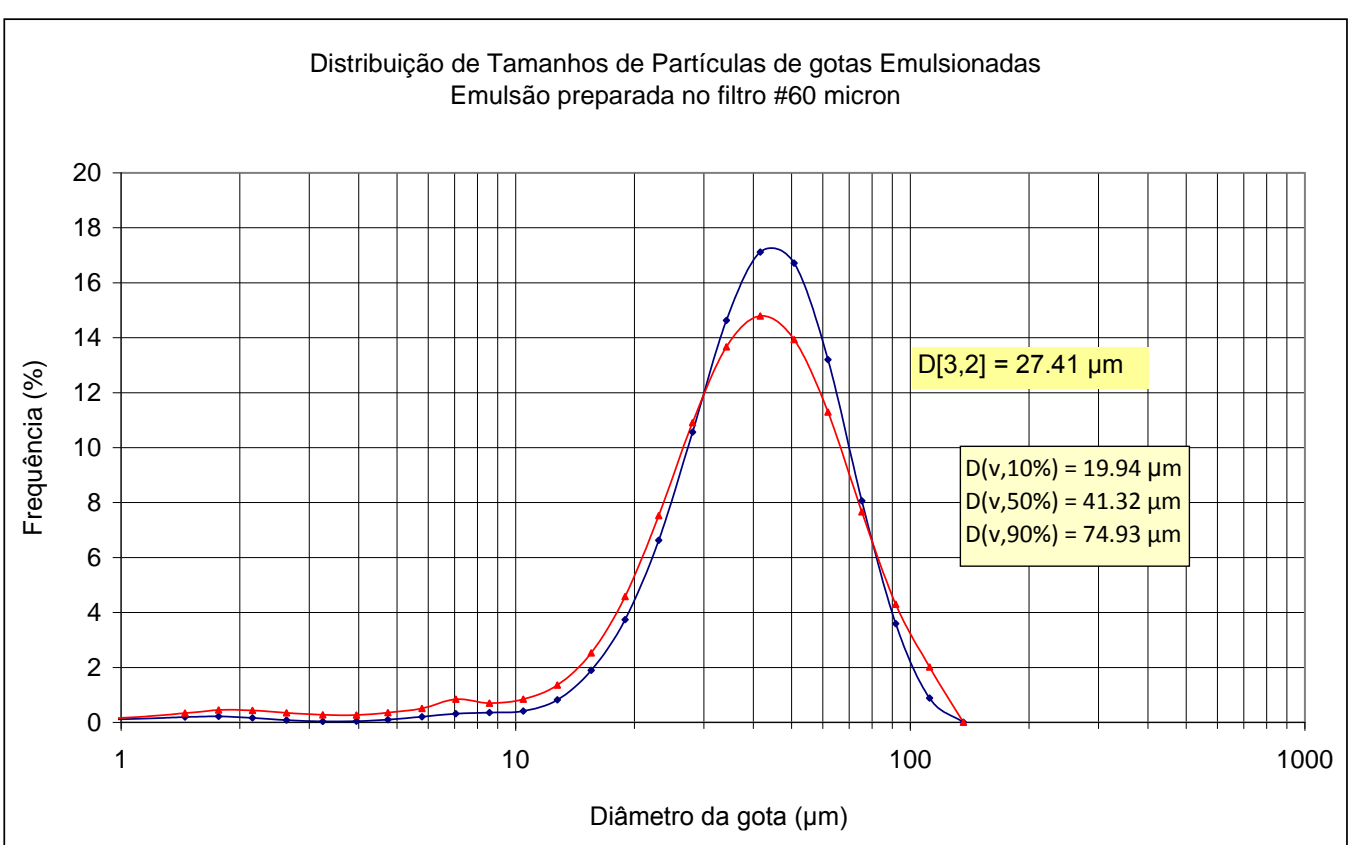

Figura 122 - Distribuição dos tamanhos de gotas da emulsão preparada no frit de abertura nominal $60 \mu \mathrm{m}$. 


\subsubsection{Medida da Tensão Interfacial}

Os valores das tensões interfaciais entre o óleo e as diferentes soluções aquosas utilizadas durante o programa experimental foram iniciados na Rice University (gota pendente) e complementados no CENPES (gota girante). Foram medidas as tensões interfaciais entre petróleo e as seguintes soluções aquosas:

a) solução de água DI @ $36.5 \mathrm{~g} / \mathrm{L}$ de $\mathrm{NaCl}$ ("água do mar sintética");

b) solução de água do mar sintética adicionada de $5 \mathrm{~mL} / \mathrm{L}$ de Steol CS$330 @ 28 \%$ ativos;

c) solução de água do mar sintética $+100 \mathrm{~g} / \mathrm{L}$ de $\mathrm{Kl}$;

As medidas, feitas no Laboratório de Fenômenos de Transporte da Rice University, utilizaram a técnica da gota pendente reversa. Esse ensaio é baseado no equilíbrio entre as forças gravitacionais e de tensão superficial aplicadas na gota mantida em equilíbrio na extremidade da agulha de teste por 60 minutos. A Figura 124 e a Figura 125 são a representação esquemática desse ensaio.

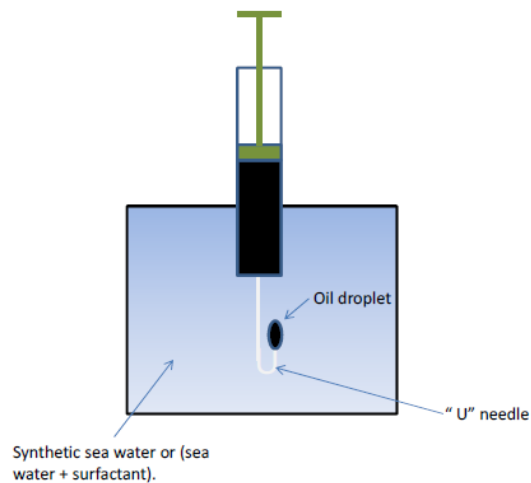

Figura 123 - Representação esquemática do ensaio da gota pendente reversa [66].

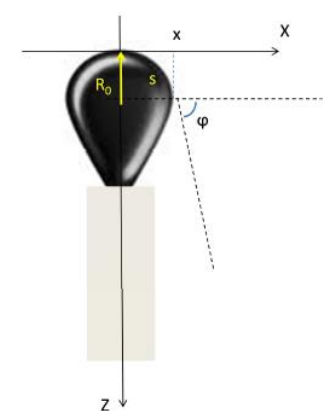

Figura 124 - Parâmetros para o cálculo da tensão interfacial [66].

Durante o ensaio, o formato da gota é constantemente alterado por conta de atividade interfacial. Por conta disso, a imagem é digitalizada 
várias vezes. Considerando a gota em equilíbrio, obtém-se a tensão interfacial por [66]:

$$
\sigma=\frac{\Delta \rho \cdot g \cdot R_{0}^{2}}{\beta}
$$

Onde:

$\sigma$ - tensão interfacial entre a solução aquosa e o óleo;

$\Delta \rho$ - diferença entre as massas específicas da solução e o óleo;

$\mathrm{R}_{0}$ - Raio da gota medido na região do topo;

$\beta$ - fator de forma;

A digitalização foi feita utilizando uma câmera JE 7362 (Javelin), enquanto a análise da imagem e posterior cálculo da tensão interfacial foram feito com o software Pendant Dropletß (Shell). A Figura 125 é uma das fotos digitalizadas durante o ensaio óleo/água do mar sintética.

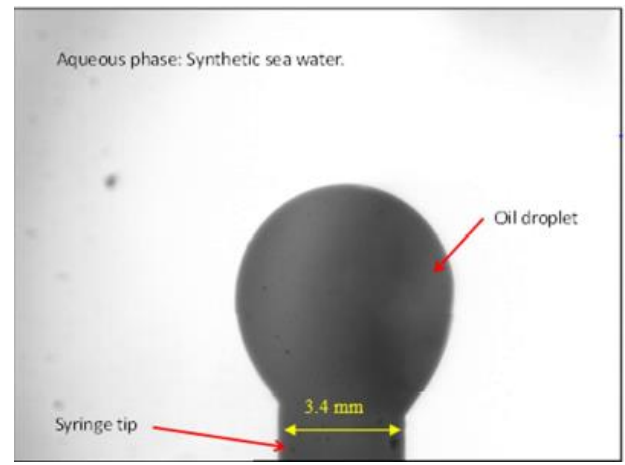

Figura 125 - Equilíbrio da gota de óleo no interior da solução aquosa [66].

As medidas de tensão interfacial foram complementadas no CENPES. Nessa etapa, utilizou-se um tensiômetro de gota girante modelo SVT 20 (Dataphysics). A Figura 126 é a representação esquemática desse ensaio. 


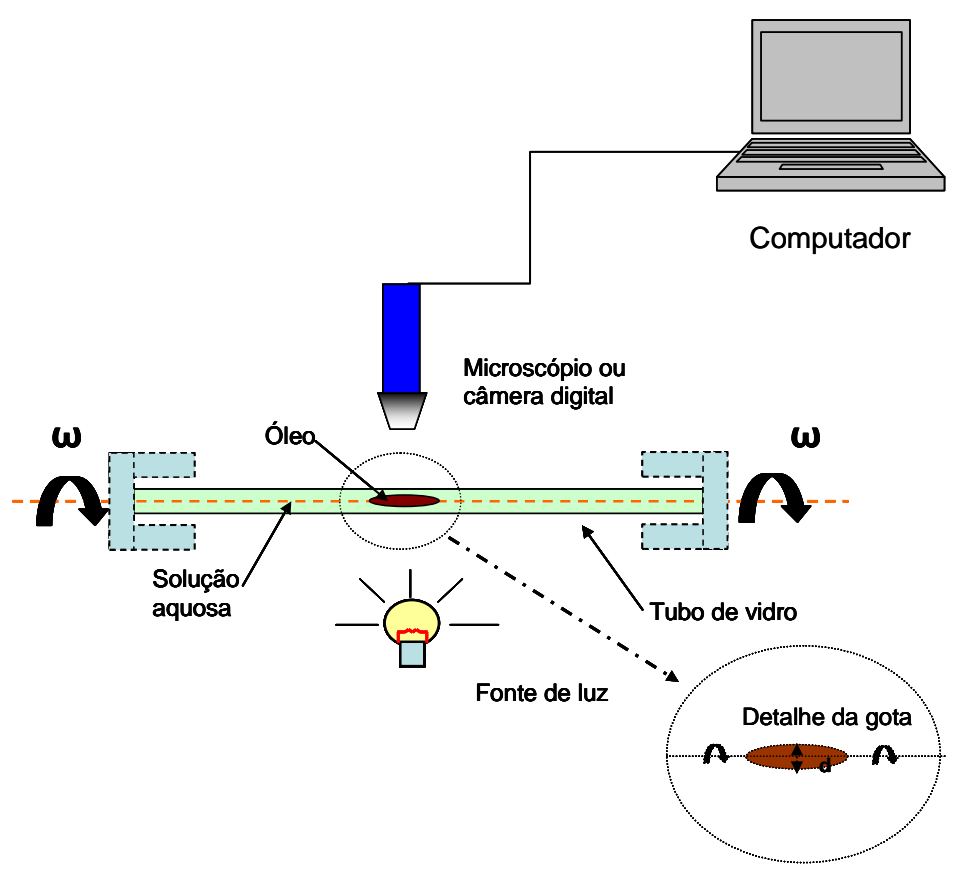

Figura 126 - Representação esquemática de um tensiômetro de gota girante.

Após a estabilização do formato da gota, a tensão interfacial é medida por:

$$
\sigma=\frac{\Delta \rho \cdot \omega^{2} \cdot d^{3}}{32}
$$

\section{Onde:}

$\sigma$ - tensão interfacial;

$\omega$ - velocidade angular do sistema;

d - diâmetro da gota.

Os resultados dos ensaios estão dispostos na Tabela 19. 
Tabela 19 - Valores experimentais da tensão interfacial entre o óleo e as soluções aquosas utilizadas durante o programa experimental.

\begin{tabular}{|l|l|c|}
\hline \multicolumn{1}{|c|}{ Solução } & Método utilizado & $\begin{array}{c}\text { Tensão interfacial } \\
\text { solução/óleo } \\
\text { (dyn/cm) }\end{array}$ \\
\hline (a) Água do mar sintética. & $\begin{array}{l}\text { Gota pendente } \\
\text { reversa }\end{array}$ & 22.85 \\
\hline $\begin{array}{l}\text { (b) Água do mar sintética }+5 \mathrm{~mL} / \mathrm{L} \text { Steol } \\
\text { CS-330. }\end{array}$ & $\begin{array}{l}\text { Gota pendente } \\
\text { reversa }\end{array}$ & 0.67 \\
\hline $\begin{array}{l}\text { (c) Água do mar sintética } \\
\text { (d) Água do mar sintética }+5 \mathrm{~mL} / \mathrm{L} \mathrm{Steol} \\
\text { CS-330 }\end{array}$ & Gota girante & 21.54 \\
\hline $\begin{array}{l}\text { (e) Água do mar sintética }+100 \mathrm{~g} / \mathrm{L} \mathrm{KI} . \\
\text { (f) Água do mar sintética }+100 \mathrm{~g} / \mathrm{L} \mathrm{KI}+5 \\
\text { mL/L de CS-330. }\end{array}$ & Gota girante & 0.60 \\
\hline
\end{tabular}

A Figura 127 mostra o aspecto da gota no ensaio óleo/solução(f) após $30 \mathrm{~min}$.

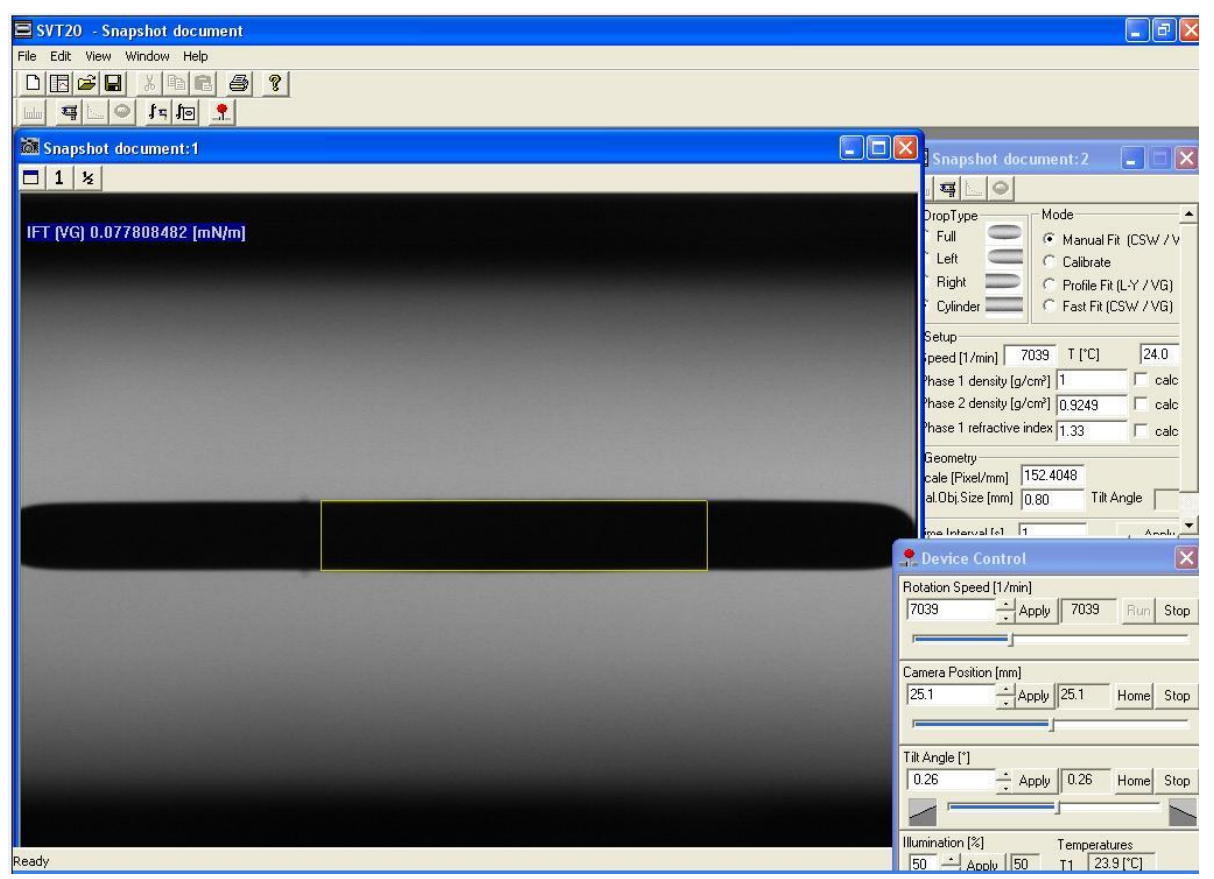

Figura 127 - Foto ao microscópio do ensaio de medida da tensão interfacial óleo/solução (f). 


\subsubsection{Medidas da Permeabilidade e Porosidade}

As permeabilidades das amostras foram medidas após sua saturação com água do mar sintética, utilizando o mesmo fluido. Os plugs de rocha foram confinados a 1000 psi em um core holder. A viscosidade e a densidade da água de formação sintética foram estimadas, respectivamente, em 1.06 cP e $1.072 @ 25^{\circ} \mathrm{C}$ com software AquaProp (desenvolvimento CENPES). Todas as amostras foram pesadas antes $\mathrm{e}$ depois da sua saturação com água para cálculo do seu volume poroso por:

$$
\varnothing=\frac{m_{\text {sandp }, \text { sat }}-m_{\text {sandp }, \text { seco }}}{\left(1.072 * V_{\text {sandp }}\right)}
$$

Onde:

$\mathrm{m}_{\text {sandp,seco }}$ - massa do sandpack saturado com $\mathrm{CO}_{2}$;

$m_{\text {sandp, sat }}$ - massa do sandpack saturado com água de formação sintética;

$\mathrm{V}_{\text {sandp }}$ - volume do sandpack.

A Figura 128 é a curva de vazão x diferencial de pressão para um plug de arenito Berea. 


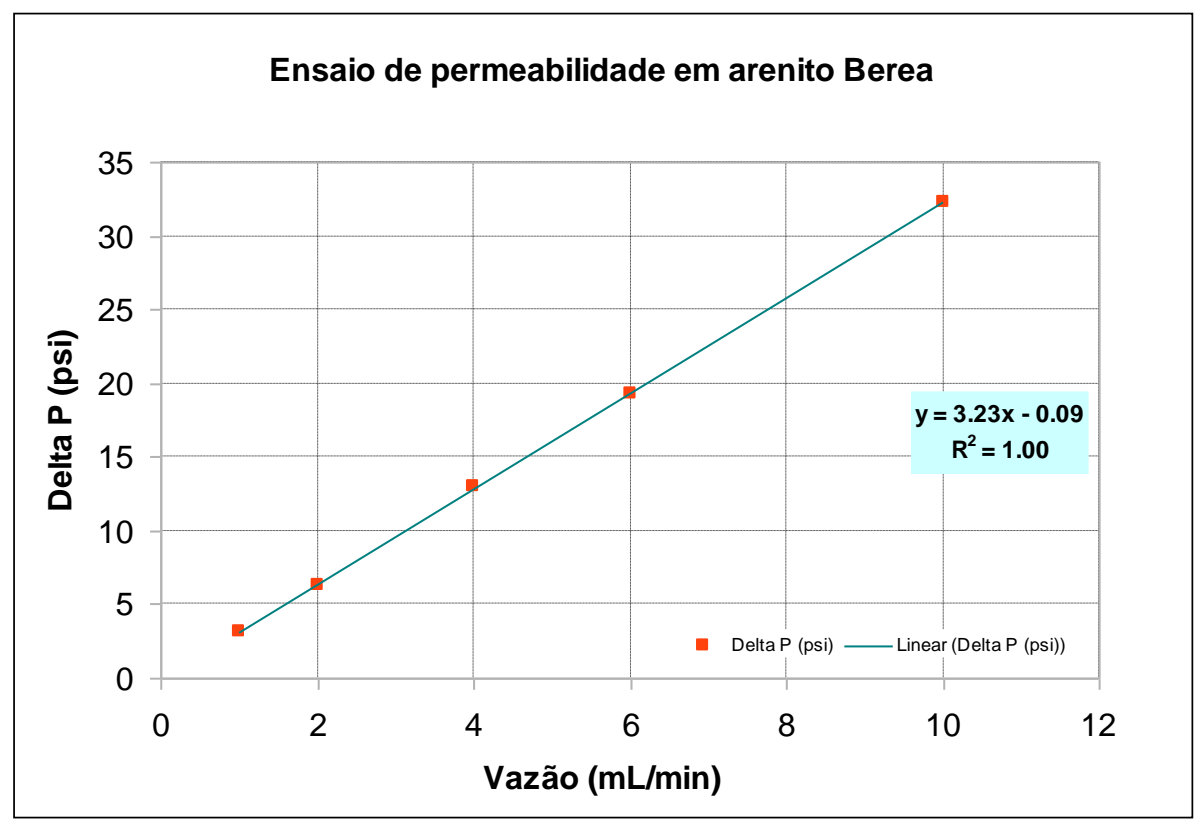

Figura 128 - Curva vazão x diferencial de pressão para uma amostra de arenito Berea.

Os valores médios calculados para os sandpacks e os plugs de rochas ensaiadas estão na Tabela 20.

Tabela 20 - Petrofísica básica para os meios porosos utilizados no programa experimental.

\begin{tabular}{|l|c|c|}
\hline \multicolumn{1}{|c|}{ Tipo da amostra } & $\begin{array}{c}\text { Permeabilidade média ao } \\
\text { líquido }(\mathrm{mD})\end{array}$ & $\begin{array}{c}\text { Porosidade média } \\
(\%)\end{array}$ \\
\hline $\begin{array}{l}\text { Sandpacks de areia fina de } \\
\text { sílica }\end{array}$ & 6300 & 39.25 \\
\hline Arenito Berea & 57.8 & 17.88 \\
\hline Arenito Bentheimer & 2300 & 23.23 \\
\hline Arenito Castlegate (ensaio 3D) & 440 & 22.35 \\
\hline
\end{tabular}




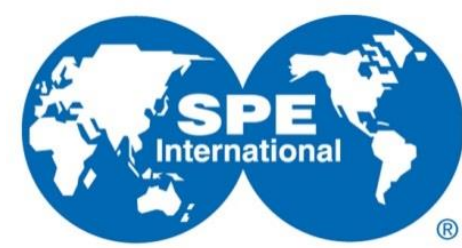

\title{
8.2. Paper SPE 152290
}

\section{A Comparative Study of Emulsion Flooding and other IOR Methods for Heavy Oil}

Manoel Leopoldino Rocha de Farias, Antônio Luiz Serra de Souza, SPE, Petrobras; Márcio da Silveira Carvalho, PUC-Rio, George Hirasaki, Clarence Miller, SPE, Rice University.

\author{
Copyright 2012, Society of Petroleum Engineers \\ This paper was prepared for presentation at the SPE Latin American and Caribbean Petroleum Engineering Conference held in Mexico City, \\ Mexico, 16-18 April 2012. \\ This paper was selected for presentation by an SPE program committee following review of information contained in an abstract submitted by \\ the author(s). Contents of the paper have not been reviewed by the Society of Petroleum Engineers and are subject to correction by the author(s). The \\ material does not necessarily reflect any position of the Society of Petroleum Engineers, its officers, or members. Electronic reproduction, distribution, or \\ storage of any part of this paper without the written consent of the Society of Petroleum Engineers is prohibited. Permission to reproduce in print is \\ restricted to an abstract of not more than 300 words; illustrations may not be copied. The abstract must contain conspicuous acknowledgment of SPE \\ copyright.
}

\begin{abstract}
Flooding experiments in sandpacks were performed to investigate the potential use of diluted oilwater macro-emulsions as an EOR agent for viscous oils. The emulsion dispersed phase was the oil in place in the sandpack. Oil recovery factors obtained with emulsion flooding were compared to synthetic sea water injection and surfactant solution injection. Results have indicated a reduction in cumulative water-oil ratio and an increase in oil production after a bank of emulsion was injected. At the appropriate conditions, emulsion oil drops block pores already swept by water flooding, changing the residual oil saturation and mobility of the water phase, and therefore mobilizing oil. The increased volume of oil produced was a function of the drop size of the emulsion. Produced water can be considered as a diluted oil-in-water emulsion. The results presented here suggest the possibility of using an effluent as a resource, after appropriate treatment, in IOR projects.
\end{abstract}

\section{Introduction}

A Waterflood typically displaces from $50 \%$ to $80 \%$ of contacted oil. Taking into account the volumetric reservoir sweep efficiency, the average oil recovery is $30 \%$ for conventional oils [1]. For heavy oilfields, the unfavorable mobility ratio reduces the range to even lower values. A possible solution is the addition of a thickener to the water phase, such as polymer or any other additives [1], [2]. This does not mobilize residual oil phase.

On the other hand, emulsion flooding may offer recovery mechanisms based on capillarydriven mobility control that lead to both a reduction in residual oil saturation as well as macroscopic sweep improvement. This, in principle, could be combined with surfactants to further increase recovery, as discussed by Guillen et al. [3]. Emulsions have also been recognized to play an important role in improved oil recovery in steam and ASP projects [4]. Oil-water emulsion can be injected directly into the reservoir. McAuliffe has performed experiments using Berea, Alhambra and Boise sandstones plugs to evaluate the potential use of emulsions as a viscous fingering control method in heavy oilfields [5]. The oil concentrations in these emulsions have varied from $0.5 \%$ to $3 \%(1 \mu \mathrm{m}<$ oil droplet size $<12 \mu \mathrm{m})$. His main conclusions were: a) for the same permeability level, small droplets caused less impairment than large ones; b) Small oil droplets were predominant in the effluent; c) the permeability reduction caused by emulsion was 
irreversible even after injection of several pore volumes of distilled water. McAuliffe's results motivated an emulsion injection project at Midway-Sunset Oilfield in USA [6]. It was injected $33,000 \mathrm{bbl}$ of oil-in-water emulsion (oil concentration $=14 \%$ ). The results were monitored through radioactive tracer injection and produced water salinity analysis. These analyses indicated an oil mobilization from unswept reservoir regions, producing an estimated additional oil of 55,000 bbl. Despite the good results, the pilot wasn't expanded.

The full understanding and design of improved oil recovery processes based on emulsion flooding relies on better understanding the flow of emulsions through porous media and the associated displacement mechanisms. Modeling the flow of emulsion in porous media is extremely challenging. Three traditional models have been used to describe the flow of emulsions in porous media: a) bulk viscosity [7]; b) droplet retardation model [8], and c) filtration model [9], [10]. The bulk viscosity model considers the emulsion as a single-phase fluid with a non-Newtonian behavior. This is the same approach used to model the flow of polymeric solutions in porous media. A material function is introduced to correlate the imposed shear rate with viscosity. It is adequate to describe only the flow of highly concentrated emulsions with small average oil droplet/average pore throat ratio. It is not able to describe the capillary dependence of mobility control, discussed by Romero et al. [11]. The droplet retardation model introduces one term to consider the flow restriction experienced by an oil droplet while it passes through a pore throat. The increased flow resistance is modeled as a local permeability reduction. The retardation imposes a time delay between 1 pore volume injected and the emulsion breakthrough. The main limitation of this model is that it predicts that porous media permeability returns to its original level if clean water is injected after emulsion. Experimental results have shown the opposite: even after several pore volumes injected it is impossible to remove the impairment caused by emulsion flooding. The filtration model is recognized as the most adequate continuous model to describe the flow of dilute emulsions in porous media. The impairment of porous media is due to oil droplets capture by pore throats where two mechanisms are present: a) pore blockage (size exclusion) and b) droplet retention caused by interactions between oil droplets and pore walls [9], [10]. These mechanisms are correlated. For example, if some droplet retention occurs, there is a pore areal reduction that can cause a future pore blockage event. Both processes cause irreversible local permeability reduction. The global effect is considered by the introduction of a filtration coefficient. However, filtration model does not describe an important aspect of emulsion flow in porous media: the permeability reduction caused by the oil drops is more pronounced at smaller differential pressure or low capillary number. Moreover, the parameters associated with the model have to be obtained by macroscopic flow measurements and new measurements would be necessary for each different porous medium. Romero et al. [12] proposed a capillary network model to seek macroscopic flow description that is based on the physics of emulsion flow at the pore scale. The oil droplets flow through each pore throat is more complex than the transport of solid particles. Solid particle are captured in a pore throat mainly by a size exclusion mechanism. Oil droplets can deform and cross pore throats smaller than their sizes. The mobility change is the result of competition between viscous and capillary forces. This balance is better represented by the capillary number $\left(\mathrm{N}_{\mathrm{c}}\right)$ given by:

$$
N_{c}=\frac{\mu . v}{\sigma},
$$

Where $\mu$ is the viscosity of the continuous phase, $v$ is the Darcy velocity, and $\sigma$ is the interfacial tension. The experiments reported by Cobos et al. [13] on the flow of emulsions through a single cylindrical microcapillary with a throat show that the effect of the dispersed phase diameter on the flow behavior is a strong function of the capillary number when the drops are larger than the constriction diameter. If the capillary number is above a critical value, the deformation of the drop as it passes through the constriction does not change the pressure gradient of the flow. This indicates that the desired mobility control can be achieved at a certain distance from the injection well, since the pressure gradient in radial flow falls as the fluid moves away from the source (well).

Guillen et al. [3] tested emulsion injection following water flooding in order to lower the mobility of the water phase, change the pore level and macroscopic flow path, and consequently increase the oil recovery factor, as sketched in Fig.1. The results show that emulsion injection can increase the efficiency of immiscible water-oil displacement. Residual oil was mobilized after the injection of an emulsion slug. These experiments were carried with synthetic oils and using high viscosity oil as the dispersed phase of the emulsion to maximize the mobility control effect. In 
practical applications, oil different than the oil in place will not be available and the emulsion dispersed phase should be the oil present in the reservoir. In this work, we study emulsion injection using the crude oil that initially saturates the sandpack as the dispersed phase.

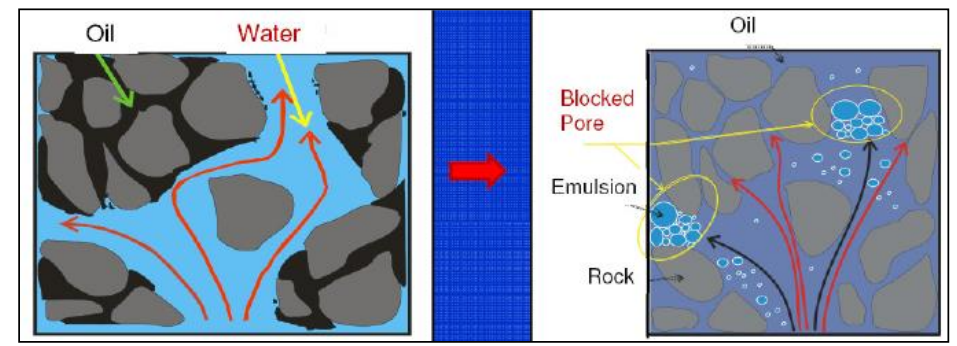

Figure 1: Reservoir Conformance Improvement induced by emulsion injection [12].

\section{Materials and Experimental Procedure}

Synthetic sea and formation water were prepared as a $\mathrm{NaCl}$ solution in DI water with concentrations of $36.5 \mathrm{~g} / \mathrm{l}$ and $100 \mathrm{~g} / \mathrm{l}$, respectively. The oil used to saturate the porous media and to prepare the emulsion was a Brazilian Crude oil from Campos Basin $\left(22^{0}\right.$ API $\left./ \mu_{\mathrm{o}}=30 \mathrm{cP}\right)$. The surfactant used to stabilize the emulsion was Steol CS-330 @ 28\% actives (Stepan Co.). Surfactant solution was prepared adding $5 \mathrm{~mL}$ of CS-330 in $1 \mathrm{~L}$ of synthetic sea water. This surfactant was chosen because it is a very effective emulsifier but it does not produce ultralow IFT.

Different $1 \mathrm{ft}$ long -1 in diameter sandpacks were prepared for this study. Silica sand (Ottawa F110, U.S. Silica Co.) was used to create the unconsolidated porous media. A glass tube was slowly filled with sand, which was compacted for approximately 20 minutes using a rubber hammer. After the glass tube was full, $\mathrm{CO}_{2}$ was forced through the porous media at low pressure for approximately 20 to 30 minutes to remove air. $\mathrm{CO}_{2}$ was then displaced by the formation water, which was later displaced by the oil, until irreducible water saturation was achieved (approximately 10\%). These steps are illustrated in Fig.2.

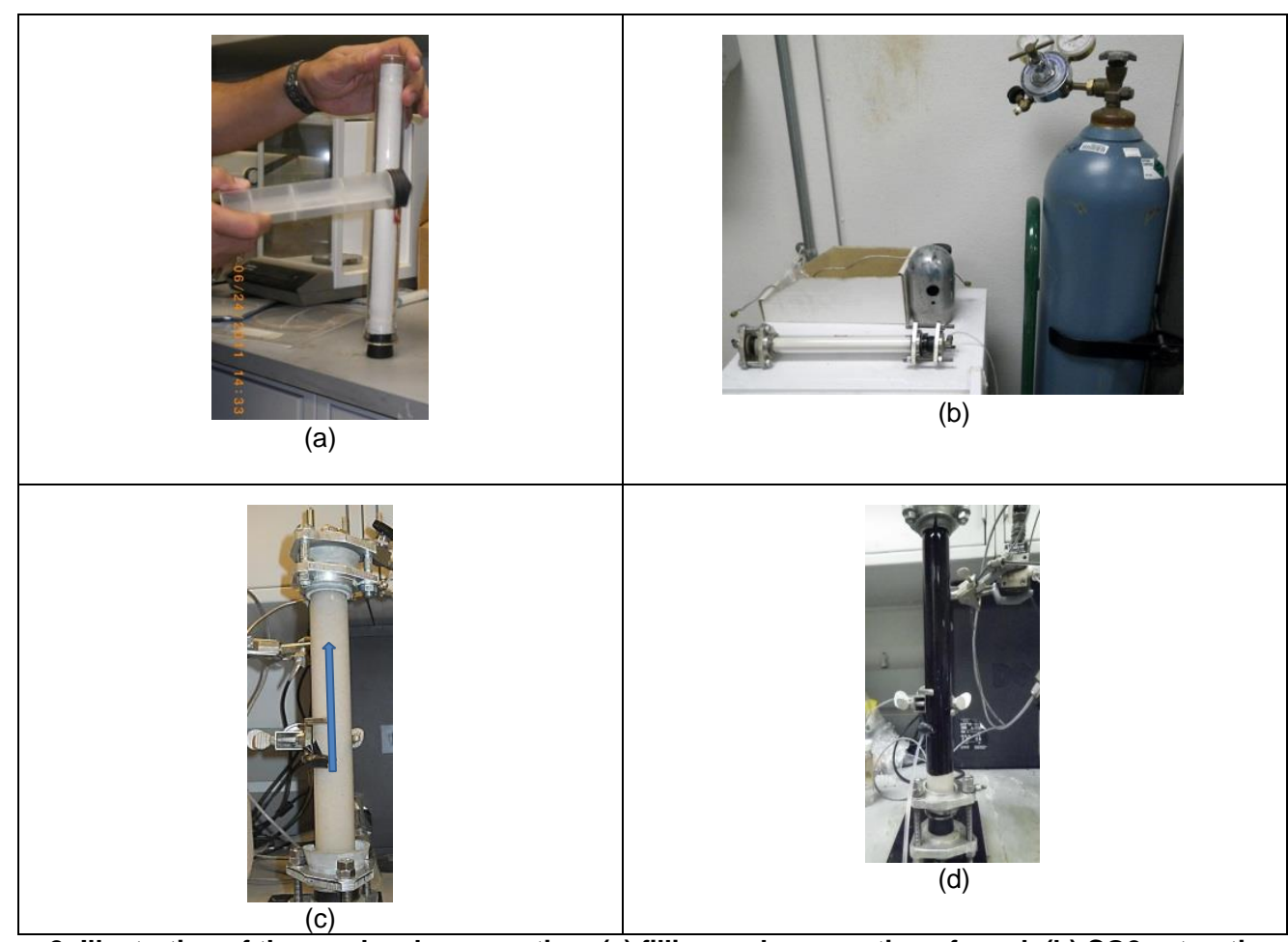

Figure 2: Illustration of the sandpack preparation: (a) filling and compaction of sand; (b) CO2 saturation: (c) Formation water displacing CO2; (d) Oil saturation.

The sandpack properties obtained after this procedure are presented in Table 1. 
Table 1: Sandpack parameters

\begin{tabular}{cc}
\hline Parameter & Values \\
\hline Permeability (D) & $6.0-9.0$ \\
Porosity (\%) & $37-40$ \\
Initial Oil Saturation (\%) & $88-91$ \\
\hline Initial Water Saturation (\%) & $12.0-9.0$ \\
\hline
\end{tabular}

An isocratic pump (Series III, Scientific Systems Inc.) was used to force the different liquids through the porous media. A pressure transducer (DP15-44) with the appropriate acquisition card board (UPC 2100 by Validyne) was used to monitor the injection pressure during the experiments. The oil-water emulsion was formed in-line, just upstream of the sandpack, by flowing water phase (surfactant solution) and oil through a filter with controlled mesh, as sketched in Fig.3. Different mesh sizes were used to obtain emulsions with different drop size distribution. It is assumed that the maximum oil drop size is equal to the mesh of the filter used $(25,60$ and $90 \mu \mathrm{m})$.

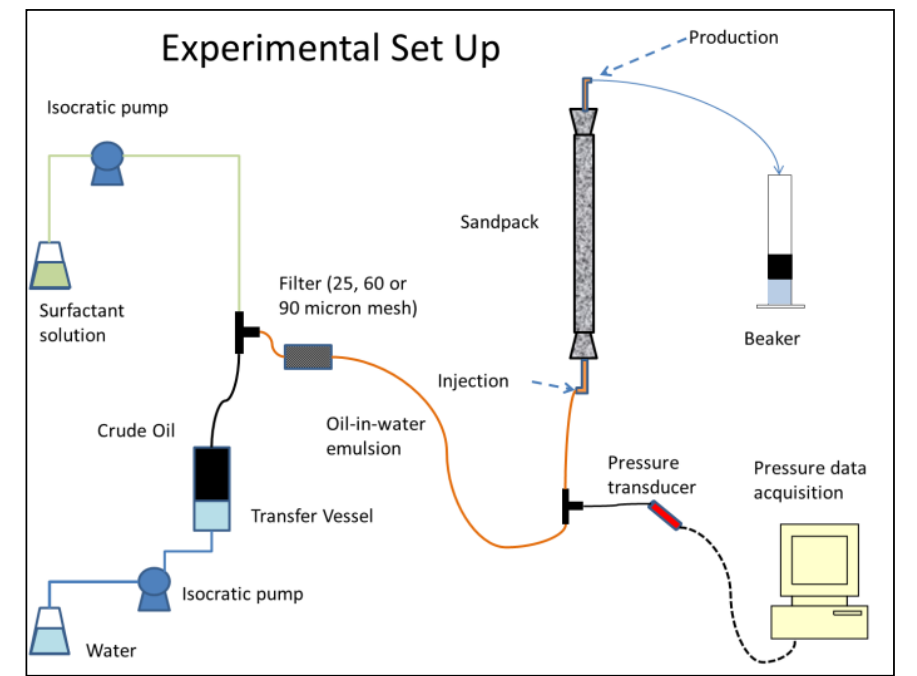

Figure 3: Schematic representation of emulsion formation and injection.

Experiments were performed at constant injection rates $\left(\mathrm{q}_{\mathrm{inj}}=0.30 \mathrm{ml} / \mathrm{min}\right)$ that corresponds to a Darcy velocity of $0.015 \mathrm{~cm} / \mathrm{min}(0.7 \mathrm{ft} /$ day). The injection of liquids was limited to 3 pore volumes. Different injection strategies were tested: a) only synthetic sea water; b) an initial synthetic sea water bank followed by a surfactant solution bank; and c) an initial synthetic water bank followed by an emulsion bank. After each surfactant or emulsion injection, $1 \mathrm{PV}$ of synthetic sea water was injected to investigate if the induced porous media impairment by emulsion was reversible. During the experiments, liquid production was measured using a graduate beaker. The oil content in the emulsions was kept high (3.3\%) to maximize its effect.

Experiments were performed to determine the final oil recovery factor and cumulative wateroil ratio using the different injection strategies, the effect of each individual slug size and the effect of oil drop size, in the case of emulsion injection. Two experiments were performed as base cases for comparison. They corresponded to 3 pore volumes of sea water injection and surfactant solution, respectively.

\section{Results}

Table 2 presents the parameters of each experiment with the final recovery factor and cumulative water-oil ratio. The average pore throat of each sandpack was estimated using Carman-Kozeny equation. In this table, emulsion bank with maximum oil droplet size equal $0 \mu \mathrm{m}$ corresponds to the surfactant solution, which was the continuous phase of the emulsion.

Experiments 1 and 2 are base cases used for comparison. 
Table 2 - Experiments performed and results

\begin{tabular}{|c|c|c|c|c|c|c|c|c|}
\hline Experiment & $\begin{array}{c}\text { Initial } \\
\text { Sea } \\
\text { water } \\
\text { bank } \\
\text { size } \\
(\mathrm{PV}) \\
\end{array}$ & $\begin{array}{c}\text { Emulsion } \\
\text { bank size } \\
\text { (PV) }\end{array}$ & $\begin{array}{c}\text { Final } \\
\text { Sea } \\
\text { water } \\
\text { bank } \\
\text { size } \\
(\mathrm{PV}) \\
\end{array}$ & $\begin{array}{c}\text { Dmax oil } \\
\text { droplets/Dpore } \\
\text { (CK equation) }\end{array}$ & $\begin{array}{c}\text { Maximum } \\
\text { oil } \\
\text { droplets } \\
\text { size }(\mu \mathrm{m})\end{array}$ & $\begin{array}{c}\text { Final Oil } \\
\text { Recovery } \\
\text { Factor } \\
(\%)\end{array}$ & $\begin{array}{c}\text { Final } \\
\text { Cumulative } \\
\text { Water-Oil } \\
\text { Ratio }\end{array}$ & Remarks \\
\hline 1 & 3 & 0 & 0 & 0.00 & 0 & 49.1 & 5.42 & $\begin{array}{c}3 \mathrm{PV} \\
\text { Synthetic } \\
\text { sea water. }\end{array}$ \\
\hline 2 & 0 & 3 & 0 & 0.00 & 0 & 55.3 & 5.20 & $\begin{array}{c}\text { Surfactant } \\
\text { solution }\end{array}$ \\
\hline 3 & 1.0 & 1.0 & 1.0 & 0.84 & 60 & 60.9 & 5.47 & \\
\hline 4 & 1.0 & 1.0 & 1.0 & 0.53 & 25 & 57.5 & 4.76 & \\
\hline 5 & 0.5 & 1.5 & 1.0 & 1.26 & 90 & 55.6 & 4.60 & \\
\hline 6 & 0.5 & 1.5 & 1.0 & 0.41 & 25 & 65.2 & 4.10 & \\
\hline 7 & 0.5 & 1.5 & 1.0 & 0.80 & 60 & 69.9 & 4.00 & \\
\hline 8 & 0.5 & 1.5 & 1.0 & 0.00 & 0 & 65.6 & 4.14 & $\begin{array}{c}\text { Surfactant } \\
\text { solution }\end{array}$ \\
\hline
\end{tabular}

The injection of an emulsion bank always improved the oil recovery, even comparing with a full surfactant solution flooding, which yielded a final recovery factor of 55.3\%. The alternating injection of $1 \mathrm{PV}$ of sea water/emulsion/sea water raised the oil recovery factors. The recovery factor increases with the drop size, reaching approximately $61 \%$ with drop size equal to $60 \mu \mathrm{m}$. The use of larger emulsion banks (1.5 PV instead of $1 \mathrm{PV})$ also increases the recovery factor, which was approximately $70 \%$ for the case of emulsion with $60 \mu \mathrm{m}$ drops. It is interesting to notice that emulsion with very large drops $(90 \mu \mathrm{m})$ did not yield the highest recovery factor. This phenomenon will be discussed later.

It is important to notice that the effect of emulsion injection on improving the efficiency of oil displacement was always stronger than the surfactant solution. The residual oil saturation is reduced not only by the surfactant but also by the oil drops changing the pore level flow path, as discussed by Guillen et al. [3].

The fluid productions during the 3rd pore volume injected (synthetic sea water) had a strong presence of a yellowish aqueous phase (oil-in-water emulsion). This phase was observed both during surfactant solution and emulsion injection experiments, but its coloration was more intense in emulsion experiments. Using an UV fluorescence oil-in-water analyzer (TD-500 D by Turner Designs), it was possible to measure an oil content varying between 1 and $1.5 \%$.

Figures 5 and 6 show the evolution of the oil recovery factor and injection pressure for experiments 1 ( $3 \mathrm{PV}$ of sea water), 2 (3 PV of surfactant solution), 3 (1 PV sea water $+1 \mathrm{PV}$ of emulsion with $60 \mu \mathrm{m}$ drops $+1 \mathrm{PV}$ sea water) and $4(1 \mathrm{PV}$ sea water $+1 \mathrm{PV}$ of emulsion with 25 $\mu \mathrm{m}$ drops $+1 \mathrm{PV}$ sea water). The increase in oil recovery factor after the emulsion slug is injected is clear in the plot. The effect is stronger with the large drops, as expected. 


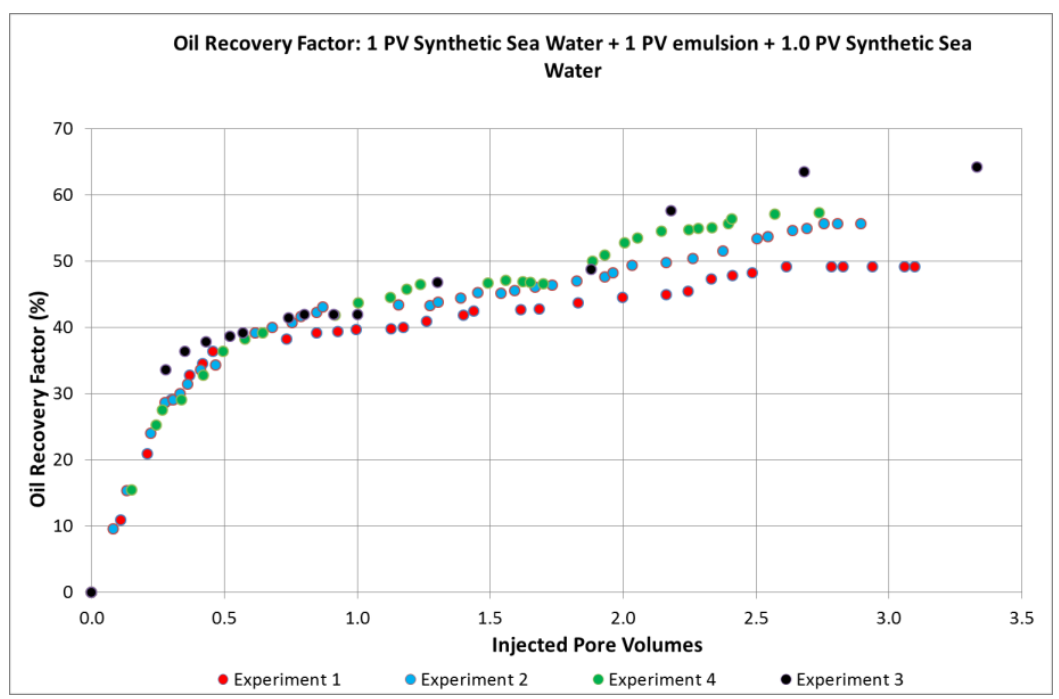

Figure 5 - Oil recovery factor vs cumulative injection - $1 \mathrm{PV}$ sea water + $1 \mathrm{PV}$ emulsion + $1 \mathrm{PV}$ sea water experiments.

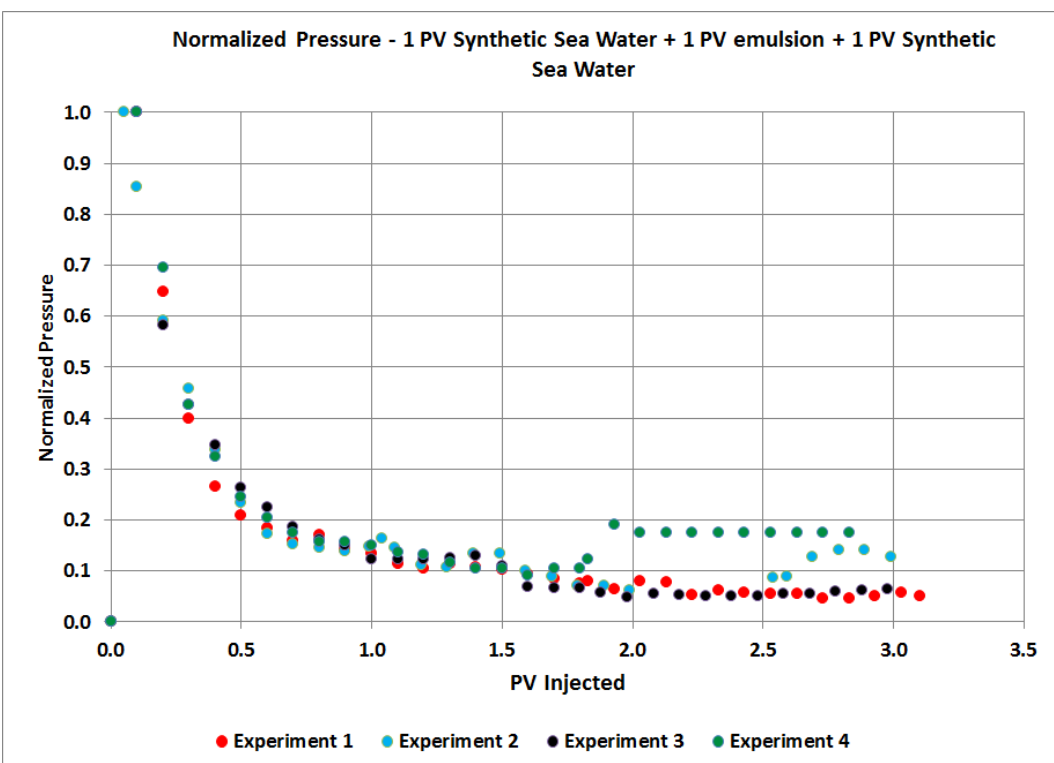

Figure 6 - Normalized Pressure vs cumulative injection - 1 PV sea water + 1 PV emulsion + 1 PV sea water experiments.

The evolution of the oil recovery factor and inlet pressure for experiments $1,4,5,6$ and 8 are presented in Figs.7 and 8. In these experiments the second slug had a volume of 1.5 pore volumes, instead of 1 pore volume, as the experiments shown in Fig.5. Again, the increase of oil recovery after emulsion injection is clear. 


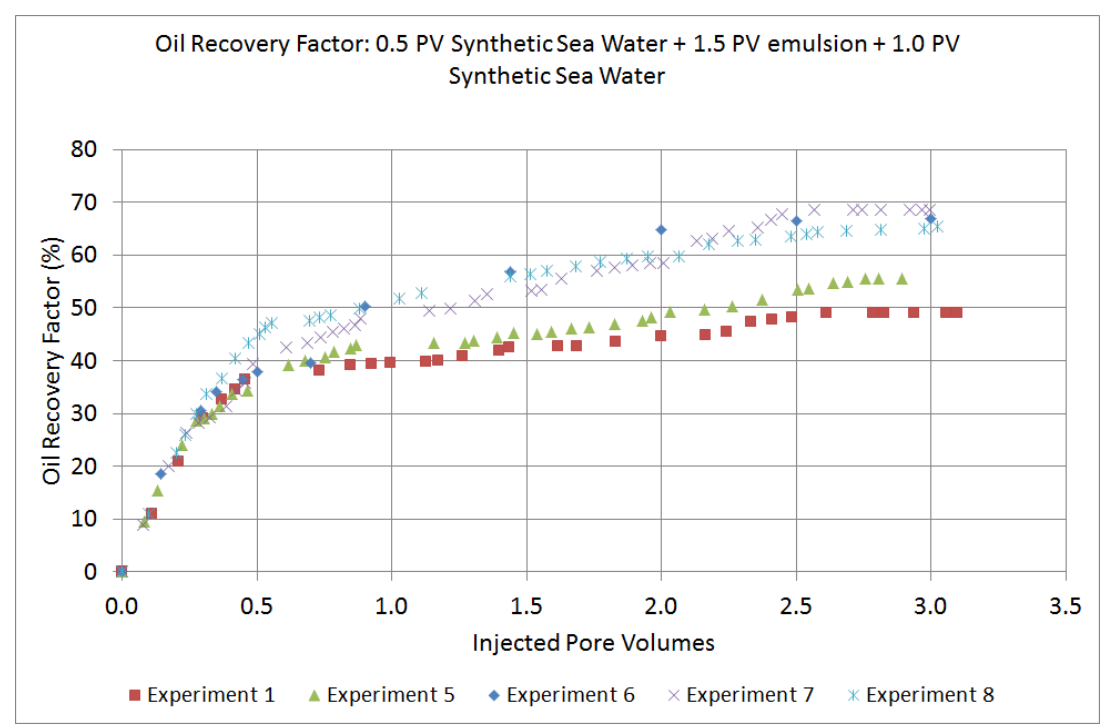

Figure 7 - Oil recovery factor vs cumulative injection -0.5 PV sea water +1.5 PV emulsion + 1 PV sea water experiments

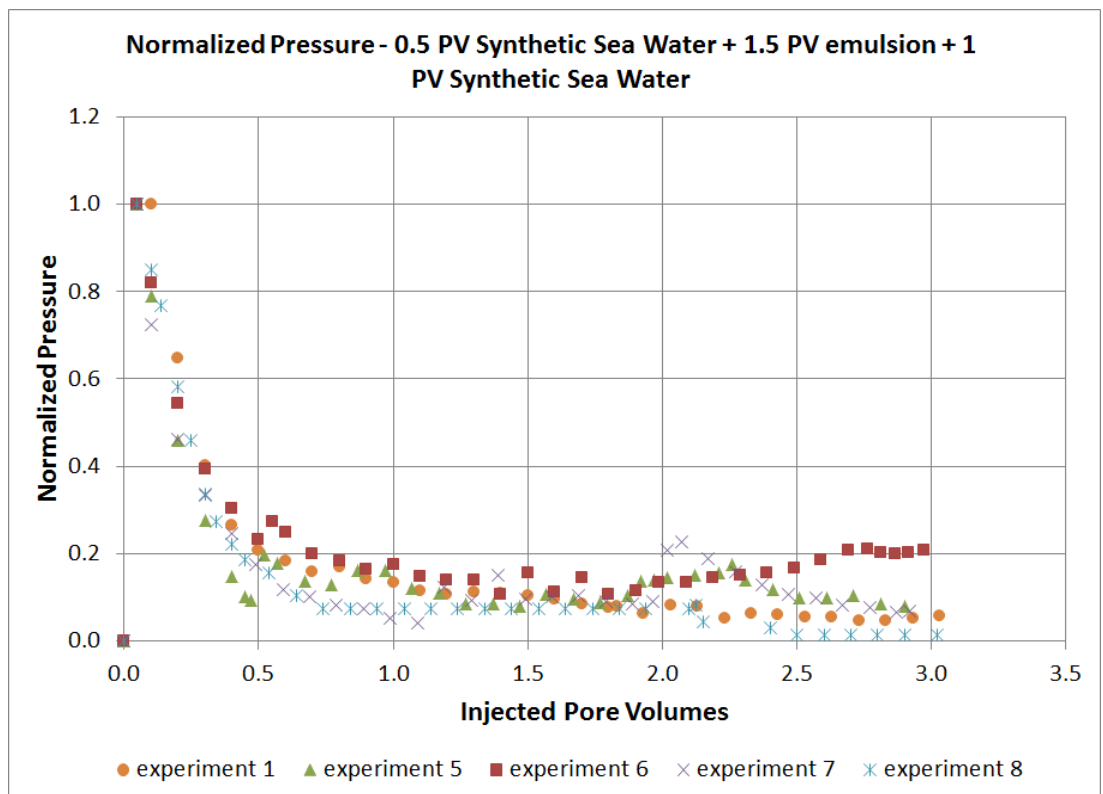

Figure 8 -Normalized Pressure vs cumulative injection -0.5 PV sea water +1.5 PV emulsion +1 PV sea water experiments

As discussed before, the oil recovery factor with emulsion with drops of $90 \mu \mathrm{m}$ is smaller than the one obtained with the other emulsions. This can be explained by observing the photographs presented in Fig.9, which show the sandpack after emulsion injection. In the case of emulsion with very large drops $(90 \mathrm{~mm})$, the capillary number is low enough that the drops are not able to flow through the porous media and they get trapped near the injection port. The sandpack itself is not flooded by these drops. 


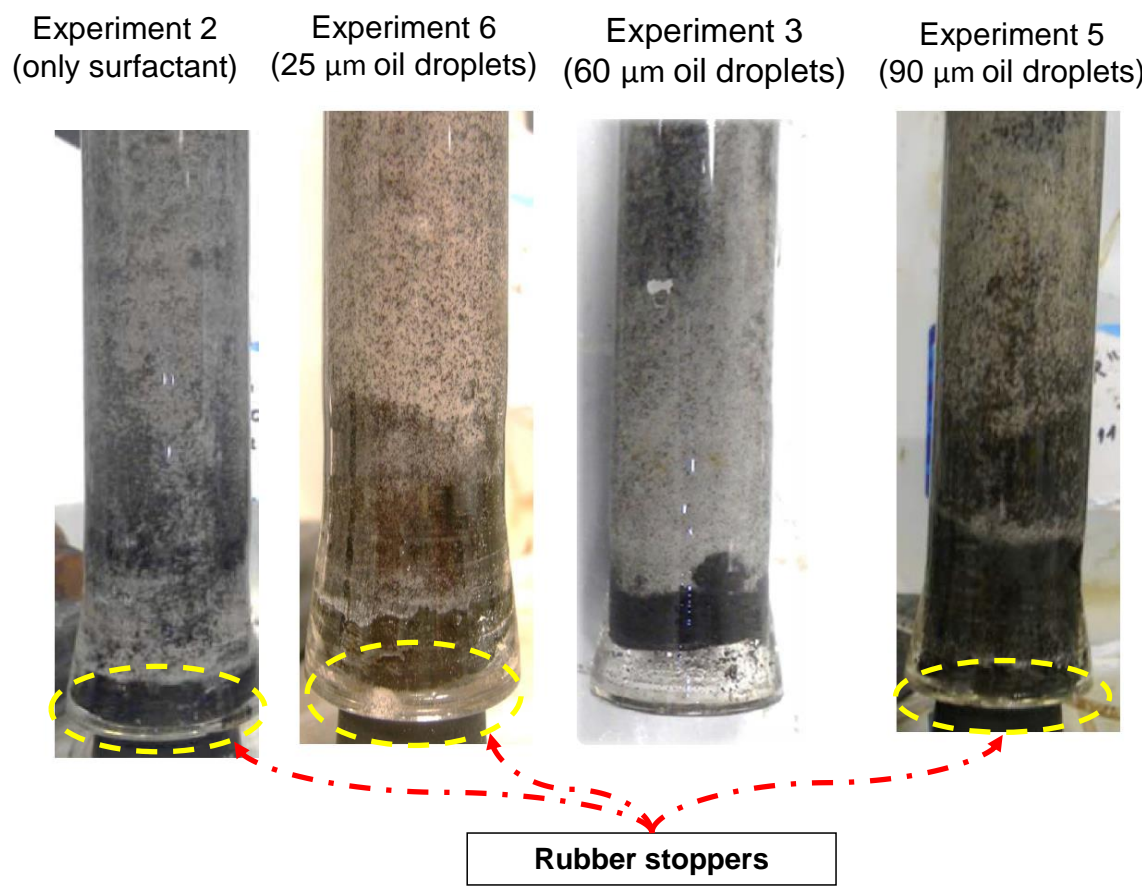

Figure 9 - Final aspects of sandpacks near the injection region (sandpack bottom).

\section{Final Remarks}

The experimental results have shown that emulsion injection can be used an alternative for improved oil recovery. The main conclusions are: a) Emulsion and surfactant solution injections were capable of increasing the final oil recovery factor if compared with synthetic sea water injection; b) Emulsion injection can reduce cumulative water-oil ratio if compared to waterflood; c) During emulsion floods there were pressure drop increases, due to an additional oil mobilization (flow diversion to areas previously unswept) and partial blockage of porous media; d) The best strategy seems to be a short sea water injection followed by the emulsion bank. If emulsion is injected too early, there is a risk of flow blockage at regions still unswept and poor oil recovery; e) The damage induced was not removed by synthetic sea water injection after emulsion injection.

The next steps of this study will be performed at Petrobras Research Center (CENPES) to explore the effect of injection rate, oil contents and permeability levels (using sandstone cores and blocks).

\section{Nomenclature}

IOR - Improved Oil Recovery;

IFT - Interfacial Tension;

ASP - Alkali-Surfactant-Polymer;

WOR - Water-Oil Ratio;

CK - Carman-Kozeny

\section{Bibliography}

[1] Lake, Larry W. - "Enhanced Oil Recovery" - Prentice-Hall - 1989;

[2] Sydanks, Robert D.; Romero-Zéron, Laura - "Reservoir Conformance Improvement" - Society of Petroleum Engineers - 2011;

[3] Guillen, V. R.; Carvalho, M. S.; Alvarado, V. - "Pore-scale and macroscopic displacement mechanisms in emulsion flooding" - Transport in Porous Media (submitted) - 2011;

[4] Wang, J.; Dong, M. - "Simulation of O/W Emulsion Flow in Alkaline/Surfactant Flood for Heavy Oil Recovery" - Journal of Canadian Petroleum Technology - vol. 49, No6 - pp. 46-52 2010

[5] McAuliffe, Clayton D. - "Oil-in-water Emulsions and Their Flow Properties in Porous Media" - SPE 4369 - Symposium of Improved Oil Recovery - Tulsa - 1972; 
[6] McAuliffe, Clayton D - "Crude Oil-in-Water Emulsions To Improve Fluid Flow in an Oil Reservoir” - Paper SPE 4370 - Symposium of Improved Oil Recovery - Tulsa - 1972;

[7] Alvarado, D.A; Marsden, S.S. - "Flow of Oil-in-water Emulsions Through Tubes and Porous Media" - Paper SPE 5859 - SPE $46^{\text {th }}$ Annual California Regional Meeting - Long Beach - 1975;

[8] Devereux, Owen F. - "Emulsion Flow in Porous Solids - I. A Flow Model" - The Chemical Engineering Journal - vol.7 - pages 121-128 - 1974;

[9] Soo, H.; Radke, C. J. - "A Filtration Model for the Flow of Dilute Stable Emulsions in Porous Media - I. Theory" - Chemical Engineering Science - vol. 41 - No 2 - pages 236-272 - 1986;

[10] Soo, H.; Radke, C. J. - "A Filtration Model for the Flow of Dilute Stable Emulsions in Porous Media - II. Parameter Evaluation and Estimation" - Chemical Engineering Science - vol. 41 - No 2 - pages 236-272 - 1986;

[11] Romero, M. I.; Carvalho, M. S.; Alvarado, V. - "Capillary-driven mobility control in emulsion flow in porous media" - International Journal of Multiphase Flow (submitted) - 2011;

[12] Romero, M. I.; Carvalho, M. S.; Alvarado, V. - "Experiments and Network Model of Flow of Oil-in-water Emulsion in Porous Media" - Physical Review E - vol. 84(4) - 046305 - 2011;

[13] Cobos, S,; Carvalho, M.S.; Alvarado, V. - "Flow of oil-in-water emulsions through constricted capillary" - International Journal of Multiphase Flow - vol. 35 - pp. 507-515 - 2009. 


\title{
8.3. Paper COBEM 2013
}

\section{NUMERICAL AND EXPERIMENTAL INVESTIGATION OF PRODUCED WATER REINJECTION ON VISCOUS OIL RECOVERY

\author{
I \\ Manoel Leopoldino Rocha de Farias, mlfarias@petrobras.com.br \\ Márcio da Silveira Carvalho, msc@puc-rio.br \\ Department of Mechanical Engineering, PUC-Rio, Rio de Janeiro, Brazil \\ Antônio Luiz Serra de Souza, alsouza@petrobras.com.br \\ CENPES/PETROBRAS, Rio de Janeiro, Brazil
}

\begin{abstract}
Produced water treatment for superficial disposal is the main operational cost in heavy oilfields. Unfavorable mobility ratio and reservoir heterogeneities contribute to water fingering phenomenon that causes poor final recoveries. The use of diluted oil-in-water macroemulsions was evaluated as a mobility control method for these cases. An extensive experimental program was performed using silica sandpacks and sandstone plugs (Berea and Bentheimer) in order to evaluate final oil recovery factors, cumulative water-oil ratio and pressure behavior, comparing water injection, surfactant solution injection and oiw emulsion injection. All porous media were saturated with crude oil from Campos Basin $\left(22^{\circ}\right.$ API). A parametric study was performed to identify influences of injection rate, oil droplets diameter distributions, emulsion oil concentration and permeability level in emulsion performance.

Although reservoir simulators don't have options specially developed to model the physical mechanisms involved (pore blockage dependent on size ratio between oil droplet/pore throat and local capillary number), it was possible to get a good match of cumulative water and oil produced for alternated water/emulsion injection and water/surfactant solution injection cases. In order to match these results it was necessary to change the oil-water relative permeability curves and to introduce an adsorption parameter to emulate oil droplet capture process by porous medium. The results obtained have indicated final oil recovery improvement and cumulative water/oil reduction. It would be possible, after some treatment, to prepare diluted oil-in-water emulsions using produced water from the oilfield. That is the way to convert an effluent in a resource with clear environmental advantages.
\end{abstract}

Keywords: Emulsions, EOR, Produced water, Porous media

\section{INTRODUCTION}

Oil and gas will keep their position as main sources of energy in the next decades. An important part of their future production will come from unconventional sources, like shale, tight formations and viscous oil reservoirs. To produce viscous oils in onshore oilfields there are some alternatives as steam flood, solvent injection and in situ combustion capable to achieve good oil recovery factors. In offshore oilfields there are few economic recovery strategies applicable. Generally, water injection is the selected alternative. Taking into account unfavorable mobility ratio and reservoir heterogeneities, the final oil recovery factors for these accumulations is, typically, less than $20 \%$. A possible solution is the addition of a thickener to the water phase, such as polymer or any other additives to mitigate the unfavorable mobility issue. This does not mobilize residual oil phase. To change residual oil saturation it is necessary to lower interfacial tension using surfactants. This paper proposes the use of dilute oil-in-water emulsions as option to enhance oil recovery factor in heavy oilfields.

McAullife (1972) presents results of an emulsion injection pilot at Midway Sunset Oilfield. A $33,000 \mathrm{bbl}$ emulsion bank ( $14 \%$ oil content) was injected in this area. The production wells in this area were monitored measuring their oil rate, water cut and produced water salinity. The results showed a reduction in their water cut and produced water salinity changes, indicating an additional 
oil mobilization of previously unswept areas. The additional oil recovery was estimated in 55,000 bbl. Despite the good results, this pilot was not convert to a full field application.

Three traditional models have been used to describe the flow of emulsions in porous media: a) bulk viscosity; b) droplet retardation model and c) filtration model.

The bulk viscosity model considers the emulsion as a single-phase fluid with a non-Newtonian behavior. This is the same approach used to model the flow of polymeric solutions in porous media. A material function is introduced to correlate the imposed shear rate with viscosity. It is adequate to describe only the flow of highly concentrated emulsions with small average oil droplet/average pore throat diameter ratio. The droplet retardation model introduces one term to consider the flow restriction experienced by an oil droplet while it passes through a pore throat. The increased flow resistance is modeled as a local permeability reduction. The retardation imposes a time delay between 1 pore volume injected and the emulsion breakthrough. The main limitation of this model is that it predicts that porous media permeability returns to its original level if clean water is injected after emulsion. Experimental results have shown the opposite: even after several pore volumes injected it is impossible to remove the impairment caused by emulsion flooding.

Soo and Radke (1986a) adapted the filtration theory to describe the flow of dilute emulsions in porous media. In their approach, the impairment of porous media is a combination of two mechanisms: a) pore blockage (size exclusion) and b) droplet retention caused by interactions between oil droplets and pore walls. These mechanisms are correlated. For example, if some droplet retention occurs, there is a pore areal reduction that can cause a future pore blockage event. Both processes cause irreversible local permeability reduction. The global effect is considered by the introduction of a filtration coefficient.

However, these models don't describe an important aspect of emulsion flow in porous media: the permeability reduction caused by the oil drops is more pronounced at smaller differential pressure or low capillary number. Moreover, the parameters associated with the model have to be obtained by macroscopic flow measurements and new measurements would be necessary for each different porous medium.

Romero et al. (2011) proposed a capillary network model to seek macroscopic flow description that is based on the physics of emulsion flow at the pore scale. The oil droplets flow through each pore throat is more complex than the transport of solid particles. Solid particle are captured in a pore throat mainly by a size exclusion mechanism. Oil droplets can deform and cross pore throats smaller than their sizes. The mobility change is the result of competition between viscous and capillary forces. This balance is better represented by the capillary number $\left(\mathrm{N}_{\mathrm{c}}\right)$ given by:

$$
N_{C}=\frac{\mu \cdot v}{\sigma}
$$

Considering a pore throat and an oil droplet larger than it, there is a critical capillary number above which the droplet can easily deform and cross this throat. So, during an emulsion flow in a porous media, it is possible to estimate how far from injection point the capture process will start. In a real case, both reservoir rock and emulsified droplets have a size distribution. Using these distributions, we can estimate where the reservoir will be partially blocked by captured droplets. In other words, diluted oil-in-water emulsions can be designed to contribute to water mobility control (Figure 1).

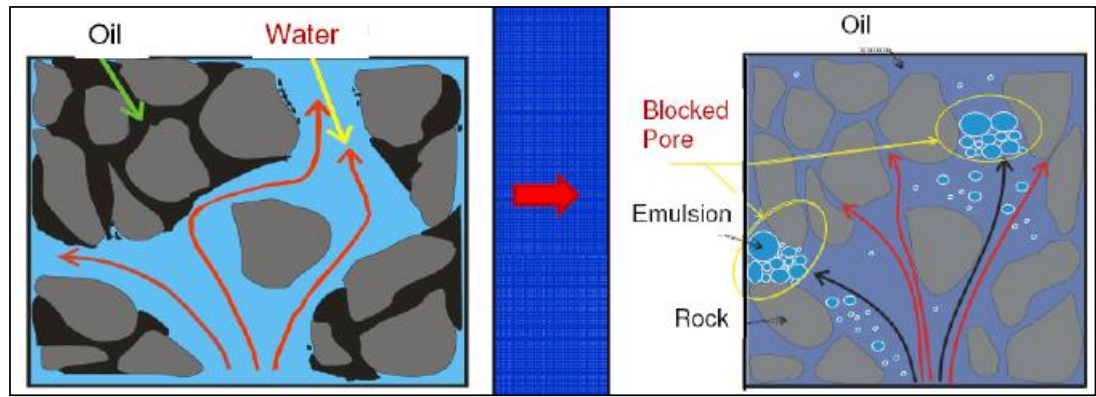

Figure 1 -Reservoir Conformance Improvement induced by emulsion injection. 


\section{MATERIALS AND METHODS}

In order to investigate the potential use of diluted oil-in-water emulsion as a mobility control agent, an experimental program was developed. Initially, silica sandpacks were saturated with crude oil (Figure 2) and submitted to alternated water/emulsion injection. Emulsions were prepared "in line" using two HPLC pumps and filters with 5, 10, 25, 60 and $90 \mu \mathrm{m}$ mesh. A commercial surfactant, Steol CS-330® from Stepan, was used to stabilize these emulsions.

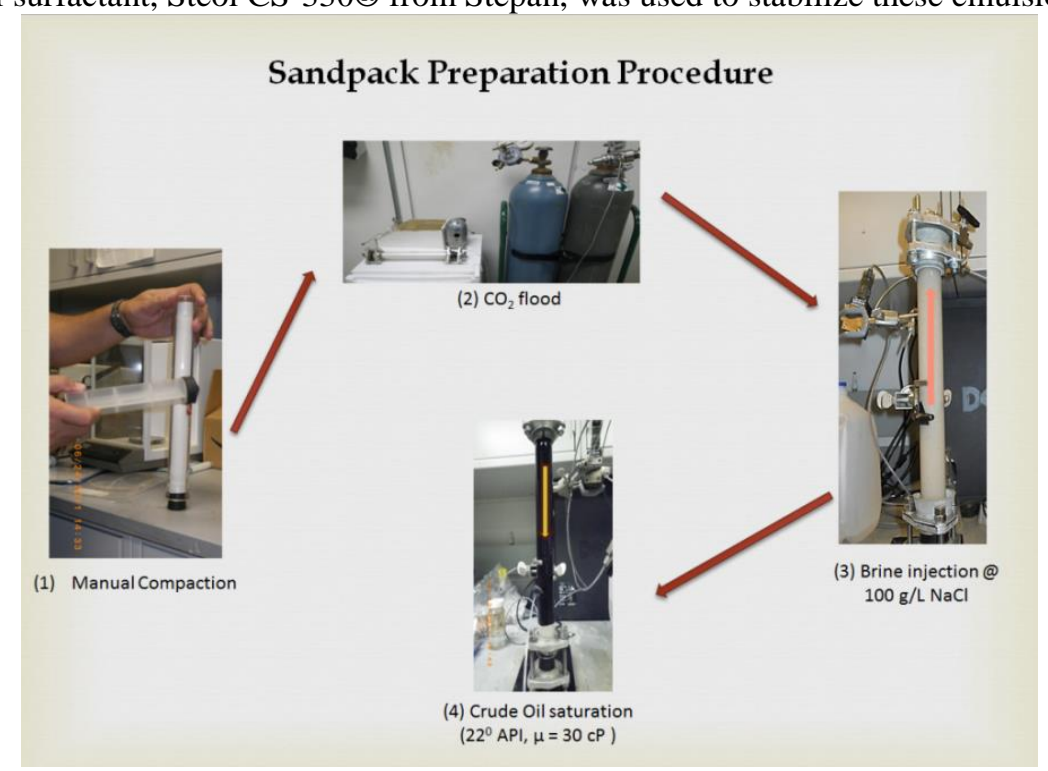

Figure 2 - Silica sandpack preparation procedure.

During the experiments, oil, water productions were measured, as well injection pressure behavior as sketched at Figure 3.

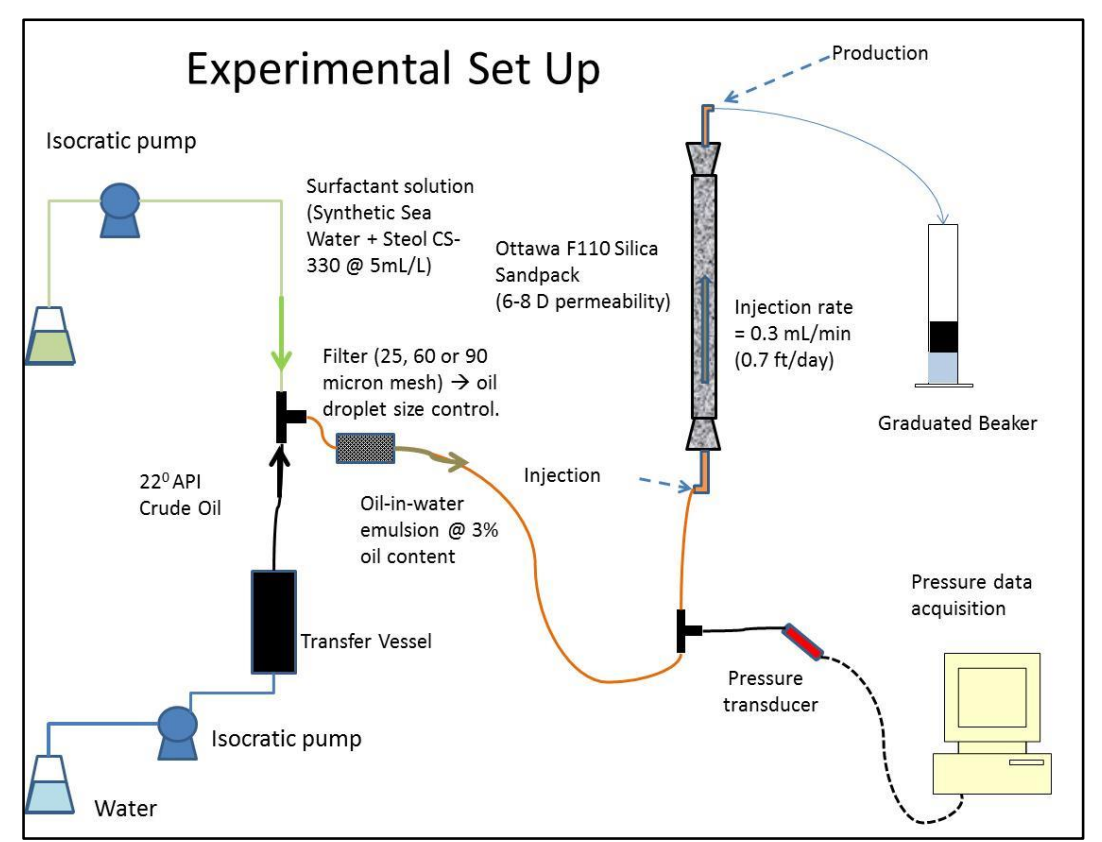

Figure 3 - Schematic representation of emulsion formation and injection.

Average values of permeability, porosity and initial fluid saturations are disposed at Table 1.

Table 1 - Permoporous properties and fluids initial saturations. 


\begin{tabular}{|l|c|c|c|c|}
\hline Porous media & $\begin{array}{l}\text { Permeability } \\
(\mathrm{mD})\end{array}$ & Porosity (\%) & $\begin{array}{l}\text { Initial Water } \\
\text { Saturation (\%) }\end{array}$ & $\begin{array}{l}\text { Initial Oil } \\
\text { Saturation(\%) }\end{array}$ \\
\hline $\begin{array}{l}\text { Silica sand } \\
\text { sandpacks }\end{array}$ & 6300.0 & 39.3 & 10.7 & 89.3 \\
\hline $\begin{array}{l}\text { Berea Sandstone } \\
\text { plugs }\end{array}$ & 57.8 & 17.9 & 25.2 & 74.8 \\
\hline $\begin{array}{l}\text { Bentheimer } \\
\text { sandstone plugs }\end{array}$ & 2300.0 & 23.2 & 18.0 & 82.0 \\
\hline
\end{tabular}

\section{EXPERIMENTAL PROGRAM}

The experimental program was developed in 2 phases at the Laboratory of Transport Phenomena at Rice University (Houston/TX) and Rock-Fluid Interaction Laboratory at Petrobras Research Center (CENPES).

Initially, 3 pore volumes alternate synthetic sea water/emulsion/synthetic sea water experiments were performed at constant injection rate $(0.3 \mathrm{ml} / \mathrm{min})$. This injection rate corresponds to a Darcy velocity of $2.5 \times 10^{-6} \mathrm{~m} / \mathrm{s}$ and a capillary number of $7.7 \times 10^{-7}$ during sea water injection and $2.6 \times 10^{-5}$ during emulsion injection.

During these experiments, effects of different oil recovery strategies were evaluated, changing: a) bank sizes; b) oil droplets sizes distributions. The emulsion oil content was kept high $(3.3 \%)$ to maximize its effects.

Table 2 presents the parameters of each experiment with the final recovery factor and cumulative water-oil ratio. The average pore throat of each sandpack was estimated using CarmanKozeny equation. In this table, emulsion bank with maximum oil droplet size equal 0 corresponds to the surfactant solution, which was the emulsion continuous phase. Experiments 1 and 2 are the base cases used for comparison.

Table 2 - Initial experiments performed and results.

\begin{tabular}{|c|c|c|c|c|c|l|}
\hline $\begin{array}{l}\text { Experime } \\
\text { nt }\end{array}$ & $\begin{array}{c}\text { Initial Sea } \\
\text { water } \\
\text { bank (PV) }\end{array}$ & $\begin{array}{c}\text { Emulsion } \\
\text { bank (PV) }\end{array}$ & $\begin{array}{c}\text { Final Sea } \\
\text { water } \\
\text { bank } \\
(\mathrm{PV})\end{array}$ & $\begin{array}{c}\text { \#Filter/av } \\
\text { erage pore } \\
\text { throat } \\
\text { rat } \\
\text { io }\end{array}$ & $\begin{array}{c}\text { Filter } \\
\text { mesh } \\
(\mu \mathrm{m})\end{array}$ & Remarks \\
\hline 1 & 3 & 0.0 & 0.0 & 0.00 & 0 & $\begin{array}{l}\text { 3 PV Synthetic } \\
\text { sea water. }\end{array}$ \\
\hline 2 & 0 & 3.0 & 0.0 & 0.00 & 0 & $\begin{array}{l}\text { Surfactant } \\
\text { solution }\end{array}$ \\
\hline 3 & 1.0 & 1.0 & 1.0 & 0.84 & 60 & \\
\hline 4 & 1.0 & 1.0 & 1.0 & 0.53 & 25 & \\
\hline 5 & 0.5 & 1.5 & 1.0 & 1.26 & 90 & \\
\hline 6 & 0.5 & 1.5 & 1.0 & 0.41 & 25 & Surfactant \\
\hline 7 & 0.5 & 1.5 & 1.0 & 0.80 & 60 & \\
\hline 8 & 0.5 & 1.5 & 1.0 & 0.00 & 0 & \\
\hline
\end{tabular}

The Figure 4 shows oil recovery fraction evolution during the alternated 1:1:1 (SW:Em:SW) experiments. The worst recovery, as expected, was achieved with 3 pore volumes of sea water injection experiment. Experiment 2 (surfactant solution injection during second pore volume) 
recovered more oil due to residual oil saturation reduction. The best results were obtained using emulsions during second pore volume injection. This extra recovered oil is attributed to an enhancement of microscopic sweep caused by emulsified oil droplets capture process (partial blockage of preferential water paths). The emulsion prepared with a 60 micron filter had a better result if compared with 25 micron emulsion. The simplest approach can be made dividing filter mesh (assumed as the same magnitude as oil droplets sizes) by the average pore throat diameter estimated by Carman-Kozeny equation. The best result was associated to a ratio close to 1 for this capillary number level (typical of oilfield waterfloods).

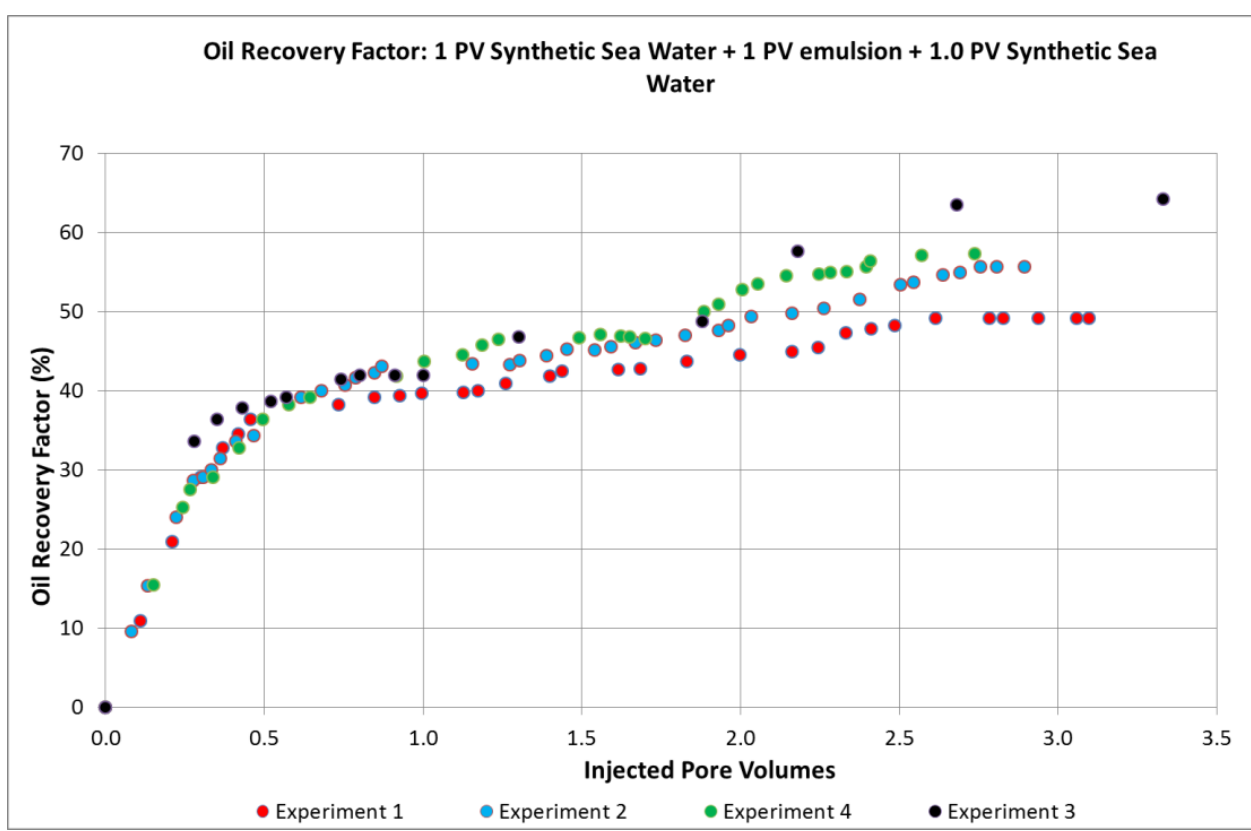

Figure 4 - Oil recovery factor vs cumulative injection - $1 \mathrm{PV}$ sea water $+1 \mathrm{PV}$ emulsion $+1 \mathrm{PV}$ sea water experiments.

Figure 5 shows effect of the injection banks sizes. The higher oil recovery compared to previous experiments can be explained as a combination of a larger and earlier injected emulsion bank. The mobility control effect caused by emulsion is more evident. The surfactant solution reduced the residual oil saturation, basically, in the pores previously swept by injected water, because it is not capable to make any flow diversion as emulsions. As we can see in Figure 5, the recovery factor has increased by changing the emulsion preparation from 25 micron to 60 micron filter, but the results obtained for 90 micron were close to sea water injection. The visual inspection of sandpacks after experiments (Figure 6) can help to understand what happened. At this capillary number level, the emulsified oil droplets in 90 micron emulsion were captured predominantly close to injection point. An early blockage occurred in this region and the injection fluid was not capable to promote any important mobility control. 


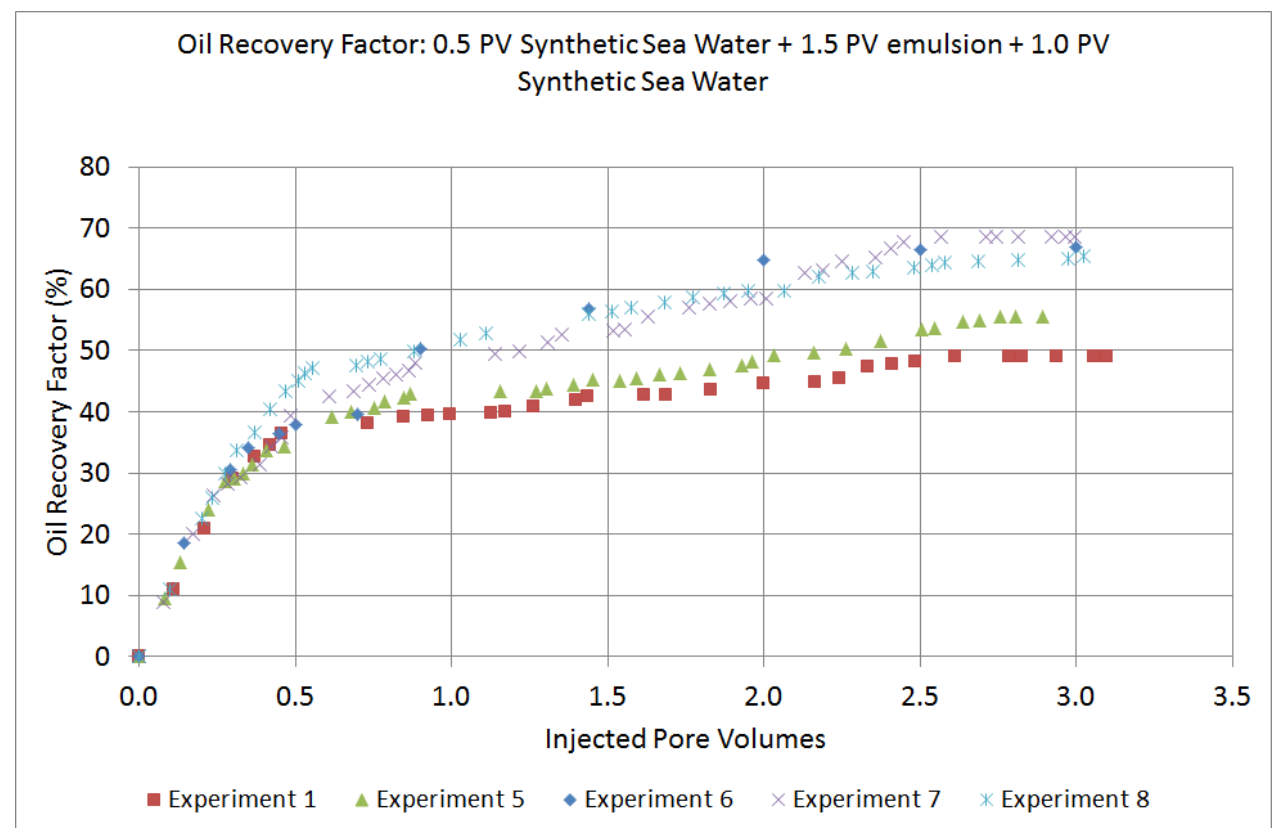

Figure 5 - Oil recovery factor vs cumulative injection $-0.5 \mathrm{PV}$ sea water $+1.5 \mathrm{PV}$ emulsion $+1 \mathrm{PV}$ sea water experiments.

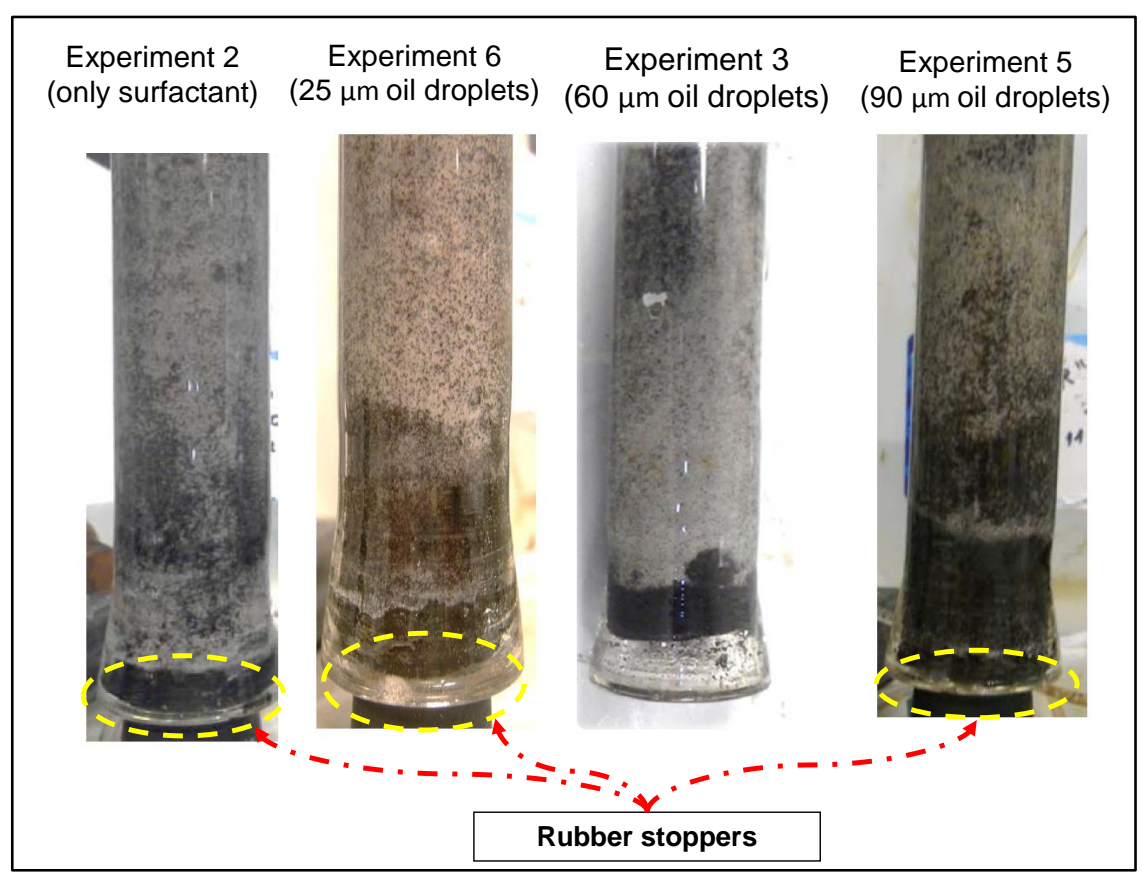

Figure 6 - Final aspects of sandpacks near the injection region (sandpack bottom).

To complement the initial results, a parametric study was developed to investigate more deeply the effects on oil recovery of the following variables:

- Oil content;

- Oil droplets size distributions;

- Permeability level;

- Injection rate;

The plot presented in Figure 7 shows the influence of emulsion oil concentration at final oil recovery. Increasing the emulsified oil content amplifies mobility control effect. Even an emulsified oil content as low as $0.1 \%$ could recover more oil than surfactant solution injection. 


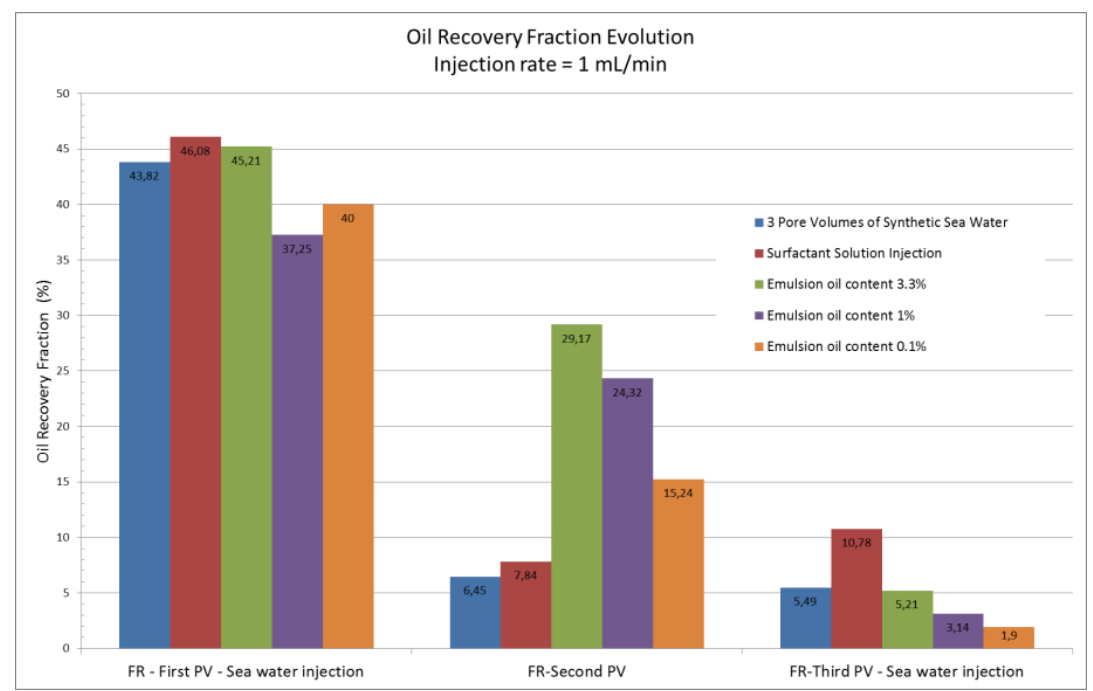

Figure 7 - Emulsion oil content influence on oil recovery (injection rate $=1 \mathrm{ml} / \mathrm{min}$ ).

The plot presented in Figure 8 shows injection rate influence on cumulative oil recovery comparing sea water injection and alternated sea water/emulsion/sea water scheme. At $0.3 \mathrm{ml} / \mathrm{min}$ $(49.1 \% \times 60.9 \%)$ and $1 \mathrm{ml} / \mathrm{min}(55.8 \% \times 80.2 \%)$ injection rates, the emulsion effects were clear. Although, at $3 \mathrm{ml} / \mathrm{min}$, the cumulative recoveries obtained of 3 pore volumes of sea water and alternated sea water/emulsion/sea water were almost the same $(70 \% \times 73 \%)$. In this case, the capillary number level is high and the majority of emulsified oil droplets could cross the entire sandpack. In this case, the mobility control was poor.

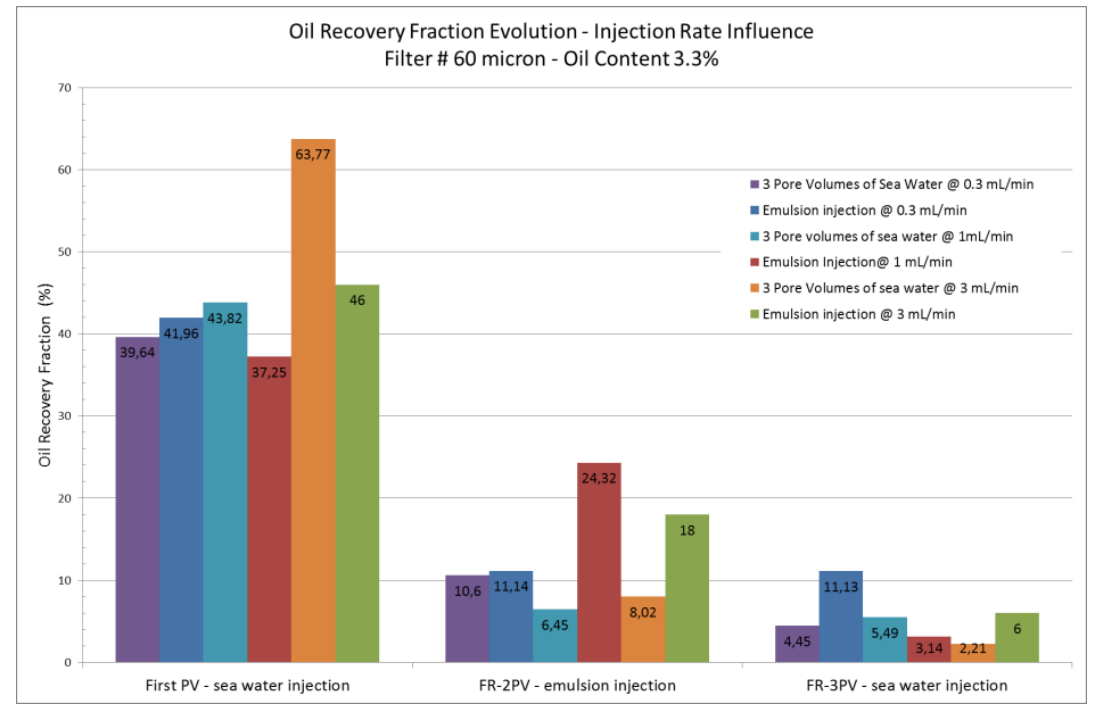

Figure 8 - injection rate effects (capillary number effects) on oil recovery.

Figure 9 shows the comparative results obtained with Berea sandstone plugs. The main goal was to test the emulsion injection effects at a different permeability level. The results obtained had the same behavior, i e, emulsions could recover more oil than sea water or surfactant solution injection. Additionally, the emulsified oil droplets sizes distribution has an important role. 


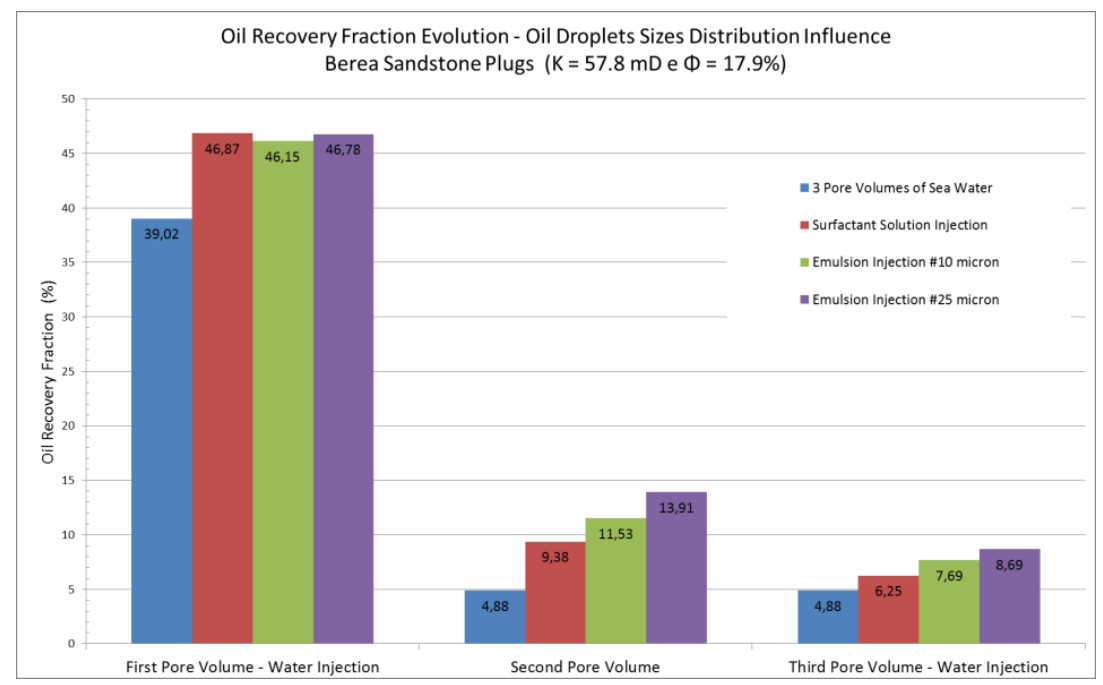

Figure 9 - Berea sandstone plugs results.

\section{Simulation Model}

Some selected 1-D cases were simulated using a commercial reservoir simulator (CMG STARS $\left.{ }^{\circ}\right)$. This software is a multiphase reservoir simulator that has some preconfigured IOR processes, like steam injection, polymers, gels and foams. The sandpacks were modeled using a radial grid layers (20 layers - 18 cells per layer). For each case, measured averages values of porosity, permeability and saturations were used to populate the grid.

The model has 4 components: water, oil, surfactant and emulsified oil droplets. The injection fluid were characterized by its molar fraction composition, as disposed on Table 3.

Table 3 - Emulsion composition on molar basis.

\begin{tabular}{|l|c|}
\hline Component & Molar fraction (\%) \\
\hline Synthetic sea water & 99.49 \\
\hline Emulsified oil droplets & 0.5 \\
\hline Surfactant & 0.01 \\
\hline
\end{tabular}

The base cases, $3 \mathrm{PV}$ of sea water injection and $3 \mathrm{PV}$ of surfactant solution injection, were history matched in order to obtain the relative permeability curves and end-points. The Figures 10 and 11 show these curves. 


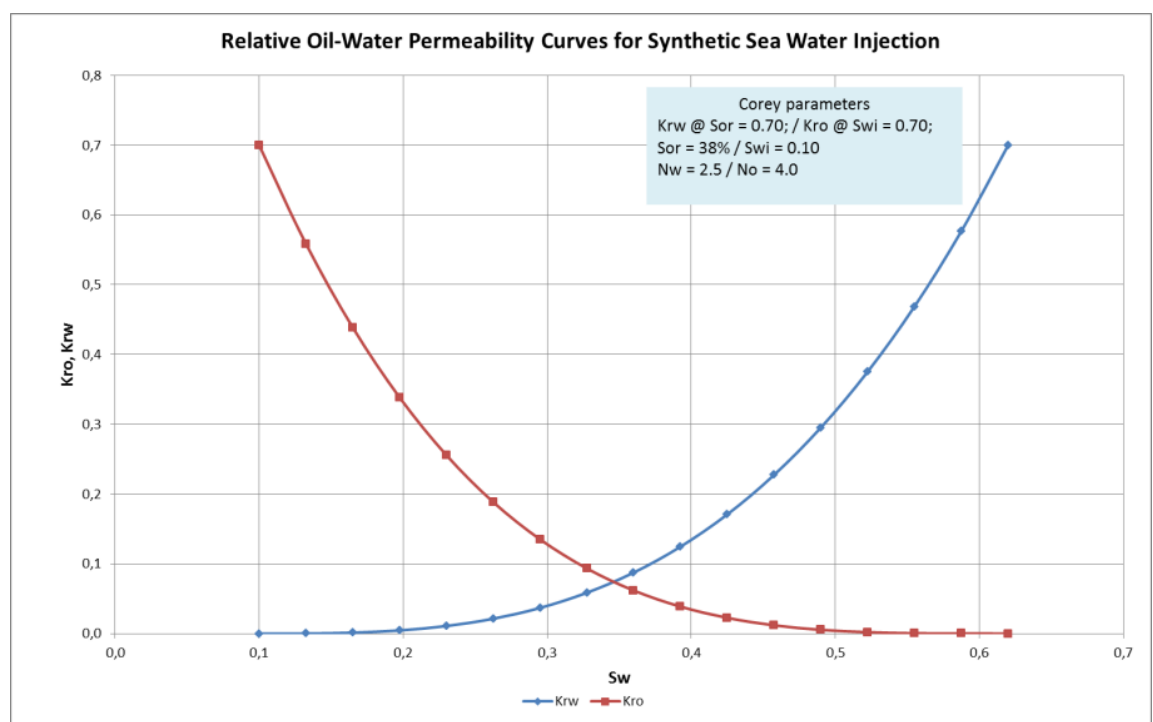

Figure 10 - Relative permeability curves obtained during initial synthetic sea water injection bank.

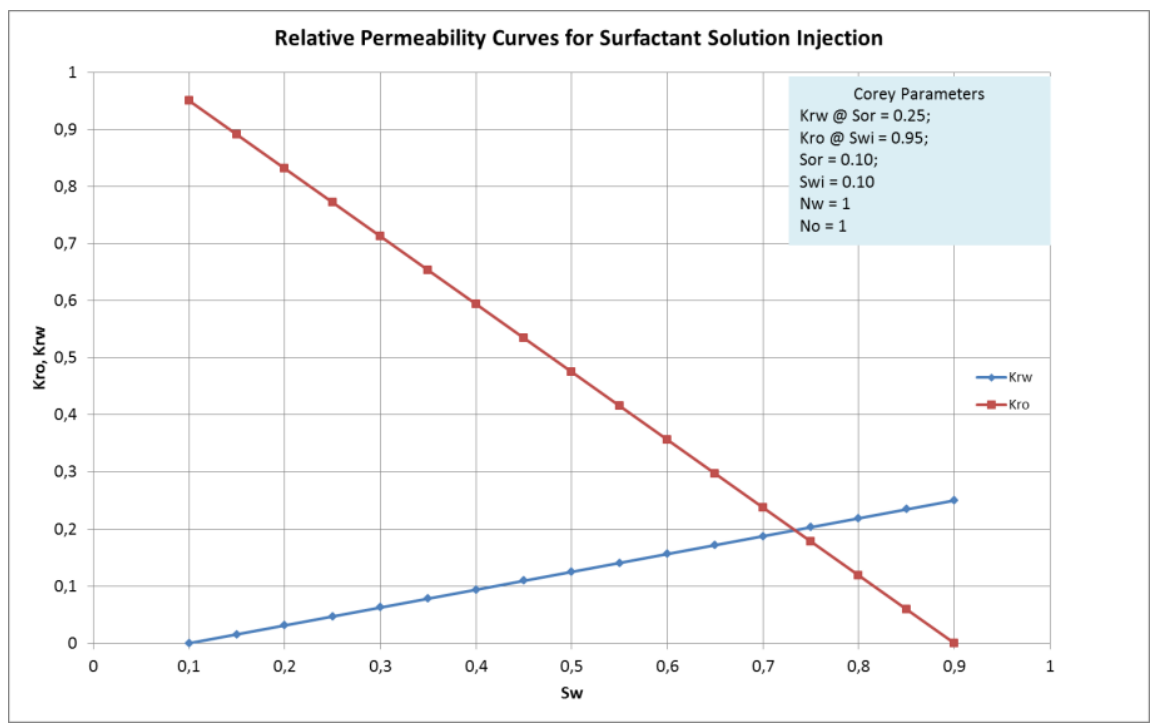

Figure 11 - Relative permeability curves for surfactant solution injection.

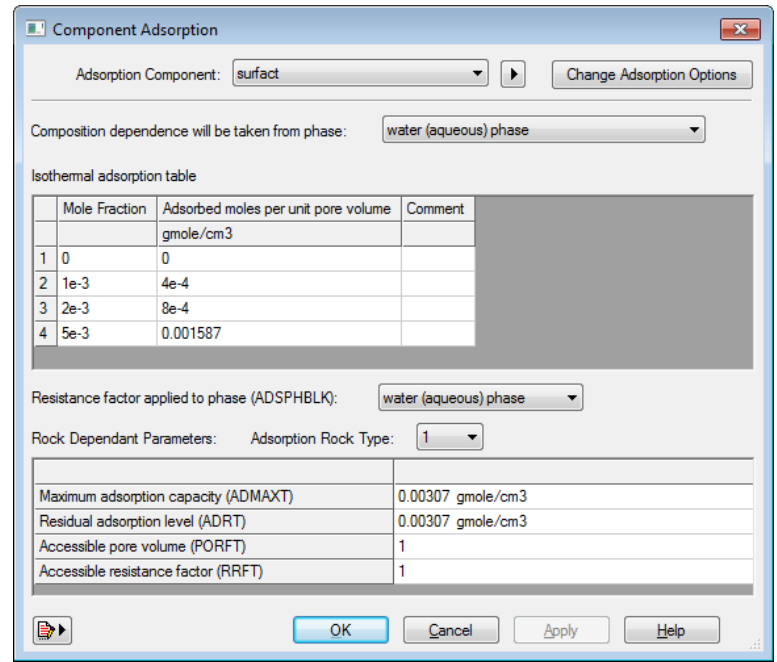

Figure 12 - Surfactant adsorption parameters. 
In order to match the experiments with surfactant were present in aqueous phase, two sets of oil-water permeability curves were considered in the simulation models. The first one was relative to high interfacial tension condition (synthetic sea water injection $\sigma_{\mathrm{ow}}=22.85 \mathrm{dyn} / \mathrm{cm}$ ) and the second was relative to low interfacial tension condition (surfactant concentration at aqueous phase $\left.=0.05 \mathrm{~mol} \rightarrow \sigma_{\mathrm{ow}}=0.67 \mathrm{dyn} / \mathrm{cm}\right)$. During alternated injection, ateach time step, the surfactant concentration in each cell was calculated and, then, oil and water relative permeability are estimated by linear interpolation of pure water and surfactant solution curves presented in Figures 11 and 12 .

The emulsion flow was described by two different approaches:

a) Modeling emulsified oil droplets capture as a adsorption phenomenon (partial blockage of water paths) + relative permeability curves (end points and Corey exponents) alteration due oil droplets and surfactant presence and

b) Modeling emulsion flow only changing relative permeability curves.

The Corey parameters and end-points obtained were summarized in Table 4.

Table 4 - Curve Corey Parameters used to match the model.

\begin{tabular}{|c|c|c|c|c|c|c|}
\hline Model & $\mathrm{K}_{\mathrm{ro}} @ \mathrm{~S}_{\mathrm{wi}}$ & $\mathrm{K}_{\mathrm{rw}} @ \mathrm{~S}_{\mathrm{or}}$ & $\mathrm{n}_{\mathrm{o}}$ & $\mathrm{n}_{\mathrm{w}}$ & $\mathrm{S}_{\mathrm{or}}$ & $\mathrm{S}_{\mathrm{wi}}$ \\
\hline $\begin{array}{l}\text { Synthetic Sea Water } \\
\text { Injection }\end{array}$ & 0.70 & 0.70 & 4 & 2.5 & 0.38 & 0.10 \\
\hline $\begin{array}{l}\text { Emulsion Injection } \\
\text { without oil droplets } \\
\text { capture parameter }\end{array}$ & 0.82 & 0.42 & 1.5 & 4.2 & 0.16 & 0.10 \\
\hline $\begin{array}{l}\text { Emulsion Injection } \\
\text { with oil droplets } \\
\text { capture parameter }\end{array}$ & 0.95 & 0.20 & 1.43 & 5.7 & 0.12 & 0.10 \\
\hline
\end{tabular}

The emulsified oil droplets capture process was modeled using the adsorption option and considering the following parameters: a) molar oil droplets concentration; b) maximum adsorption rock capacity; c) a water permeability reduction fraction due to droplets capture (Figure 13).

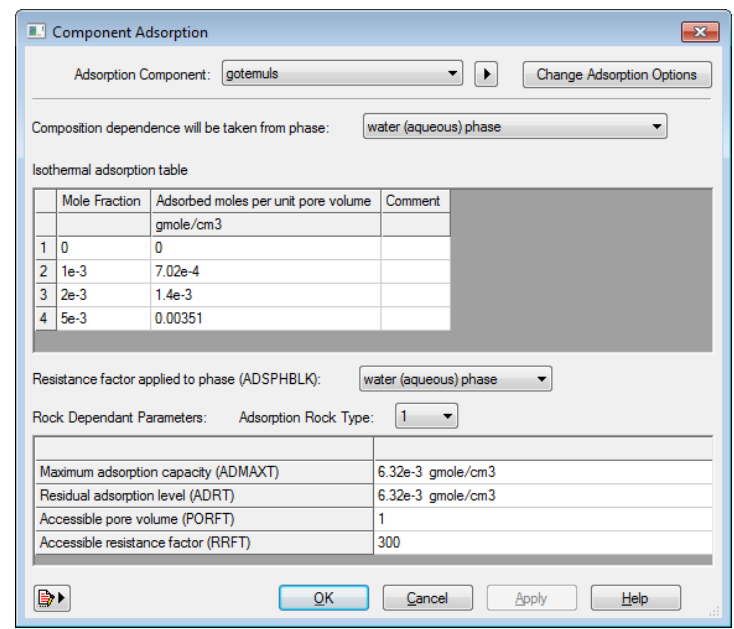

Figure 13 - Emulsified oil droplets capture parameters.

The permeability reduction factor RKw is calculated as a function of oil droplets adsorbed per cell and an experimental parameter called residual resistance factor according the following equation:

$$
R K_{w}=1+(R R F T-1) * A D(C, T) / A D(T)_{\text {máx }}
$$


Where:

$\mathrm{RK}_{\mathrm{W}}-$ Water reduction permeability factor;

RRFT - Residual reduction fator at cell temperature;

$\mathrm{AD}(\mathrm{C}, \mathrm{T})$ - Adsorption level (function of temperature and droplets concentration);

$\mathrm{AD}(\mathrm{T})_{\text {máx }}-$ Maximum adsorption capacity $\left(\mathrm{gmol} / \mathrm{cm}^{3}\right.$ of rock) at cell temperature.

The STARS models developed were isothermal. So, all previous parameters were only functions of oil droplets concentration.

After an initial manual history match, CMOST® was used to improve the predictions. The Figure 14 compares the curves for the models with adsorption parameter (continuous lines) and without adsorption parameter (dashed lines).

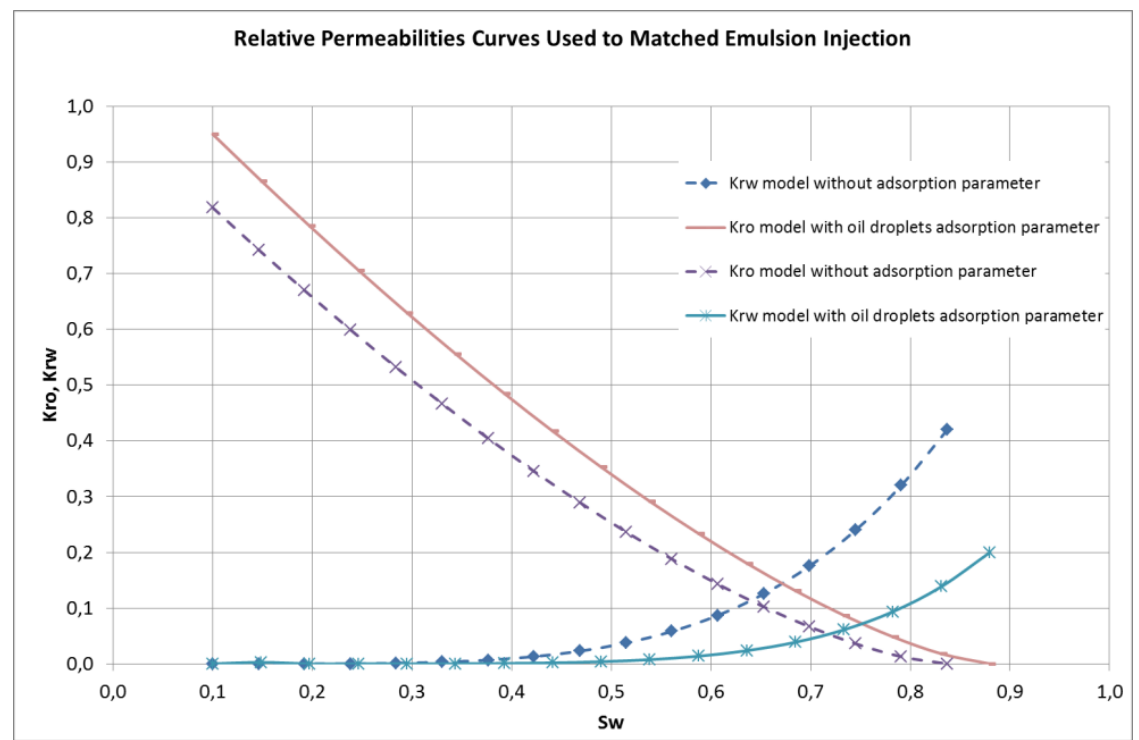

Figure 14 - Relative permeability curves used to match emulsion injection.

Figure 14 shows the history match obtained. At a first glance, they are very similar. Although, looking to simulated oil rate curves, it is possible to notice an important difference. The model without the oil droplet capture parameter exhibited an oil peak at beginning of emulsion injection (Figure 16). These oil peaks were not observed during experiments. In all experiments, it was necessary to inject from 0.2 to $0.4 \mathrm{PV}$ of emulsion bank in order to observe its effect on oil production. 
Sandpack 111 - Sea water/Emulsion/Sea Water Injection Injection rate of $1 \mathrm{~mL} / \mathrm{min}$ (\#60 micron filter mesh @1\% oil content) PRODUTORES-PRO

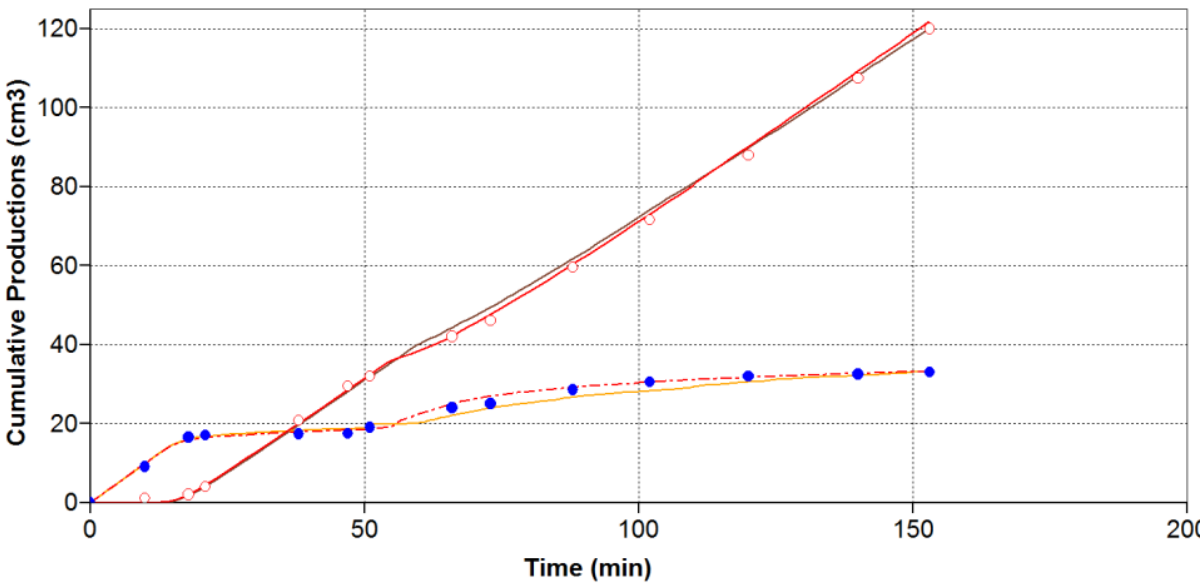

CumulativeWater Production - Model with Adsorption Parameter Cumulative Oil Production - Model with Adsorption Parameter

Cumulative Water Production - Model without Adsorption Paramete Cumulative Oil Production - Model without Adsorption Parameter Cumulative Water Production History

Figure 15 - Cumulative Oil and Water Histories matches for sandpack 111 experiment.

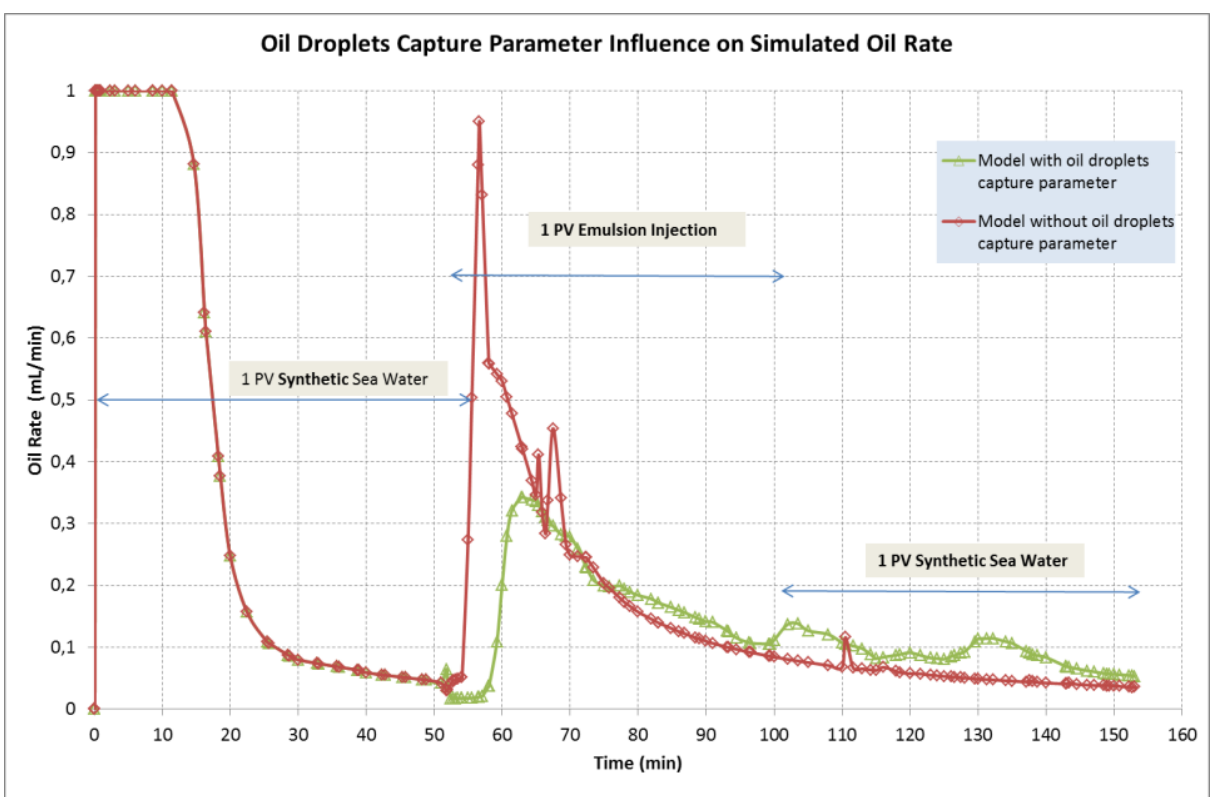

Figure 16 - Simulated oil rate obtained in the simulated models.

\section{Final Remarks}

The experimental results have shown that emulsion injection can be used as an alternative for improved oil recovery. The main conclusions are:

a) Emulsion and surfactant solution injections were capable of increasing the final oil recovery factor if compared to synthetic sea water injection;

b) Emulsion injection can reduce cumulative water-oil ratio if compared to waterflood;

c) During emulsion floods, the pressure drop rises due to an additional oil mobilization (flow diversion to areas previously unswept) and partial blockage of porous media;

d) The best strategy seems to be a short sea water injection followed by the emulsion bank. If emulsion is injected too early, there is a risk of flow blockage at regions still unswept and poor oil recovery; 
e) It is possible to use a commercial reservoir simulator to match $1 \mathrm{D}$ experiments results; e) It is necessary to develop options to allow to model emulsified oil droplets capture dependent of local capillary number and pore and emulsified oil droplets distributions.

\section{Nomenclature}

IOR - Improved Oil Recovery;

IFT - Interfacial Tension;

ASP - Alkali-Surfactant-Polymer;

WOR - Water-Oil Ratio;

CK - Carman-Kozeny

\section{REFERENCES}

Farias, Manoel L. R. de; Carvalho, Márcio da S.; Souza, A.L.S de; Hirasaki, George J.; Miller, Clarence - "A Comparative Study of Emulsion Flooding and Other IOR Methods for Heavy Oil", SPE Paper 152290, presented at LACPEC 2012, Mexico City.

McAuliffe, Clayton D. - "Crude-Oil-in-Water Emulsions To Improve Fluid Flow in an Oil Reservoir”, Paper SPE 4370 - Symposium of Improved Oil Recovery 1972, Tulsa.

Romero, Mao I.; Carvalho, M.S.; Alvarado, V. - "Experiments and network model of flow of oilwater emulsion in porous media" - Physical Review E. 00.006300 - American Physical Society 2001.

Soo, H; Radke, C.J. - "A Filtration Model for the Flow of Dilute, Stable Emulsions in Porous Media - I. Theory” - Chemical Engineering Science - Vol. 41 - No 2 -1986a.

Soo, H; Radke, C.J. - "A Filtration Model for the Flow of Dilute, Stable Emulsions in Porous Media - II. Parameter Evaluation and Estimation" - Chemical Engineering Science - Vol. 41 - No $2-1986 b$.

\section{RESPONSIBILITY NOTICE}

The authors are the only responsible for the printed material included in this paper. 